\title{
Study of the Effect of Surface Modification and Sulfur Impurities in Syngas on the Fischer-Tropsch Performance of Cobalt Catalysts
}

Ashish Suresh Bambal

West Virginia University

Follow this and additional works at: https://researchrepository.wvu.edu/etd

\section{Recommended Citation}

Bambal, Ashish Suresh, "Study of the Effect of Surface Modification and Sulfur Impurities in Syngas on the Fischer-Tropsch Performance of Cobalt Catalysts" (2012). Graduate Theses, Dissertations, and Problem Reports. 4828.

https://researchrepository.wvu.edu/etd/4828

This Dissertation is protected by copyright and/or related rights. It has been brought to you by the The Research Repository @ WVU with permission from the rights-holder(s). You are free to use this Dissertation in any way that is permitted by the copyright and related rights legislation that applies to your use. For other uses you must obtain permission from the rights-holder(s) directly, unless additional rights are indicated by a Creative Commons license in the record and/ or on the work itself. This Dissertation has been accepted for inclusion in WVU Graduate Theses, Dissertations, and Problem Reports collection by an authorized administrator of The Research Repository @ WVU.

For more information, please contact researchrepository@mail.wvu.edu. 


\title{
Study of the Effect of Surface Modification and Sulfur Impurities in Syngas on the Fischer-Tropsch Performance of Cobalt Catalysts
}

\author{
A dissertation submitted to the \\ College of Engineering and Mineral Resources \\ at West Virginia University \\ in partial fulfillment of the requirements \\ for the degree of \\ Doctor of Philosophy \\ in \\ Chemical Engineering
}

Submitted by

Ashish Suresh Bambal

\author{
Advisory and Examining Committee \\ Dady B. Dadyburjor, PhD, Chair \\ Edwin L. Kugler, PhD \\ Todd H. Gardner, PhD \\ John H. Penn, PhD \\ John W. Zondlo, PhD
}

Department of Chemical Engineering

Morgantown, West Virginia

2012

Keywords: cobalt, chelating agent, Fischer-Tropsch, impurities, poison, silica, sulfur 


\section{ABSTRACT \\ Study of the Effect of Surface Modification and Sulfur Impurities in Syngas on the Fischer-Tropsch Performance of Cobalt Catalysts}

Ashish S. Bambal

The effect of surface modification of the silica support on the Fischer-Tropsch (FT) activity and the selectivity of cobalt catalyst were studied. The catalysts were characterized by $\mathrm{N}_{2}$ physisorption, X-ray diffraction (XRD), X-ray photoelectron spectroscopy (XPS), temperature programmed reduction (TPR) and hydrogen chemisorption. FT was carried out in a fixed-bed reactor at $230{ }^{\circ} \mathrm{C}, 20$ bar and $9000 \mathrm{sccm} / \mathrm{h} / \mathrm{g}_{\mathrm{cat}}$, using syngas with $\mathrm{H}_{2} / \mathrm{CO}=2.0$. Surface modification with chelating agents (CAs), i.e., nitrilotriacetic acid (NTA) and ethylenediaminetetracetic acid (EDTA), results in a smaller crystallite size of cobalt oxides after the calcination. In addition, the CA-modified catalysts contain well-dispersed cobalt oxides and higher number of catalytic sites on the surface. The CO conversions and the hydrocarbon yields, i.e., $\mathrm{gC} / \mathrm{Kg}_{\mathrm{cat}} / \mathrm{h}$, are notably higher for the CA-modified catalysts at different operating temperatures. The structure-activity relationships based on the findings confirm the advantage of CA modification of the support during catalyst synthesis. In the next step, catalysts were subjected to poisoning by 10 and $50 \mathrm{ppm}$ sulfur in the syngas. At both the concentrations, the sulfur is noted to adsorb irreversibly on the surface and to cause permanent loss in the activity. In the presence of sulfur, the performance of both CA-modified catalysts is better compared to that of the base catalyst. The sulfur poison affects the hydrogenation and the chainpropagation ability of the catalysts, and shifts the product selectivity towards short-chain hydrocarbons with a higher percentages of olefins. Highly dispersed CA-modified catalysts have a longer life in the presence of sulfur poison. 


\section{ACKNOWLEDGEMENTS}

I would like to gratefully acknowledge the Department of Chemical Engineering, West Virginia University for providing me this fantastic opportunity to pursue PhD in the department. I would like express my sincere gratitude and appreciation to the enthusiastic supervision of Dr. Dady Dadyburjor during this doctoral research work. With his enthusiasm, his inspiration, and his great efforts to explain things clearly and simply, he helped to make this work, a great experience for me. Throughout my research, he provided encouragement, sound advice, good teaching, good company, and lots of sensible ideas. The work would be impossible without the always involved Dr. Edwin Kugler. My sincere thanks Dr. Todd Gardner for giving the opportunity through this project to work at NETL. I would also like to acknowledge Dr. John Zondlo and Dr. John Penn, for their willingness to serve as a member of my examining committee.

Beyond the educational and technical guidance, my deepest thanks must go to my mother Sandhya Bambal and father Suresh Bambal who made everything in my life possible. Their love, belief, and guidance will never go unappreciated. I am forever indebted to my brother Manish Bambal and sister-in-law Trupti Bambal for their understanding, endless patience and encouragement when it was most required throughout the life. Finally, I am also grateful to uncle Ramesh Bambal and aunt Vijaya Bambal for their support and guidance. 


\section{TABLE OF CONTENTS}

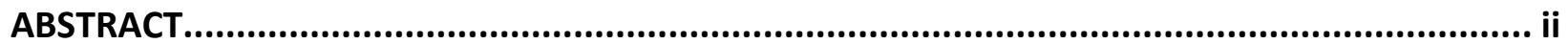

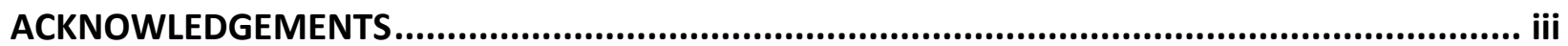

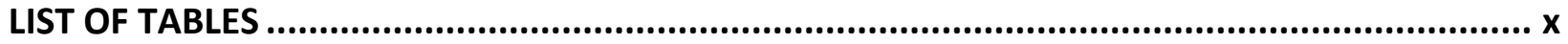

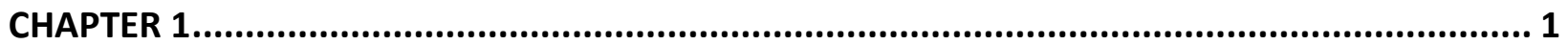

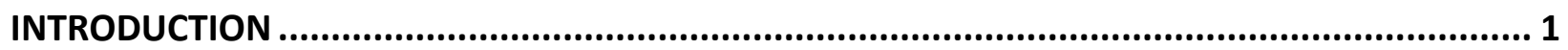

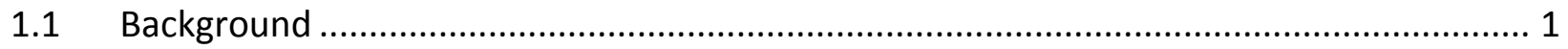

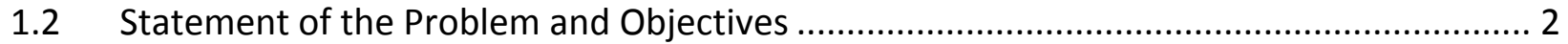

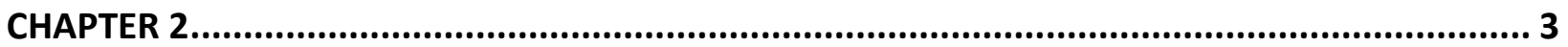

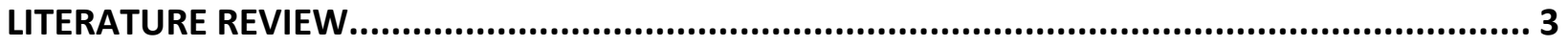

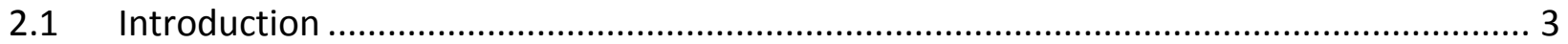

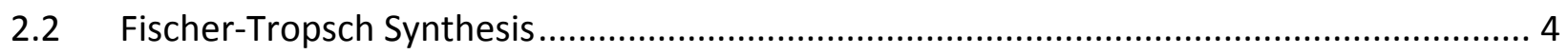

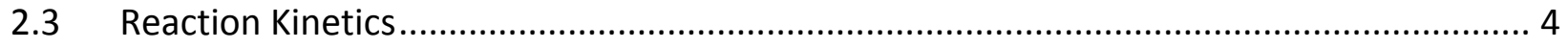

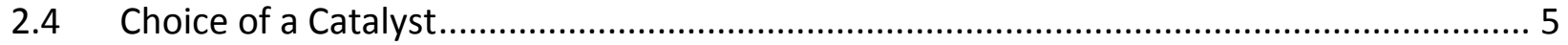

2.5 Operating Conditions and Product Selectivity .................................................. 6

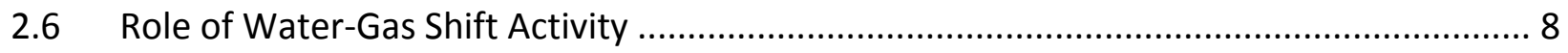

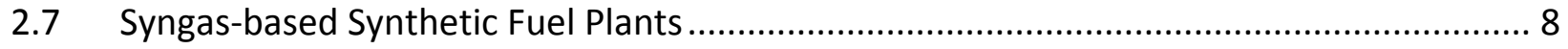

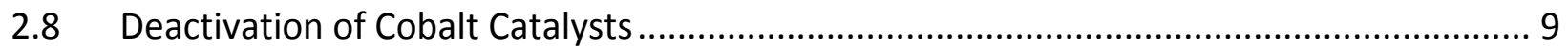

2.8.1 Strong Metal-Support Interaction ................................................................ 9

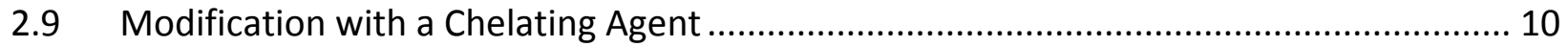

2.10 Potential Biomass Feedstock for Syngas Production............................................. 12

2.11 Contaminants Present in Biomass-derived Syngas................................................... 16

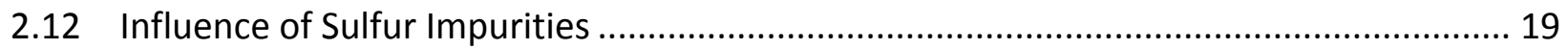

2.13 Development of Sulfur-Tolerant Catalysts ........................................................ 20 
2.13.1 Laboratory Scale Study of Catalyst Poisoning .................................................. 21

2.13.2 Response of Promoted FT Catalysts to Sulfur Impurities ....................................... 22

2.14 Relation of Literature Studies to Research Plan ................................................... 25

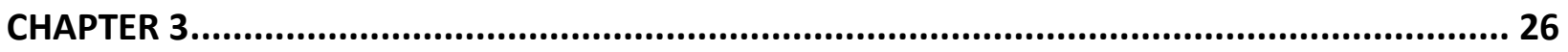

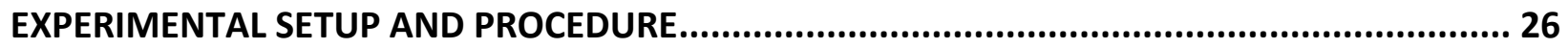

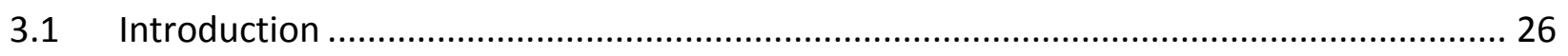

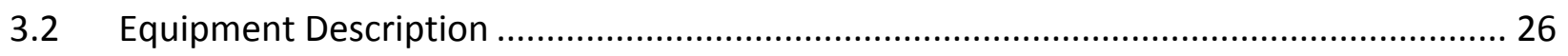

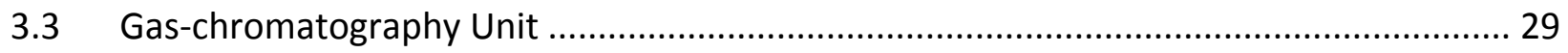

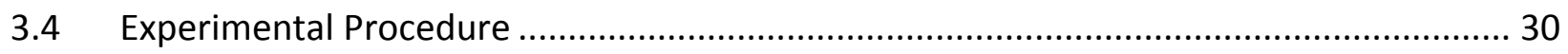

3.5 Characterization Equipment and Procedures..................................................... 31

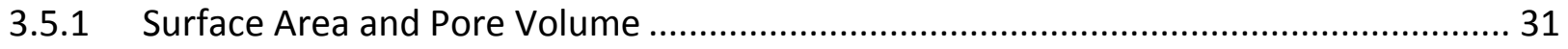

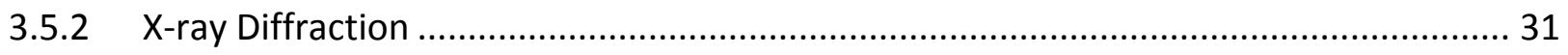

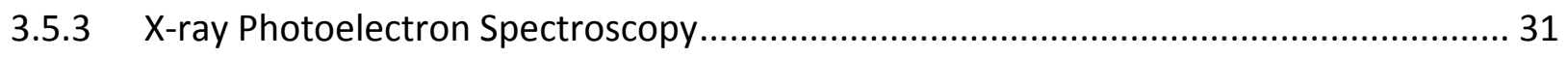

3.5.4 Scanning Electron Microscopy and Energy Dispersive Spectroscopy......................... 32

3.5.5 Temperature-Programmed Reduction.............................................................. 32

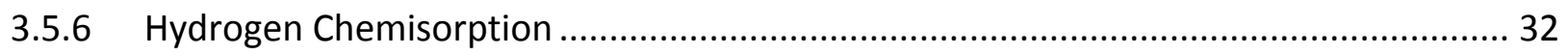

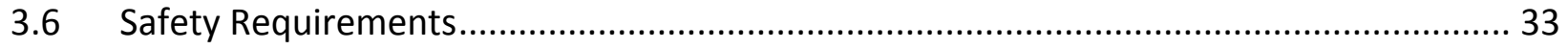

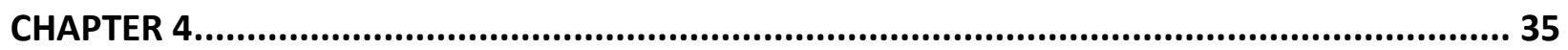

SYNTHESIS AND PRE-REACTION CHARACTERIZATION OF CATALYSTS............................... 35

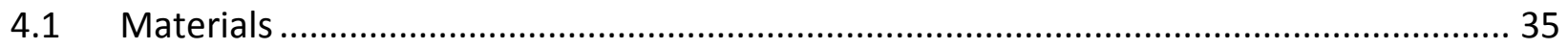

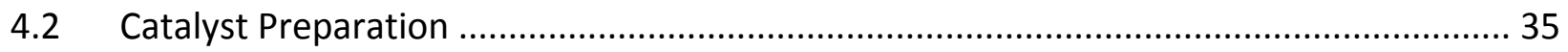

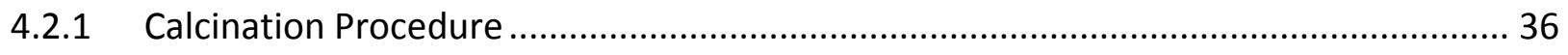

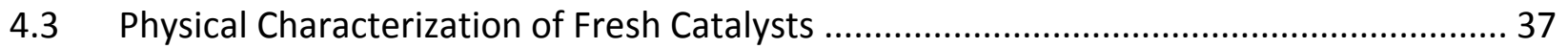

4.3.1 EDS Analysis of Silica Support and Cobalt Catalyst ............................................ 37 
4.3.2 Nitrogen Physisorption Measurement........................................................... 38

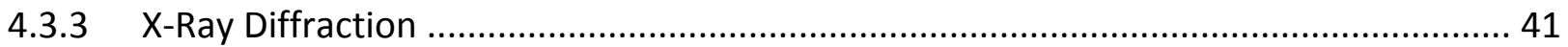

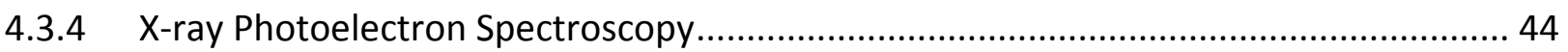

4.3.5 Temperature-Programmed Reduction................................................................. 46

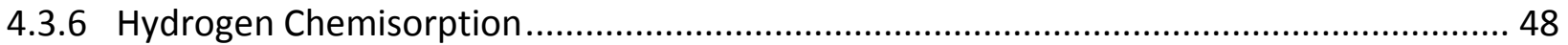

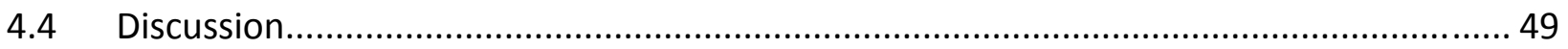

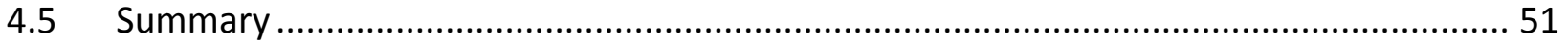

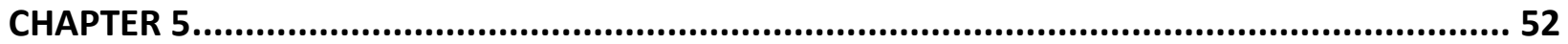

CONVERSION AND PRODUCT DISTRIBUTION: PERFORMANCE OF COBALT-ONLY CATALYST .. 52

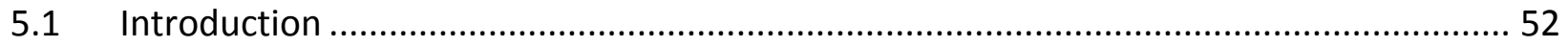

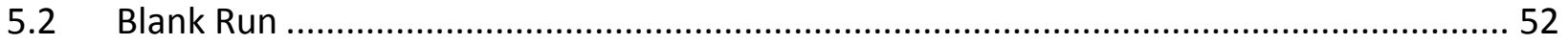

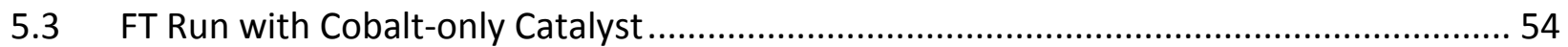

5.4 Qualitative and Quantitative Analysis of Products .................................................... 55

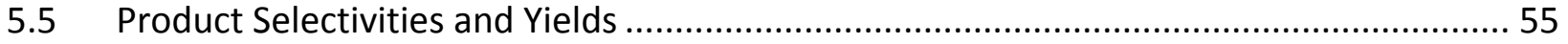

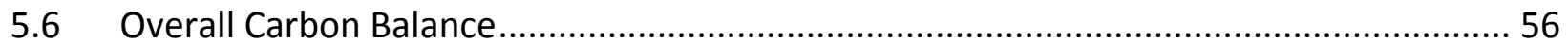

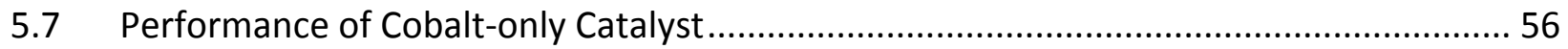

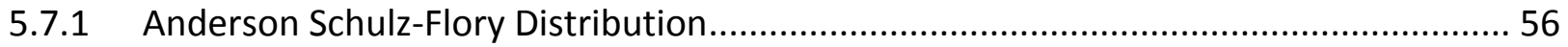

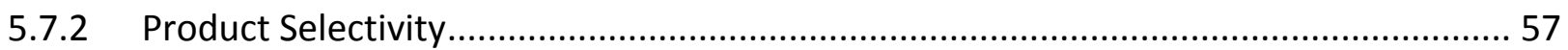

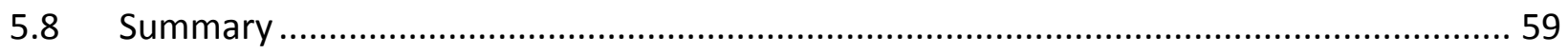

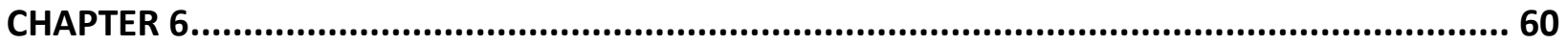

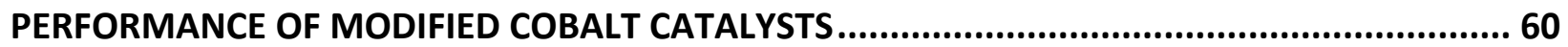

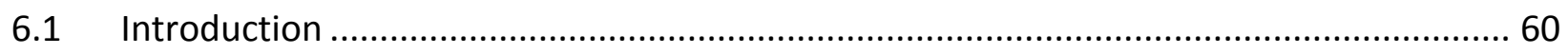

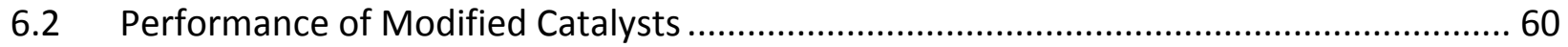

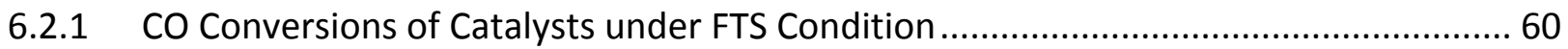




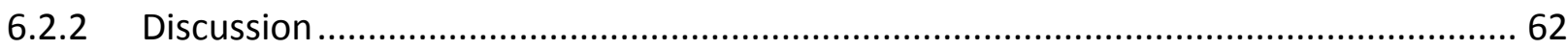

6.3 Comparison of Hydrocarbon Selectivities .............................................................. 63

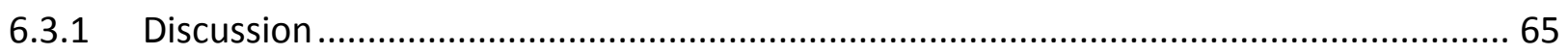

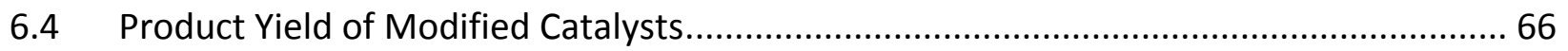

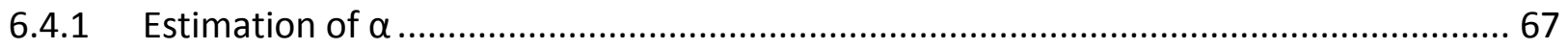

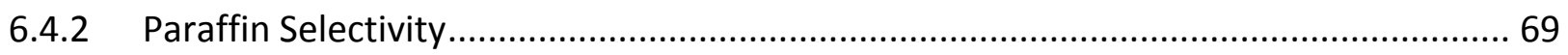

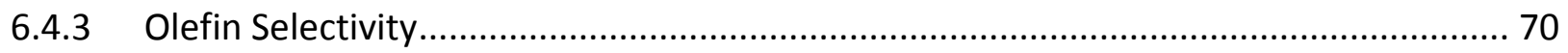

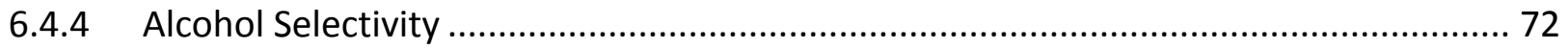

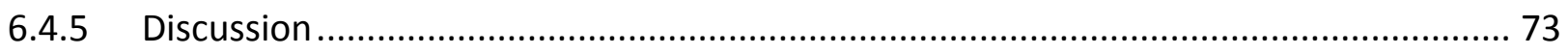

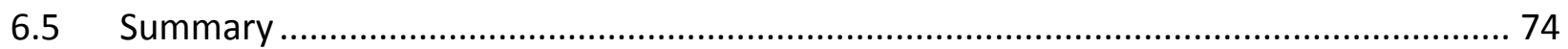

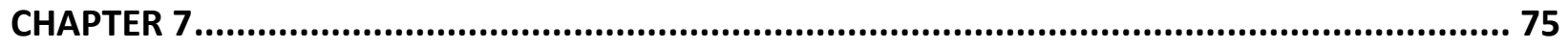

DETERMINATION OF KINETIC PARAMETERS AND MASS-TRANSFER LIMITATIONS FOR FT

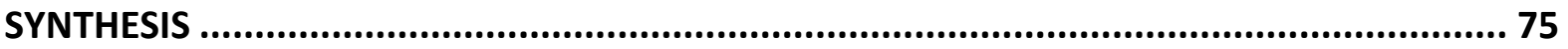

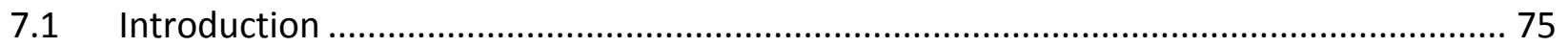

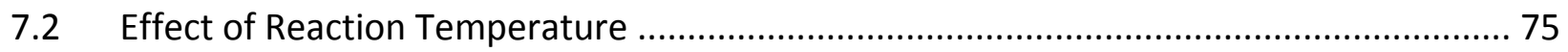

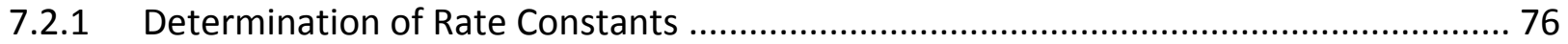

7.2.2 Rate Constant and Reaction Rates of CA-modified Catalysts ................................. 80

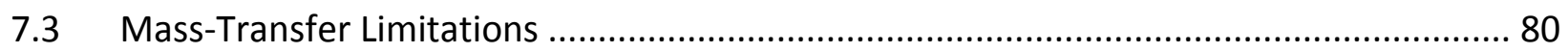

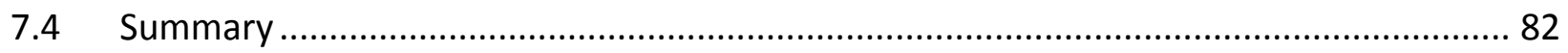

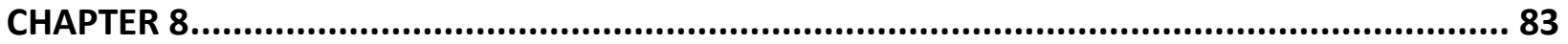

EFFECT OF SULFUR IMPURITIES IN THE INLET SYNGAS ON THE PERFORMANCE OF FT CATALYST

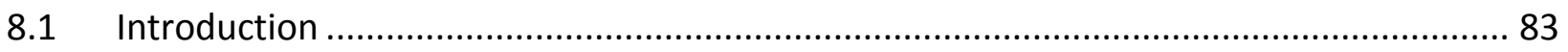

8.2 Selection of Solvent and Organic Sulfur ............................................................... 83 


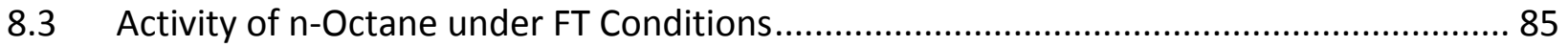

8.4 Performance of the Cobalt Catalyst in the Presence of n-Octane Only ........................ 87

8.4.1 Revised Procedure for Paraffin Product Analysis.................................................. 88

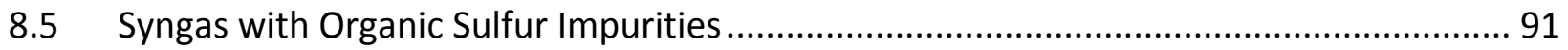

8.5.1 Preparation of Butanethiol and n-Octane Mixture ............................................... 91

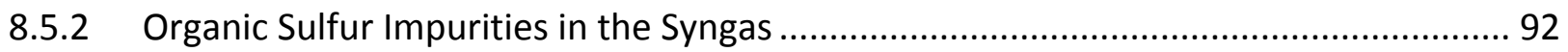

8.6 Effect of Organic Sulfur Impurities on CO Conversion and FT Rate............................. 93

8.6.1 CO Conversions of Base Case Catalyst .............................................................. 93

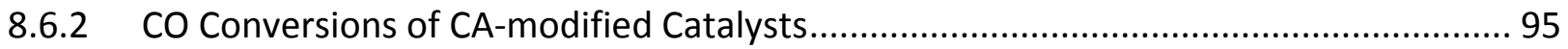

8.6.3 Reaction Rates, TOF and Percent Site Lost due to Poisoning ................................ 97

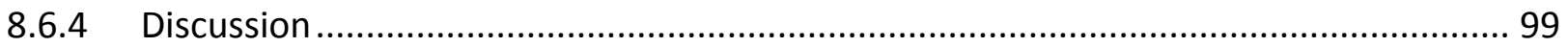

8.7 Effect of Sulfur Poisoning on Product Selectivities.................................................. 100

8.7.1 Hydrocarbon Selectivity of the Base Catalyst ................................................... 100

8.7.2 Hydrocarbon Selectivity of the CA-modified Catalysts ........................................ 103

8.7.3 $\mathrm{CO}_{2}$ Selectivity of the Base Catalyst ........................................................... 105

8.7.4 $\mathrm{CO}_{2}$ Selectivity of the CA-modified Catalysts ................................................. 106

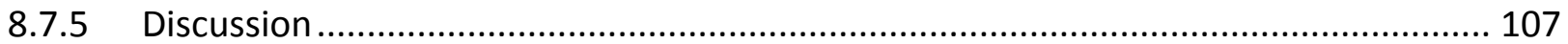

8.8 Effect of Sulfur Poisoning on the Product Yield and Distribution.................................. 109

8.8.1 Product Yield and Percent Product Distribution of the Base Catalyst...................... 110

8.8.2 Product Yield and Percent Product Distribution of the CA-modified Catalysts........... 112

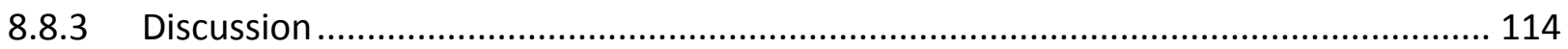

8.9 Kinetic Modeling of the Deactivation ............................................................... 116

8.9.1 Determination of Deactivation Constant and Half-life of Catalysts........................... 117

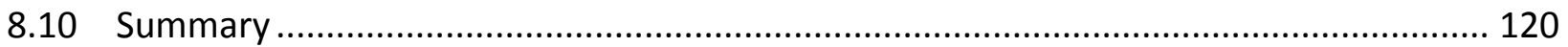




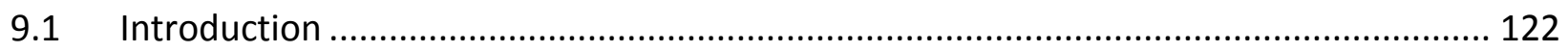

9.2 Characterization of the Spent Catalysts Subjected to Pure Syngas.............................. 122

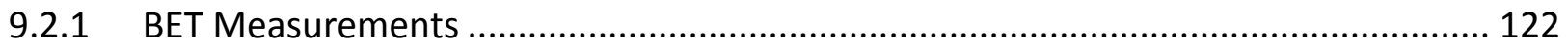

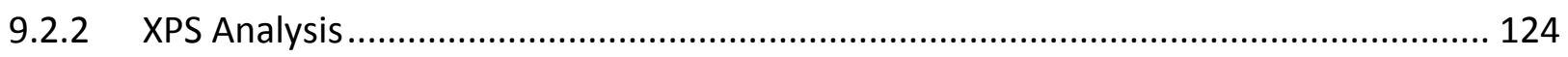

9.3 Characterization of the Spent Catalysts Subjected to Sulfur Impurities ...................... 125

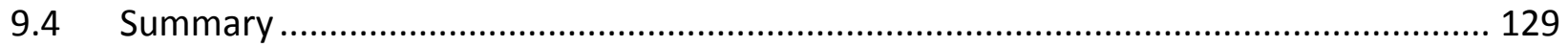

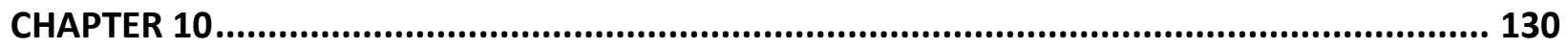

CONCLUSIONS AND FUTURE RECOMMENDATIONS ....................................................... 130

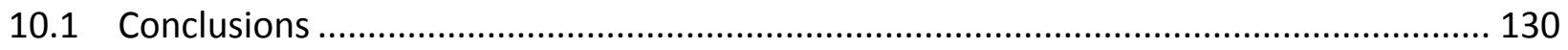

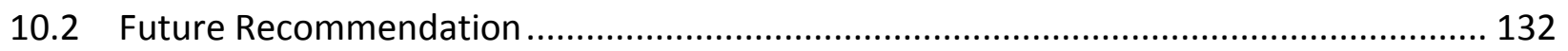

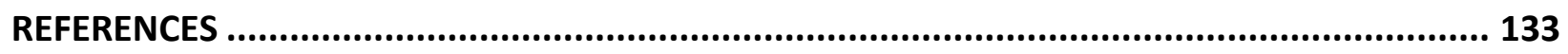

APPENDIX A: CALIBRATION OF MASS-FLOW CONTROLLERS (MFCs) .................................. 144

APPENDIX B: ONLINE GAS-CHROMATOGRAPHY UNIT ................................................... 147

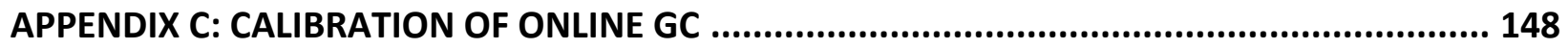

APPENDIX D : OFFLINE GAS-CHROMATOGRAPHY UNIT ................................................. 153

APPENDIX E: CALIBRATION OF OFFLINE GC............................................................. 154

APPENDIX F: MATERIAL SAFETY DATA SHEETS (MSDSS) ............................................ 155

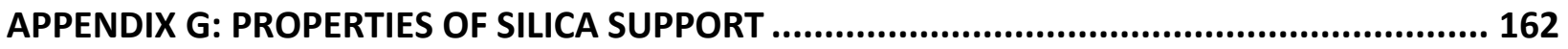

APPENDIX H: SAMPLE GAS CHROMATOGRAPHS...................................................... 163

APPENDIX I: CALCULATION PROCEDURE............................................................... 168

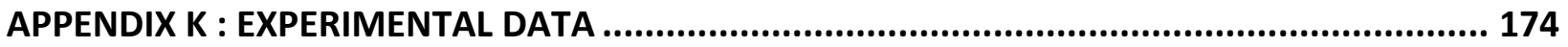




\section{LIST OF TABLES}

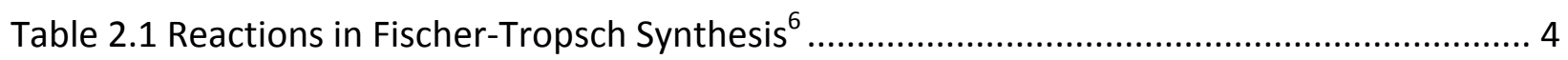

Table 2.2 Selectivity control in Fischer-Tropsch synthesis by process conditions ......................... 7

Table 2.3 Potential biomass feedstock available for gasification ............................................... 13

Table 2.4 Composition of syngas derived from biomass in different gasification processes....... 15

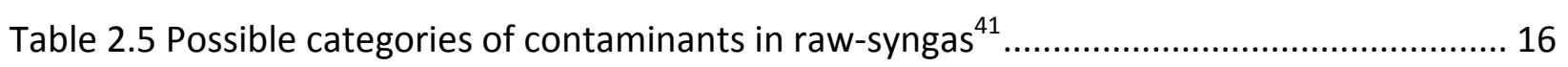

Table 2.6 Acceptable Levels of Contaminants in Syngas for Various Applications ....................... 18

Table 2.7 Effect of Sulfur Contaminants of FT product Selectivities ............................................. 24

Table 4.1 Surface area and pore volume results of silica support and catalysts ......................... 39

Table 4.2 Physical properties and crystallite sizes of cobalt catalysts for $\mathrm{CA} / \mathrm{Co}=1 \ldots \ldots \ldots \ldots \ldots \ldots . . . .42$

Table 4.3 Physical properties and crystallite sizes of cobalt catalysts for $\mathrm{CA} / \mathrm{Co}=0.5$................ 44

Table 4.4 Binding energies of $\mathrm{Co} 2 \mathrm{p} 3 / 2$ and $\mathrm{Co} 2 \mathrm{p} 1 / 2$ for the $\mathrm{Co}_{3} \mathrm{O}_{4}$ phase of cobalt catalysts.. 45

Table 4.5 Hydrogen chemisorption and dispersion data for catalysts ......................................... 49

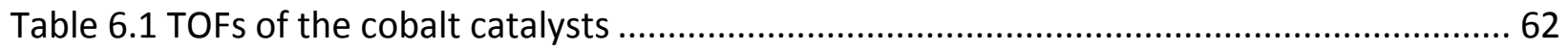

Table $6.2 \mathrm{CO}_{2}$ selectivity and olefin/paraffin ratio of modified catalysts ....................................6 65

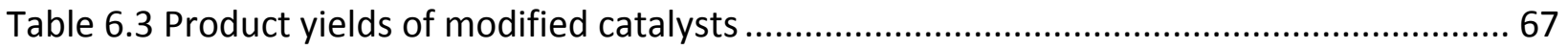

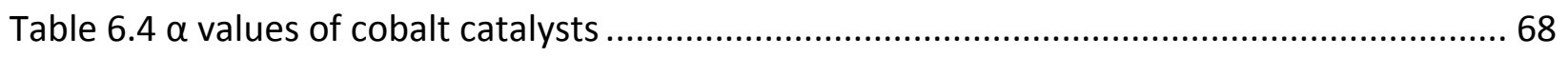

Table 7.1 Effect of temperature on average CO conversion and TOF ......................................... 76

Table 7.2 Rate constant for the base-case cobalt catalyst ......................................................... 79

Table 7.3 Rate constant and reaction rates of CA-modified catalysts ......................................... 80

Table 7.4 Effect of GHSV on CO conversion and TOF of the base catalyst.................................. 81

Table 8.1 Physical properties of the solvent and sulfur carrier ${ }^{106}$................................................ 85

Table 8.2 Reaction rates, TOF and percent sites lost by poisoning of cobalt catalysts................ 98

Table 8.3 Overall HC selectivity of cobalt catalyst for different sulfur concentration ................. 101

Table 8.4 HC Selectivity for the CA-modified catalysts in the presence of 10 ppm sulfur ......... 104

Table 8.5 Summary of the product yield and the product distribution of $\mathrm{Co} / \mathrm{SiO}_{2}$ catalyst under different sulfur concentrations 111

Table 8.6 Product yield and percent product distribution of CA-modified catalysts in the presence of $10 \mathrm{ppm}$ sulfur. 113 
Table 8.7 Deactivation constant, half-life and intercept of FT catalysts under sulfur poison.... 120

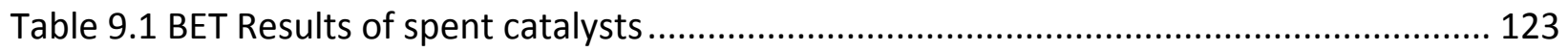

Table 9.2 Binding energies of $\mathrm{Co} 2 \mathrm{p} 3 / 2$ and $\mathrm{Co} 2 \mathrm{p} 1 / 2$ for the $\mathrm{Co}_{3} \mathrm{O}_{4}$ phase of spent catalysts. 125

Table A.1 rRF of TCD components of online GC ............................................................ 151

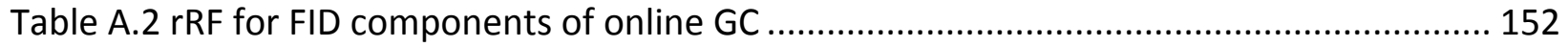

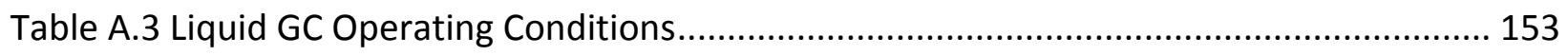

Table A.4 FID Areas of reference standards and cyclohexanol ............................................ 154

Table A.5 Physical properties of $\mathrm{SiO}_{2}$ support as received .............................................. 162 


\section{LIST OF FIGURES}

Figure 2.1 Effect of modification with chelating agent on the space-time yield (STY) of $\mathrm{C}_{10}-\mathrm{C}_{20}$ hydrocarbons obtained with reduced $\mathrm{Co} / \mathrm{SiO}_{2}$ catalysts ${ }^{34}$ 12

Figure 3.1 BenchCAT ${ }^{\mathrm{TM}}$ fixed-bed reactor setup at National Energy Technology Laboratory, Department of Energy, Morgantown, WV 27

Figure 4.1 Energy dispersive X-ray spectroscopy of silica support........................................ 37

Figure 4.2 Energy dispersive X-ray spectroscopy of cobalt catalyst...................................... 38

Figure 4.3 SEM images of cobalt catalysts (a) 20-40 mesh size particles and (b) a well-dispersed cobalt oxide phase 38

Figure 4.4 Nitrogen adsorption (BET) isotherms for $\mathrm{SiO}_{2}$ support before impregnation and silica supported cobalt catalysts 40

Figure 4.5 Pore size distribution curves (PSD) for $\mathrm{SiO}_{2}$ support before impregnation and silica supported cobalt catalysts 40

Figure 4.6 X-ray diffraction patterns: (a) $\mathrm{SiO}_{2}$ support, (b) calcined $\mathrm{Co} / \mathrm{SiO}_{2}$, (c) calcined $\mathrm{Co} / \mathrm{NTA} / \mathrm{SiO}_{2}$, and (d) calcined $\mathrm{Co} / \mathrm{EDTA} / \mathrm{SiO}_{2}$. Calcinations are at $250{ }^{\circ} \mathrm{C}, \mathrm{CA} / \mathrm{Co}=1$. 41

Figure 4.7 X-ray diffraction patterns: (a) $\mathrm{SiO}_{2}$ support, (b) calcined $\mathrm{Co} / \mathrm{SiO}_{2}$, (c) calcined $\mathrm{Co} / \mathrm{NTA} / \mathrm{SiO}_{2}$, and (d) calcined $\mathrm{Co} / \mathrm{EDTA} / \mathrm{SiO}_{2}$. Calcinations are at $350{ }^{\circ} \mathrm{C}, \mathrm{CA} / \mathrm{Co}=1$ 42

Figure $4.8 \mathrm{X}$-ray diffraction patterns: (a) $\mathrm{SiO}_{2}$ support, (b) calcined $\mathrm{Co} / \mathrm{SiO}_{2}$, (c) calcined $\mathrm{Co} / \mathrm{NTA} / \mathrm{SiO}_{2}$, and (d) calcined $\mathrm{Co} / \mathrm{EDTA} / \mathrm{SiO}_{2}$. Calcinations are at $250{ }^{\circ} \mathrm{C}, \mathrm{CA} / \mathrm{Co}=0.5$ 43

Figure 4.9 X-ray diffraction patterns: (a) $\mathrm{SiO}_{2}$ support, (b) calcined $\mathrm{Co} / \mathrm{SiO}_{2}$, (c) calcined $\mathrm{Co} / \mathrm{NTA} / \mathrm{SiO}_{2}$, and (d) calcined $\mathrm{Co} / \mathrm{EDTA} / \mathrm{SiO}_{2}$. Calcinations are at $350{ }^{\circ} \mathrm{C}, \mathrm{CA} / \mathrm{Co}=0.5$ 44

Figure 4.10 Comparison between the $\mathrm{Co} 2 \mathrm{p}$ XPS spectra of $\mathrm{Co}_{3} \mathrm{O}_{4}$ for base catalyst and CAmodified catalysts. 45

Figure 4.11 Temperature-programmed reduction profiles of various cobalt catalysts 47

Figure 5.1 Inlet and outlet molar flow rate of $\mathrm{CO}$ for a run of quartz chips filled reactor under FT conditions 53

Figure 5.2 Syngas conversion for a run of quartz chips filled reactor under FT conditions ......... 53

Figure $5.3 \mathrm{CO}$ conversions vs. TOS for a $\mathrm{Co} / \mathrm{SiO}_{2}$ catalyst................................................... 54

Figure 5.4 ASF distribution over the base-case catalyst 57 
Figure 5.5 Product selectivities as a function of carbon numbers over a $\mathrm{Co} / \mathrm{SiO}_{2}$ catalyst ......... 58 Figure $6.1 \mathrm{CO}$ conversions of the base catalyst and the CA-modified catalysts at $\mathrm{T}_{\text {cat }}=220^{\circ} \mathrm{C}$ and $\mathrm{T}_{\text {cat }}=230^{\circ} \mathrm{C}$. 61

Figure $6.2 \mathrm{CO}$ conversion and hydrocarbons selectivity with CA-modified catalysts at $\mathrm{T}_{\text {cat }}=230{ }^{\circ} \mathrm{C}$ 64

Figure 6.3 CO conversion and hydrocarbons selectivity with CA-modified catalysts at .............64

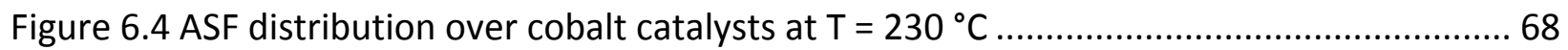

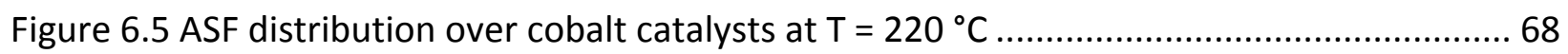

Figure 6.6 Paraffins selectivity as a function of carbon number over CA-modified catalysts...... 69

Figure 6.7 Paraffins selectivity as a function of carbon number over CA-modified catalysts...... 70

Figure 6.8 Olefin selectivity as a function of carbon number over CA-modified catalysts .......... 71

Figure 6.9 Olefin selectivity as a function of carbon number over CA-modified catalysts .......... 71

Figure 6.10 Alcohol selectivity as a function of carbon number over CA-modified catalysts ...... 72

Figure 6.11 Alcohol selectivity as a function of carbon number over CA-modified catalysts ...... 73

Figure 7.1 Arrhenius-plot of CO conversion for the base catalyst ........................................ 79

Figure 7.2 CO conversion as a function of TOS (h) for the base catalyst at flow rates of 200, 225 and $250 \mathrm{sccm}$ (experimental conditions: $\mathrm{T}=230^{\circ} \mathrm{C} ; \mathrm{P}=20 \mathrm{bar} ; \mathrm{H}_{2} / \mathrm{CO}$ inlet molar ratio $=2$ )

Figure 7.3 Plot of CO conversion vs. space velocity for the base catalyst.............................. 82

Figure 8.1 CO conversion and molar inlet and outlet CO flow rates for a blank run with n-octane,

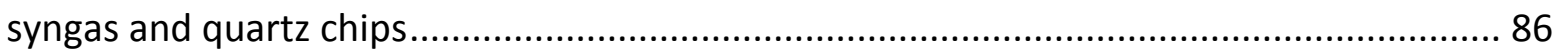

Figure $8.2 \mathrm{CO}$ conversion for $\mathrm{Co} / \mathrm{SiO}_{2}$ catalyst during a dry run ("normal” run) and with n-octane 88

Figure 8.3 Weight distribution of paraffins as a function of carbon numbers over a $\mathrm{Co} / \mathrm{SiO}_{2}$ catalyst (a) for $24-48 \mathrm{~h}$ and (b) for $48-72 \mathrm{~h}$ 89

Figure 8.4 Weight distribution of paraffins collected at the end of $48 \mathrm{~h}$ after subtracting the blank run data for $\mathrm{C}_{8}$. 91

Figure $8.5 \mathrm{CO}$ conversion data for $\mathrm{Co} / \mathrm{SiO}_{2}$ catalyst with addition of 10 and 50 ppm sulfur (Experimental conditions: $\mathrm{T}=230^{\circ} \mathrm{C} ; \mathrm{P}=20 \mathrm{bar} ; \mathrm{GHSV}=13,500 \mathrm{sccm} / \mathrm{h} / \mathrm{g}_{\text {cat }}$ ) 93 
Figure 8.6 $\mathrm{CO}$ conversion for the $\mathrm{Co} / \mathrm{SiO}_{2}$ catalyst with different inlet: (a) "normal" run with syngas feed, (b) run with syngas and n-octane feed, (c) syngas with 10 ppmv S equivalent,

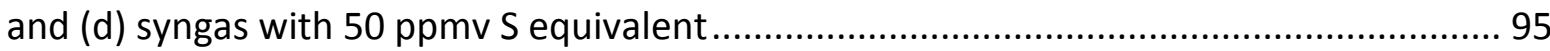

Figure $8.7 \mathrm{CO}$ conversion data for $\mathrm{Co} / \mathrm{EDTA} / \mathrm{SiO}_{2}$ and $\mathrm{Co} / \mathrm{NTA} / \mathrm{SiO}_{2}$ catalyst in presence of....... 96

Figure $8.8 \mathrm{CO}$ conversions data for CA-modified catalyst: (a) $\mathrm{Co} / \mathrm{EDTA} / \mathrm{SiO}_{2}$ at $\mathrm{GHSV}=9000$ $\mathrm{sccm} / \mathrm{h} / \mathrm{g}_{\text {cat }}$ and no $\mathrm{S}$, (b) Co/EDTA $/ \mathrm{SiO}_{2}$ at $\mathrm{GHSV}=13,500 \mathrm{sccm} / \mathrm{h} / \mathrm{g}_{\text {cat }}$ with $10 \mathrm{ppmv} \mathrm{S}$ equivalent, (c) $\mathrm{Co} / \mathrm{NTA} / \mathrm{SiO}_{2}$ at $\mathrm{GHSV}=9000 \mathrm{sccm} / \mathrm{h} / \mathrm{g}_{\mathrm{cat}}$ and no $\mathrm{S}$, and (d) $\mathrm{Co} / \mathrm{NTA} / \mathrm{SiO}_{2}$ at GHSV $=13,500 \mathrm{sccm} / \mathrm{h} / \mathrm{g}_{\text {cat }}$ with $10 \mathrm{ppmv}$ S equivalent

Figure $8.9 \mathrm{CO}_{2}$ selectivity for the $\mathrm{Co} / \mathrm{SiO}_{2}$ catalyst with different inlet: (a) "normal" run with syngas feed, (b) run with syngas and n-octane feed, (c) syngas with 10 ppmv S equivalent, and (d) syngas with 50 ppmv S equivalent 106

Figure $8.10 \mathrm{CO}_{2}$ selectivity for the catalyst in the presence of $10 \mathrm{ppmv} \mathrm{S}$ equivalent: (a) $\mathrm{Co} / \mathrm{SiO}_{2}$ catalyst, (b) $\mathrm{Co} / \mathrm{EDTA} / \mathrm{SiO}_{2}$ catalyst, and (c) $\mathrm{Co} / \mathrm{NTA} / \mathrm{SiO}_{2}$ catalyst 107

Figure 8.11 Plot of $f\left(X_{C O}\right)$ vs. $(t-24)$ for the $10 \mathrm{ppm}$ sulfur poisoning run for $\mathrm{Co} / \mathrm{SiO}_{2}$ catalyst 118

Figure 8.12 Plot of $f\left(X_{\mathrm{CO}}\right)$ vs. $(t-24)$ for the $50 \mathrm{ppm}$ sulfur poisoning run for $\mathrm{Co} / \mathrm{SiO}_{2}$ catalyst

Figure 8.13 Plot of $f\left(X_{C O}\right)$ vs. $(t-24)$ for the $10 \mathrm{ppm}$ sulfur poisoning run on $\mathrm{Co} / \mathrm{EDTA} / \mathrm{SiO}_{2}$ catalyst 119

Figure 8.14 Plot of $f\left(X_{\mathrm{CO}}\right)$ vs. $(t-24)$ for the $10 \mathrm{ppm}$ sulfur poisoning run on $\mathrm{Co} / \mathrm{NTA} / \mathrm{SiO}_{2}$ catalyst

Figure 9.1 Nitrogen adsorption (BET) isotherms for the spent cobalt catalysts ......

Figure 9.2 Pore size distribution curves (PSD) for the spent cobalt catalysts 124

Figure 9.3 Comparison between the $\mathrm{Co} 2 \mathrm{p}$ XPS spectra of $\mathrm{CO}_{3} \mathrm{O}_{4}$ for spent catalyst 125

Figure 9.4 EDS analysis of $\mathrm{Co} / \mathrm{SiO}_{2}$ catalyst (a) fresh sample, (b) spent catalyst with pure-noctane run, (c) spent catalyst with $10 \mathrm{ppm}$ sulfur run and (d) spent catalyst with $50 \mathrm{ppm}$ sulfur run

Figure 9.5 EDS analysis of the spent CA-modified catalyst with 10 ppm sulfur in the feed (a), (b) different particles of Co/EDTA/SiO ${ }_{2} ;(\mathrm{c})$, (d) different particles of spent $\mathrm{Co} / \mathrm{NTA} / \mathrm{SiO}_{2} \ldots . . .128$ 


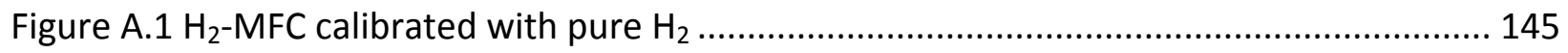

Figure A.2 CO-MFC calibrated with syngas mixture ...................................................... 145

Figure A.3 He-MFC calibrated with pure He .................................................................. 146

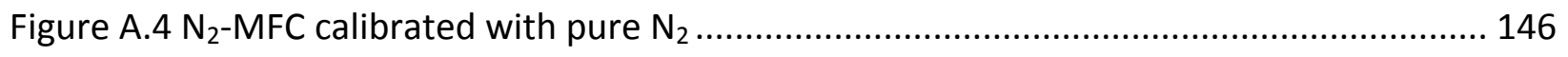

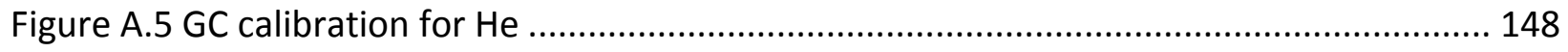

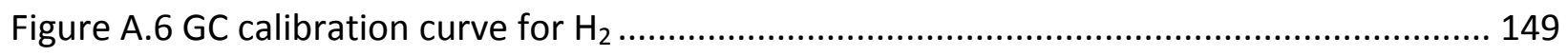

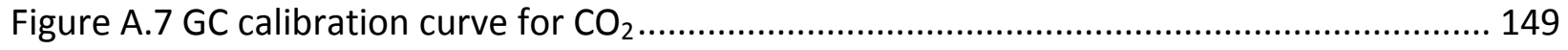

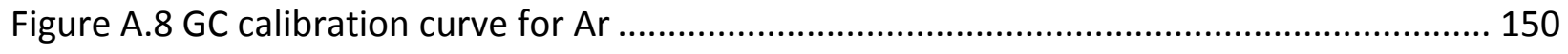

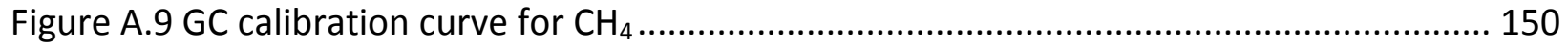

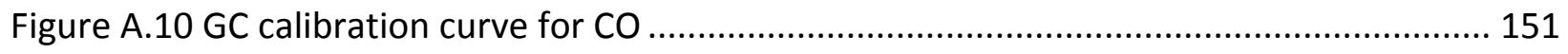

Figure A.11 TCD chromatograph of base catalyst on online GC ......................................... 164

Figure A.12 FID chromatograph of base catalyst on online GC ........................................... 165

Figure A.13 FID chromatograph of oil phase of base catalyst on offline GC ......................... 166

Figure A.14 FID chromatograph of aqueous phase of base catalyst on offline GC ................. 167 


\section{CHAPTER 1 \\ INTRODUCTION}

\subsection{Background}

Fischer-Tropsch synthesis (FTS) has been recognized as the promising technology for the conversion of coal, natural gas and biomass-derived syngas into liquid fuels and chemicals. The worldwide depleting oil reserves, energy supply security concerns, pollution abatements laws and most notably ever-increasing fuel prices have fuelled the research interest in commercialization of Fischer-Tropsch for the future. The FTS reaction in general is represented by,

$$
\mathrm{CO}+2 \mathrm{H}_{2} \rightarrow \frac{1}{n}\left(-\mathrm{CH}_{2}-\right)_{n}+\mathrm{H}_{2} \mathrm{O}
$$

Improvements in the performance (activity, stability, selectivity etc.) of the catalyst materials are needed to accelerate the commercialization of Fischer-Tropsch technology based on coal and/or biomass derived syngas. Especially, the rapid deactivation of catalyst in the presence of gas impurities, such as sulfur, has been one of the major areas in catalyst development needing more attention. Sulfur impurities in biomass- and coal-derived syngas are found in the form of organic and inorganic sulfur causing severe damage to catalyst activity. The activity of cobalt catalysts has been known to drop from a few months to a few days, due to the presence of ppm levels of sulfur in syngas. Therefore, there is an opportunity to improve the performance of cobalt catalysts to withstand syngas impurities.

In this work, the aim is to improve the performance and stability of silica-supported cobalt (i.e., $\mathrm{Co} / \mathrm{SiO}_{2}$ ) catalysts. A cobalt loading of 20 wt\% is used, consistent with the conventional catalysts. The silica support is modified with one of the two chelating agents (nitrilotriacetic acid or ethylenediaminetetracetic acid) before impregnation of the cobalt salt. The activity of the base catalyst and the modified catalysts are evaluated under relevant FT conditions in a fixed-bed reactor. The catalysts are compared on the conversion of syngas and product selectivities. In addition, the catalysts are characterized before and after the reaction in order to establish the structure-activity relationship. 
In the next step, a protocol is developed to introduce organic sulfur impurities with the aid of a liquid delivery system. The base catalyst is subjected to various levels of sulfur impurities and the performance is monitored in the pre-poisoning, the poisoning and the postpoisoning stage. Similarly, the CA-modified catalysts are subjected to the sulfur impurities to study the effect of poisoning.

\subsection{Statement of the Problem and Objectives}

Silica-supported cobalt catalysts have often been reported to suffer from a strong interaction between the metal and the support, leading to the poor performance of the catalyst. Strong bonding can result in the availability of fewer metal atoms on the surface for reaction (i.e., lower metal dispersion) causing a significant drop in the activity. Therefore, the modification of the support surface by a chelating agent is proposed to improve the performance of $\mathrm{Co} / \mathrm{SiO}_{2}$ catalysts. In addition, the cobalt catalysts commonly used for FT synthesis are sensitive towards impurities in syngas. There are very few studies in the literature focusing on the catalyst poisoning due to organic sulfur impurities present in the coal- and/or biomass-derived syngas.

Objectives of the study are as follows:

1. To compare the syngas conversions and the hydrocarbon selectivities of the base catalyst and the CA-modified catalysts at 220 and $230{ }^{\circ} \mathrm{C}$.

2. To perform physical characterization of the fresh and spent catalysts to establish the structure-activity relationship.

3. To evaluate the effect of operating temperature, and space velocity on catalysts.

4. To determine the kinetic parameters and mass-transfer limitation for catalysts investigated in this study.

5. To develop a procedure to introduce sulfur impurities into the inlet syngas with the existing laboratory reactor setup.

6. To study the poisoning effect of organic sulfur impurities in the form of butanethiol on the base catalyst and CA-modified catalysts by comparing the activities and product selectivities. 


\section{CHAPTER 2 \\ LITERATURE REVIEW}

\subsection{Introduction}

Since its arrival in the 1920s, Fischer-Tropsch (FT) synthesis has seen a growing interest as a tool for processing synthesis gas ( $\mathrm{CO}$ plus $\mathrm{H}_{2}$, syngas) into premium quality fuels such as naphtha, jet fuel, diesel, and gasoline. The major driving force for the commercialization of gasto-liquid (GTL) technology is the high crude-oil prices and the growing demand for clean diesel fuel in the world ${ }^{1-5}$. The viability of any commercial fuel production process is generally governed by the performance of a catalyst used. In practice therefore, the selection of a suitable catalyst is generally based on its activity and stability.

At present, the interest in the hydrocarbon fuels has shifted towards maximizing the yield of diesel range FT products (i.e., $\mathrm{C}_{10}-\mathrm{C}_{20}$ ). Moreover, the recent laws for sulfur emissions abatement have increased a demand for low-sulfur diesel. The syngas derived from a gasification of coal and/or biomass may contain impurities such as sulfur, chlorine etc. The impurities are carried along with the syngas to a catalytic bed of the FT unit, causing a severe catalyst deactivation. Hence, the development of a catalyst displaying a functional balance to produce liquid hydrocarbons selectively and able to withstand the sulfur impurities is the goal of this study.

In this chapter, an introduction to FT synthesis and reactions involved in the process is presented. The selection of cobalt as a catalyst in this study, to process coal and/or biomassderived syngas, has been supported by some of the previous studies from the literature. The types of biomass which can be used as a feedstock for syngas production are reviewed and compared based on their $\mathrm{C}$ and $\mathrm{H}$ content. In addition, a brief overview on the potential syngas impurities and their effects on the catalyst performance are presented in the context of the present research. Finally, the performance of $\mathrm{Co} / \mathrm{SiO}_{2}$ catalysts modified by chelating agents is reviewed. 


\subsection{Fischer-Tropsch Synthesis}

The FT process is a catalyzed chemical reaction in which a mixture of hydrogen and carbon monoxide, often called synthesis gas (syngas) is converted into different forms of hydrocarbons (HCs). The reactions involved in Fischer-Tropsch synthesis (FTS) are summarized in Table $2.1^{6}$. FTS comprises of many polymerization reactions initiated by the formation of a methyl or methylene monomer on a solid catalyst. Therefore, the primary FT products due to the polymerization reaction include paraffins, olefins and alcohols, in addition to $\mathrm{CO}_{2}$ and water ${ }^{6}$.

Table 2.1 Reactions in Fischer-Tropsch Synthesis ${ }^{6}$

\begin{tabular}{|l|l|}
\hline \multicolumn{2}{|l|}{ Overall Reactions } \\
\hline Main Reaction & $(2 n+1) \mathrm{H}_{2}+n C O \rightarrow \mathrm{C}_{n} \mathrm{H}_{2 n+2}+n \mathrm{H}_{2} \mathrm{O}$ \\
\hline 1. Paraffins & $2 n \mathrm{H}_{2}+n \mathrm{CO} \rightarrow \mathrm{C}_{n} \mathrm{H}_{2 n}+n \mathrm{H}_{2} \mathrm{O}$ \\
\hline 2. Olefins & $\mathrm{CO}+\mathrm{H}_{2} \mathrm{O} \leftrightarrow \mathrm{CO}_{2}+\mathrm{H}_{2}$ \\
\hline 3. WGS reaction & $2 n \mathrm{H}_{2}+n \mathrm{CO} \rightarrow \mathrm{C}_{2} \mathrm{H}_{2 n+2} \mathrm{O}+(n-1) \mathrm{H}_{2} \mathrm{O}$ \\
\hline Side Reactions & $\left(\right.$ ii) $\mathrm{M}_{x} \mathrm{O}_{y}+y \mathrm{H}_{2} \leftrightarrow y \mathrm{H}_{2} \mathrm{O}+x M$ \\
\hline 4. Alcohols & (ii) $M_{x} \mathrm{O}_{y}+y \mathrm{CO} \leftrightarrow y \mathrm{CO}_{2}+x M$ \\
\hline $\begin{array}{l}\text { 5. Catalyst } \\
\text { oxidations/reductions } \\
\text { (M-metal sites) }\end{array}$ & $y \mathrm{C}+x M \leftrightarrow M_{x} \mathrm{C}_{y}$ \\
\hline 6. Bulk carbide formation & $2 \mathrm{CO} \rightarrow \mathrm{C}+\mathrm{CO}_{2}$ \\
\hline 7. Boudouard reaction &
\end{tabular}

\subsection{Reaction Kinetics}

Reaction steps contributing to the formation of linear hydrocarbons on cobalt catalyst are summarized in brief below ${ }^{7}$.

i. In the first step, $\mathrm{H}_{2}$ and $\mathrm{CO}$ species are assumed to adsorb dissociatively on the cobalt surface. The adsorption process results in the formation of several species like $\mathrm{CH}, \mathrm{CH}_{2}$, and $\mathrm{CH}_{3}$, as mentioned in the literature ${ }^{8,9}$.

ii. Chain growth of the adsorbed species occurs by insertion of methylene $\left(\mathrm{CH}_{2}\right)$ species ${ }^{6}$. Methylene species are considered as a monomer for the carbide mechanism, the most plausible mechanism for the hydrocarbon formation on the cobalt ${ }^{10}$ and iron ${ }^{11}$ catalysts.

iii. Chain termination is known to proceed with the addition of the $\mathrm{CH}_{3}$ species, the addition of $\mathrm{H}$ to paraffins or by the abstraction of hydrogen to olefins ${ }^{9}$. 
iv. Finally, secondary reactions occur with desorption of the primary products from the catalyst surface and further interaction with other catalytic sites prior to formation of end products such as $\alpha$-olefins and iso-paraffins ${ }^{12}$. Such secondary reactions can therefore greatly influence the type and the molecular weight of the hydrocarbons from FT synthesis ${ }^{6}$.

During the FTS process, a hydrogen molecule may react either in the molecular state or via dissociative adsorption. The adsorption process of hydrogen can be influenced by parameters such as the catalyst material, the reaction conditions and co-adsorption of the other species ${ }^{6}$. Most transition metals commonly used as the FTS catalyst are capable of dissociating hydrogen on the catalyst surface before hydrogen undergoes a reaction to form long-chain hydrocarbons ${ }^{8,10,13}$. Similarly, CO reaction may occur either with associative or dissociative adsorption. Associated adsorption of CO proceeds with carbon-metal bond formations. It in turn acts as a precursor to dissociate $\mathrm{CO}$ and form the carbide species ${ }^{13,14}$. On the other hand, in dissociative adsorption CO directly dissociates on the metal.

\subsection{Choice of a Catalyst}

The products of FT synthesis cover a wide range of hydrocarbons such as paraffins, olefins and alcohols (see Table 2.1). In recent years however, the hydrocarbons with a narrower carbon number range, e.g., $\mathrm{C}_{8}-\mathrm{C}_{20}$, have drawn a great deal of attention, due to applicability as a fuel or fuel additives without further upgrading ${ }^{8,13,15,16}$. Typically, the middle $\mathrm{HC}$ fraction (i.e., $\mathrm{C}_{7}-\mathrm{C}_{14}$ ) among FT products displays a high cetane number which contributes to a superior combustion and reduced emissions when used as a diesel fuel ${ }^{6}$. Numerous studies have been successful in correlating the observed distribution of FT products, with the types of catalyst and selected operating conditions $s^{6,17}$. Therefore, the choice of a catalyst is vital and is often governed by the desired product distribution.

Metals commonly used as catalyst for FTS include Group VIII elements such as nickel, iron and cobalt. The average molecular weight of hydrocarbon produced by a FT catalyst decreases in the following sequence: $\mathrm{Ru}>\mathrm{Fe}>\mathrm{Co}>\mathrm{Rh}>\mathrm{Ni}$. Therefore, only ruthenium, iron, and cobalt have catalytic properties useful for the commercial production ${ }^{18,19}$. Nickel predominantly is a methanation catalyst; cobalt favors synthesis of straight-chain paraffins 
whilst iron gives paraffins, olefins and oxygenated products ${ }^{8,19-22}$. Alternatively, ruthenium is a very active, but expensive, choice for FTS catalyst, as compared to Fe and Co. Ru produces higher quantities of methane at relatively low operating pressure ( $P<100$ bar), whereas at relatively low temperatures and high pressures, $\mathrm{Ru}$ is selective towards high-molecular-weight waxes $^{20-24}$. Since cost is a major driving force in the selection of a catalyst, iron usually has an obvious advantage over Co and Ni. Among all the choices, however, cobalt catalysts are reported to offer highest hydrocarbon yields, longest lifetimes and predominantly linear alkanes during the synthesis ${ }^{10,20,21,25}$.

Additionally, the $\mathrm{H}_{2}$-to- $\mathrm{CO}$ ratio of the syngas governs the choice of catalyst metal to some extent. Syngas derived from coal is generally rich in $\mathrm{CO}$ and has a $\mathrm{H}_{2}$-to-CO molar ratio anywhere from 0.5 to 1.0. On the other hand, biomass-derived syngas is richer in $\mathrm{H}_{2}$, with molar ratios ranging from 2 to 3 . The cobalt catalysts show lower activity towards WGS activity (see Table 2.1), hence they require a higher syngas ratio due to their inability to convert additional $\mathrm{CO}$ into $\mathrm{H}_{2}{ }^{26}$. However, cobalt catalysts are not significantly inhibited by moisture present in the syngas, resulting in higher productivity at high synthesis-gas conversion. Iron is known to oxidize at much lower $\mathrm{H}_{2} \mathrm{O} / \mathrm{H}_{2}$ ratios than cobalt, which causes significant loss of activity for iron during the process ${ }^{6,17,27}$. For these reasons, cobalt-based catalysts are preferentially used in the natural-gas-based and the biomass-derived syngas processing. The detailed comparison of cobalt and iron catalyst has been made elsewhere ${ }^{17}$.

\subsection{Operating Conditions and Product Selectivity}

Irrespective of the operating conditions, the FT products comprise a wide range of HCs. The distribution of these products can be tuned to some extent by thoughtful selection of the operating conditions, feed-gas composition, catalyst type and promoters. The carbon-number distribution for FTS commonly shows the highest concentration around $\mathrm{C}_{1}$ and a monotonic decrease for higher carbon numbers after a local maximum around $C_{3}-C_{4}{ }^{6,17}$. Over the past two decades, extensive efforts have been made to improve the selectivity of FTS catalysts for $\mathrm{C}_{5+}$ hydrocarbons to maximize gasoline-range or diesel-range HCs. 
Table 2.2 shows the general influence of the operating parameters on the selectivity of hydrocarbons ${ }^{6}$. Increasing the temperature shifts the selectivity towards the lower carbon number and to more hydrogenated products. As the degree of branching increases, the formation of secondary products such as ketones and aromatics is enhanced. On the other hand, increasing the pressure increases the extent of conversion and the chain length of the products. At lower partial pressure of $\mathrm{CO}$, the surface coverage by intermediate $\mathrm{CH}_{2}$ species is lower, and hence the desorption probability of $\left(\mathrm{CH}_{2}\right)_{\mathrm{n}}$ is higher. On the contrary, higher partial pressures of $\mathrm{H}_{2}$ increase the termination of surface species, to form more paraffins. Thus, one may expect a higher selectivity of lighter and more saturated hydrocarbons with a higher $\mathrm{H}_{2} / \mathrm{CO}$ ratio. This could, however, be an oversimplification, as many other parameters contribute to selectivity in FTS reactions.

Table 2.2 Selectivity control in Fischer-Tropsch synthesis by process conditions ( $\uparrow$, increase with increasing parameter; $\downarrow$, decrease with parameter; ${ }^{*}$, complex relation)

\begin{tabular}{lcccccc}
\hline Parameter & $\begin{array}{c}\text { Chain } \\
\text { Length }\end{array}$ & $\begin{array}{c}\text { Chain } \\
\text { Branching }\end{array}$ & $\begin{array}{c}\text { Olefin } \\
\text { Selectivity }\end{array}$ & $\begin{array}{c}\text { Alcohol } \\
\text { Selectivity }\end{array}$ & $\begin{array}{c}\text { Carbon } \\
\text { Deposition }\end{array}$ & $\begin{array}{c}\text { Methane } \\
\text { Activity }\end{array}$ \\
\hline Temperature & $\downarrow$ & $\uparrow$ & $*$ & $\downarrow$ & $\uparrow$ & $\uparrow$ \\
Pressure & $\uparrow$ & $\downarrow$ & $*$ & $\uparrow$ & $*$ & $\downarrow$ \\
$\mathrm{H}_{2} /$ CO & $\downarrow$ & $\uparrow$ & $\downarrow$ & $\downarrow$ & $\downarrow$ & $\uparrow$ \\
Conversion & $*$ & $*$ & $\downarrow$ & $\downarrow$ & $\uparrow$ & $\uparrow$ \\
Space Velocity & $*$ & $*$ & $\uparrow$ & $\uparrow$ & $*$ & $\downarrow$ \\
\hline
\end{tabular}

The kinetic and selectivity studies of FTS have been divided in two parts in the literature. In the first case, major consideration has been given to catalyst improvements and postulating empirical power-law kinetics for the reaction rates. Subsequently, the distribution of hydrocarbon yield is modeled by an Anderson-Schulz-Flory (ASF) distribution to study the selectivity of the products formed. In the second case, there are very few studies and they aim at understanding the reaction mechanism. Several authors have explained the reactant consumption and product distribution by deriving the rate expressions based on the LangmuirHinshelwood-Hougen-Watson (LHHW) model ${ }^{6}$. However, models which can effectively combine overall consumption and the product distribution are very scarce in the literature but are of great importance. 


\subsection{Role of Water-Gas Shift Activity}

The water-gas shift (WGS) reaction shown in Table 2.1 is an important step when a nonstoichiometric syngas is to be processed. The WGS can reach equilibrium at high temperatures $\left(\mathrm{T}>250^{\circ} \mathrm{C}\right.$ ) over an active catalyst. Most iron-based catalysts show very high activity towards WGS, as compared to cobalt and ruthenium ${ }^{2,27,28}$. For iron catalysts, magnetite $\left(\mathrm{Fe}_{3} \mathrm{O}_{4}\right)$ is considered to be the most active phase for WGS activity. It is generally assumed that WGS and FT reactions proceed on different active sites on the catalyst. WGS has been proposed to proceed by several mechanisms reported elsewhere in the literature ${ }^{2,28}$. Studies over iron and cobalt catalysts suggest that the formation of formate species is responsible for the WGS activity $^{5}$. The formate species are said to form by the reaction between a hydroxyl species (or water) and carbon monoxide in the gas phase or in adsorbed phase ${ }^{7}$. The hydroxyl intermediates may be formed by decomposition of water over the catalyst surface. Carbon dioxide is formed after reduction of such hydroxyl intermediates. However, some studies refute the formate formation mechanism and propose the direct oxidation of $\mathrm{CO}$ to form $\mathrm{CO}_{2}{ }^{2,3,6,27}$, 29.

\subsection{Syngas-based Synthetic Fuel Plants}

The industrial application of FT started in Germany in 1938, with nine operating plants having total annual capacity of about $660 \times 10^{3}$ tons (TPA). Production was ceased soon after WWII due to poor economics. In 1950, a $360 \times 10^{3}$ TPA plant based on $\mathrm{CH}_{4}$-derived syngas was built in Brownsville, Texas. By 1982, Sasol (South Africa) commissioned three plants with combined capacity of $4200 \times 10^{3}$ TPA. In 1993, Shell built a FT operation plant in Malaysia for synthesis of high-quality diesel fuel and waxes. In 2006, the Sasol Oryx 34,000 billion per day (bpd) plant was inaugurated. Sasol-Chevron is currently building its Escarvos GTL plant in Nigeria. Shell and Exxon have signed an agreement on building 140,000 and 150,000 bpd GTLFT plants in Qatar. Many production plants are in construction phase or are being planned by ExxonMobil, Syntroleum, BP and Chinese companies due to renewed interest in FTS because of rising crude-oil prices ${ }^{30}$. 


\subsection{Deactivation of Cobalt Catalysts}

The deactivation of cobalt catalyst can occur mainly due to a number of different mechanisms ${ }^{31}$, such as, (i) oxidation of the active cobalt metal to an inactive cobalt oxide, (ii) cobalt-support interaction resulting in formation of cobalt silicates and cobalt aluminates, (iii) poisoning by impurities present on the syngas, (iv) sintering of small crystallites into larger ones, (v) surface reconstruction, and (vi) carbon formation.

\subsubsection{Strong Metal-Support Interaction}

A strong interaction between an active metal and support is undesirable and may result in poor FT activity. In general, the drop in catalytic activity has been attributed to the depressed reducibility of the oxide precursor, which results in the availability of fewer metal atoms for reaction ${ }^{6,17,27,29}$. The type of metal precursor (in addition to many other parameters) can have an impact on catalyst behavior. The cobalt ions in an impregnating solution are surrounded by water ligands. These ions may interact with the silica support and form surface complexes. The species responsible for such interactions on silica are silanol groups, which are amphoteric materials. Depending on the $\mathrm{pH}$ of the impregnating solution, they may exist in the form of $\mathrm{SiOH}, \mathrm{SiO}^{-}$or $\mathrm{SiOH}_{2}{ }^{+}$species. The polarized nature of both transition metal complexes and inorganic oxides causes the adsorption of species due to electrostatic interaction between them. The result of this interaction is a strong metal-support interaction on a catalyst ${ }^{32-34}$.

The effect of a metal precursor, used for impregnation of $\mathrm{Co} / \mathrm{SiO}_{2}$ catalysts, on its reducibility and dispersions properties has been studied ${ }^{35}$. Complexes from an acetate precursor were assumed to interact with dissociated silanol groups and thus to form larger amounts of cobalt silicate. In addition, the formation of cobalt silicate was shown to be influenced by $\mathrm{pH}$ of the impregnation solution, surface area of the support, extent of solvent polarity and calcination and drying temperatures.

It must be noted that during the calcination step, the formation of small Co oxide clusters (e.g., $\mathrm{CoO}, \mathrm{CO}_{3} \mathrm{O}_{4}$ ) needs some assistance from the support for their growth. However, a strong interaction is undesirable and may depress the extent of reduction for Co species. The effect of mixed Co-precursor such as cobalt (II) nitrate and cobalt (II) acetate on FT activity of $\mathrm{Co} / \mathrm{SiO}_{2}$ catalyst has been studied ${ }^{36}$. The performance of catalysts with a mixed precursor was 
compared with the catalyst prepared with a single precursor. The cobalt catalyst with the acetate precursor displayed a strong metal interaction with $\mathrm{SiO}_{2}$ support and showed a difficulty in reduction, as compared to a nitrate precursor. However, in case of the mixed precursor catalyst, Co sites existing from a nitrate precursor were found to provide assistance to the reduction process of highly-dispersed Co-species from an acetate precursor.

\subsection{Modification with a Chelating Agent}

Silica and alumina are commonly used as supports for commercial cobalt catalysts. In case of the silica-supported catalyst, the interaction between metal and support is relatively weak; leading to a better reducibility of oxides of cobalt. On the other hand, cobalt dispersion is much lower in the silica-supported catalysts compared to alumina-supported ones. Therefore, synthesis of silica-supported cobalt catalysts with high dispersion is one of the challenges in designing a high-performance FT catalyst ${ }^{17}$.

A chelating agent is a multidentate ligand which, when contacted with metal ions, forms several bonds with each metal ion. The complex formed by a chelating agent and metal is called a chelate. Chelating agents have been widely used in metallurgy for separation of minerals, in textile industries to remove metal contaminants, and for removal of metals from food. However, use of a chelating agent in the preparation of a solid catalyst is fairly new ${ }^{37}$.

Recently, the effect of catalyst modification with chelating agents on the performance of $\mathrm{Co} / \mathrm{SiO}_{2}$ catalyst in FT synthesis has been investigated ${ }^{32-34,37,38}$. The impregnating solution containing cobalt nitrate was modified with different chelating agents, nitrilotriacetic acid (NTA), ethylenediaminetetraacetic acid (EDTA) or trans-1,2-diaminocyclohexane- $N, N, N^{\prime}, N^{\prime}$ tetracetic acid (CyDTA). Catalysts containing 5 w\% modified with a chelating agent showed a more-dispersed phase of $\mathrm{CO}_{3} \mathrm{O}_{4}$ after calcination, as compared to calcined catalysts without any chelating agent. NTA was seen to be a particularly effective chelating agent among three. Typically, in the case of NTA-modified catalysts after reductions at $800{ }^{\circ} \mathrm{C}$, ca. $90 \%$ of $\mathrm{Co}_{3} \mathrm{O}_{4}$ species formed after calcination changed into metallic Co. This catalyst showed significantly high selectivity for $\mathrm{C}_{10}-\mathrm{C}_{20}$ hydrocarbons when used for FT synthesis. Furthermore, with NTAmodified catalyst, CO conversion jumped to ca. $60 \%$ over $20 \mathrm{~h}$ of time on stream, in contrast to 
$20 \%$ for catalyst with no chelating agent. Overall $C_{5+}$ selectivities of modified catalysts were seen to be slightly lower than catalysts with no chelating agents. Although a detailed mechanism of the influence of a chelating agent is still unclear, it is hypothesized that the complex formed between $\mathrm{Co}^{2+}$ and NTA in the impregnating solution prevents the sintering of Co species during drying and calcination. The complex formed possibly shows resistance to sintering as it contains a bulky structure where metal ions are surrounded by ligands. Figure 2.1 compares the space-time yield (STY) of $\mathrm{C}_{10}-\mathrm{C}_{20}$ hydrocarbons (equivalent to diesel fraction) over the different catalysts ${ }^{34}$, each containing 5 w\% cobalt. The STY of $C_{10}-C_{20}$ hydrocarbon is higher for the catalyst with chelating agents. In particular, the preparation with NTA increases the STY of $\mathrm{C}_{10}-\mathrm{C}_{20}$ hydrocarbons by factor of ca. 3 .

Koizumi et al. ${ }^{34}$ studied the activity enhancement of the cobalt catalyst prepared by the co-impregnation of the chelating agents and the metal precursor, at lower metal loading of 5 w\%. They found NTA to be particularly effective among all the CAs studied. The conversion over NTA-Co/SiO 2 was observed to be ca. 3 times higher than that over $\mathrm{Co} / \mathrm{SiO}_{2}$. They reported the order of enhancement in FT activity due to CA modification as; $\mathrm{Co} / \mathrm{SiO}_{2}<\mathrm{EDTA}-\mathrm{Co} / \mathrm{SiO}_{2}<$ $\mathrm{NTA}-\mathrm{Co} / \mathrm{SiO}_{2}$ for the shorter duration of TOS of $20 \mathrm{~h}$. They also pointed out that the control of interaction between cobalt ions, chelating agents and $\mathrm{SiO}_{2}$ surface was crucial to the preparation of CA-modified Co catalyst with higher FT activity.

Therefore, based on the literature, the surface treatment of silica support can be potentially used for improving properties of $\mathrm{Co} / \mathrm{SiO}_{2}$ catalyst. The $\mathrm{CA}$ modification would also be a cost-effective way to improve catalyst performance, compared to the use of costly transition metals as promoters. Further, there exist no studies focusing on the support modification by CA at higher cobalt loading, $20 \mathrm{wt} \%$. Therefore the present study is undertaken to evaluate the effect of CA modification on the performance of FT catalyst with higher cobalt loading, 20 wt\%. 


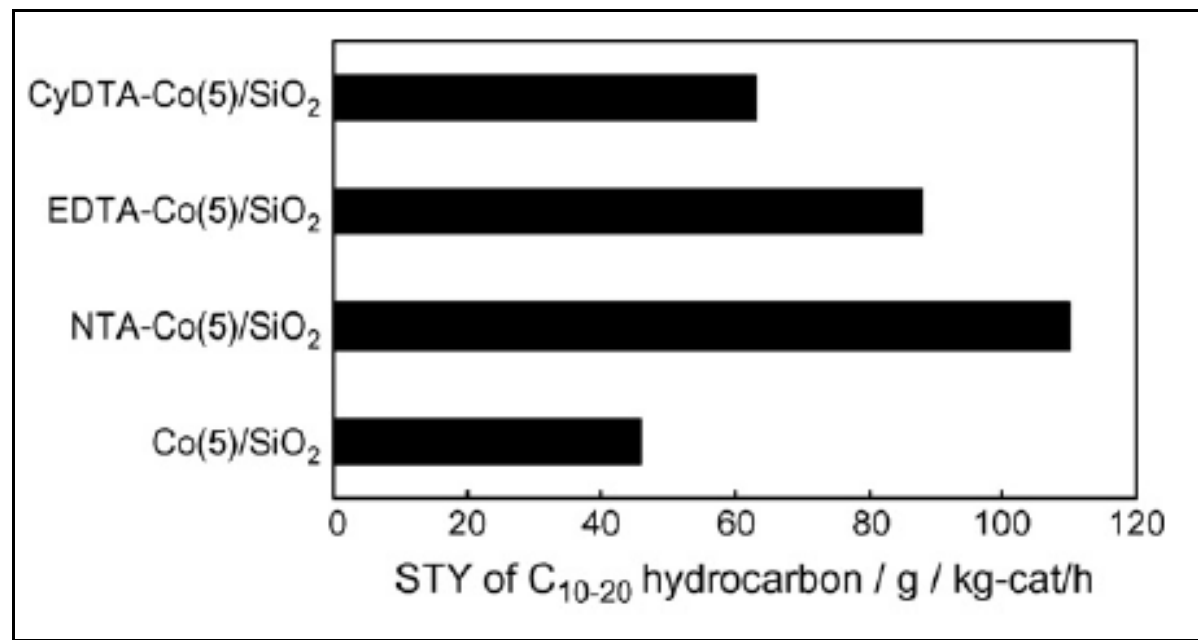

Figure 2.1 Effect of modification with chelating agent on the space-time yield (STY) of $\mathrm{C}_{10}-\mathrm{C}_{20}$ hydrocarbons obtained with reduced $\mathrm{Co} / \mathrm{SiO}_{2}$ catalysts ${ }^{34}$. (Reaction conditions; $503 \mathrm{~K}, 1.1 \mathrm{MPa}, 5.0 \mathrm{~g}$-cat h mol-CO ${ }^{-1}$ )

\subsection{Potential Biomass Feedstock for Syngas Production}

Syngas can be produced by the gasification and/or reforming of biomass, coal, and natural gas. Biomass is now well recognized as a potential renewable source of energy. Biomass sources available for gasification include wood wastes, agricultural remnants, residues from logging and forest management, fast-growing energy crops, and municipal wastes. Some of the potential feed-stocks that can be used to produce syngas are characterized in Table 2.3. The major constituents of any biomass include cellulose, hemi-cellulose and lignin. Generally, the main constituents of the biomass minerals are $\mathrm{Si}, \mathrm{Ca}, \mathrm{K}, \mathrm{Na}$ and $\mathrm{Mg}$, with smaller amounts of $\mathrm{Fe}$, $\mathrm{Mn}$ and Al. These mineral constituents may occur in the form of oxides, silicates, carbonates, sulfates, chlorides or phosphates ${ }^{39}$. The gasification of biomass primarily produces hydrogen and carbon monoxide, with lesser amounts of carbon dioxide, water, methane, higher hydrocarbons and nitrogen. The interest in biomass gasification to syngas arises from the fact that $\mathrm{H}_{2}$ and $\mathrm{CO}$ carry more than $70 \%$ of the energy stored in the biomass. 
Table 2.3 Potential biomass feedstock available for gasification

\begin{tabular}{|c|c|c|c|c|c|c|c|c|c|}
\hline \multirow[b]{2}{*}{ Biomass Feedstock } & \multicolumn{4}{|c|}{$\begin{array}{l}\text { Ultimate Analysis } \\
\text { (\% dry ash free basis) }\end{array}$} & \multicolumn{4}{|c|}{$\begin{array}{l}\text { Proximate Analysis } \\
\text { (wt \% basis) }\end{array}$} & \multirow[b]{2}{*}{ Reference } \\
\hline & C & $\mathbf{H}$ & $\mathbf{N}$ & 0 & Moisture & $\begin{array}{c}\text { Volatile } \\
\text { (daf) }\end{array}$ & $\begin{array}{l}\text { Fixed } \\
\text { Carbon }\end{array}$ & $\begin{array}{c}\text { Heating Value } \\
(\mathrm{MJ} / \mathrm{kg})\end{array}$ & \\
\hline Bagasse & 43.8 & 5.8 & 0.4 & 47.1 & - & 84.2 & - & - & 39 \\
\hline Coconut Shell & 50.2 & 5.7 & 0.0 & 43.4 & - & 80.2 & - & - & \\
\hline Groundnut shell & 48.3 & 5.7 & 0.8 & 39.4 & - & 83.0 & - & - & \\
\hline Rice Husk & 38.9 & 5.1 & 0.6 & 32.0 & - & 81.6 & - & - & \\
\hline Rice Straw & 36.9 & 5.0 & 0.4 & 37.9 & - & 80.2 & - & - & \\
\hline Wheat straw & 47.5 & 5.4 & 0.1 & 35.8 & - & 83.9 & - & - & \\
\hline Sawdust & 42.5 & 6.3 & 0.2 & - & 8.5 & 77.4 & 12.9 & 18.8 & 40 \\
\hline Thistle & 40.8 & 5.5 & 0.3 & - & 10.0 & 60.7 & 15.7 & 16.1 & \\
\hline Corn Cob & 49.0 & 5.4 & 0.4 & 44.6 & 5.8 & 76.5 & 15 & 17 & 41 \\
\hline Beech Wood & 50.4 & 7.2 & 0.3 & 41.0 & 19.0 & 85 & 14 & 18.4 & \\
\hline Pine Sawdust & 48.3 & 7.3 & 0.3 & 43.4 & 9.1 & 84.1 & 15.2 & 19.8 & 42 \\
\hline Olive Husk & 47.5 & 5.8 & 1.5 & 45.2 & 9.0 & - & - & - & 43 \\
\hline Pine Pinaster Chips & 50.0 & 5.7 & 0.2 & 44.1 & 12.0 & 75.0 & 12.5 & 18.8 & 44 \\
\hline $\begin{array}{l}\text { Pine and bark } \\
\text { woodchips }\end{array}$ & 41.8 & 5.3 & 0.2 & 52.7 & 11.1 & 74.4 & 12.4 & 18.5 & 45 \\
\hline Jute Stick & 49.8 & 6.0 & 0.2 & 41.7 & 3.0 & $76-78$ & $21.4-23.4$ & 19.1 & 46 \\
\hline Cedar Wood & 51.1 & 5.9 & 0.1 & 42.5 & 10 & $68-70$ & $29.7-31.7$ & 19.1 & \\
\hline
\end{tabular}


Table 2.4 presents the composition of product gas and $\mathrm{H}_{2} / \mathrm{CO}$ ratios after gasification of various biomass feedstocks reported in the literature. In principle, biomass gasification with air yields syngas with a $\mathrm{H}_{2}$-to-CO ratio close to or lower than 1 , which would be appropriate if the produced syngas is used as fuel by burning. However, a $\mathrm{H}_{2} / \mathrm{CO}$ ratio of 2 or higher is desired, if syngas is subjected to fuel production by the FT route. Thus, a gasifying medium with steam or a mixture of steam and oxygen is generally used to improve the $\mathrm{H}_{2}$-to-CO ratio to higher than 2 , more suitable for activity of cobalt catalyst ${ }^{47}$. The presence of low $\mathrm{H}_{2} / \mathrm{CO}$ ratios and a large excess of carbon dioxide in the syngas produced from biomass could pose problems for the production of methanol or dimethyl ether (DME). The overall yield of such products has been reported to be lowered by the large amounts of $\mathrm{CO}_{2}$ in syngas ${ }^{43}$. The $\mathrm{H}_{2} / \mathrm{CO}$ ratio can be adjusted either by adding hydrogen or by using the water-gas-shift (WGS) reaction. Although hydrogen addition uses the carbon contained in the biomass more efficiently, it requires a large supplementary capital investment. In contrast, WGS can convert the excess $\mathrm{CO}$ to $\mathrm{CO}_{2}$ and stoichiometric adjustment can be accomplished economically by excess carbon dioxide removal. However, an efficient and economical $\mathrm{CO}_{2}$ removal system is still a developing technology ${ }^{47}$. 
Table 2.4 Composition of syngas derived from biomass in different gasification processes (BFW, bubbling fluidized bed; DBG, dual-bed gasifier; FIB, fluidized bed; FxB, fixed bed)

\begin{tabular}{|c|c|c|c|c|c|c|c|c|c|}
\hline \multirow[t]{2}{*}{ Biomass Feedstock } & \multicolumn{2}{|c|}{ Process Conditions } & \multicolumn{4}{|c|}{$\begin{array}{l}\text { Product Gas Composition } \\
\text { (mol\%) }\end{array}$} & \multirow[t]{2}{*}{ Reactor } & \multirow{2}{*}{$\begin{array}{l}\mathrm{H}_{2}: \mathrm{CO} \\
\text { Ratio }\end{array}$} & \multirow[t]{2}{*}{ Reference } \\
\hline & $\mathrm{T}\left({ }^{\circ} \mathrm{C}\right)$ & $\mathbf{P}$ (atm) & $\mathrm{H}_{2}$ & $\mathrm{CO}$ & $\mathrm{CO}_{2}$ & $\mathrm{CH}_{4}$ & & & \\
\hline Wheat Straw & $650-780$ & 1.1 & - & - & - & - & FIB & $1.1-2.4$ & \multirow{4}{*}{40} \\
\hline Thistle & $650-780$ & 1.1 & - & - & - & - & FIB & $1.7-2.4$ & \\
\hline Sawdust & $650-780$ & 1.1 & - & - & - & - & FIB & $1.8-2.3$ & \\
\hline Wood Chips & $650-780$ & 1.1 & - & - & - & - & FIB & $1.4-2.3$ & \\
\hline Bagasse Char & $700-850$ & 1 & $67-76$ & $9-18$ & $12-17$ & $0.4-1.3$ & FxB & $3.8-7.8$ & 48 \\
\hline Municipal Solid Waste & - & - & 23.4 & 39.1 & 24.4 & 4.93 & FIB & 0.6 & 41 \\
\hline Pine Sawdust & 800 & 1 & 33 & 16 & 20 & 7 & BFW & 2 & 42 \\
\hline Pinewood Chips & $750-780$ & 1 & $13-31$ & $42-52$ & $14-36$ & $6-7$ & BFW & 0.5 & 44,49 \\
\hline Pinus & $780-890$ & 1 & - & - & - & - & FIB & $0.3-0.8$ & \\
\hline \multicolumn{10}{|l|}{ Pinaster Chips } \\
\hline Biomass Derived Oil & - & - & 33.3 & 29 & 4.9 & 17 & FIB & $1.2-2.4$ & 45 \\
\hline Biomass Derived Char & & - & 70 & 14 & 14 & 1 & FIB & $4-7$ & \\
\hline Cedar Wood & $823-923$ & 1 & - & - & - & - & DBG & $1.2-1.3$ & 46 \\
\hline Jute & $823-923$ & 1 & - & - & - & - & DBG & $1.1-1.3$ & \\
\hline Rice Straw & $823-923$ & 1 & - & - & - & - & DBG & $1-1.2$ & \\
\hline
\end{tabular}




\subsection{Contaminants Present in Biomass-derived Syngas}

Syngas produced from biomass gasification may have one or more of the categories of contaminants listed in Table $2.5^{41}$. Impurities entering the downstream processes along with syngas may include $\mathrm{S}, \mathrm{Cl}, \mathrm{As}, \mathrm{Ca}, \mathrm{K}, \mathrm{Na}, \mathrm{F}, \mathrm{P}, \mathrm{NH}_{3}$, and $\mathrm{Hg}$. The identity and amount of these contaminants varies largely with the type of feedstock and the process conditions used for gasification. These impurities may exist in a particulate or gaseous form. Tars and naphthalene are also considered as a potential hazard if syngas is processed in the absence of a gas-cleaning stage $^{50}$.

Of these contaminants, the alkali metals, ammonia, phosphorous and tars are not found when coal is gasified. If the particulates do not vaporize in the combustion process and consequently are allowed to enter the hot section, a high rate of contaminant deliveries to the wall surface can result in severe damage of equipment even at low concentration ${ }^{47}$. For example, carbon monoxide from syngas can potentially extract Fe from piping and other materials of construction, and this may result in a higher concentration of Fe-contaminants in downstream gases.

The most critical factors affecting the type and rate of degradation are the size distribution of particulates and levels of molten phases arriving at material surface. Greater material degradation such as corrosion, erosion and deposition has been reported for turbines operated with these impurities in the advanced gasification systems. Accordingly, many parts have needed more-frequent replacement for biomass-derived syngas as compared to syngas from natural gas, considered highly pure ${ }^{51}$.

Table 2.5 Possible categories of contaminants in raw-syngas ${ }^{41}$

\begin{tabular}{lll}
\hline Contaminants & Example & Potential Problem \\
\hline Particle & Ash, char, fluid bed material & Erosion \\
Alkali Metals & $\mathrm{Na}$ and K compounds & Hot corrosion, catalyst poisoning \\
Nitrogen Compounds & $\mathrm{NH}_{3}$ and $\mathrm{HCN}$ & Emissions \\
Tars & Refractive aromatics & Clogging of filters \\
Sulfur, Chlorine & $\mathrm{H}_{2} \mathrm{~S}$ and $\mathrm{HCl}$ & Corrosion, emission, catalyst poising \\
\hline
\end{tabular}

According to the Synthesis Gas Rule defined by EPA ${ }^{52}$, produced syngas should contain less than 200 ppmv $\mathrm{H}_{2} \mathrm{~S}$, less than 300 ppmv of total nitrogen (other than $\mathrm{N}_{2}$ ), and less than 1 
ppmv of total halogens ${ }^{53}$. Rule-of-thumb specifications for impurities that might be present in biomass-derived syngas are: less than $1 \mathrm{ppmv}$ for both the total sulfur $\left(\mathrm{H}_{2} \mathrm{~S}, \mathrm{COS}\right.$ and $\left.\mathrm{CS}_{2}\right)$ and nitrogen-containing impurities $\left(\mathrm{NH}_{3}\right.$ and $\mathrm{HCN}$ ), and less than $10 \mathrm{ppbv}$ for both the total halides and the alkaline metals. For naphthalene, this corresponds to an allowable content of 2 ppmv, while for the benzene compounds this corresponds to 2500 ppmv $^{52}$.

Normally, due to high levels of sulfur in coal, the $\mathrm{H}_{2} \mathrm{~S}$ content found in syngas after gasification is as large as $10^{3}$ to $10^{4} \mathrm{ppm}^{47}$. Sulfur present in biomass can be converted to hydrogen sulfide or sulfur oxides during gasification. Wood typically contains less than 0.1 wt\% sulfur and herbaceous crops may contain about 0.3-0.4 wt\% sulfur ${ }^{46}$. A higher sulfur content in the sewage sludge, as compared to biomass, is the major contributing factor towards the higher concentration of sulfur impurities in the derived syngas. As a result of low levels of sulfur in the biomass, the $\mathrm{H}_{2} \mathrm{~S}$ and SOx levels in the product gases are below those requiring a clean-up stage in most applications ${ }^{54}$. However, even at low concentrations, sulfur can pose significant problems. For example, the catalyst used for methanol production from syngas is known to get severely poisoned by sulfur impurities. In addition, some tar-cracking catalysts are also sulfur sensitive ${ }^{46,53,54}$.

The primary species of a nitrogen-containing contaminant in raw syngas is $\mathrm{NH}_{3}$. Highprotein feed-stocks such as animal waste or alfalfa can result in greater ammonia concentration in the product stream, since protein acts as source of nitrogen during gasification. Ammonia is undesired in the product stream since ammonia can lead to NOx formation ${ }^{55}$.

Levels of tolerance for different applications widely vary and generalization is not possible. However, the level of contaminants in general, permitted in a syngas for various applications is presented in Table 2.6. For example, syngas of very high quality is needed for the synthesis of methanol and FT fuels, whereas in case of applications such as turbines in power plants, for which syngas is used as a fuel, relatively high contaminant levels may be acceptable ${ }^{46,53}$. 
Table 2.6 Acceptable Levels of Contaminants in Syngas for Various Applications

\begin{tabular}{|c|c|c|c|c|c|c|}
\hline Syngas Application & Contaminants & Levels & $\begin{array}{c}\text { Temp. } \\
\left({ }^{\circ} \mathrm{C}\right)\end{array}$ & $\begin{array}{c}\text { Pressure } \\
\text { (bar) }\end{array}$ & $\mathrm{H}_{2} / \mathrm{CO}$ & Reference \\
\hline \multirow[t]{3}{*}{ Synthetic Fuels } & Sulfur & $<1 \mathrm{ppm}$ & & & & \\
\hline & Particulates & Low & $200-400$ & $20-30$ & 0.6 & 41 \\
\hline & $\mathrm{CO}_{2}$ & Low & & & & \\
\hline \multirow[t]{6}{*}{ Methanol } & Sulfur & $<1 \mathrm{ppm}$ & & & & \\
\hline & Particulates & Low & & & & \\
\hline & $\mathrm{CO}_{2}$ & Low & $100-200$ & 50 & 2.0 & 41,47 \\
\hline & Tars & $<0.1 \mathrm{mg} / \mathrm{Nm}^{3}$ & & & & \\
\hline & $\mathrm{NH}_{3}$ & $<10 \mathrm{ppm}$ & & & & \\
\hline & Halides & $<0.001 \mathrm{ppm}$ & & & & \\
\hline \multirow[t]{3}{*}{ Fuel Gas for Turbines } & Hydrocarbons & High & & & Not & \\
\hline & Particulates & Low & $500-600$ & 400 & Important & 41 \\
\hline & Metals & Low & & & & \\
\hline \multirow[t]{2}{*}{ PEM Fuel Cells } & $\mathrm{CO}$ & $<10 \mathrm{ppm}$ & - & - & - & 47 \\
\hline & $\mathrm{H}_{2} \mathrm{~S}$ & $<1 \mathrm{ppm}$ & & & & \\
\hline
\end{tabular}




\subsection{Influence of Sulfur Impurities}

Sulfur compounds that are generally found in syngas derived from coal and biomass are considered as a poison to FT catalysts. The sulfur impurities in syngas may be present in the form of hydrogen sulfide $\left(\mathrm{H}_{2} \mathrm{~S}\right)$, carbon disulfide $\left(\mathrm{CS}_{2}\right)$, carbonyl sulfide $(\mathrm{COS})$ or thio-ethers $(\mathrm{RSR})^{47}$. Among these sulfur compounds, $\mathrm{H}_{2} \mathrm{~S}$ is a more commonly observed form and particularly poisonous to catalysts. The presence of $\mathrm{H}_{2} \mathrm{~S}$ in as low as few ppm of concentration can limit the life of a catalyst to few hours or few days ${ }^{56,57}$. The extent of gas impurities in syngas can be notably high especially if syngas is derived from the gasification of a coal or biomass in absence of a catalyst or a post-processing stage (e.g., gas cleaning) ${ }^{58}$. For example, $\mathrm{H}_{2} \mathrm{~S}$ contents in the range of 20 to $200 \mathrm{ppm}$ have been reported for syngas produced from a non-catalytic gasification of biomass ${ }^{59}$. Moreover, the syngas derived from waste plastic was noted to contain $\mathrm{H}_{2} \mathrm{~S}$ and COS impurities of ca. 300 ppm in concentrations ${ }^{60}$. Initially, a practical upper limit of sulfur concentration in synthesis gas was reported to be as high as 1 to $2 \mathrm{mg} / \mathrm{m}^{3}$ mentioned elsewhere ${ }^{61}$. However, with a better understanding of a detrimental effect of sulfur on FT catalysts over the years, the acceptable level of sulfur in syngas has been reduced to few $\mathrm{ppm}^{47}$.

Sulfur interaction with the FT catalyst appears to be quite complex and ambiguous as addressed in the literature over the last five decades ${ }^{32,60,62}$. The earlier work on development of a sulfur-tolerant FT catalyst over four decades (1930-1970s) has been critically reviewed ${ }^{63}$. In several studies, sulfur has been shown to have an overall beneficial effect, in contrast to a mere catalyst deactivation. A lack of complete understanding of sulfur-catalyst interaction has been the reason for the inability in explaining a notable change in product distribution and catalyst deactivation.

In general, different catalytic sites on the same catalyst are believed to catalyze different reactions in different ways ${ }^{64}$. In spite of availability of numerous catalytic sites, sulfur tends to adsorb preferentially on thermodynamically favored sites, thus inhibiting reactions which normally occurs on those sites. Therefore, observed changes in product distribution have been largely attributed to selective blocking of catalytic sites by sulfur ${ }^{63}$. In addition, the changes in product selectivities can be explained by the newly formed catalytically active sites 
during interaction between sulfur and the active metal, contributing to enhanced activity of catalysts ${ }^{63-65}$. For example, the performance of $\mathrm{Pd} / \mathrm{CeO}_{2}$ catalysts have been evaluated for methanol synthesis from syngas in presence of $\mathrm{H}_{2} \mathrm{~S}$ impurities. The $\mathrm{H}_{2} \mathrm{~S}$ molecules were reported to oxidize over the surface of $\mathrm{Pd} / \mathrm{CeO}_{2}$ catalyst, in contrast to a sulfide formation generally seen on $\mathrm{Cu} / \mathrm{ZnO}$ and $\mathrm{Pd} / \mathrm{Al}_{2} \mathrm{O}_{3}$ catalysts. Surprisingly, $\mathrm{Pd} / \mathrm{CeO}_{2}$ catalysts exhibited improved stability for methanol synthesis in presence of $30 \mathrm{ppm} \mathrm{H}_{2} \mathrm{~S}$ at $240-250^{\circ} \mathrm{C}, 2.5-4.0 \mathrm{MPa}$ and 1000-2000 $\mathrm{h}^{-1} 66$.

Catalyst poisoning studies are extremely important as they can provide information about the amount of poisons catalyst can tolerate. This information can be used to decide the optimum level of syngas cleaning and to design sulfur-tolerant catalysts. Some laboratory studies in the literature have highlighted the detrimental effect of sulfur on the performance of FT catalysts. However, there are very few of those focused on cobalt catalysts. In general, cobalt is known to show strong sensitivity towards sulfur poisoning, as compared to the iron catalyst ${ }^{63,65,67}$. Furthermore, most of these studies (e.g., Visconti et al. ${ }^{68}$ ) have been performed by pre-sulfiding the catalyst. However, the ex-situ poisoning approach does not represent the actual physical situation where the impurities are present in the inlet syngas. Moreover, in-situ studies of sulfur poisoning have been mostly performed with $\mathrm{H}_{2} \mathrm{~S}$ (e.g., Bartholomew et al. ${ }^{67}$ ) and studies with organic sulfur are almost nonexistent (e.g., Pansare et al. ${ }^{69}$ ). The literature focusing on the design of novel FT catalysts and their reaction pathways is numerous (e.g., Laan et al. ${ }^{6}$ ), but again relatively few studies have looked into the poisoning effect. This can be explained by the complexity and the safety issues present with the sulfur compounds: sulfur has tendency to adsorb on process lines and can therefore damage parts of the reactor setup. Therefore, there exists an opportunity to study the poisoning effect of sulfur on the performance of cobalt catalyst.

\subsection{Development of Sulfur-Tolerant Catalysts}

In a commercial Fischer-Tropsch process, a desulfurizing unit is necessary to process raw syngas and to reduce the sulfur contents to a desired level. Desulfurizing units in general are capable of efficiently removing the sulfur compounds completely from the raw syngas to as low 
as $1 \mathrm{ppm}$ of concentration levels in a processed gas ${ }^{32}$. The development of a sulfur-resistant catalyst is expected to minimize the load on de-sulfurizers and hence allow processing of a bio-syngas (derived from coal, biomass etc.) in a more economical way.

Over the years, several attempts have been made to improve the sulfur tolerance of FT catalysts ${ }^{32,57,63-66}$. However, compared to significant efforts in the development of a novel FT catalyst, there are very few studies in literature which highlight catalyst poisoning. In the past, attention was mainly focused on the reaction using coal-derived syngas that has a low $\mathrm{H}_{2} / \mathrm{CO}$ ratio and contains large amounts of $\mathrm{H}_{2} \mathrm{~S}\left(10^{3}\right.$ to $\left.10^{4} \mathrm{ppm}\right)$. There are very few studies focusing on processing biomass-derived syngas that have relatively high $\mathrm{H}_{2} / \mathrm{CO}$ ratio and low sulfur content $^{32}$.

\subsubsection{Laboratory Scale Study of Catalyst Poisoning}

Sulfur compounds can be easily adsorbed on walls of a reactor and piping, therefore designing of a laboratory sulfur-poisoning experiment needs careful attention to be paid to material selection. Stainless steel components are the least susceptible to sulfur interaction, and have been successfully used for FT synthesis in laboratories. All the experimental components are therefore strictly fabricated from stainless steel to minimize the adsorption problem $^{70}$. Specially designed gas cylinders are required for gas storage in order to minimize the sulfur diffusion into the walls.

Laboratory-scale poisoning experiments can be carried out in two ways. Firstly, the FT catalysts can be pre-sulfided with sulfur precursor (e.g., ammonium sulfide) and the catalyst performance can be subsequently evaluated at FT conditions ${ }^{63}$. In the second approach, impurities such as $\mathrm{H}_{2} \mathrm{~S}$ or $\mathrm{COS}$ can be first premixed with syngas and then can be subjected to $\mathrm{FTS}^{67}$. The latter approach resembles conditions commonly experienced by a catalyst in a commercial process and therefore, is implemented to provide better understanding of the poisoning process.

The development of sulfur-resistant catalysts to date has been based on two approaches; the first approach incorporates the use of a 'sulfur-sink' additive to adsorb sulfurbased impurities selectively ${ }^{71}$; the second approach includes the pre-treatment of catalyst with gases such as $\mathrm{H}_{2}, \mathrm{CO}$, and pre-nitriding ${ }^{63}$. Of the two approaches, the use of additives (or 
promoters) has shown promising results in context of syngas conversions, selectivities for longchain HCs, along with ease of regeneration for a deactivated-catalyst. On the other hand, the pre-treatment method has been effective at extending the shelf life of Fe-based catalysts compared to cobalt ${ }^{63}$.

\subsubsection{Response of Promoted FT Catalysts to Sulfur Impurities}

Addition of a promoter to a catalyst matrix can extend the shelf-life of a catalyst. Commonly used promoters include transition metals and have been shown to improve the performance of catalysts even in small quantities ${ }^{67}$. Promoters can selectively adsorb impurities

and assist the reduction of a metal during pre-treatment ${ }^{15,63}$. The promotional effect of alkali metals on FT catalysts has been proved to have a notable effect in improving stability against sulfur impurities $20,21,23,24,72$.

The promotional effect of boron addition on $\mathrm{Fe} / \mathrm{SiO}_{2}$ and $\mathrm{Co} / \mathrm{SiO}_{2}$ catalyst has been studied in the presence of $\mathrm{H}_{2} \mathrm{~S}$ impurities ${ }^{67}$. During in-situ exposure of $0.5 \mathrm{ppm}$ of $\mathrm{H}_{2} \mathrm{~S}$ for several days, the normalized activity (i.e. specific activity at any time t, divided by the initial activity at $\mathrm{t}=0$ ) of the boron promoted Fe catalyst was noted to increase by $40 \%$ than in the absence of boron. This was explained by the selective adsorption of $\mathrm{H}_{2} \mathrm{~S}$ on boron sites of a catalyst. Boron assisted in delaying the deactivation of Fe-sites especially at low $\mathrm{H}_{2} \mathrm{~S}$ concentrations. In contrast, the normalized activity for a $\mathrm{Co} / \mathrm{SiO}_{2}$ catalyst in the same study was reported to decrease from 1 to 0.5 . Furthermore, $\mathrm{Co} / \mathrm{SiO}_{2}$ catalyst showed a shift in selectivity to high molecular weight HCs.

The sulfur poisoning of a precipitated Fe catalyst has been reported elsewhere ${ }^{71,73}$. The addition of a large amount of $\mathrm{MnO}$ in Fe-catalysts was observed to improve the $\mathrm{H}_{2} \mathrm{~S}$ tolerance (ca. $300 \mathrm{ppm}$ ) for both $\mathrm{H}_{2}$-rich and CO-rich syngas processing. In addition, the observed increase in selectivities of such precipitated Fe-MnO catalysts towards $\mathrm{C}_{2}-\mathrm{C}_{4}$ olefins was attributed to the modifications of active sites by $\mathrm{MnO}$ over the catalyst surface.

The effect of sulfur addition during preparation of $\mathrm{Co} / \mathrm{Zn} / \mathrm{TiO}_{2}$ catalyst has been investigated $^{74}$. The unsulfided catalysts with or without zinc were found to produce more higher-molecular-weight products $\left(\mathrm{C}_{12+}\right)$ and less methane. On the contrary, a drastic increase in the $C_{1}-C_{11}$ selectivity and a decrease in the $C_{12+}$ selectivities were observed for sulfided 
catalysts, as as presented in Table 2.7. The changes in the selectivities were explained by preferential adsorption of sulfur on cobalt and zinc causing blocking of active sites for FT reactions. The effect of sulfur contaminants on FT product selectivities is also presented in Table 2.7.

Another aspect of improving the stability of FT catalyst follows a pre-treatment step with $\mathrm{H}_{2}, \mathrm{CO}, \mathrm{H}_{2} \mathrm{~S}$ or $\mathrm{H}_{2} / \mathrm{CO}$ gases before subjecting the catalyst to FTS. For example, a Fe-Rh/SiO 2 catalyst after $\mathrm{H}_{2}$ treatment showed higher selectivity towards straight-chain hydrocarbons ${ }^{32}$. On the other hand, sulfided catalysts showed greater selectivity towards alcohol (e.g. methanol).

A notable increase in the CO conversion with increase in the zirconium content of a $\mathrm{Co} / \mathrm{SiO}_{2}$ catalyst has been reported ${ }^{75}$. The $\mathrm{C}_{5+}$ selectivities and the secondary hydrogenation activity were noted to pass through a maximum with increasing zirconium content ${ }^{75}$. Furthermore, addition of a promoter to a catalyst can greatly improve the dispersion of a metal on the support ${ }^{20,76}$. Noble metals such as iridium, ruthenium, rhodium, rhenium or platinum assist the reduction of divalent cobalt $\left(\mathrm{Co}^{2+}\right)$ to the metallic state, thereby keeping the cobalt highly dispersed on the support ${ }^{3,8,23}$. In general, noble metals have strong inclination for hydrogen activation and hence during reduction the oxides of cobalt are reduced to the metallic form by a hydrogen spill-over mechanism ${ }^{2,6,17}$. For example, the effect of addition of a promoter such as $\mathrm{Re}$ and $\mathrm{Rh}$ on $\mathrm{Co} / \mathrm{Al}_{2} \mathrm{O}_{3}$ catalysts was shown ${ }^{77}$ to enhance the selectivity of FT towards higher-molecular-weight hydrocarbons. 
Table 2.7 Effect of Sulfur Contaminants of FT product Selectivities

\begin{tabular}{|c|c|c|c|c|c|c|c|}
\hline \multirow[t]{2}{*}{ Catalyst } & \multirow{2}{*}{$\begin{array}{l}\text { Sulfur } \\
\text { Loading }\end{array}$} & \multirow[t]{2}{*}{$T, P$} & \multirow[t]{2}{*}{ CO conversion $\%$} & \multicolumn{3}{|c|}{ Selectivities \% } & \multirow[t]{2}{*}{ Reference } \\
\hline & & & & $\mathrm{CH}_{4}$ & $\mathrm{C}_{2}-\mathrm{C}_{5}$ & $\mathrm{C}_{5+}$ & \\
\hline $\mathrm{Co} / \mathrm{TiO}_{2}$ & $0 \%$ & $220^{\circ} \mathrm{C}$ & 29.9 & 15.3 & 10.1 & 74.5 & 74 \\
\hline $\mathrm{Co} / \mathrm{S} / \mathrm{TiO}_{2}$ & $1 \%$ & 8 bar, & 19.1 & 25.4 & 19.8 & 54.8 & \\
\hline $\mathrm{Co} / \mathrm{Zn} / \mathrm{TiO}_{2}$ & $0 \%$ & $\mathrm{H}_{2} / \mathrm{CO}=2$ & 43.4 & 18.3 & 12.5 & 69.2 & \\
\hline $\mathrm{Co} / \mathrm{Zn} / \mathrm{S} / \mathrm{TiO}_{2}$ & $1 \%$ & & 27.8 & 20.2 & 13.3 & 67.4 & \\
\hline $\mathrm{Co} / \mathrm{S} / \mathrm{Zn} / \mathrm{TiO}_{2}$ & $1 \%$ & & 24.4 & 22.4 & 15.8 & 62.0 & \\
\hline $\mathrm{Co} / \mathrm{B} / \mathrm{TiO}_{2}$ & $0 \mathrm{ppm}$ & $250^{\circ} \mathrm{C}$ & 43.2 & 11.5 & 9.4 & 79.6 & 57 \\
\hline \multirow[t]{3}{*}{$\mathrm{S} / \mathrm{Co} / \mathrm{B} / \mathrm{TiO}_{2}$} & 100 ppm & 8 bar, & 43.0 & 13.5 & 16.1 & 69.0 & \\
\hline & 200 ppm & $\mathrm{H}_{2} / \mathrm{CO}=2$ & 44.0 & 16.0 & 18.0 & 66.1 & \\
\hline & 500 ppm & & 24.0 & 39.0 & 36.6 & 23.4 & \\
\hline \multirow[t]{5}{*}{$\mathrm{Co} / \mathrm{SiO}_{2}$} & $0 \mathrm{ppm}$ & $220^{\circ} \mathrm{C}$, & 25 & 8 & 18 & 74 & 78 \\
\hline & $10 \mathrm{ppm}$ & 20 bar, & 19 & 9 & 18 & 73 & \\
\hline & 100 ppm & $\mathrm{H}_{2} / \mathrm{CO}=2$ & 15 & 9 & 20 & 71 & \\
\hline & 250 ppm & & 9 & 18 & 38 & 44 & \\
\hline & 1000 ppm & & 2 & 29 & 45 & 26 & \\
\hline Fe-Mn-K/AC & $0 \mathrm{ppm}$ & $360^{\circ} \mathrm{C}$ & 97.4 & - & - & - & 79 \\
\hline $\mathrm{S}^{2-}$ anions & 500ppm & $1.5 \mathrm{MPa}$ & 24.8 & - & - & - & \\
\hline $\mathrm{SO}_{4}{ }^{2-}$ anions & 500ppm & $\mathrm{H}_{2} / \mathrm{CO}=2$ & 90.4 & - & - & - & \\
\hline \multirow[t]{3}{*}{$\mathrm{Fe} / \mathrm{Cu} / \mathrm{K} / \mathrm{SiO}_{2}$} & 150 ppm & $230^{\circ} \mathrm{C}$ & 56.7 & 3.4 & 15.5 & 81.1 & 80 \\
\hline & & $2.0 \mathrm{MPa}$ & & & & & \\
\hline & & $\mathrm{H}_{2} / \mathrm{CO}=2$ & & & & & \\
\hline
\end{tabular}




\subsection{Relation of Literature Studies to Research Plan}

The commercialization of cobalt catalysts needs an improvement in the FT performance of the catalyst. More often, the silica-supported cobalt catalysts have poor dispersions and hence fewer catalytic sites. The surface treatment of silica can be used to engineer the properties of cobalt catalysts. Preliminary studies with modification by a chelating agent have shown promising outcomes, and this technique needs to be further evaluated for the conventional $\mathrm{Co} / \mathrm{SiO}_{2}$ catalyst. Furthermore, very few studies have discussed the effect of catalyst poisoning due to organic sulfur in the inlet syngas under relevant FT situations. Also, the effect of organic sulfur on the product selectivity needs to be carefully examined.

Accordingly, the protocol for the present research work is designed after careful review of previous studies. In the first part, the effect of CA modification on the FT performance of catalysts is investigated. In the next step, a novel procedure to study organic sulfur poisoning in the laboratory reactor setup is discussed. Finally, the performance of cobalt catalysts, with and without CA addition, is determined in the presence of sulfur impurities. 


\section{CHAPTER 3 \\ EXPERIMENTAL SETUP AND PROCEDURE}

\subsection{Introduction}

A brief explanation of various components of the BenchCAT unit, used to perform Fischer-Tropsch (FT) synthesis, is provided with the technical specifications. Also, different characterization techniques used for investigating physical properties of solid catalysts are noted.

\subsection{Equipment Description}

The BenchCAT ${ }^{\mathrm{TM}}$ unit was designed and built by Altamira Instruments to carry out FT synthesis. The block diagram of the reactor system is shown in Figure 3.1. The unit has been designed to operate at maximum process conditions of $500{ }^{\circ} \mathrm{C}$ and 1500 psig. A brief description of the various process components used in the BenchCAT system is given below. The reactor unit has four inlet gas lines for feeding $\mathrm{CO}, \mathrm{H}_{2}, \mathrm{~N}_{2}$ and $\mathrm{He} / \mathrm{Ar}$. The system uses Brooks 5850S mass-flow controllers (MFCs) to feed gases to the process manifold. The setup also includes a liquid delivery system consisting of a syringe pump followed by an evaporator and a volume expander. Heat tapes or trace heaters wrap the plumbing from where the various feeds mix to the reactor. The heat tapes have a maximum set point of $230{ }^{\circ} \mathrm{C}$. A dial pressure gauge is located on each end of the reactor for constant visual display of the pressure. Additionally, pressure transducers, one each located before and after the reactor, are used to measure and record the pressure in the system. The reactor pressure is controlled using a Brooks 5866 pressure control valve (PCV). 


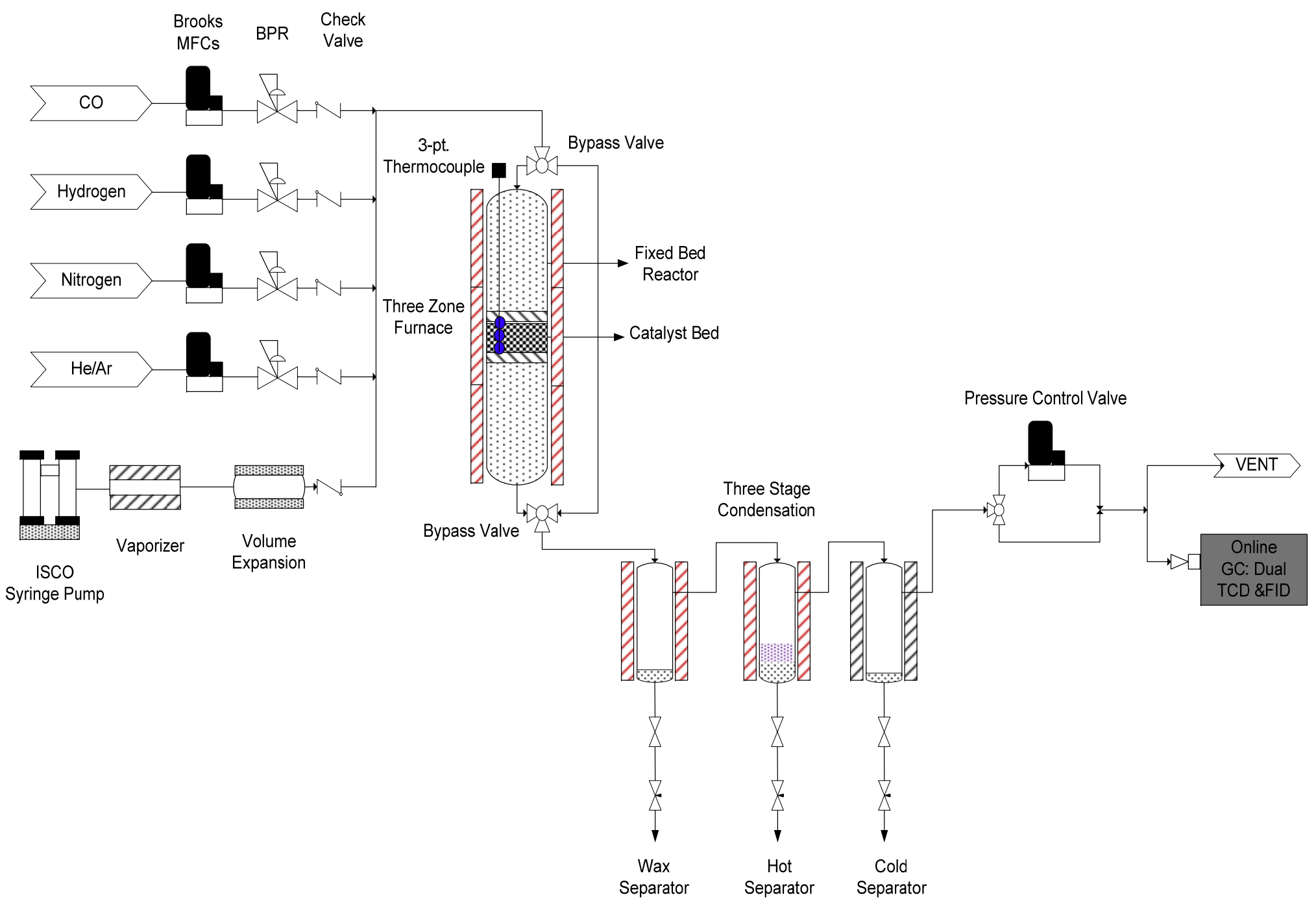

Figure 3.1 BenchCAT ${ }^{\mathrm{TM}}$ fixed-bed reactor setup at National Energy Technology Laboratory, Department of Energy, Morgantown, WV 
The system includes a stainless-steel reactor tube with 1 " O.D. $\times 0.688^{\prime \prime}$ I.D. $\times 35^{\prime \prime} \mathrm{L}$ specifications. A three-point thermocouple with points at $0^{\prime \prime}, 2$, , and 4" is inserted into the top of the reactor to read the temperature within the catalyst bed. A set of two three-way valves is used to by-pass the reactor. The installed furnace is used to maintain the temperature of the reactor tube. The reactor furnace is rated at $2400 \mathrm{~W}$ and has a maximum operating temperature of $700{ }^{\circ} \mathrm{C}$. The reactor furnace is a three-zone split tube, approximately $30^{\prime \prime}$ in length and 10 " in outside diameter. The reactor furnace opens for removal of the reactor tube between the test runs.

Heat tapes or trace heaters also wrap the plumbing from the reactor exit to the liquid separation section. The BenchCAT system incorporates three stages of liquid separation after the reactor exit. The first stage of liquid separation is the wax separator. The wax separator has a volume of $500 \mathrm{~mL}$ and is designed to operate at a temperature up to $200{ }^{\circ} \mathrm{C}$. The wax separator is primarily designed to condense the high-molecular-weight waxes formed during the Fischer-Tropsch process. The second, hot-liquid, stage has a volume of $1000 \mathrm{~mL}$ and is designed to operate at up to $100{ }^{\circ} \mathrm{C}$. Most of the aqueous phase, along with some liquid hydrocarbons, would condense in this separator. The final stage consists of a tube-in-tube condenser. The inner tube is $1 / 4^{\prime \prime}$ diameter stainless steel. The outside tube is $5 / 8^{\prime \prime}$ diameter copper. For efficient condensation, the condenser is operated with water as a cooling medium at a flow rate of $1-2 \mathrm{~L} / \mathrm{min}$ at $4{ }^{\circ} \mathrm{C}$ or colder. This condenser serves to condense traces of any condensable products escaping from first two condensers. Therefore, the final stage condenser helps in avoiding product condensation in the exit lines, since condensation can damage the PCV and GC detectors. Typically, during the actual run, the wax separator is operated at $190{ }^{\circ} \mathrm{C}$, the hot separator at $40^{\circ} \mathrm{C}$, and the cold separator at $4{ }^{\circ} \mathrm{C}$.

The non-condensable products leave the condensation stages and are sent to vent lines and GC analysis. The product gases exiting the BenchCat during the run are analyzed by the GC unit at regular (short) intervals. On the other hand, the condensed products are collected at longer intervals and are analyzed by an offline GC unit. The details of the product analysis procedure are provided in the following section. 
The electrical cabinet accepts power from the main power station and distributes it to the various components. The electrical cabinet also serves as the power source to the rest of the unit and the communication port between the process and the computer. The unit uses the FieldPoint ${ }^{\mathrm{TM}}$ modular interface system. The system includes a variety of isolated analog and digital I/O modules, terminal bases, and network interfaces that allow connection to standard networking technologies. The function of the control part of the cabinet is to accept analog types of process signals, convert those to digital signals, and transmit them to the computer. The computer system accepts all the process signals and maintains a digital log of all the variables. All components are controlled through the computer by simple ON/OFF commands, by analog voltage signals, or through PID loops. The computer control system acts to maintain the system's parameters automatically. Therefore, the operating parameters such as flow rate, temperature and pressure can be controlled from the computer. Conversely, the electrical side of the cabinet accepts the digital signals from the computer, converts them to various analog controlling signals and transmits them to the processes. The electrical cabinet also controls process shutdown, independent of the computer, to protect the process during any malfunction. The process is protected by over-pressure by a relief valve and from overtemperature by temperature-safety-switches (TSS). The settings on these protection devices are based on standard practices. The TSS would automatically shut down the entire system, independent of a computer shut-down.

LabVIEW software by National Instruments is chosen to perform the monitoring, data acquisition, and operator interface for the system. The software is configured for the control strategies, data acquisition, and process display to suit this application best.

The unit is periodically pressure-leak tested to 350 psi, using either helium or argon and a bubble leak-detection fluid. The MFCs are calibrated by a soap-bubble flow meter. The calibration charts of the MFCs are presented in Appendix A.

\subsection{Gas-chromatography Unit}

A Perkin-Elmer GC unit (Claurus 500) is attached to the FT reactor setup for on-line analysis of the noncondensible products. As mentioned earlier, the outlet gases are analyzed 
every $0.5 \mathrm{~h}$, using a HaySep packed column with a dual thermal-conductivity detector (TCD) and a capillary column with a flame-ionization detector (FID). The operating conditions for the online GC are given in Appendix B. The calibration charts are provided in Appendix C.

As mentioned earlier, the condensed products are collected every $24 \mathrm{~h}$ during the entire run and are analyzed by an off-line GC (HP 3400). The GC used for liquid analysis is located in the ERB lab of WVU. The organic phase of the liquid samples is analyzed with a capillary column and FID, whereas the aqueous phase is analyzed by a Propak-Q packed column and FID. The operating conditions for the off-line GC are given in Appendix D. The calibration charts are provided in Appendix E.

Typically, the CO hydrogenation experiments are carried out in the system described in Section 3.2 and 3.3. Poisoning studies require some modifications to the equipment and the procedure, and these are described in Chapter 8.

\subsection{Experimental Procedure}

Prior to FTS, the catalyst (approximately $1000 \mathrm{mg}$ ) is reduced in-situ by $\mathrm{H}_{2}$ at $400{ }^{\circ} \mathrm{C}, 1$ atm and $200 \mathrm{cc} / \mathrm{min}$ for $12 \mathrm{~h}$. At the end of the reduction step, the hydrogen is replaced by inert He to flush the lines while cooling to $170{ }^{\circ} \mathrm{C}$. At this stage, the system is pressurized under syngas up to $300 \mathrm{psig}$. Thereafter, the temperature of the bed is slowly increased at $1^{\circ} \mathrm{C} / \mathrm{min}$ to the desired temperature, $230^{\circ} \mathrm{C}$. It must be noted that slow temperature ramping is desired in order to avoid run-away situations due to the exothermic CO hydrogenation reaction.

The nominal operating conditions for FTS used at the start of the study were: $\mathrm{H}_{2} / \mathrm{CO}=2$ (mol ratio) at $230{ }^{\circ} \mathrm{C}, 300 \mathrm{psi}$, and $9000 \mathrm{GHSV}\left(\mathrm{sccm} / \mathrm{h} / \mathrm{g}_{\text {cat }}\right.$ ) for $72 \mathrm{~h}$. The feed gas is pre-mixed syngas. Towards the later part of the study, it was necessary to use separate cylinders for CO and $\mathrm{H}_{2}$. The additional MFC necessitated an increase in the flow rate from $150 \mathrm{sccm}$ to 225 $\mathrm{sccm}$, and a resulting increase in the GHSV to $13,500 \mathrm{sccm} / \mathrm{h} / \mathrm{g}_{\text {cat }}$. In both the cases, the unreacted gases and the reaction products from the reactor pass through a wax separator kept at $190{ }^{\circ} \mathrm{C}$, a hot separator at $40{ }^{\circ} \mathrm{C}$, and a cold separator at $4{ }^{\circ} \mathrm{C}$ for the separation of organic and aqueous products. Incondensable gases leaving the third condenser include $\mathrm{He}, \mathrm{H}_{2}, \mathrm{CO}_{2}, \mathrm{Ar}$, $\mathrm{CH}_{4}$, and $\mathrm{CO}$, and were analyzed every $30 \mathrm{~min}$ by an online GC. Finally, liquid and wax which 
contain higher hydrocarbons and alcohols products were collected every $24 \mathrm{~h}$ during the entire run and were analyzed by an offline GC.

\subsection{Characterization Equipment and Procedures}

\subsubsection{Surface Area and Pore Volume}

Surface area and pore volume of the support and calcined catalysts were measured on a Micromeritics Autochem 2020 instrument. The instrument is located at NETL, Morgantown. The sample (0.15 g) was evacuated at $400{ }^{\circ} \mathrm{C}$ for $4 \mathrm{~h}$ prior to measurement. In the next step, nitrogen adsorption and desorption isotherms were measured at liquid nitrogen temperature. The Brunauer-Emmett-Teller (BET) area was estimated by $\mathrm{N}_{2}$ adsorption at relative pressures $\left(P / P_{0}\right)$ between 0.06 and 0.2 , where $P$ and $P_{0}$ are the measured and equilibrium pressures, respectively. The total pore volume was calculated from the amount of vapor adsorbed at a relative pressure close to $\mathbf{0 . 9 9 5}$. The nitrogen desorption branch was chosen for the pore size analysis. The pore size distribution was established by applying the Barrett-Joyner-Halenda (BJH) method.

\subsubsection{X-ray Diffraction}

X-ray diffraction (XRD) was used to obtain the crystallographic structure and chemical composition of solids. The XRD patterns of the support and the prepared catalysts were obtained using a PANalytical diffractometer (XPert PRO) with $\mathrm{Cu}(K \alpha)$ radiation $(1.5418 \AA$ ) operated at $40 \mathrm{kV}$ and $25 \mathrm{~mA}$. The catalysts were crushed to fine powders prior to measurement. The samples were scanned from $2 \theta=5^{\circ}$ to $120^{\circ}$ at a rate of $0.05^{\circ} / \mathrm{s}$. The observed peaks were assigned by referring to the International Centre for Diffraction Data (ICDD) database. The phase identification of silica and cobalt oxide was performed by comparing with the standard diffraction patterns available in database PDF-00-004-0379 and PDF-01-073-2750, respectively.

\subsubsection{X-ray Photoelectron Spectroscopy}

X-ray photoelectron spectroscopy (XPS) allows us to obtain the chemical state of elements. XPS spectra were recorded with a Physical Electronics Model SAM 590 equipped with a cylindrical-mirror analyzer and a 15 kV X-ray source from Physical Electronics. The instrument 
is located at NETL, Morgantown. The system was routinely operated within a pressure range from $10^{-9}$ to $10^{-8}$ Torr $\left(1.3 \times 10^{-7}\right.$ to $\left.1.3 \times 10^{-6} \mathrm{~Pa}\right)$. The instrument was calibrated using the photoemission lines $E_{B}\left(\mathrm{Cu} 2 \mathrm{p}_{3 / 2}\right)=932.4 \mathrm{eV}$ and $E_{B}\left(\mathrm{Au} 4 \mathrm{f}_{7 / 2}\right)=83.8 \mathrm{eV}$.

\subsubsection{Scanning Electron Microscopy and Energy Dispersive Spectroscopy}

Scanning electron microscopy (SEM) is used to view the surface morphology. In addition, energy dispersive spectroscopy (EDS) yields qualitative information on elemental composition. The SEM and EDS characterization of the catalyst particles was performed using a Hitachi S-4700 scanning electron microscope with an EDAX energy dispersive spectrometer.

\subsubsection{Temperature-Programmed Reduction}

Reducibility of the catalysts (cobalt oxides) in the presence of $\mathrm{H}_{2}$ was evaluated by temperature-programmed reduction (TPR). The experiments were performed using a Micromeritics Autochem 2950. The instrument is located at NETL, Morgantown. The calibration was performed by the reduction of a reference $\mathrm{Ag}_{2} \mathrm{O}$ sample.

Prior to the $\mathrm{H}_{2}$-TPR experiment, the sample $(0.1 \mathrm{~g}, 100-200 \mu \mathrm{m})$ was first heated at 120 ${ }^{\circ} \mathrm{C}$ for $1 \mathrm{~h}$ to remove moisture. The sample was subsequently cooled down to $50{ }^{\circ} \mathrm{C}$. The heating and cooling steps were performed in the presence of inert Ar gas. In the next step, the temperature was ramped to $1000^{\circ} \mathrm{C}$ at $5{ }^{\circ} \mathrm{C} / \mathrm{min}$ in the presence of a $10 \% \mathrm{H}_{2} / \mathrm{Ar}$ mixture. The flow rate of $\mathrm{H}_{2} / \mathrm{Ar}$ mixture was kept constant at $50 \mathrm{cc} / \mathrm{min}$. The products gases from the reactor outlet were passed through a condenser. A cold trap containing a mixture of 2-propanol and dry ice was used to control the condenser temperature. The condenser eliminates traces of water from the product gas. The dry gas from the condenser outlet was subsequently analyzed with a TCD. The hydrogen consumption was measured by comparing the thermal conductivity of the exit gas with that of a reference gas stream containing a $10 \% \mathrm{H}_{2} / \mathrm{Ar}$ mixture.

\subsubsection{Hydrogen Chemisorption}

Hydrogen adsorption isotherm measurements allow estimation of the chemisorbed hydrogen and metal dispersion. The experiments were performed with a Micromeritics ASAP 2020 unit. The unit is located at NETL, Morgantown.

Initially, the sample was loaded in a sample tube and evacuated while heating to $350^{\circ} \mathrm{C}$ at $10{ }^{\circ} \mathrm{C} / \mathrm{min}$. The evacuation step was followed by cooling to $100{ }^{\circ} \mathrm{C}$. In the next step, the 
sample was reduced by increasing the temperature to $350{ }^{\circ} \mathrm{C}$ at $10{ }^{\circ} \mathrm{C} / \mathrm{min}$ under $\mathrm{H}_{2}$ flow. The sample was subsequently evacuated and cooled to $35^{\circ} \mathrm{C}$. An adsorption isotherm was recorded at $35{ }^{\circ} \mathrm{C}$ in the pressure interval from 75 to $400 \mathrm{~mm} \mathrm{Hg}$. The amount of chemisorbed hydrogen was determined by extrapolating the straight-line portion of the isotherm to zero pressure. In order to calculate the dispersion, it was assumed that two cobalt sites were covered by one hydrogen molecule. The turnover frequencies (TOFs), i.e., the number of CO molecules converted per catalytic site per second, were calculated using the number of surface cobalt atoms based on $\mathrm{H}_{2}$-chemisorption.

\subsection{Safety Requirements}

The following safety measures were strictly followed while performing the experiments;

- Any source of ignition near experiment area was avoided since the reactant gases used $\left(\mathrm{H}_{2}\right.$ and $\mathrm{CO}$ ) are highly flammable.

- Since the reactions are carried out at high pressure, gas lines and joints were checked for leaks prior to each run.

- Personal protective equipment (PPE) such as safety goggles, lab coat, steel-toed shoes and safety gloves were used while performing the experiments.

- The experiments involve the use hazardous gases and chemicals. Therefore, indoor quality of the air inside the laboratory area was monitored by gas sensors connected to emergency alarms.

- Compressed gas cylinders were handled with cylinder caps tightly fitted during replacements.

- The fume hood, eye-wash station, safety showers and fire extinguishers were regularly maintained.

- Material safety data sheets (MSDSs) were available for all chemicals used (gases, liquids, and solids) in the experiment. The MSDSs for all chemicals used in the study are provided in Appendix F.

- A list of personnel to be contacted in an emergency situation was posted near the entrance of laboratory. 
- Emergency shut-down procedures were documented to avoid any incidents.

- Operators are committed to comply with NETL and WVU safety policies, and any violation can result in termination of future entry in the laboratories. 


\section{CHAPTER 4 \\ SYNTHESIS AND PRE-REACTION CHARACTERIZATION OF CATALYSTS}

\subsection{Materials}

Cobalt nitrate $\left(\mathrm{Co}\left(\mathrm{NO}_{3}\right)_{2} \cdot 6 \mathrm{H}_{2} \mathrm{O}, 99+\%\right.$ pure $)$, nitrilotriacetic acid $\left(\mathrm{C}_{6} \mathrm{H}_{9} \mathrm{NO}_{6}, 99+\%\right.$ pure $)$ and ethylenediaminetetracetic acid $\left(\mathrm{C}_{10} \mathrm{H}_{16} \mathrm{~N}_{2} \mathrm{O}_{8}, 99+\%\right.$ pure) were obtained from ACROS Organics. Ammonium hydroxide $\left(\mathrm{NH}_{4} \cdot \mathrm{OH}, 99+\%\right.$ pure) was obtained from Fisher Scientific. All these chemicals were used without further purification.

The commercial technical-grade $\mathrm{SiO}_{2}$ support (SS61138) ${ }^{81}$ was received from SaintGobain Norpro. The properties of the $\mathrm{SiO}_{2}$ support, provided by the manufacturer, are given in Appendix G. Before the synthesis step, $\mathrm{SiO}_{2}$ pellets were thoroughly washed with deionizedwater (DI) and dried overnight at $110^{\circ} \mathrm{C}$, in order to remove any soluble impurities present on the support. The drying step was followed by calcination at $400{ }^{\circ} \mathrm{C}$ to remove adsorbed species from the surface. The pretreated silica was sieved to 20-40 mesh and was stored in a sealed container to use as a standard support for all the catalysts prepared in this study.

\subsection{Catalyst Preparation}

All the catalysts investigated here were prepared by the incipient-wetness method ${ }^{82}$. The $\mathrm{SiO}_{2}$ support was impregnated with an aqueous solution containing cobalt nitrate and, if necessary, one of the chelating agent nitrilotriacetic acid (NTA) or ethylenediaminetetracetic acid (EDTA), as detailed below.

The conventionally selected Co loading of 20 w\% was used for all the catalysts prepared here. In the stepwise synthesis, if the catalyst was to be modified, an aqueous solution of a chelating agent (NTA or EDTA) was first impregnated on silica support. The samples were subsequently dried at $110{ }^{\circ} \mathrm{C}$ for $12 \mathrm{~h}$. The molar ratio of the chelating agent to Co was selected as unity for all these catalysts. The $\mathrm{pH}$ of the aqueous solution was maintained at 5.5 by using aqueous $\mathrm{NH}_{4} \mathrm{OH}$. In the next step, the solid was impregnated by an aqueous solution of cobalt nitrate in two steps, each step equivalent to $10 \mathrm{w} \%$ of cobalt loading. The samples were dried 
again at the same conditions, $110^{\circ} \mathrm{C}$ for $12 \mathrm{~h}$. Finally, the dried samples were calcined at $350{ }^{\circ} \mathrm{C}$ for $4 \mathrm{~h}$. The calcination procedure is discussed in following Section 4.2.1.

The range of the $\mathrm{pH}$ was decided on the basis that chelating agents are known to form Co-complexes selectively in the selected $\mathrm{pH}$ range ${ }^{33}$. The catalyst samples in this study were denoted as $\mathrm{Co} / \mathrm{X} / \mathrm{SiO}_{2}$, representing modification of $\mathrm{Co} / \mathrm{SiO}_{2}$ by a chelating agent $\mathrm{X}$.

\subsubsection{Calcination Procedure}

The calcination treatment of impregnated catalysts decomposes the nitrate precursor into the oxide phase. The nitrate decomposition is an exothermic reaction, and hence phase transformations during calcination are accompanied by the heat release. Therefore, both the final calcination temperature and the rate of decomposition influence the properties of the cobalt catalysts.

The catalysts prepared in this study were calcined in a muffler furnace. The furnace set-up allowed control of only the desired set-point and not the ramp rate. Initially, when catalysts were subjected to calcination at 250 or $350{ }^{\circ} \mathrm{C}$, the furnace was operated with the desired temperature set-point. However, the resulting high rates of decomposition resulted in complete disintegration of the materials. In fact, the 20-40 mesh particles turned into fine powder after the calcination step. Therefore, more efficient heat and mass releases from the catalyst pores were desired during the decomposition, to avoid material breakdown.

A procedure was developed in which the final calcination temperature was reached in stepwise increment of temperature. Accordingly, in the absence of any control over the ramprate, the furnace temperature was manually increased by $30{ }^{\circ} \mathrm{C}$ every $30 \mathrm{~min}$. Therefore, the desired calcination temperature of $250{ }^{\circ} \mathrm{C}$ was reached in ca. $250 \mathrm{~min}$ and similarly $350{ }^{\circ} \mathrm{C}$ was achieved in ca. $350 \mathrm{~min}$. After reaching the final desired temperature, the temperature was held constant for $4 \mathrm{~h}$. The slow temperature rise during the calcination assisted in efficient heat and mass release from the materials. Therefore, with the controlled calcination approach, the catalysts retained their structural characteristics and did not show any disintegration. 


\subsection{Physical Characterization of Fresh Catalysts}

\subsubsection{EDS Analysis of Silica Support and Cobalt Catalyst}

The silica support and cobalt catalyst were subjected to energy-dispersive spectroscopy (EDS) in order to investigate the presence of any surface impurities. The results from the analysis are presented in Figure 4.1 for the silica support, and in Figure 4.2 for the base-case cobalt catalyst. The spectrum shows peaks due to $\mathrm{Si}$ and $\mathrm{O}$ from silica (i.e., $\mathrm{SiO}_{2}$ ) pellets. The presence of an $\mathrm{Al}$ peak is attributed to the small content of $\mathrm{Al}_{2} \mathrm{O}_{3}$ normally present in silica supports. The Au peak in Figure 4.1 and $\mathrm{Ag}$ peak in Figure 4.2 are due to coating, performed to make a conducting surface while carrying out an EDS experiment. Finally, the absence of any halide impurities can be confirmed by the absence of halide peaks.

The SEM images of the fresh cobalt catalyst, shown in Figure 4.3, offer more insights into the surface morphology. Particles of 20-40 mesh size (i.e., 0.42-0.85 mm) were used in all the experiments performed here and can be confirmed from Figure 4.3a. In addition, a welldispersed cobalt oxide phase on the silica support after impregnation can also be confirmed from Figure 4.3b.

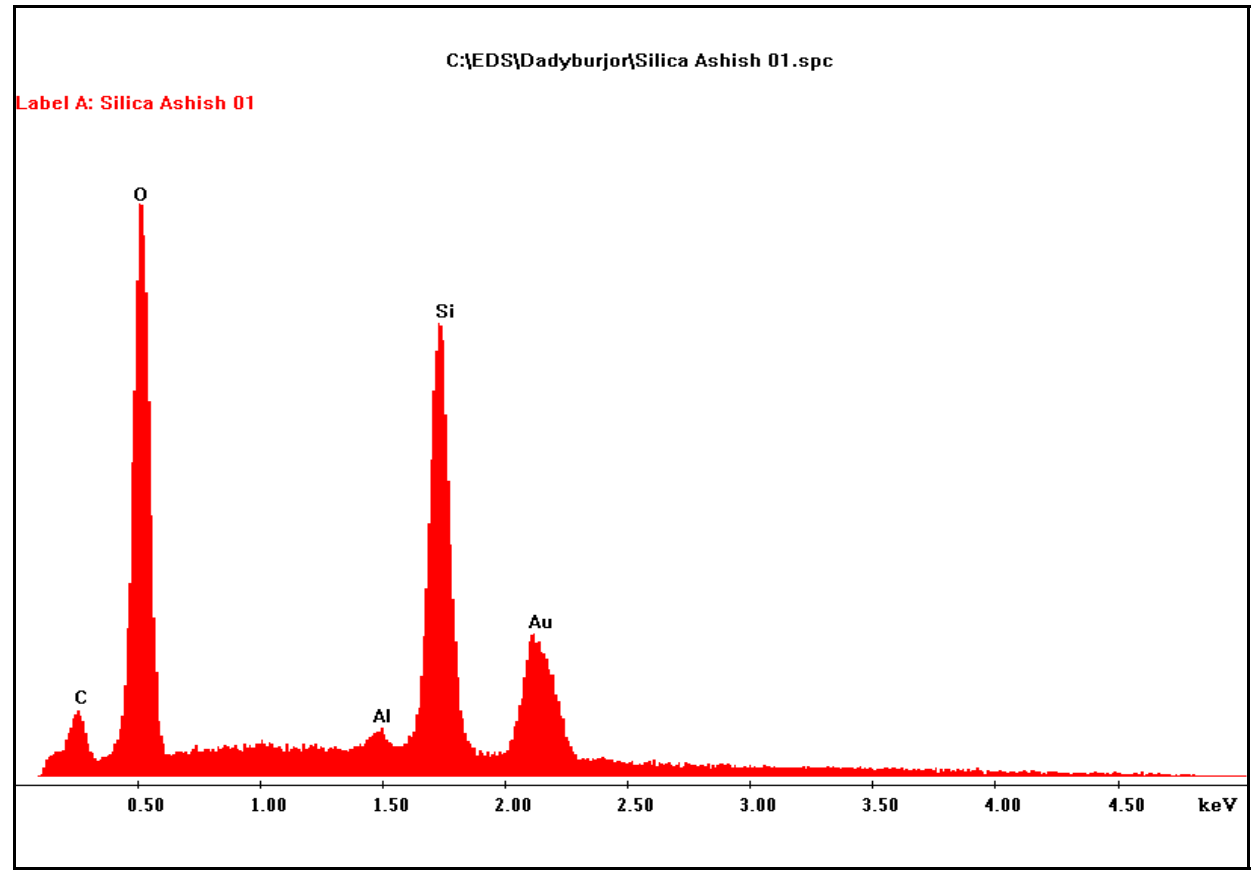

Figure 4.1 Energy dispersive X-ray spectroscopy of silica support 


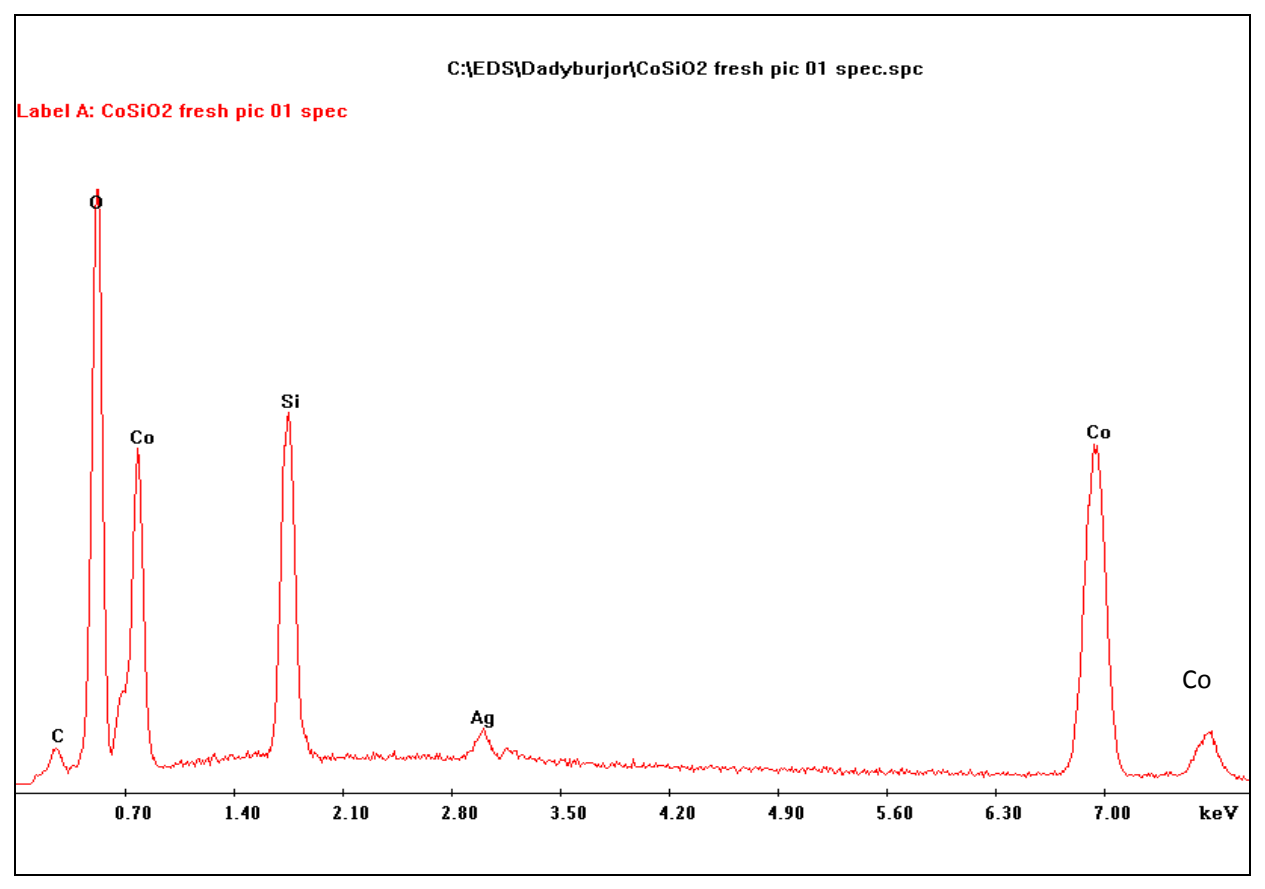

Figure 4.2 Energy dispersive X-ray spectroscopy of cobalt catalyst
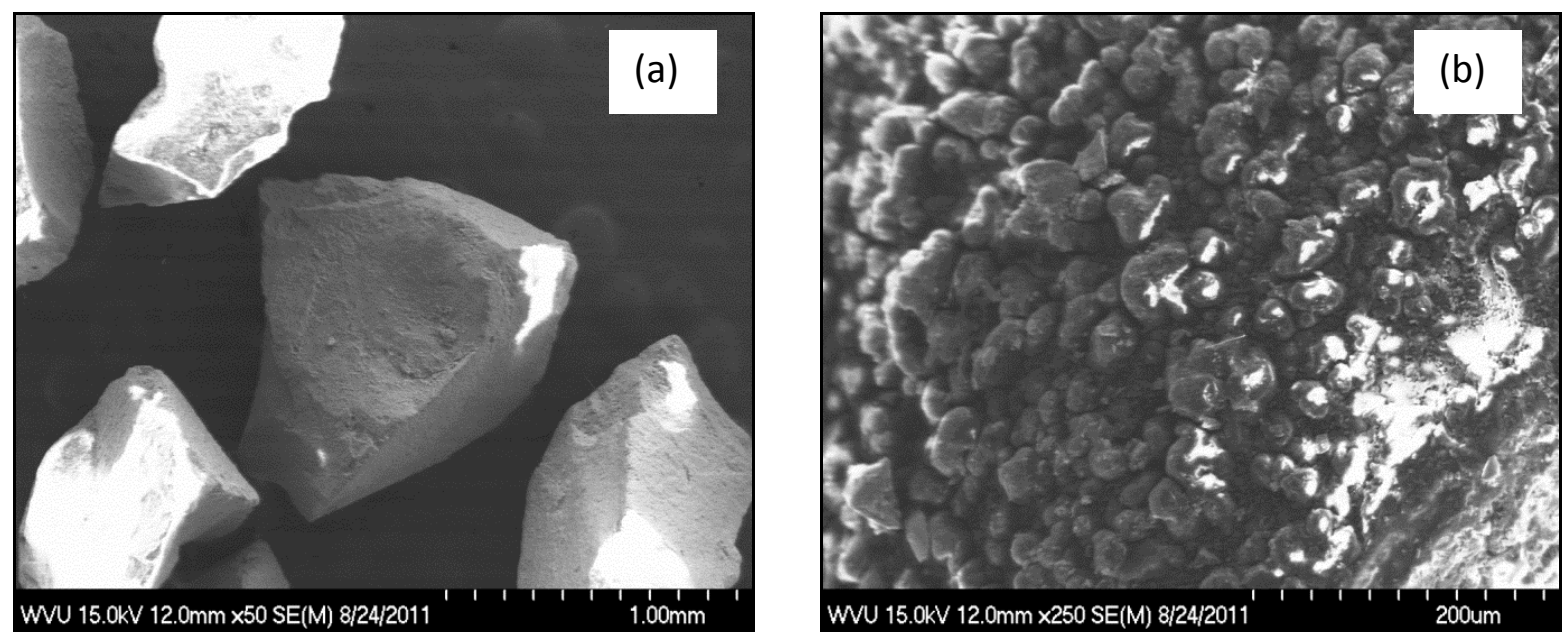

Figure 4.3 SEM images of cobalt catalysts (a) 20-40 mesh size particles and (b) a well-dispersed cobalt oxide phase

\subsubsection{Nitrogen Physisorption Measurement}

The BET surface area, pore volume and average pore diameter measured by $\mathrm{N}_{2}$ physisorption for the $\mathrm{SiO}_{2}$ support, $\mathrm{Co} / \mathrm{SiO}_{2}, \mathrm{Co} / \mathrm{NTA} / \mathrm{SiO}_{2}$ and $\mathrm{Co} / \mathrm{EDTA} / \mathrm{SiO}_{2}$ catalysts are presented in Table 4.1. 
The silica support before impregnation has a surface area of $224 \mathrm{~m}^{2} / \mathrm{g}$ and a pore volume of $0.93 \mathrm{~cm}^{3} / \mathrm{g}$ with a monomodal pore size distribution centered around $12.4 \mathrm{~nm}$. The CA modification of the silica support and subsequent impregnation with cobalt precursor is seen to result in the reduction of surface area and pore volume. This trend is also observed for the base catalyst prepared in the absence of any chelating agent. In fact, all the three catalysts showed ca. $22 \%$ drop in surface area and ca. 26 \% drop in pore volume after impregnation.

Table 4.1 Surface area and pore volume results of silica support and catalysts

\begin{tabular}{|l|c|c|c|}
\hline & \multicolumn{3}{|c|}{ Fresh Catalyst } \\
\cline { 2 - 4 } & $\begin{array}{c}\text { Surface area } \\
\left(\mathbf{m}^{2} / \mathbf{g}\right)\end{array}$ & $\begin{array}{c}\text { Pore volume } \\
\left(\mathbf{c m}^{\mathbf{3}} / \mathbf{g}\right)\end{array}$ & $\begin{array}{c}\text { Pore diameter } \\
\text { (nm) }\end{array}$ \\
\hline $\mathrm{SiO}_{2}$ support & 224 & 0.93 & 12.4 \\
\hline $\mathrm{Co} / \mathrm{SiO}_{2}$ & 163 & 0.67 & 12.5 \\
\hline $\mathrm{Co} / \mathrm{NTA} / \mathrm{SiO}_{2}$ & 187 & 0.73 & 11.6 \\
\hline $\mathrm{Co} / \mathrm{EDTA} / \mathrm{SiO}_{2}$ & 170 & 0.65 & 11.7 \\
\hline
\end{tabular}

The isotherms for $\mathrm{N}_{2}$ adsorption and the pore size distribution for the $\mathrm{SiO}_{2}$ support and the supported cobalt catalysts are shown in Figure 4.4 and Figure 4.5, respectively. The shapes of the isotherms for the support and all catalysts are similar, suggesting that the structural characteristics remain even after the chelation steps. The drop in surface area and volume can be attributed to the fact that the impregnated metal precursor flows inside the pores of the support and grows with subsequent drying and calcination steps. 


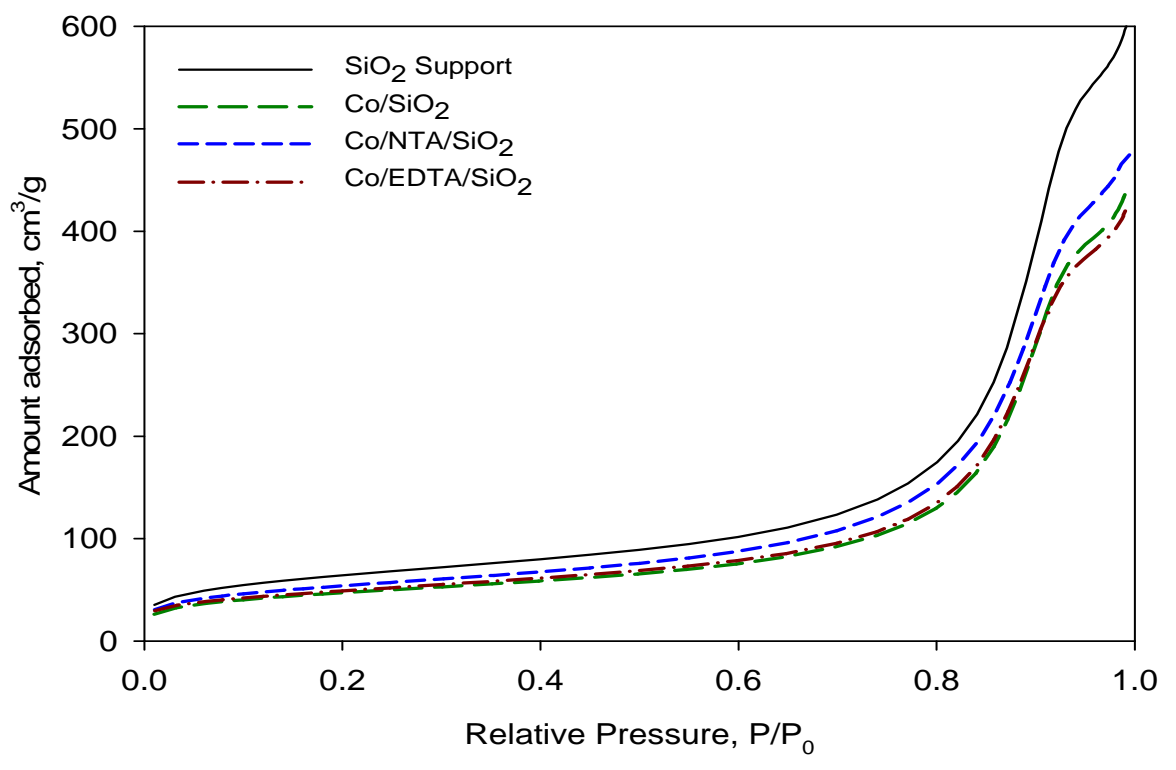

Figure 4.4 Nitrogen adsorption (BET) isotherms for $\mathrm{SiO}_{2}$ support before impregnation and silica supported cobalt catalysts

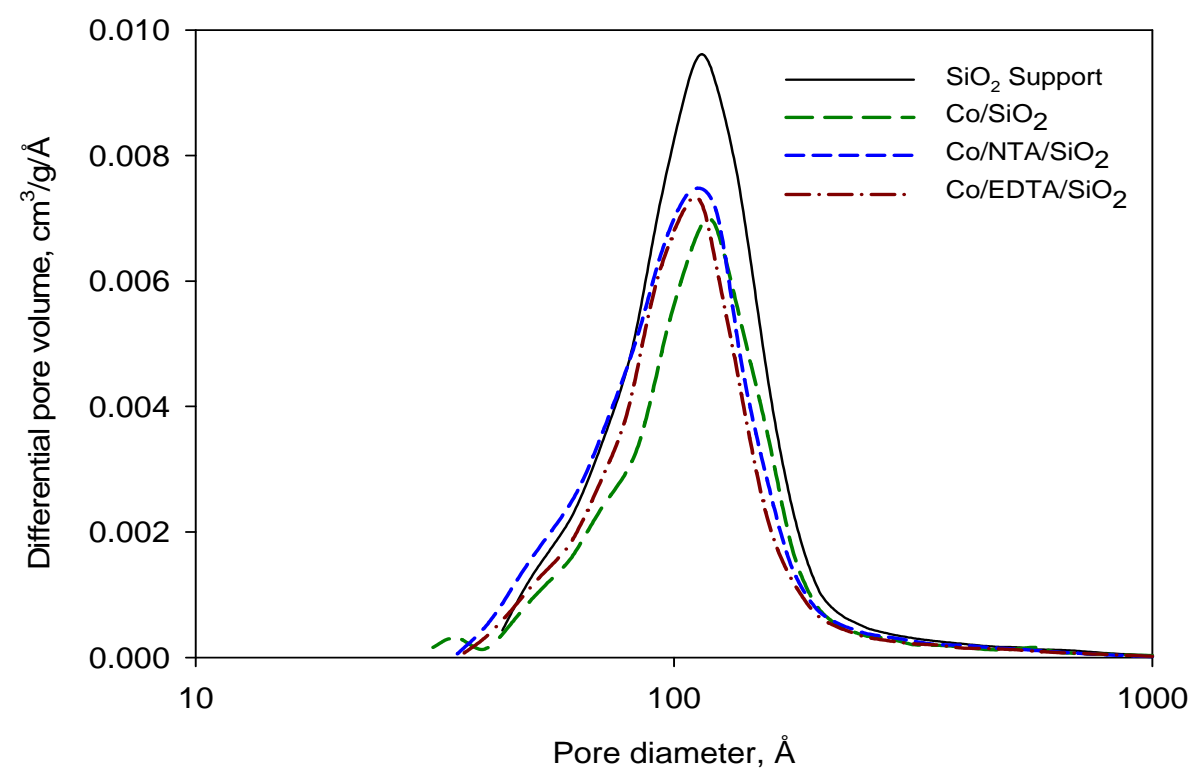

Figure 4.5 Pore size distribution curves (PSD) for $\mathrm{SiO}_{2}$ support before impregnation and silica supported cobalt catalysts 


\subsubsection{X-Ray Diffraction}

The impregnated catalysts were calcined at 250 and $350{ }^{\circ} \mathrm{C}$ before being subjected to diffraction studies. The calcination step decomposes the nitrate precursor of cobalt into the cobalt oxide phases. The diffraction patterns of a silica support and cobalt catalysts after calcination at 250 and $350{ }^{\circ} \mathrm{C}$ at $\mathrm{CA} / \mathrm{Co}=1.0$ are shown in Figure 4.6 and Figure 4.7, respectively.

A broad diffraction peak, a characteristic of amorphous silica, is located at $\theta=22^{\circ}$ (see Figure 4.6a and Figure 4.7a). Furthermore, after calcination, the presence of the $\mathrm{Co}_{3} \mathrm{O}_{4}$ phase on $\mathrm{Co} / \mathrm{SiO}_{2}, \mathrm{Co} / \mathrm{NTA} / \mathrm{SiO}_{2}$ and $\mathrm{Co} / \mathrm{EDTA} / \mathrm{SiO}_{2}$ catalysts can be confirmed (curves b-d, respectively). The average particle sizes of the $\mathrm{Co}_{3} \mathrm{O}_{4}$ phases were calculated from the Scherrer equation for the most intense peak (311) located at $\theta=36.8^{\circ}$. Using the full width at half maximum (FWHM) of the diffraction peak and Scherrer's equation, the average $\mathrm{Co}_{3} \mathrm{O}_{4}$ crystallite sizes for $\mathrm{Co} / \mathrm{SiO}_{2}, \mathrm{Co} / \mathrm{NTA} / \mathrm{SiO}_{2}$ and $\mathrm{Co} / \mathrm{EDTA} / \mathrm{SiO}_{2}$ were determined as shown in Table 4.2 .

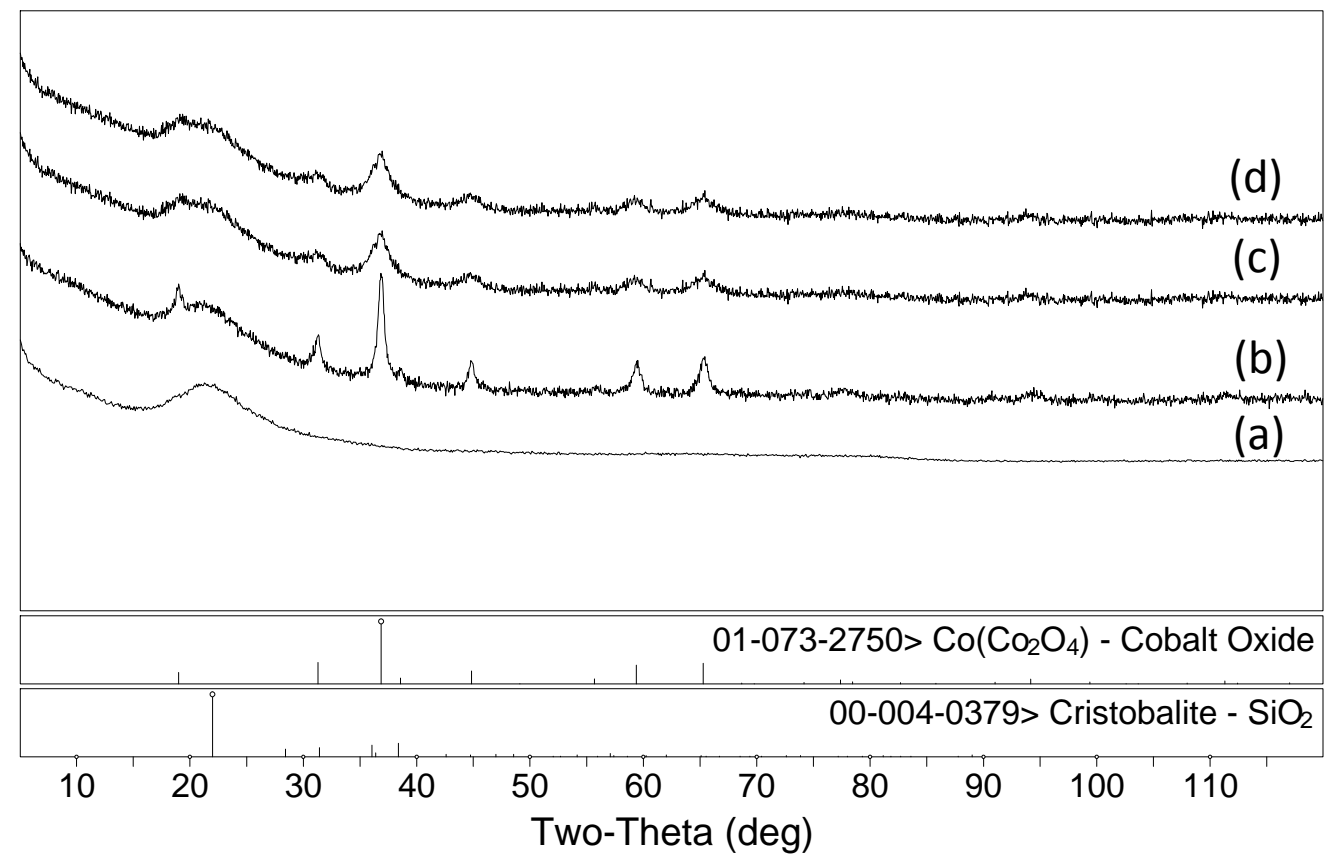

Figure 4.6 X-ray diffraction patterns: (a) $\mathrm{SiO}_{2}$ support, (b) calcined $\mathrm{Co} / \mathrm{SiO}_{2}$, (c) calcined $\mathrm{Co} / \mathrm{NTA} / \mathrm{SiO}_{2}$, and (d) calcined $\mathrm{Co} / \mathrm{EDTA} / \mathrm{SiO}_{2}$. Calcinations are at $250{ }^{\circ} \mathrm{C}, \mathrm{CA} / \mathrm{Co}=1$ 


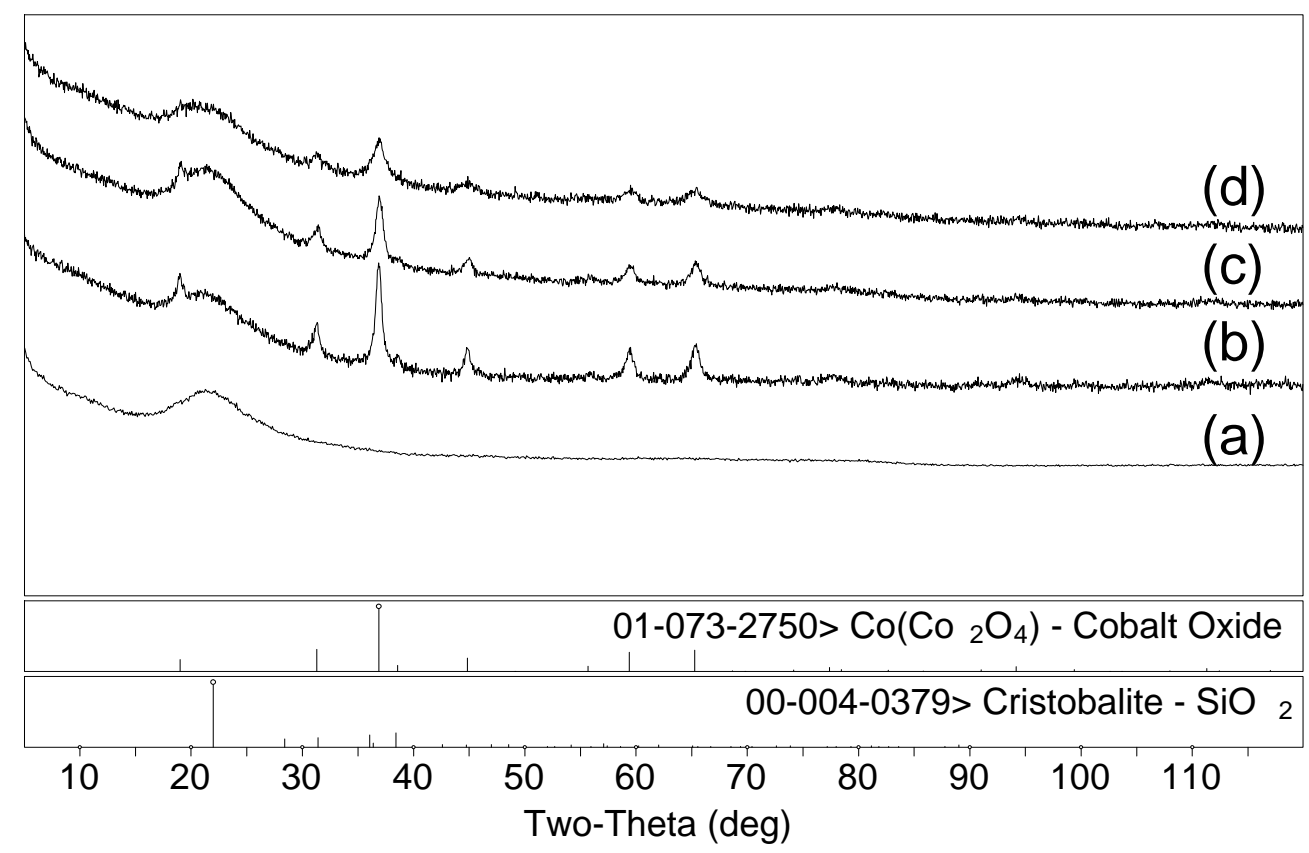

Figure 4.7 X-ray diffraction patterns: (a) $\mathrm{SiO}_{2}$ support, (b) calcined $\mathrm{Co} / \mathrm{SiO}_{2}$, (c) calcined $\mathrm{Co} / \mathrm{NTA} / \mathrm{SiO}_{2}$, and (d) calcined $\mathrm{Co} / \mathrm{EDTA} / \mathrm{SiO}_{2}$. Calcinations are at $350{ }^{\circ} \mathrm{C}, \mathrm{CA} / \mathrm{Co}=1$

Table 4.2 Physical properties and crystallite sizes of cobalt catalysts for $\mathrm{CA} / \mathrm{Co}=1$

\begin{tabular}{|l|c|c|c|}
\hline \multicolumn{1}{|c|}{ Catalyst } & \multirow{2}{*}{$\begin{array}{c}\text { Surface Area } \\
\text { (m² }\end{array}$} & & $\mathrm{Co}_{3} \mathbf{O}_{\mathbf{4}}$ Crystallite Size (nm) \\
\cline { 3 - 4 } & & $250^{\circ} \mathrm{C}$ & $350^{\circ} \mathrm{C}$ \\
\hline $\mathrm{SiO}_{2}$ & 224 & $\mathrm{NA}$ & $\mathrm{NA}$ \\
\hline $\mathrm{Co} / \mathrm{SiO}_{2}$ & 163 & 15.1 & 17.7 \\
\hline $\mathrm{Co} / \mathrm{NTA} / \mathrm{SiO}_{2}$ & 187 & 13.1 & 16.0 \\
\hline $\mathrm{Co} / \mathrm{EDTA} / \mathrm{SiO}_{2}$ & 170 & 13.8 & 11.0 \\
\hline
\end{tabular}

For the catalysts calcined at $250{ }^{\circ} \mathrm{C}$, the analysis suggests that the CA-modified catalysts show smaller $\mathrm{CO}_{3} \mathrm{O}_{4}$ crystallites than the base catalyst (without any $\mathrm{CA}$ modification). At the higher calcination temperature, $350{ }^{\circ} \mathrm{C}$, the $\mathrm{Co}_{3} \mathrm{O}_{4}$ crystallites are bigger. Formation of bigger crystallites at higher calcination temperatures has been previously reported for the $\mathrm{Co} / \mathrm{SiO}_{2}$ catalyst $^{6,34,76,83,84}$. Even after the higher temperature calcination, the CA-modified catalysts show smaller crystallites of $\mathrm{CO}_{3} \mathrm{O}_{4}$ compared with those for the base catalyst.

In order to verify further the role of CA modification on crystallite size, the concentration ratio of chelating agent to $\mathrm{Co}$ (i.e., CA/Co) was decreased from 1.0 to 0.5. Similar to the approach used for evaluating the catalysts with CA/Co ratios of 1.0 , the catalysts were 
calcined at two temperatures, 250 and $350{ }^{\circ} \mathrm{C}$. The diffraction patterns of a silica support and cobalt catalysts after calcination at 250 and $350{ }^{\circ} \mathrm{C}$ at $\mathrm{CA} / \mathrm{Co}=0.5$ are shown in Figure 4.8 and Figure 4.9, respectively. The crystallite sizes at the lower molar ratios are presented in Table 4.3. For the NTA-modified catalyst, at CA/Co ratio of 0.5 , the crystallite size at $250{ }^{\circ} \mathrm{C}$ is $14.0 \mathrm{~nm}$, larger than at $\mathrm{CA} / \mathrm{Co}$ ratio of 1.0 at same temperature. At $350{ }^{\circ} \mathrm{C}$, the crystallites sizes are unchanged for different CA/Co ratios. For the EDTA-modified catalyst, the crystallite size at 250 ${ }^{\circ} \mathrm{C}$ is $11 \mathrm{~nm}$, smaller than at CA/Co ratio of 1.0 at the same calcination temperature. At $350{ }^{\circ} \mathrm{C}$, the crystallite size is $16.1 \mathrm{~nm}$ at CA/Co ratio of 0.5 , larger than the one noticed at ratio of 1 .

These results further support the hypothesis that surface modification of silica with chelating agents can be effectively used as a way to control the size of cobalt oxide phase during calcination.

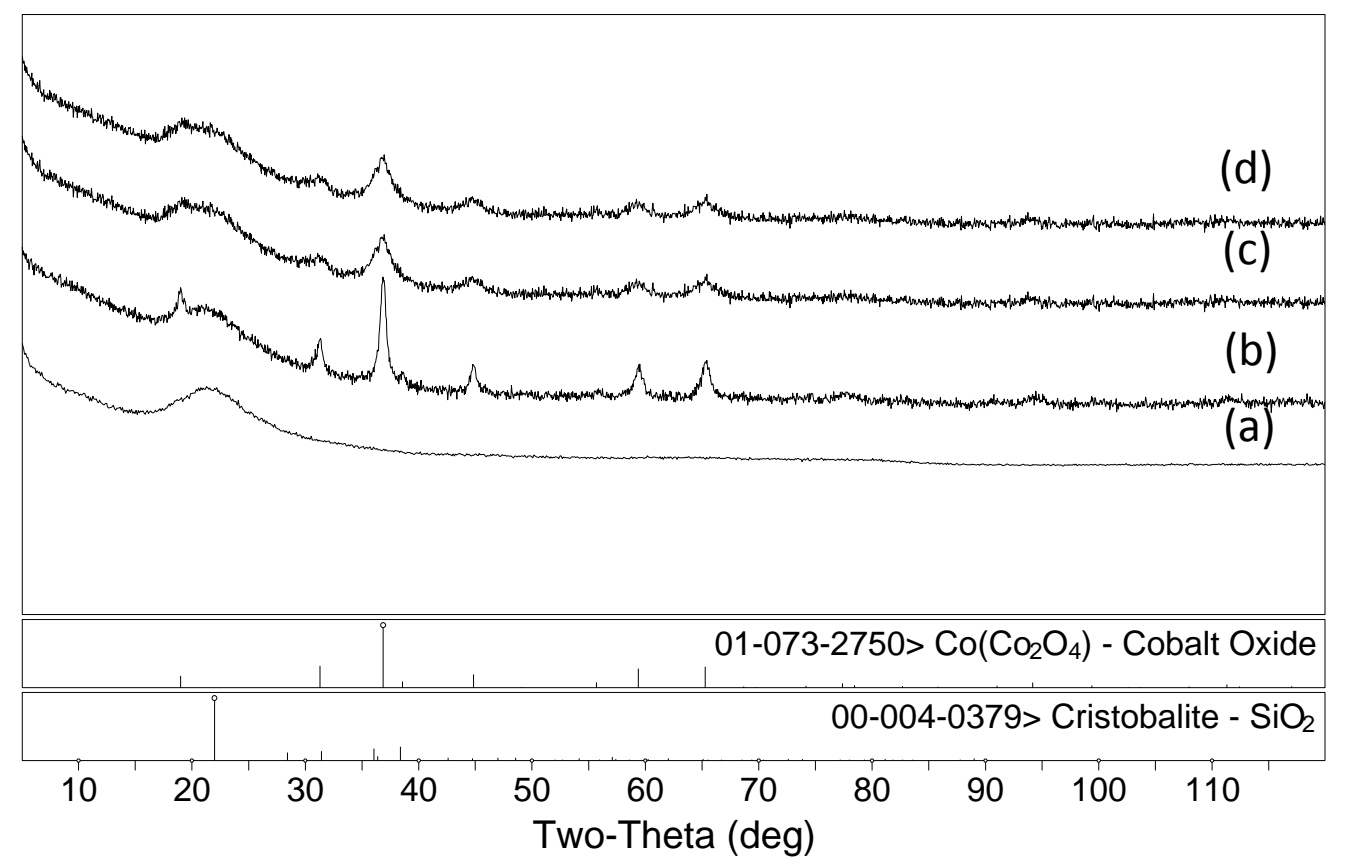

Figure 4.8 X-ray diffraction patterns: (a) $\mathrm{SiO}_{2}$ support, (b) calcined $\mathrm{Co} / \mathrm{SiO}_{2}$, (c) calcined $\mathrm{Co} / \mathrm{NTA} / \mathrm{SiO}_{2}$, and (d) calcined $\mathrm{Co} / \mathrm{EDTA} / \mathrm{SiO}_{2}$. Calcinations are at $250{ }^{\circ} \mathrm{C}, \mathrm{CA} / \mathrm{Co}=0.5$ 


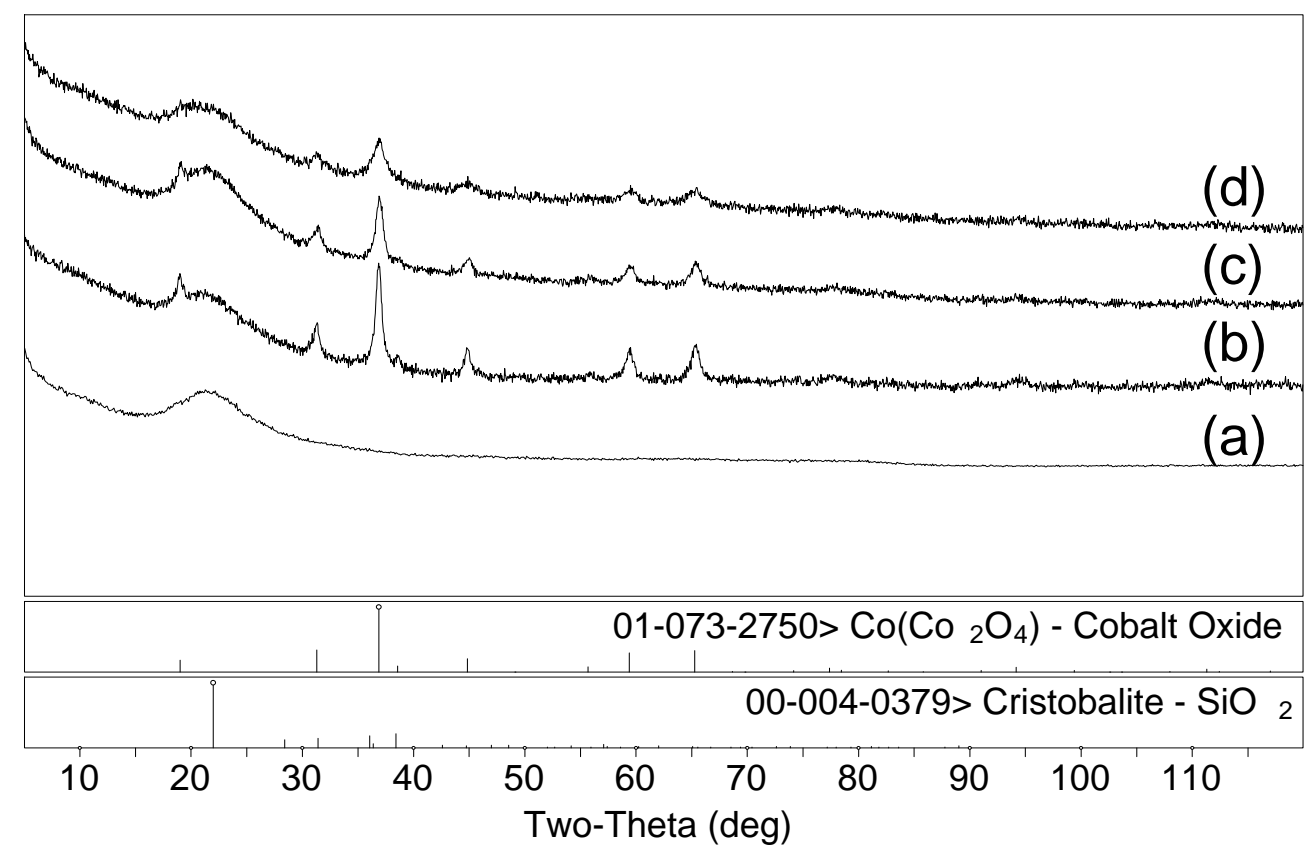

Figure 4.9 X-ray diffraction patterns: (a) $\mathrm{SiO}_{2}$ support, (b) calcined $\mathrm{Co} / \mathrm{SiO}_{2}$, (c) calcined $\mathrm{Co} / \mathrm{NTA} / \mathrm{SiO}_{2}$, and (d) calcined $\mathrm{Co} / \mathrm{EDTA} / \mathrm{SiO}_{2}$. Calcinations are at $350{ }^{\circ} \mathrm{C}, \mathrm{CA} / \mathrm{Co}=0.5$

Table 4.3 Physical properties and crystallite sizes of cobalt catalysts for $\mathrm{CA} / \mathrm{Co}=0.5$

\begin{tabular}{|l|c|c|c|}
\hline \multicolumn{1}{|c|}{ Catalyst } & \multirow{2}{*}{$\begin{array}{c}\text { Surface Area } \\
\text { (m² }\end{array}$} & & $\mathbf{C o}_{\mathbf{3}} \mathbf{O}_{\mathbf{4}}$ Crystallite Size (nm) \\
\cline { 3 - 4 } & & $250^{\circ} \mathrm{C}$ & $350^{\circ} \mathrm{C}$ \\
\hline $\mathrm{SiO}_{2}$ & 224 & $\mathrm{NA}$ & $\mathrm{NA}$ \\
\hline $\mathrm{Co} / \mathrm{SiO}_{2}$ & 163 & 15.1 & 17.7 \\
\hline $\mathrm{Co} / \mathrm{NTA} / \mathrm{SiO}_{2}$ & 181 & 14.0 & 16.0 \\
\hline $\mathrm{Co} / \mathrm{EDTA} / \mathrm{SiO}_{2}$ & 173 & 11.0 & 16.1 \\
\hline
\end{tabular}

\subsubsection{X-ray Photoelectron Spectroscopy}

The base-case catalysts and CA-modified catalysts, after calcination at $350{ }^{\circ} \mathrm{C}$, were subjected to XPS study. The XPS spectra in the energy region of Co $2 p$ for these catalysts are given in Figure 4.10. The binding energies (BEs) of Co $2 p$ spectra, with reference to the BEs of standard $\mathrm{CO}_{3} \mathrm{O}_{4}$, confirm that $\mathrm{CO}_{3} \mathrm{O}_{4}$ is the dominant cobalt phase present in calcined catalysts. The decomposition of the $\mathrm{Co} 2 \mathrm{p}$ spectrum of the $\mathrm{Co}_{3} \mathrm{O}_{4}$ phase exhibits the contributions from Co"l (octahedral), Co" (tetrahedral) and Co" satellite. The binding energies of Co $2 \mathrm{p}$ after peak decomposition, given in Table 4.4, are in good agreement with the reported values for supported cobalt catalysts ${ }^{85,86}$. The binding energy difference between the peak of $\mathrm{Co}^{11}$ and its 
satellite peak for the $\mathrm{Co}_{3} \mathrm{O}_{4}$ phase is about $6 \mathrm{eV}$. In general, higher intensities of the satellite peak and a shift of the XPS line toward the higher-energy region of the Co $2 p$ spectra, indicate the presence of $\mathrm{Co}^{2+}$ ions in interaction with the silica surface.

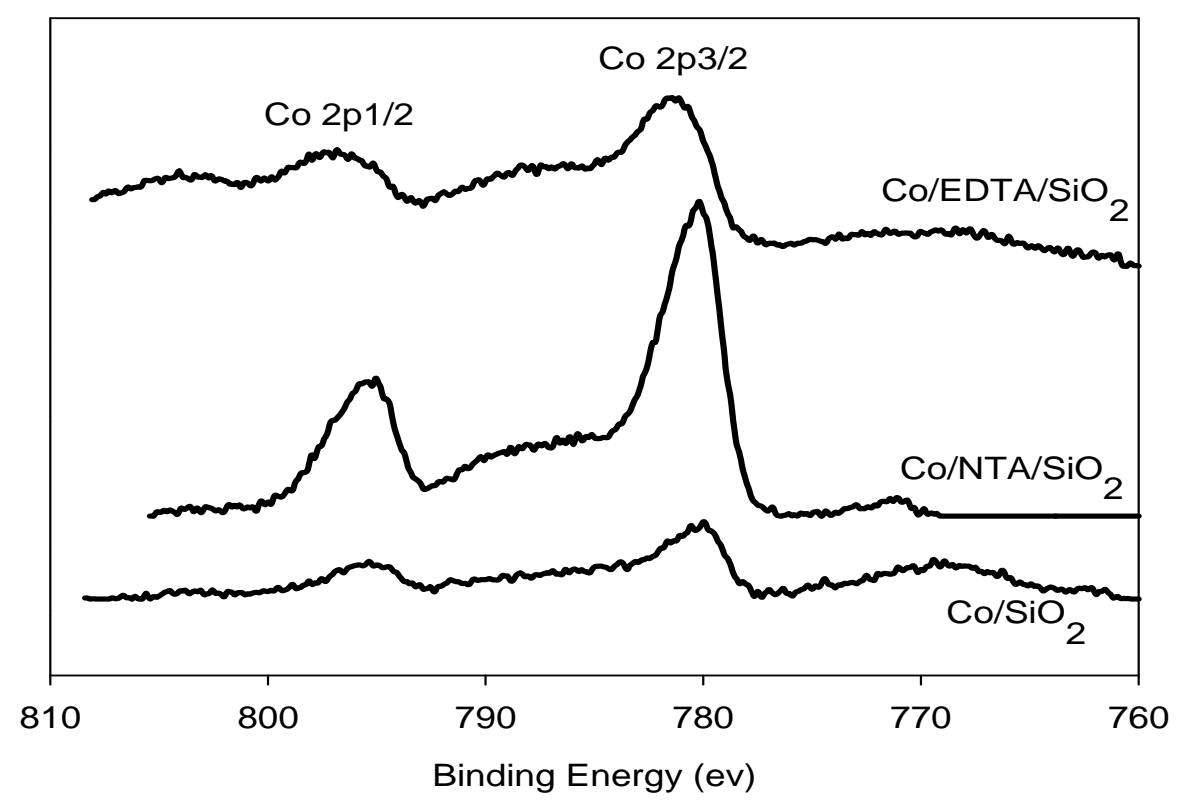

Figure 4.10 Comparison between the $\mathrm{Co} 2 \mathrm{p}$ XPS spectra of $\mathrm{CO}_{3} \mathrm{O}_{4}$ for base catalyst and CAmodified catalysts

Table 4.4 Binding energies of $\mathrm{Co} 2 \mathrm{p} 3 / 2$ and $\mathrm{Co} 2 \mathrm{p} 1 / 2$ for the $\mathrm{Co}_{3} \mathrm{O}_{4}$ phase of cobalt catalysts

\begin{tabular}{|c|c|c|c|c|c|c|c|}
\hline \multirow[t]{2}{*}{ Catalyst } & \multicolumn{3}{|c|}{ Binding Energy $\mathrm{Co} 2 \mathrm{p} 3 / 2(\mathrm{eV})$} & \multicolumn{3}{|c|}{ Binding Energy Co2p1/2 (eV) } & \multirow[t]{2}{*}{$I_{\mathrm{Co}} / I_{\mathrm{Si}}$ ratio } \\
\hline & $\mathrm{Co}^{\prime \prime I}$ & Co" & Co" satellite & $\mathrm{Co}^{\mathrm{III}}$ & Co" & Co" satellite & \\
\hline $\mathrm{CoO}^{87}$ & 778.5 & - & 784.2 & 794.3 & - & - & - \\
\hline $\mathrm{CO}_{3} \mathrm{O}_{4}{ }^{87}$ & 778.6 & - & 788.0 & 794.1 & - & - & - \\
\hline$\alpha-\mathrm{Co}_{2} \mathrm{SiO}_{4}{ }^{87}$ & 781.5 & - & 786.1 & 797.9 & - & - & - \\
\hline $\mathrm{Co} / \mathrm{SiO}_{2}$ & 780.0 & 781.4 & 787.4 & 795.0 & 796.5 & 801.5 & 0.6 \\
\hline $\mathrm{Co} / \mathrm{NTA} / \mathrm{SiO}_{2}$ & 780.1 & 781.6 & 787.6 & 795.2 & 796.6 & 801.6 & 1.5 \\
\hline $\mathrm{Co} / \mathrm{EDTA} / \mathrm{SiO}_{2}$ & 781.1 & 782.0 & 787.9 & 796.0 & 797.5 & 802.7 & 1.7 \\
\hline
\end{tabular}

For the NTA-modified catalyst, the binding energy of Co"l (ca. $780.1 \mathrm{eV}$ ) and Co" (ca. $781.6 \mathrm{eV}$ ) peaks are similar to values for the base catalyst. However, in the case of the EDTAmodified catalyst, higher binding energies of $\mathrm{CO}^{\text {III }}$ and $\mathrm{CO}^{\prime \prime}$ may suggest the presence of a cobalt ion interaction with the silica surface. Furthermore, the higher intensity of a satellite peak in the EDTA-modified catalyst relative to the base catalyst is well evident. These spectral features 
are characteristics of cobalt-silicate-like phases (see values of $\alpha-\mathrm{CO}_{2} \mathrm{SiO}_{4}$ in Table 4.4). Therefore, such species are expected to be present on the surface of the EDTA-containing catalyst, but less so for the NTA-modified catalyst. The $\mathrm{CO}_{3} \mathrm{O}_{4}$ species on the EDTA-containing catalyst has the smallest crystallite size, as confirmed by the XRD at $350{ }^{\circ} \mathrm{C}$ for CA/Co ratio of 1 (see Table 4.2). The smaller crystallite can more easily interact with the support during the drying and calcination steps, resulting in the formation of silicate-like structures.

The surface charges present on the silica support determine the extent of electronic attraction or repulsion with the impregnated cobalt ions. If the $\mathrm{pH}$ of the impregnating solution is higher than the point of zero charge (PZC) of silica (PZC of 1.7 to 3.5), the surface of silica is negatively charged. The negatively charged silica support exhibits a certain extent of attraction towards cobalt ions. In contrast, at $\mathrm{pH}$ values below the PZC of silica, the positively charged silica surface repels the impregnated cobalt ions and hence can result in non-uniform cobalt distribution, resulting in poor metal dispersion.

Therefore, the $\mathrm{I}_{\mathrm{Co}} / \mathrm{I}_{\mathrm{Si}}$ ratio of the XPS intensities can be used to provide useful information about the distribution of cobalt ions on silica surface ${ }^{88}$. Higher $I_{\mathrm{Co}} / \mathrm{I}_{\mathrm{Si}}$ ratios are characteristic of higher cobalt dispersion in the calcined cobalt catalyst. On the other hand, lower ratios would mean a poorly dispersed metal phase on the outer surface of catalyst. The ratio of intensities of Co $2 \mathrm{p} 3 / 2$ and Si $2 p$ peaks (i.e. $I_{\mathrm{Co}} / \mathrm{I}_{\mathrm{Si}}$ ) are also listed in Table 4.4. These intensity ratios are clearly higher for the CA-modified catalysts than that for the base-case catalyst. This confirms that the CA-modified catalysts possess a well-dispersed cobalt oxide phase, mainly due to presence of smaller crystallites. In the present work, the EDTA-containing catalyst has the smallest $\mathrm{CO}_{3} \mathrm{O}_{4}$ size among all. Therefore, for such a well-dispersed catalyst, a metal-support interaction is expected to exist. As mentioned earlier, the study of reduction behavior of these oxide phases can further provide insights into catalyst structure.

\subsubsection{Temperature-Programmed Reduction}

The temperature-programmed reduction (TPR) profiles of the catalysts are shown in Figure 4.11. The occurrence of multiple reduction peaks indicates the presence of a number of 
reducible cobalt species. A sharp reduction peak in TPR generally indicates an instantaneous process whereas broad peaks are attributed to difficult-to-reduce phases.

For the $\mathrm{Co} / \mathrm{SiO}_{2}$ catalyst, two strong peaks are located at 229 and $291{ }^{\circ} \mathrm{C}$ and a small high-temperature peak at $665{ }^{\circ} \mathrm{C}$. Similarly, the NTA-modified $\mathrm{Co} / \mathrm{SiO}_{2}$ catalyst shows two peaks at 230 and $293{ }^{\circ} \mathrm{C}$ and a peak at $642{ }^{\circ} \mathrm{C}$. However, the EDTA-modified sample shows a single weak peak at $170{ }^{\circ} \mathrm{C}$ followed by a single strong peak at $215^{\circ} \mathrm{C}$ and another strong peak at higher temperature of $685{ }^{\circ} \mathrm{C}$. In addition, for $\mathrm{Co} / \mathrm{EDTA} / \mathrm{SiO}_{2}$ a broad region of hydrogen consumption is observed between 300 and $500^{\circ} \mathrm{C}$.

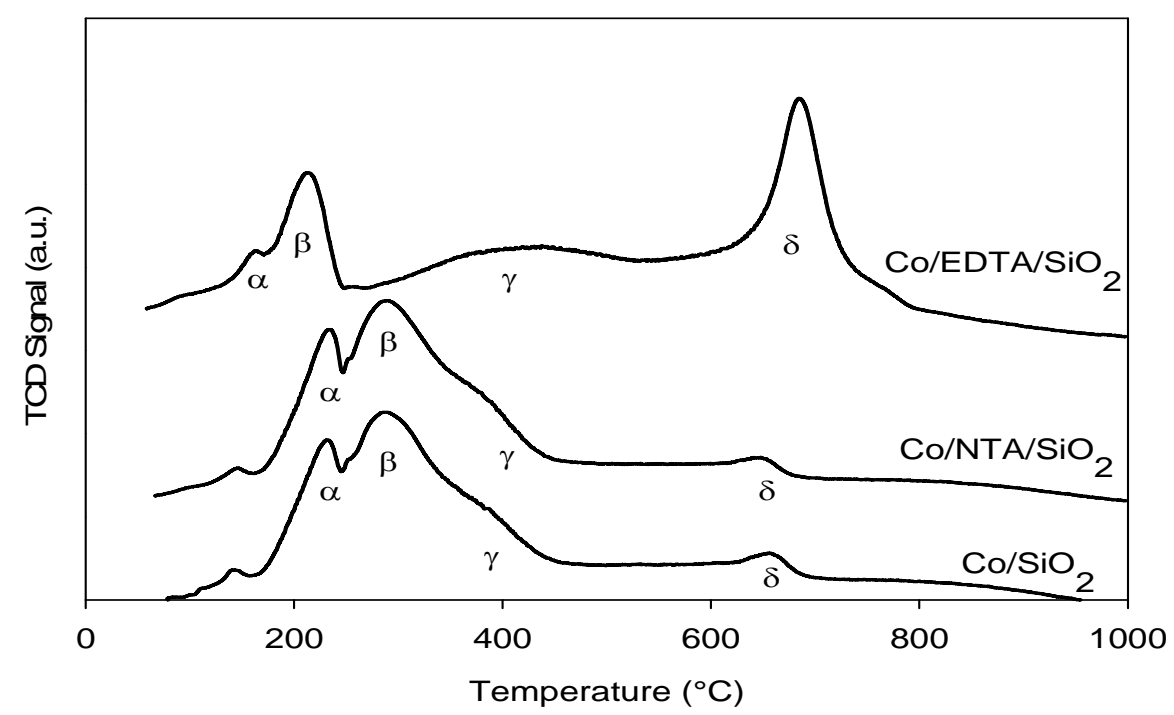

Figure 4.11 Temperature-programmed reduction profiles of various cobalt catalysts (Experimental conditions: temperature increase with $5{ }^{\circ} \mathrm{C} / \mathrm{min} ; 10 \% \mathrm{H}_{2} / \mathrm{Ar}$ mixture; total flow rate, $50 \mathrm{sccm}$; catalyst wt., $0.15 \mathrm{~g}$ )

The TPR peak assignments as shown in Figure 4.11 can be explained as follows;

$\alpha$, reduction of $\mathrm{CO}_{3} \mathrm{O}_{4}$ into $\mathrm{CoO}$;

$\beta$, reduction of $\mathrm{CoO}$ into metallic $\mathrm{Co}$;

$\gamma$, reduction of a oxide with a mild $\mathrm{Co}-\mathrm{SiO}_{2}$ interaction; and

$\delta$, reduction of a oxide with stronger interactions, such as the formation of silicates or hydrosilicates 
The two lower-temperature peaks (at ca. 230 and $291^{\circ} \mathrm{C}$ ) can be assigned to a two-step reduction of $\mathrm{CO}_{3} \mathrm{O}_{4}$ (i.e., $\alpha$ and $\beta$ phases). The reduction is known ${ }^{84,86,89}$ to proceed via formation of $\mathrm{CoO}$ species represented as:

$$
\mathrm{Co}(\mathrm{III})_{2} \mathrm{Co}(\mathrm{II}) \mathrm{O}_{4} \rightarrow \mathrm{Co}(\mathrm{II}) \mathrm{O} \rightarrow \mathrm{Co}
$$

The reduction of $\mathrm{CO}_{3} \mathrm{O}_{4}$ into metallic cobalt is followed by a broad region of hydrogen consumption between 300 and $500{ }^{\circ} \mathrm{C}$. This broad region can be ascribed to a very slow reduction of $\mathrm{CoO}$ species present inside the pores (i.e., $y$ phase). In fact, it has been previously reported ${ }^{84}$ that the rate of reduction from $\mathrm{CoO}$ to $\mathrm{Co}$ is lower than that of $\mathrm{Co}_{3} \mathrm{O}_{4}$ to $\mathrm{CoO}$.

Based on the concept of a strong oxide-oxide interaction (SOOI) proposed by Lund and Dumesic ${ }^{90}$, the $\mathrm{Co}^{2+}$ is said to be stabilized by the $\mathrm{SiO}_{2}$ support and consequently resists further reduction. Although the interaction of silica and Co metal is assumed to be weak, it is unlikely that the silica-supported Co catalyst can be easily reduced.

The most pronounced difference between the catalysts is observed in the highertemperature region. For the EDTA-chelated cobalt, the presence of a sharp peak at $685{ }^{\circ} \mathrm{C}$ suggests the reduction of very small Co species which may be interacting with the $\mathrm{SiO}_{2}$ support ${ }^{91}$ (i.e., $\delta$ phase). Such a higher-temperature reduction peak is also observed in $\mathrm{Co} / \mathrm{SiO}_{2}$ and $\mathrm{Co} / \mathrm{NTA} / \mathrm{SiO}_{2}$ samples. However, the lower intensity of the peak in the case of $\mathrm{Co} / \mathrm{SiO}_{2}$ and $\mathrm{Co} / \mathrm{NTA} / \mathrm{SiO}_{2}$ suggests a weaker interaction in comparison to the EDTA-modified samples ${ }^{92}$.

Based on the TPR results, catalyst reduction is performed at $400{ }^{\circ} \mathrm{C}$ to ensure optimum reduction prior to FTS experiments.

\subsubsection{Hydrogen Chemisorption}

The chemisorbed hydrogen measurements and the calculation of the metal dispersion of catalyst samples are presented in Table 4.5. The number of cobalt sites present on the catalysts is calculated by assuming that two cobalt sites are covered by one hydrogen molecule. It is evident that both the CA-modified catalysts display higher amounts of chemisorbed hydrogen, and hence higher densities of active sites, compared to the base catalyst. Therefore, the metal dispersion of the NTA- and EDTA-modified catalysts is higher than that of the base catalyst. These findings are in total accordance with the results from XPS showing higher intensity ratios for the CA-modified catalyst. 
Table 4.5 Hydrogen chemisorption and dispersion data for catalysts

\begin{tabular}{|l|c|c|c|c|}
\hline & $\begin{array}{c}\mathbf{H}_{\mathbf{2}} \text { chemisorbed } \\
(\boldsymbol{\mu \mathbf { m o l }} / \mathbf{g})\end{array}$ & $\begin{array}{c}\text { Co surface sites } \\
(\boldsymbol{\mu m o l} / \mathbf{g})\end{array}$ & $\begin{array}{c}\text { Metallic Surface Area } \\
\left(\mathbf{m}^{\mathbf{2}} / \mathbf{g} \text { metal }\right)\end{array}$ & $\begin{array}{c}\text { Dispersion } \\
\mathbf{\%}\end{array}$ \\
\hline $\mathrm{Co} / \mathrm{SiO}_{2}$ & 18.8 & 9.4 & 7.5 & 1.1 \\
\hline $\mathrm{Co} / \mathrm{NTA} / \mathrm{SiO}_{2}$ & 40.7 & 20.4 & 16.2 & 2.4 \\
\hline $\mathrm{Co} / \mathrm{EDTA} / \mathrm{SiO}_{2}$ & 41.7 & 20.9 & 16.2 & 4.7 \\
\hline
\end{tabular}

\subsection{Discussion}

The pretreatment conditions used for the preparation of cobalt catalysts can have a great influence on the surface states of cobalt species, and in turn can determine the FT activity. Although the FT activity of cobalt catalysts is the outcome of the entire preparation procedure, the decomposition step is one of the crucial steps in determining the overall performance $^{83}$. As explained earlier, the slow temperature rise during the calcination step assisted in minimizing the material disintegration for the catalysts prepared here.

The surface modification of an oxide support has been used as a way to improve the properties of FT catalysts. Shi et al. ${ }^{93}$, for example, have reported that the organic modification of $\mathrm{SiO}_{2}$ for a supported cobalt catalyst can result in smaller crystallite sizes. In particular, they found that the modification of $\mathrm{SiO}_{2}$ by a $\left(\mathrm{CH}_{3}\right)_{3}$ - group slightly increases $\mathrm{CO}_{3} \mathrm{O}_{4}$ crystallite sizes, whereas that by a $\mathrm{COOH}$ - group, a $\mathrm{NH}_{2}$ - group, or a $\mathrm{NH}_{2}\left(\mathrm{CH}_{2}\right)_{2} \mathrm{NH}$-group decreases $\mathrm{CO}_{3} \mathrm{O}_{4}$ crystallite sizes.

In addition, the surface charges present on the silica can also play a vital role in the properties of the catalysts. For example, surface-functional groups such as silanol (i.e. SiOH groups) on a silica support can interact with cobalt oxides during the calcination step ${ }^{34,37,38 .}$ These interactions may result in the formation of cobalt silicate which is not easy to reduce and often requires higher temperatures of reduction. The migration of silica during cobalt nitrate decomposition and the thermal pretreatment has been reported by Puskas et al. ${ }^{94}$, and this could affect the final structure of the FT catalyst.

Shi et al. ${ }^{95}$ investigated the effect of $\mathrm{SiO}_{2}$ modification with various organic groups such as $\left(\mathrm{CH}_{3}\right)_{3^{-}}, \mathrm{COOH}-, \mathrm{NH}_{2^{-}}$, and $\mathrm{NH}_{2}\left(\mathrm{CH}_{2}\right)_{2} \mathrm{NH}$ - species. The organic modification of $\mathrm{SiO}_{2}$ was reported to influence the reducibility and catalytic properties of cobalt catalyst. The organic 
modification by the $\left(\mathrm{CH}_{3}\right)_{3}$ - group reduces surface silanol concentration on silica support and suppresses the interaction between metal and support.

In addition, Sun et al. ${ }^{36}$ studied the FT performance of cobalt catalysts prepared from nitrate and acetate precursors. The impregnation of the support with a mixture of cobalt acetate and cobalt nitrate results in a highly active cobalt catalyst compared to impregnation by only nitrate or acetate precursor. As mentioned earlier, the formation of highly dispersed cobalt catalysts is believed to originate from small $\mathrm{CoO}$ or $\mathrm{CO}_{3} \mathrm{O}_{4}$ crystallites. The formation of smaller oxide crystallites needs a strong interaction between the support and the metal precursor. However, too strong an interaction can form irreducible phases and hence suppress the reduction. Likewise, for the EDTA-modified catalyst, the intensity of the high temperature reduction peak is higher due to the presence of small crystallites.

It is confirmed from the characterization study that the modification of silica support by a chelating agent affects the structure of cobalt catalysts. However, the precise role of chelating is still not clear. Koizumi and co-workers $33,34,37,38$, performed temperature-programmed oxidation (TPO) over a NTA-modified catalyst prepared by stepwise impregnation. The chelating agent is said to form stable complexes with $\mathrm{Co}^{2+}$ and sustain the heat treatment during the drying step (less than $110{ }^{\circ} \mathrm{C}$ ). Koizumi and co-workers attributed the evolved $\mathrm{NO}$ and $\mathrm{NO}_{2}$ during TPO, below $227^{\circ} \mathrm{C}$, to decomposition of a nitrate precursor in case of a Co/SiO ${ }_{2}$ catalyst. On the contrary, the NTA-modified catalyst during decomposition below $327{ }^{\circ} \mathrm{C}$ shows additional species $\mathrm{CO}$ and $\mathrm{CO}_{2}$. Therefore, the evolution of $\mathrm{CO}$ and $\mathrm{CO}_{2}$ in chelated catalysts was assumed to be due to decomposition and/or combustion of NTA- $\mathrm{Co}^{2+}$ complexes. Koizumi and co-workers hypothesized that the bulky structure of complexes formed between NTA and $\mathrm{Co}^{2+}$ prevents sintering of Co species at high temperature. Therefore, the capsulation effect of CA is hypothesized to assist in the formation of a well-dispersed Co species after calcination.

The CA modification can therefore be seen as a grafting step used to modify the surface silanol. This in turn can minimize the direct interaction of cobalt and silica during heat treatments. This grafting process may then partially assist in facilitating the dispersion of the $\mathrm{CO}_{3} \mathrm{O}_{4}$ phase during the calcination. This eventually results in a reduced crystallite size at the end of the calcination step. 


\subsection{Summary}

In summary, both XRD and XPS strongly suggest that the calcination step completely decomposes the nitrate precursor and $\mathrm{CO}_{3} \mathrm{O}_{4}$ phase is formed. The slow temperature rise during the calcination assists in minimizing the material disintegration. In addition, the CA modification alters the particle size, reduction behavior and metal-support interaction of the cobalt catalyst studied here. In particular, the crystallite size of CA-modified catalysts is smaller than that of the base-case catalyst. Also, the metal dispersion is enhanced by the CA-modification. In case of the catalyst with smaller crystallites, e.g., for the EDTA-modified catalyst, the higher reduction temperature is required for the reduction of difficult-to-reduce phases.

In order to investigate the effect of such structural changes on the catalyst activity, the catalysts are subjected to FTS and findings are presented in the next chapter. 


\section{CHAPTER 5 \\ CONVERSION AND PRODUCT DISTRIBUTION: PERFORMANCE OF COBALT-ONLY CATALYST}

\subsection{Introduction}

In this chapter, the activity of reactor components in the absence of cobalt catalyst is determined. In addition, the FT performance of a base-case cobalt catalyst is evaluated. The approach used for the qualitative and quantitative analysis of products is discussed. The components of carbon balance and determination of product selectivities are also discussed.

\subsection{Blank Run}

Initially, the activity of various components towards syngas under the FT conditions was determined. For this case, the reactor tube was filled with only quartz chips and no catalyst material. The reduction was performed in the presence of $\mathrm{H}_{2}$ at $400{ }^{\circ} \mathrm{C}, 1 \mathrm{~atm}$ and $200 \mathrm{cc} / \mathrm{min}$ for $12 \mathrm{~h}$. The operating conditions for the run were similar to routine FT runs: $\mathrm{T}=230^{\circ} \mathrm{C} ; \mathrm{P}=20$ bars; $\mathrm{SV}=9000 \mathrm{sccm} / \mathrm{h} / \mathrm{g}_{\text {cat }} ;$ and $\mathrm{H}_{2} / \mathrm{CO}=2.0$.

The inlet and outlet molar rates of CO are compared in Figure 5.1. The observed outlet flow rate of $\mathrm{CO}$ is close to the inlet flow rate of $0.00401 \mathrm{~mol} / \mathrm{min}$. The $\mathrm{CO}$ and overall syngas conversion is plotted in Figure 5.2 for this run. The observed CO conversion is well below $1 \%$ in both the cases. The small differences between the measured inlet and outlet molar rate measurement can be attributed to accuracy of GC measurements. Therefore, it can be safely assumed that the wall of the reactor, quartz chips and other components of the setup do not show any noticeable activity for FTS under relevant conditions. In order to represent the real FT activity of catalyst, the blank-run conversion is subtracted from the observed conversion for the catalytic FT runs. 


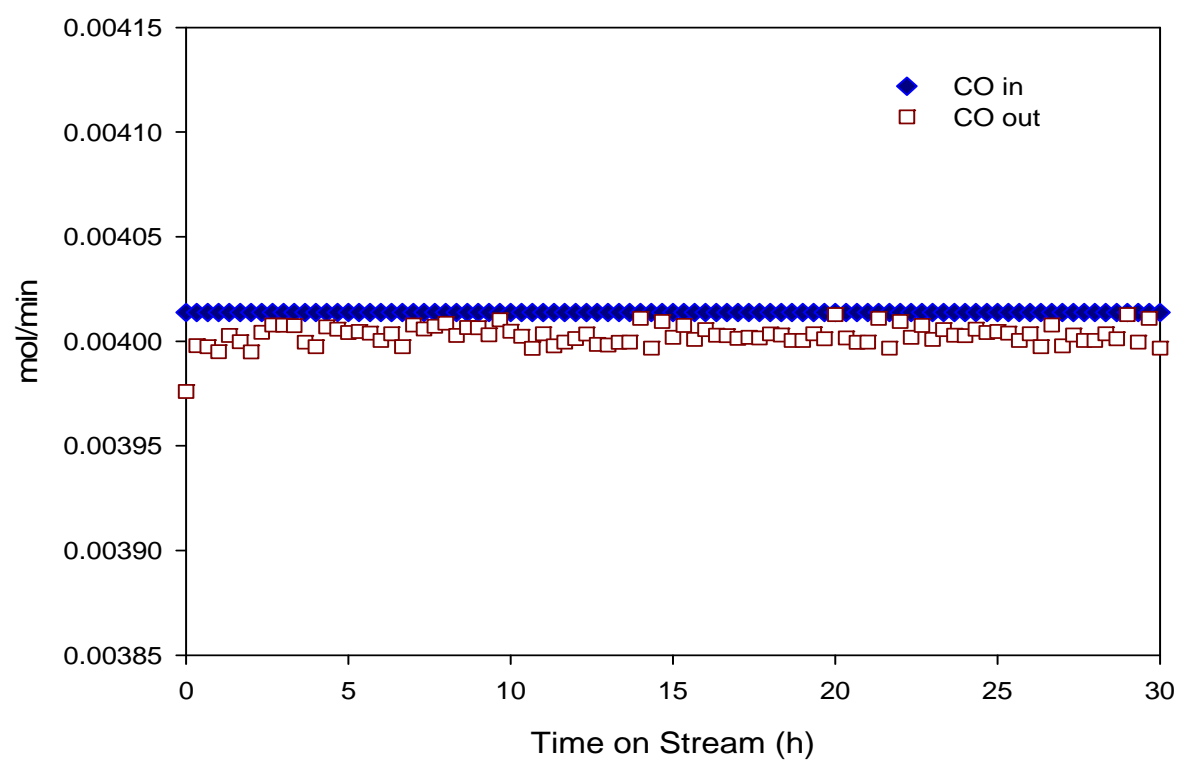

Figure 5.1 Inlet and outlet molar flow rate of CO for a run of quartz chips filled reactor under FT conditions

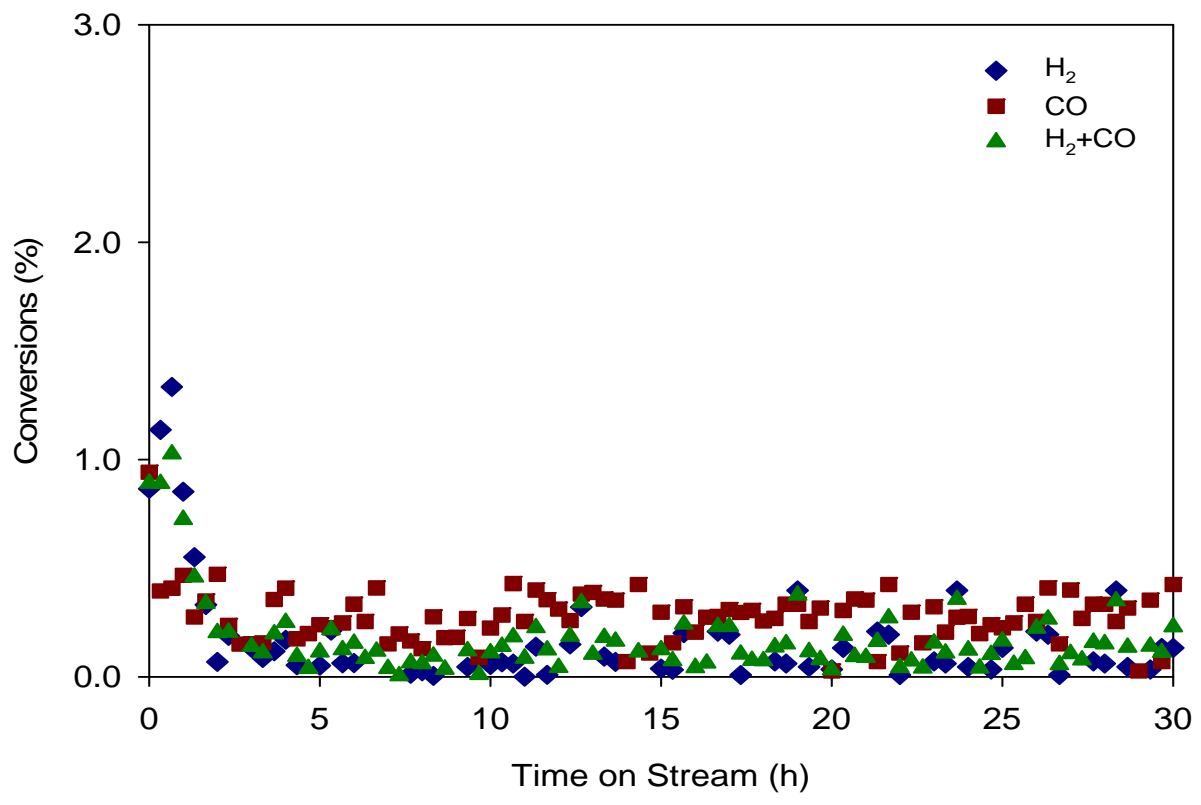

Figure 5.2 Syngas conversion for a run of quartz chips filled reactor under FT conditions 


\subsection{FT Run with Cobalt-only Catalyst}

In the next step, the reactor was loaded with $1 \mathrm{~g}$ of a base-case $\mathrm{Co} / \mathrm{SiO}_{2}$ catalyst. Prior to FTS, the catalyst was reduced in-situ by $\mathrm{H}_{2}$ at $400{ }^{\circ} \mathrm{C}, 1 \mathrm{~atm}$ and $200 \mathrm{cc} / \mathrm{min}$ for $12 \mathrm{~h}$. The operating conditions were as mentioned earlier. The observed CO conversions of the base catalyst are shown in Figure 5.3. The time on stream (TOS) for the catalyst is $72 \mathrm{~h}$. At first, the CO conversion slowly increases and reaches $33 \%$. Thereafter, the CO conversion shows a gradual drop in activity and steadies at $21 \%$ after $48 \mathrm{~h}$.

The gas products were analyzed with the online GC every $30 \mathrm{~min}$. The liquid products formed during the run were collected every $24 \mathrm{~h}$ and were analyzed by the off-line $\mathrm{GC}$ as described in Section 5.4. The data from the second period, i.e. 24-48 $\mathrm{h}$ TOS, were used to calculate the average conversion, turnover frequency (TOF) and product selectivity values. This averaging approach discounts the transient behavior of a fixed-bed reactor ${ }^{2}$ and represents the product selectivities at a relatively stable syngas conversion. The initial period, where the catalyst slowly reaches a maximum activity is referred to as the induction period ${ }^{96}$.

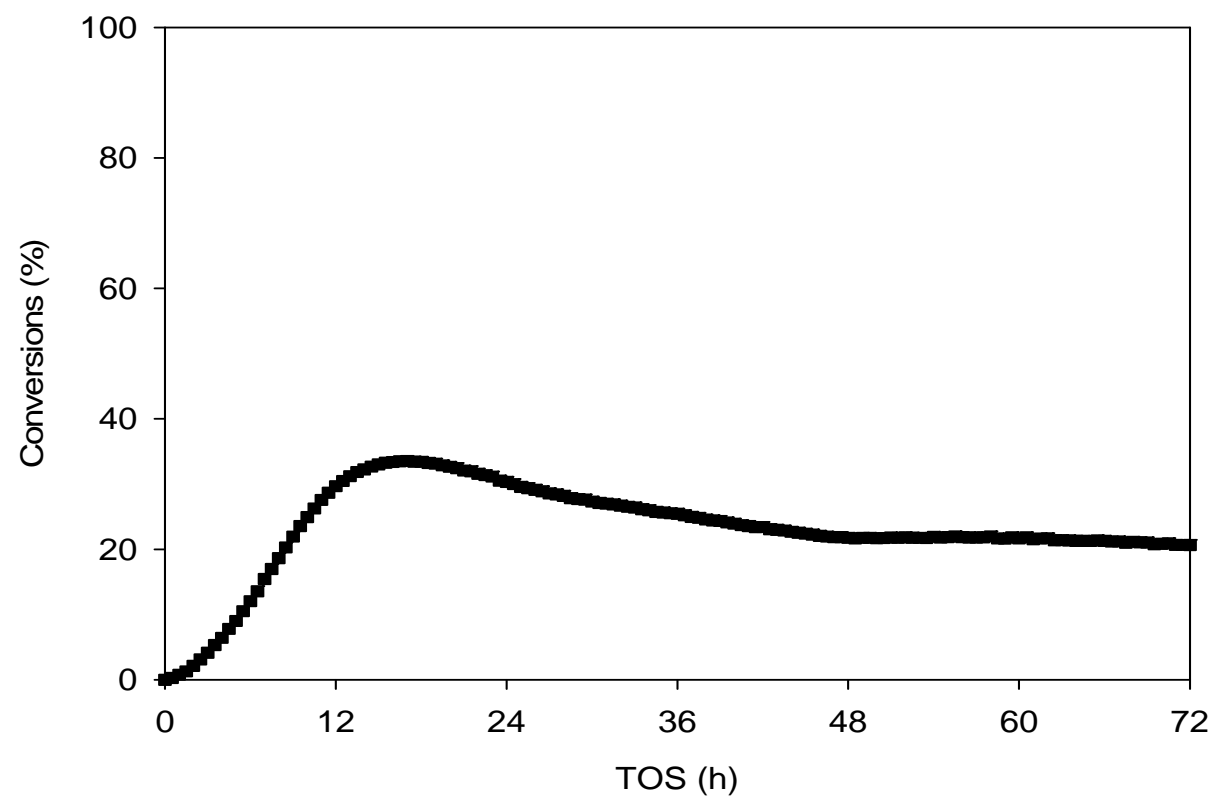

Figure $5.3 \mathrm{CO}$ conversions vs. TOS for a $\mathrm{Co} / \mathrm{SiO}_{2}$ catalyst

(Experimental conditions: $\mathrm{T}=230{ }^{\circ} \mathrm{C} ; \mathrm{P}=20$ bars, $\mathrm{H}_{2} / \mathrm{CO}=2.0$ and syngas $\mathrm{SV}=9000 \mathrm{sccm} / \mathrm{h} / \mathrm{g}_{\text {cat }}$ ) 


\subsection{Qualitative and Quantitative Analysis of Products}

The liquid products recovered from the run contained an oil layer and an aqueous layer which were separated before the analysis. The phases were separated after allowing them to settle for $24 \mathrm{~h}$. The weights of the separated oil and aqueous phases were noted before initiating the quantitative analysis. The separated oil layer contains paraffins and olefins, while the aqueous layer consists of alcohols and water. The wax from the wax separator was collected and weighed. The wax too consists of paraffins and olefins.

The detailed procedures for the quantitative analysis of these paraffins, olefins and alcohols are provided in Appendix G. The chromatographs from the GC analysis of the products are provided in Appendix $\mathrm{H}$. Based on the procedure described in Appendix G, the molar flow rates of all the components are calculated.

\subsection{Product Selectivities and Yields}

The following expressions are used to calculate the performance of various cobalt catalysts for Fischer-Tropsch synthesis.

$$
\begin{aligned}
& \text { CO conversion }(\%)=\frac{\text { mol rate of CO consumption }}{\text { mol rate of CO inlet }} \times 100 \\
& \mathrm{H}_{2} \text { conversion }(\%)=\frac{\text { mol rate of } \mathrm{H}_{2} \text { consumption }}{\text { mol rate of } \mathrm{H}_{2} \text { inlet }} \times 100
\end{aligned}
$$$$
\text { Turnover frequency }\left(\mathrm{TOF}, \mathrm{s}^{-1}\right)=\frac{\text { mole rate of CO consumption }}{\text { mol of cobalt }}
$$

Hydrocarbon Yield $\left(\frac{\mathrm{g}}{\mathrm{kg} \text { cat.h }}\right)=\frac{\text { hydrocarbon production rate }\left(\frac{g}{h}\right)}{\text { catalyst mass }(\mathrm{kg})}$

$$
\text { Alcohol Yield }\left(\frac{g}{\mathrm{~kg} \text { cat.h }}\right)=\frac{\text { alcohol production rate }\left(\frac{g}{h}\right)}{\text { catalyst mass }(\mathrm{kg})}
$$

Selectivity of HC with carbon number of $n(w \%)=\frac{\text { rate of } H C \text { produced with } C \text { no.of } n}{\text { rate of total HC produced }} \times 100$ 
Selectivity of alcohol with carbon no. of $n(w \%)=\frac{\text { rate of alcohol produced with } C \text { no.of } n}{\text { rate of total alcohol produced }} \times 100$

$$
\begin{aligned}
& \text { Selectivity of } \mathrm{CO}_{2}(\mathrm{~mol} \%)=\frac{\text { mol of } \mathrm{CO}_{2} \text { formed }}{\text { mol of CO reacted }} \times 100 \\
& \text { Ratio of olefin to paraffin }=\frac{\text { production rate of olefin }}{\text { production rate of paraffin }}
\end{aligned}
$$

The performance of various catalysts is evaluated by comparing the CO conversions, TOFs, product selectivities and hydrocarbon productivities.

\subsection{Overall Carbon Balance}

The carbon balance was established after careful quantification of each component in the products. Therefore, the overall carbon balance incorporates the carbon entering the system in the form of $\mathrm{CO}$, leaving as unreacted $\mathrm{CO}$, in the form of oxide product (i.e., $\mathrm{CO}_{2}$ ), gaseous hydrocarbons (i.e., $C_{1}$ to $C_{5}$ ), liquid-phase (including wax) hydrocarbons (i.e., paraffin and olefins) and aqueous-phase oxygenates (i.e. alcohols).

The C-balance can be represented by:

$$
C_{\text {in }}^{C O}=C_{\text {out }}^{C O}+C_{\text {out }}^{\text {gas } H C}+C_{\text {out }}^{\mathrm{CO}_{2}}+C_{\text {out }}^{\text {liq para }}+C_{\text {out }}^{\text {liq ole }}+C_{\text {out }}^{\text {liq oxy }}
$$

After establishing the carbon balance for each run, the product selectivities were determined. Typically, the closure on carbon balance is $5 \%$ for all the runs performed here.

\subsection{Performance of Cobalt-only Catalyst}

The yields of the products are calculated from the procedure described earlier. The product yield $\left(\mathrm{g} / \mathrm{kg}_{\mathrm{cat}} / \mathrm{h}\right)$, for the base case catalyst at $230{ }^{\circ} \mathrm{C}$, includes $141.2 \mathrm{~g}$ of paraffins, 12.2 $\mathrm{g}$ of olefins and $16.3 \mathrm{~g}$ of alcohols. The TOF value for the base catalyst is $0.0092 \mathrm{~s}^{-1}$. The yield values and TOF are consistent with other cobalt catalyst ${ }^{69}$.

\subsubsection{Anderson Schulz-Flory Distribution}

In general, the product distribution of hydrocarbons formed during FTS follows an Anderson Schulz-Flory (ASF) distribution ${ }^{4,6,28}$. The weight fraction, $W_{n}$, of a hydrocarbon chain with $\mathrm{n}$ carbon atoms is given by the ASF model as follows, 


$$
W_{n}=n(1-\alpha)^{2} \alpha^{n-1}
$$

where the propagation probability $\alpha$ is independent of the chain length. Higher value of $\alpha$ suggests higher probability of formation of longer-chain hydrocarbon ${ }^{4}$. For the base-case catalyst, the ASF distribution is plotted in Figure 5.4. The slope of the line is used to determine the value of $\alpha$. The reported ${ }^{97-99}$ values of $\alpha$ are in the range of 0.55-0.9 for cobalt catalysts. The calculated value of the propagation probability, $\alpha$, for the base-case catalyst is 0.73 , indicating a satisfactory performance of a base catalyst.

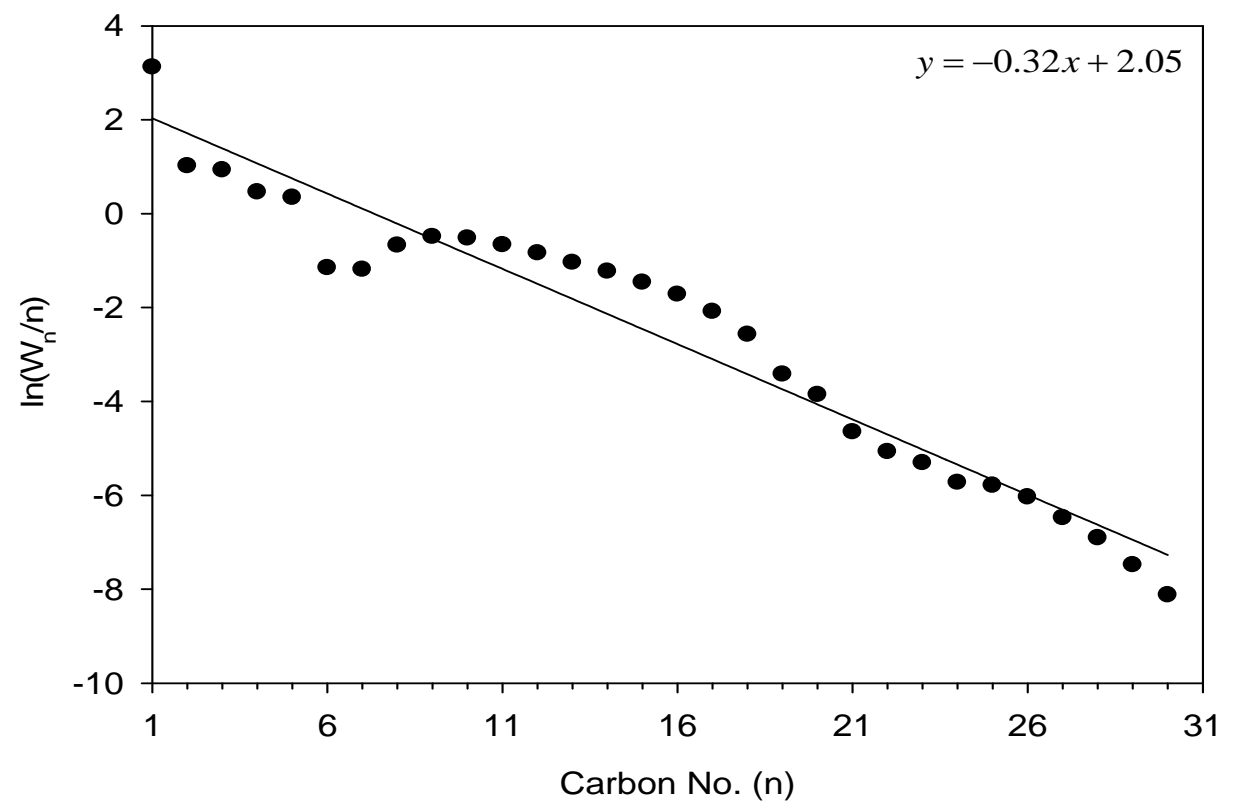

Figure 5.4 ASF distribution over the base-case catalyst

\subsubsection{Product Selectivity}

The products from the FTS contain paraffins, olefins and alcohols. Qualitative and quantitative product analyses were performed, as described in Section 5.4. The product selectivities were calculated after establishing the carbon balance. For the base catalyst, the selectivities of paraffins, olefins, and alcohols as a function of carbon number are plotted in Figure 5.5a-c, respectively. 

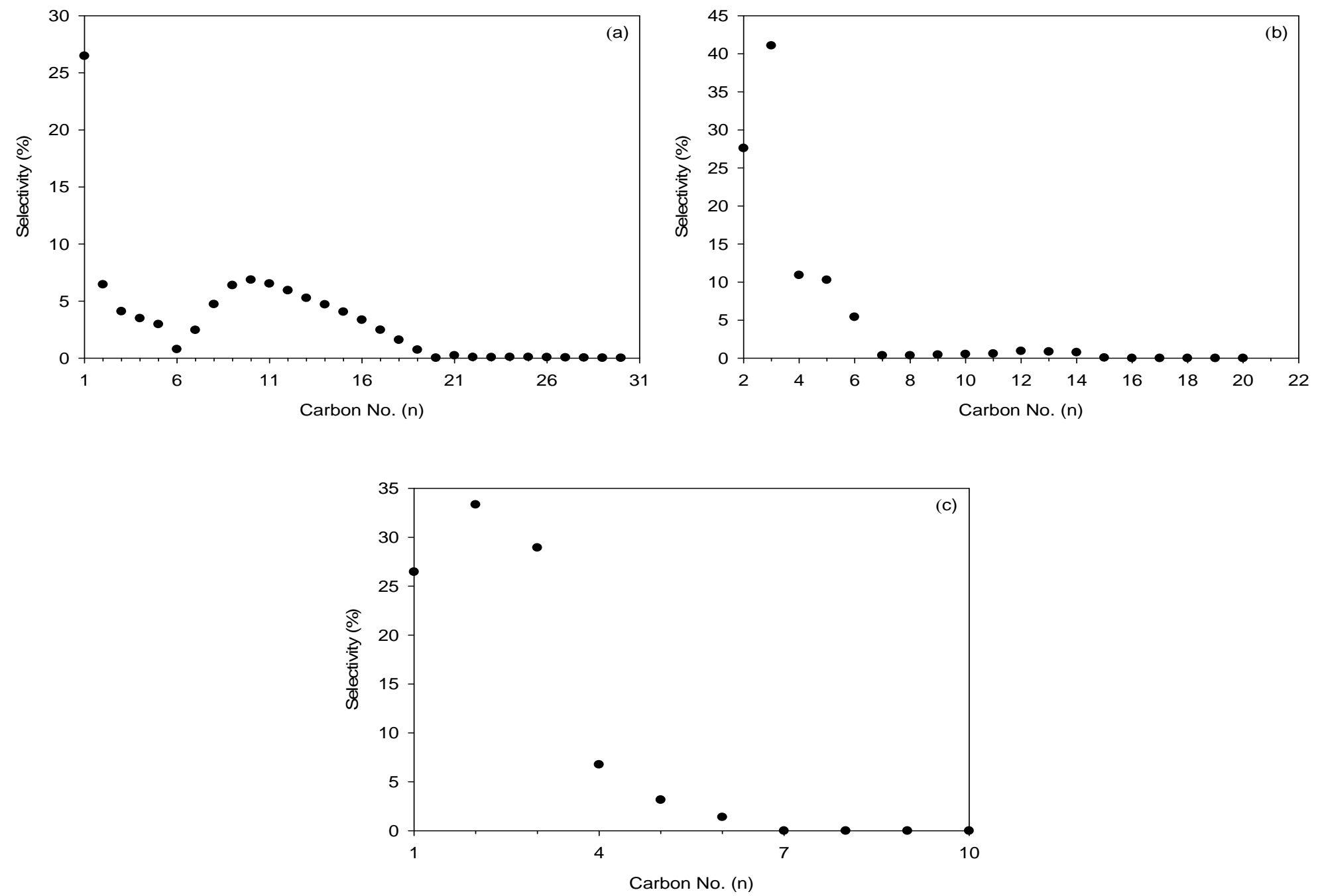

Figure 5.5 Product selectivities as a function of carbon numbers over a $\mathrm{Co} / \mathrm{SiO}_{2}$ catalyst (a) paraffins, (b) olefins, and (c) alcohols 
The paraffin selectivity starts with the highest value for $C_{1}$ and then drops progressively up to $C_{6}$. The selectivity increases thereafter and shows a maximum at $C_{10}$. Thereafter, the selectivity continuously drops for carbon number greater than 10.

The olefin selectivity increases from $C_{2}$, reaches a maximum for $C_{3}$ and drops after $C_{3}$ before showing slight increase at $C_{7}$. Similar to the trend of paraffin selectivity, the olefin selectivity shows increasing trend for the carbon number greater than $C_{7}$ and reaches a maximum for $C_{12}$. The olefin selectivity for carbon numbers, greater than $C_{12}$, decreases after reaching a maximum.

The alcohol selectivity initially increases from $C_{1}$ to $C_{2}$. Thereafter, the alcohol selectivity shows progressive drop for higher carbon numbers.

\subsection{Summary}

The wall of the reactor, quartz chips and other components of the setup do not show any noticeable activity for FTS under relevant conditions. The performance of the base catalyst is evaluated under relevant FTS conditions. The procedure for the product analysis is established. The product selectivities are determined by establishing a carbon balance. The value of $\alpha$ for the base-case catalyst is 0.73 . The TOF value for the base catalyst is $0.0092 \mathrm{~s}^{-1}$. The base catalyst shows satisfactory performance. The performances of the CA-modified catalysts are compared with the base catalyst to investigate the effect of CA modification. 


\section{CHAPTER 6 \\ PERFORMANCE OF MODIFIED COBALT CATALYSTS}

\subsection{Introduction}

The FT performance of the CA-modified cobalt catalyst was evaluated under relevant conditions and compared with the base catalyst. The FTS runs were carried at two different temperatures. The product yields and selectivities of the paraffins, olefins and alcohols were used to compare the catalyst performance. Finally, the effect of the CA modification on the FT performance of the cobalt catalyst was determined.

\subsection{Performance of Modified Catalysts}

The $\mathrm{Co} / \mathrm{NTA} / \mathrm{SiO}_{2}$ and $\mathrm{Co} / \mathrm{EDTA} / \mathrm{SiO}_{2}$ catalysts prepared earlier were subjected to $\mathrm{FTS}$. Prior to FTS, the catalyst (approximately $1000 \mathrm{mg}$ ) was reduced in-situ by $\mathrm{H}_{2}$ at $400{ }^{\circ} \mathrm{C}, 1 \mathrm{~atm}$ and $200 \mathrm{cc} / \mathrm{min}$ for $12 \mathrm{~h}$. Each catalyst was screened at two operating temperatures, 220 and $230{ }^{\circ} \mathrm{C}$. As before, the operating conditions during the run were, $\mathrm{P}=20$ bars; SV $=9000$ $\mathrm{sccm} / \mathrm{h} / \mathrm{g}_{\text {cat }} ;$ and $\mathrm{H}_{2} / \mathrm{CO}=2.0$. The product gases were analyzed by the online $\mathrm{GC}$ and the liquid collected was analyzed by the offline GC. In the following sections, the performances of the catalysts are compared based on the CO conversions, the TOFs, the product selectivities and the product yields as outlined in Section 5.5.

\subsubsection{CO Conversions of Catalysts under FTS Condition}

The CO conversions are plotted versus time on stream (TOS) in Figure 6.1 for bed temperatures of 220 and $230{ }^{\circ} \mathrm{C}$. In addition, the conversions for the base catalyst are also shown (also see Figure 5.3). As mentioned earlier, for the base catalyst at $230{ }^{\circ} \mathrm{C}$, the $\mathrm{CO}$ conversion slowly increases and reaches $33 \%$. Thereafter, the CO conversion shows a gradual drop in the activity and steadies at ca. $21 \%$. The CA-modified cobalt catalysts also show similar time dependences of the conversion. The NTA-modified catalyst at $230{ }^{\circ} \mathrm{C}$ shows a slightly higher conversion and steadies around $25 \%$ at the end of $72 \mathrm{~h}$ of operation. 


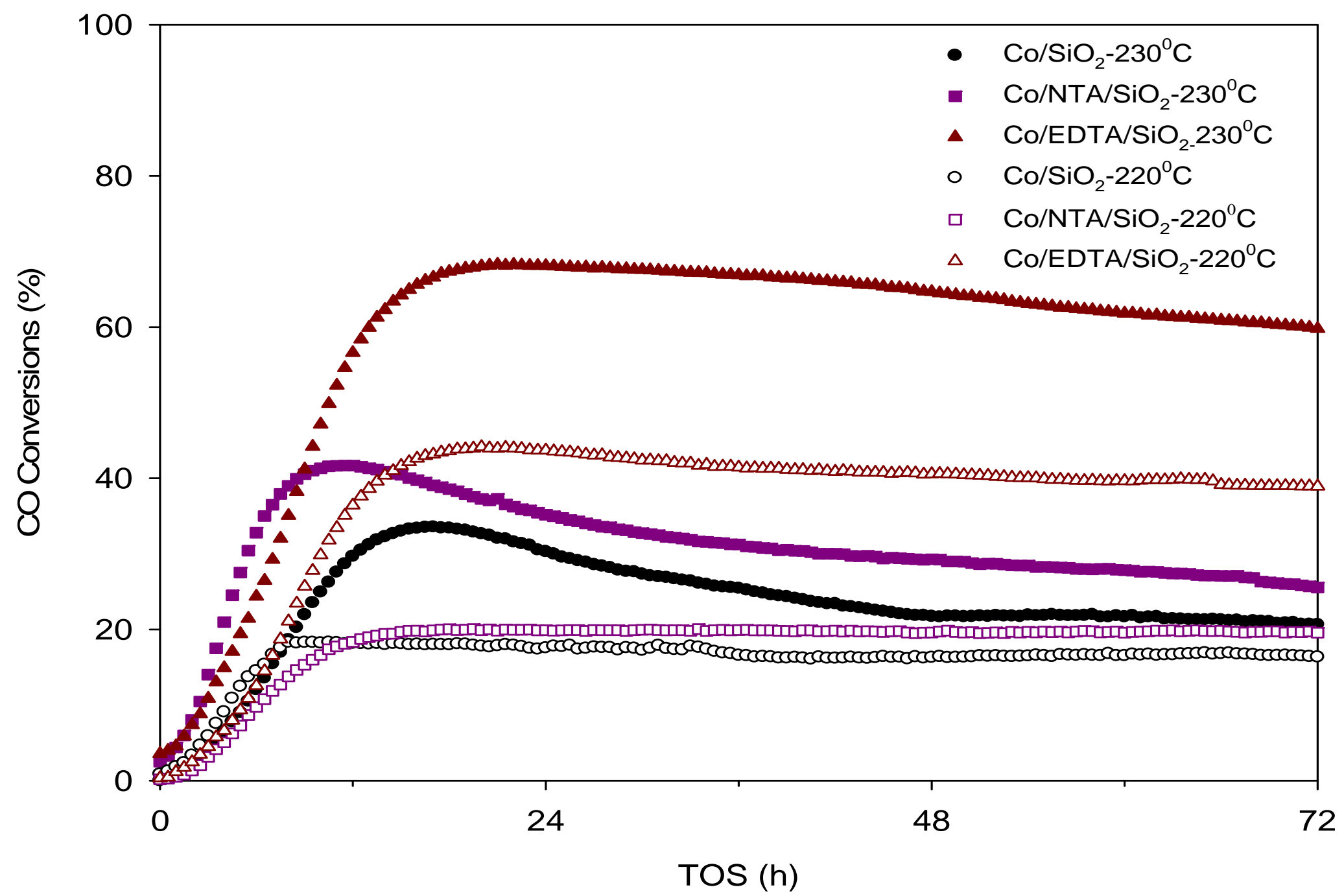

Figure $6.1 \mathrm{CO}$ conversions of the base catalyst and the CA-modified catalysts at $\mathrm{T}_{\text {cat }}=220^{\circ} \mathrm{C}$ and $\mathrm{T}_{\text {cat }}=2300^{\circ} \mathrm{C}$ (Experimental conditions: catalyst load $1 \mathrm{~g}$, diluted with $1: 27 \mathrm{w} / \mathrm{w} \mathrm{SiC} ; \mathrm{P}=20 \mathrm{bar} ; \mathrm{H}_{2} / \mathrm{CO}=2.0 ; \mathrm{GHSV}=9000 \mathrm{sccm} / \mathrm{h} / \mathrm{g}_{\mathrm{cat}}$ ) 
Interestingly, the EDTA-modified catalyst, at the same temperature, shows an improved performance, with nearly a two-fold increase in the CO conversions. Also, at the end of $72 \mathrm{~h}$ TOS, the CO conversions for the EDTA-modified catalyst are notably higher than those of the NTA-modified and the base catalyst.

At the bed temperature of $220^{\circ} \mathrm{C}$, the $\mathrm{CO}$ conversion follows a similar trend: an initial increase in the CO conversion and thereafter a steady conversion. Further, the higher CO conversion for the NTA-modified catalyst compared to the base catalyst is consistent with the measurements at $230^{\circ} \mathrm{C}$. It is also noteworthy that, even at the lower operating temperature, the EDTA-modified catalyst shows the highest CO conversion (ca. $38 \%$ ) in comparison to the NTA-modified and the base catalyst.

The values of TOFs for the three catalysts are listed in Table 6.1. The EDTA-modified catalysts display the highest values of TOFs at both the temperatures. The NTA-modified catalysts display the smallest values of TOFs at both the temperatures. The calculated TOFs are comparable to the reported ${ }^{98}$ values for cobalt catalysts.

Table 6.1 TOFs of the cobalt catalysts

\begin{tabular}{|l|c|c|}
\hline & \multicolumn{2}{|c|}{ TOFs (s-1) } \\
\hline & $\mathrm{T}=230{ }^{\circ} \mathrm{C}$ & $\mathrm{T}=220^{\circ} \mathrm{C}$ \\
\hline $\mathrm{Co} / \mathrm{SiO}_{2}$ & 0.0092 & 0.0067 \\
\hline $\mathrm{Co} / \mathrm{NTA}^{-} \mathrm{SiO}_{2}$ & 0.0052 & 0.0033 \\
\hline $\mathrm{Co} / \mathrm{EDTA}_{\mathrm{SiO}}$ & 0.0107 & 0.0067 \\
\hline
\end{tabular}

\subsubsection{Discussion}

The CO conversions of the CA-modified catalysts are higher than that of the base catalyst. As mentioned earlier, the metal dispersion values are higher for the CA-modified catalysts than the base catalyst. As a result, there exist more catalytic sites for CO adsorptions on the CA-modified catalysts, resulting in the higher CO conversions.

The three catalysts display relatively steady CO conversions during $72 \mathrm{~h} \mathrm{TOS}$, at $220^{\circ} \mathrm{C}$, the lower bed temperature. On the other hand, at $230{ }^{\circ} \mathrm{C}$, the $\mathrm{CO}$ conversion is observed to display a gradual drop in activity. This can be explained as follows. The metallic cobalt phase of FT catalyst is considered as the active site for $\mathrm{CO}$ adsorption during the reaction. These metallic active sites may undergo oxidation during FTS in the presence of considerable water partial 
pressure, formed as a primary product of $\mathrm{FTS}^{17}$. Also, the higher $\mathrm{CO}$ conversions correspond to the higher yields of products as well as water formation. Therefore, the drop in the number of active cobalt sites due to oxidation with advancement of TOS at higher temperature could possibly cause a gradual drop in the activity.

\subsection{Comparison of Hydrocarbon Selectivities}

The gaseous and liquid products formed during the run for three catalysts were quantitatively analyzed. The data are averaged for the second $24 \mathrm{~h}$ interval (i.e. 24-48 h). Based on the carbon balance of each individual run, the product selectivities are determined. Figure 6.2 and Figure 6.3 show the average $\mathrm{CO}$ and $\mathrm{H}_{2}$ conversion, along with the product selectivities to methane, $\mathrm{C}_{2}-\mathrm{C}_{5}, \mathrm{C}_{5+}$ and a diesel fraction $\mathrm{C}_{10}-\mathrm{C}_{20}$ at 230 and $220{ }^{\circ} \mathrm{C}$, respectively. In addition, the $\mathrm{CO}_{2}$ selectivities and olefin-to-paraffin ratios are presented in Table 6.2

At $230^{\circ} \mathrm{C}$, the NTA- and EDTA-modified catalysts show an increase in the CO conversion and the $\mathrm{H}_{2}$ conversion compared to the base catalyst. In terms of product selectivities, all three catalysts display indistinct behavior. $\mathrm{A} \mathrm{CH}_{4}$ selectivity of ca. $20 \%$ is measured for these catalysts. In addition, the overall selectivity of ca. $42 \%$ towards the $\mathrm{C}_{2}-\mathrm{C}_{5}$ fraction and ca. $38 \%$ towards $\mathrm{C}_{5+}$ is nearly same for all the catalysts. However, selectivities towards the diesel fraction (i.e., $\mathrm{C}_{10}-\mathrm{C}_{20}$ ) show some changes. The base catalyst displays a higher selectivity towards the diesel fraction of liquid products than do the CA-modified catalysts, especially the $\mathrm{Co} / \mathrm{EDTA} / \mathrm{SiO}_{2}$ catalyst.

At $220^{\circ} \mathrm{C}$, the $\mathrm{CO}$ conversion drops with lowering the bed temperature. Interestingly, at $220^{\circ} \mathrm{C}$, the $\mathrm{CH}_{4}$ selectivity shows a marginal increase for all the three catalysts, when compared at $230{ }^{\circ} \mathrm{C}$. The hydrocarbon selectivities are noticeably different for cobalt catalysts at 220 and $230{ }^{\circ} \mathrm{C}$. An increase in the selectivities for shorter-chain hydrocarbon is clearly visible with lowering the operating temperature. Also, the $\mathrm{C}_{5+}$ selectivities are lower at lower temperature. In particular, the diesel fraction selectivities drop at the lower bed temperature. These findings are consistent with the trend discussed in Table 2.2. 


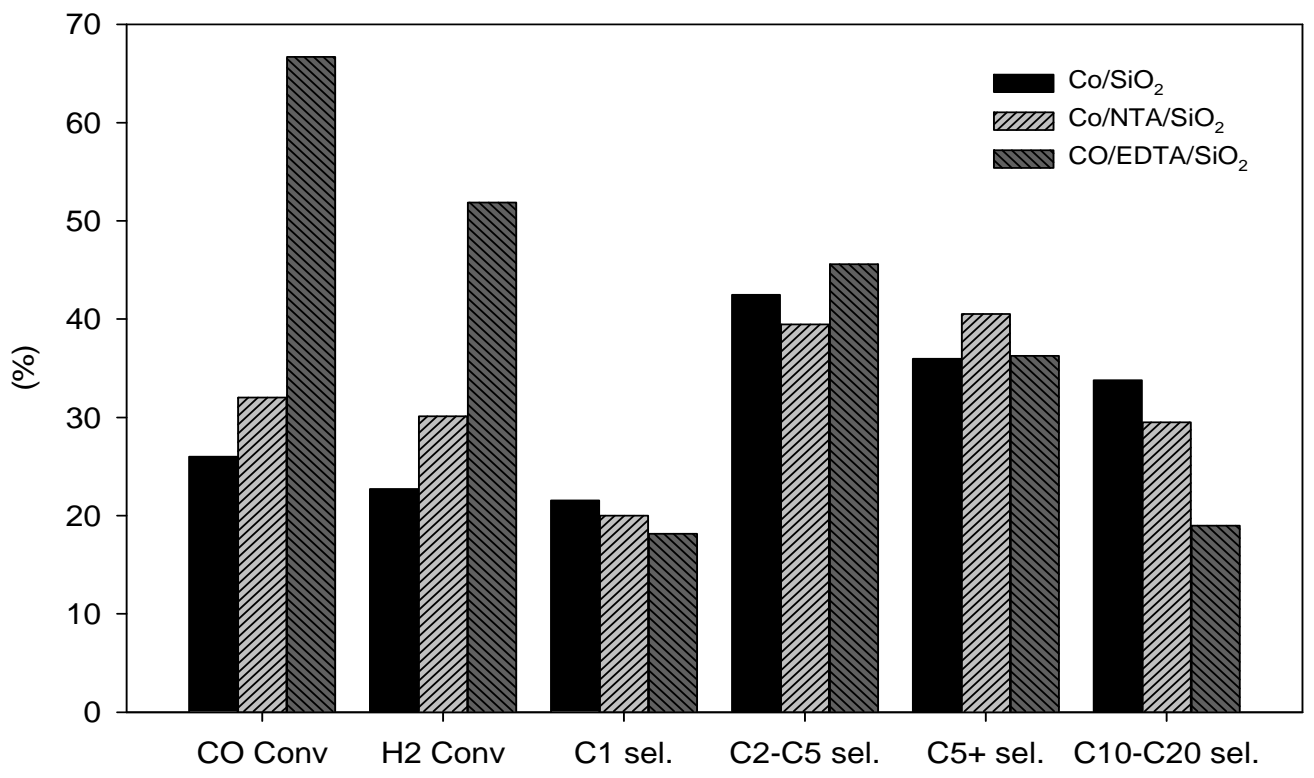

Figure $6.2 \mathrm{CO}$ conversion and hydrocarbons selectivity with CA-modified catalysts at $\mathrm{T}_{\text {cat }}=230^{\circ} \mathrm{C}$ (Experimental conditions: $\mathrm{P}=20$ bar; $\mathrm{H}_{2} / \mathrm{CO}=2 ; \mathrm{GHSV}=9000 \mathrm{sccm} / \mathrm{h} / \mathrm{g}_{\text {cat }}$ )

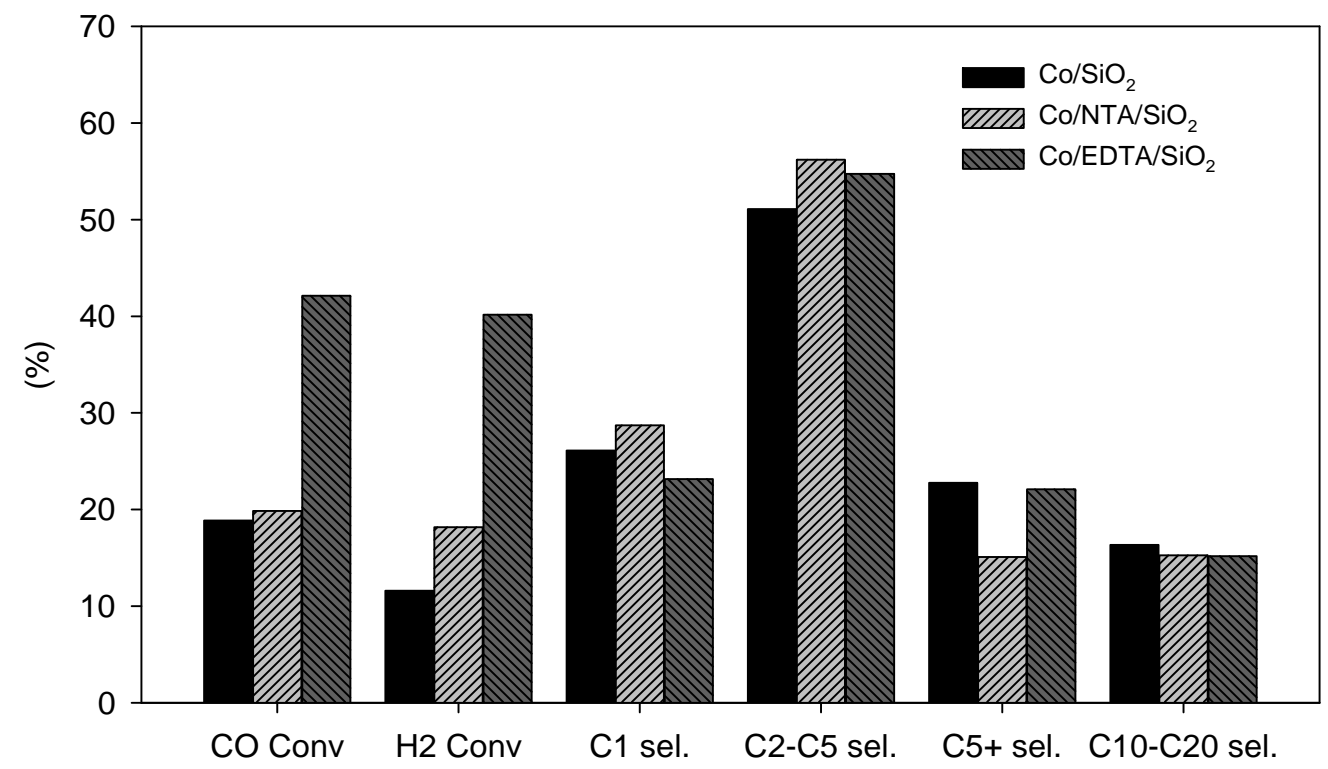

Figure $6.3 \mathrm{CO}$ conversion and hydrocarbons selectivity with CA-modified catalysts at $\mathrm{T}_{\text {cat }}=220^{\circ} \mathrm{C}$

(Experimental conditions: $\mathrm{P}=20$ bar; $\mathrm{H}_{2} / \mathrm{CO}=2 ; \mathrm{GHSV}=9000 \mathrm{sccm} / \mathrm{h} / \mathrm{g}_{\text {cat }}$ ) 
Table $6.2 \mathrm{CO}_{2}$ selectivity and olefin/paraffin ratio of modified catalysts

\begin{tabular}{|l|c|c|c|c|c|c|}
\hline \multicolumn{1}{|c|}{ Catalyst } & \multicolumn{2}{|c|}{$\mathbf{C o} / \mathbf{S i O}_{\mathbf{2}}$} & \multicolumn{2}{c|}{ Co/NTA/SiO } & \multicolumn{2}{c|}{ Co/EDTA/SiO } \\
\hline Temperature, ${ }^{\circ} \mathrm{C}$ & 220 & 230 & 220 & 230 & 220 & 230 \\
\hline $\mathrm{CO}_{2}$ selectivity, mol\% & 12.8 & 9.4 & 10.4 & 9.5 & 9.5 & 11.7 \\
\hline Olefin/paraffin ratio & 0.8 & 0.6 & 0.8 & 0.6 & 0.6 & 0.6 \\
\hline
\end{tabular}

For the base catalyst and the NTA-modified catalyst, the $\mathrm{CO}_{2}$ selectivities increase on lowering the temperature but decrease for the EDTA-modified catalyst.

The olefin-to-paraffin ratios for all the catalysts are 0.6 at $230{ }^{\circ} \mathrm{C}$ and increase to 0.8 at $220^{\circ} \mathrm{C}$, except for the EDTA-modified catalyst. Therefore, it can be said that the CA modification does not significantly change the hydrogenation rate of olefins, as the olefin-to-paraffin ratio is nearly same at both the temperatures. In general, with lowering the bed temperature, the CO conversion drops and the product selectivity shifts to the shorter-chain hydrocarbons, for all the catalysts studied here. Also, at both the temperatures, the CA-modified catalysts display improved CO conversions.

\subsubsection{Discussion}

At both 220 and $230{ }^{\circ} \mathrm{C}$, the $\mathrm{CO}$ conversions increase in the following order; $\mathrm{Co} / \mathrm{SiO}_{2}<$ $\mathrm{Co} / \mathrm{NTA} / \mathrm{SiO}_{2}<\mathrm{Co} / \mathrm{EDTA} / \mathrm{SiO}_{2}$. The improvement in the $\mathrm{CO}$ conversions can be explained as follows. The activity of a cobalt-based catalyst in FTS has been shown to depend strongly on the number of cobalt atoms exposed on the surface ${ }^{98,100}$. The higher density of cobalt surface sites normally assists in improving the catalytic activity of FT catalysts ${ }^{17,20}$. In this study, the characterizations of the catalysts confirm the presence of a well-dispersed cobalt oxide phase. Therefore, the higher $\mathrm{CO}$ conversion can be attributed to the improved dispersion of CAmodified catalyst.

The preparation of the supported cobalt catalyst with the higher metal dispersion is challenging as it requires control over metal-support interactions. Soled et al. $^{25,101}$ have detailed the strategies to control the interaction between metal precursor and a support. The challenge in employing such strategies is having a strong enough interaction to achieve good dispersion but not so strong that it would prevent the reduction of the oxide phases at lower temperature. Similar to the approach adopted here, many groups have attempted surface 
modification of support to improve the properties of a FT catalyst. The effects of CA modification on the performance of the cobalt catalyst in the present investigation are comparable to other surface modifications studies as described in Chapter 2. Accordingly, the organic modification of the support can reduce the surface silanol $(\mathrm{Si}-\mathrm{OH})$ species on silica and therefore suppressed the direct interaction between the metal and a support. Therefore, the resulting catalysts with suppressed metal-support interaction display the improved dispersion.

At the same temperature, the hydrocarbon selectivities for all the three catalysts are comparable. Selectivity control, generally, is one of the most important and difficult challenges of FT synthesis. It is commonly assumed that the formation of heavier hydrocarbons is favored when carbon monoxide and intermediates adsorb strongly on a catalyst surface ${ }^{102}$. Looking at the product distribution in the present work, it can be said that the CA modification may assist in improving the $\mathrm{CO}$ conversion without affecting the product selectivities.

For the NTA-modified catalyst and the base catalyst, at lower temperature, the $\mathrm{C}_{1}$ selectivities and the $\mathrm{CO}_{2}$ selectivities are higher. However, for the EDTA-modified catalyst, the $\mathrm{CO}_{2}$ selectivities increase with the temperature increase. The higher methane selectivities are usually attributed to the presence of small cobalt particles in the narrow pores ${ }^{102}$. Reuel and Bartholomew ${ }^{103}$ have related the higher $\mathrm{CH}_{4}$ selectivities to the presence of stable unreduced cobalt oxide phases that are capable of catalyzing the water-gas-shift reaction. The WGS activity thus can result in higher $\mathrm{H}_{2}$-to- $\mathrm{CO}$ ratio on the surface of catalyst. $\mathrm{H}_{2}$ being a smaller molecule, compared to $\mathrm{CO}$, it can more easily diffuse into small pores of the support. Hence, the diffusion limitation of $\mathrm{CO}$ further contributes to increase in $\mathrm{H}_{2}$-to-CO ratio. The higher $\mathrm{H}_{2}$ partial pressure in the pore can decrease the probability of chain polymerization and can therefore result in higher $\mathrm{CH}_{4}$ selectivity, due to hydrogenation of adsorbed intermediates. In summary, the higher $\mathrm{CH}_{4}$ and $\mathrm{CO}_{2}$ selectivity is due to unreduced cobalt oxide phases and small Co particles on the catalyst surface resulting in high WGS activity.

\subsection{Product Yield of Modified Catalysts}

The paraffins, olefins and alcohols yields for three catalysts are presented in Table 6.3. As mentioned earlier, the product yields of the base catalyst are comparable to other cobalt 
catalysts. At $230{ }^{\circ} \mathrm{C}$, the product yields of the CA-modified catalysts are higher than the base catalyst. In fact, the EDTA-modified shows the highest value of the total product yield. For all the three catalysts, the product yields at $220^{\circ} \mathrm{C}$ are lower compare to those at $230^{\circ} \mathrm{C}$. The total product yields for the CA-modified catalysts are still higher than the base catalyst at the lower temperature, and the EDTA-modified once again shows the highest value. Therefore, it is evident that both the CA-modified catalysts display higher yields of paraffins, olefins and alcohols. The higher product yields of the CA-modified catalysts are consistent with the higher conversions observed over these catalysts. Therefore, it can be said that the modification of silica by a chelating agent not only improves the $\mathrm{CO}$ conversions but also results in the higher yields of the products.

Table 6.3 Product yields of modified catalysts

\begin{tabular}{|l|c|c|c|c|c|c|}
\hline \multicolumn{1}{|c|}{ Catalyst } & \multicolumn{2}{c|}{$\mathbf{C o} / \mathbf{S i O}_{2}$} & \multicolumn{2}{c|}{ Co/NTA/SiO } & \multicolumn{2}{c|}{ Co/EDTA/SiO } \\
\hline Temperature, ${ }^{\circ} \mathrm{C}$ & 220 & 230 & 220 & 230 & 220 & 230 \\
\hline CO conversion, $\%$ & 18.9 & 26.0 & 19.8 & 32.0 & 42.1 & 66.7 \\
\hline \multicolumn{7}{|c|}{ Product yield, $\mathrm{gC} / \mathrm{kg}_{\text {cat }} / \mathrm{h}$} \\
\hline Paraffin & 95.1 & 141.2 & 132.7 & 239.9 & 287.5 & 523.5 \\
\hline Olefin & 15.1 & 12.2 & 21.5 & 24.0 & 45.0 & 85.3 \\
\hline Alcohol & 4.4 & 16.3 & 10.5 & 36.7 & 25.3 & 37.1 \\
\hline Total & 114.6 & 169.7 & 164.7 & 300.6 & 357.8 & 645.9 \\
\hline
\end{tabular}

\subsubsection{Estimation of $\alpha$}

The ASF distributions of the hydrocarbons over the three catalysts are plotted in Figure 6.4 and Figure 6.5, for $230{ }^{\circ} \mathrm{C}$ and $220{ }^{\circ} \mathrm{C}$, respectively. The values of the propagation probability, $\alpha$, determined from the slopes are presented in Table 6.4. The values of $\alpha$ are comparable to the reported values for other cobalt catalysts 15,104 . At $230{ }^{\circ} \mathrm{C}$, the values of $\alpha$ for the CA-modified catalysts are smaller than that of the base catalyst. On the other hand, at 220 ${ }^{\circ} \mathrm{C}$, all three catalysts show same values for $\alpha$. The variation in values of $\alpha$ due to CA modifications of the cobalt catalysts is not significant. It suggests that the hydrocarbon distribution is not significantly affected due the CA modification. This can be further supported by the fact that all three catalysts show comparable hydrocarbon selectivities (see Figure 6.2 and Figure 6.3). 


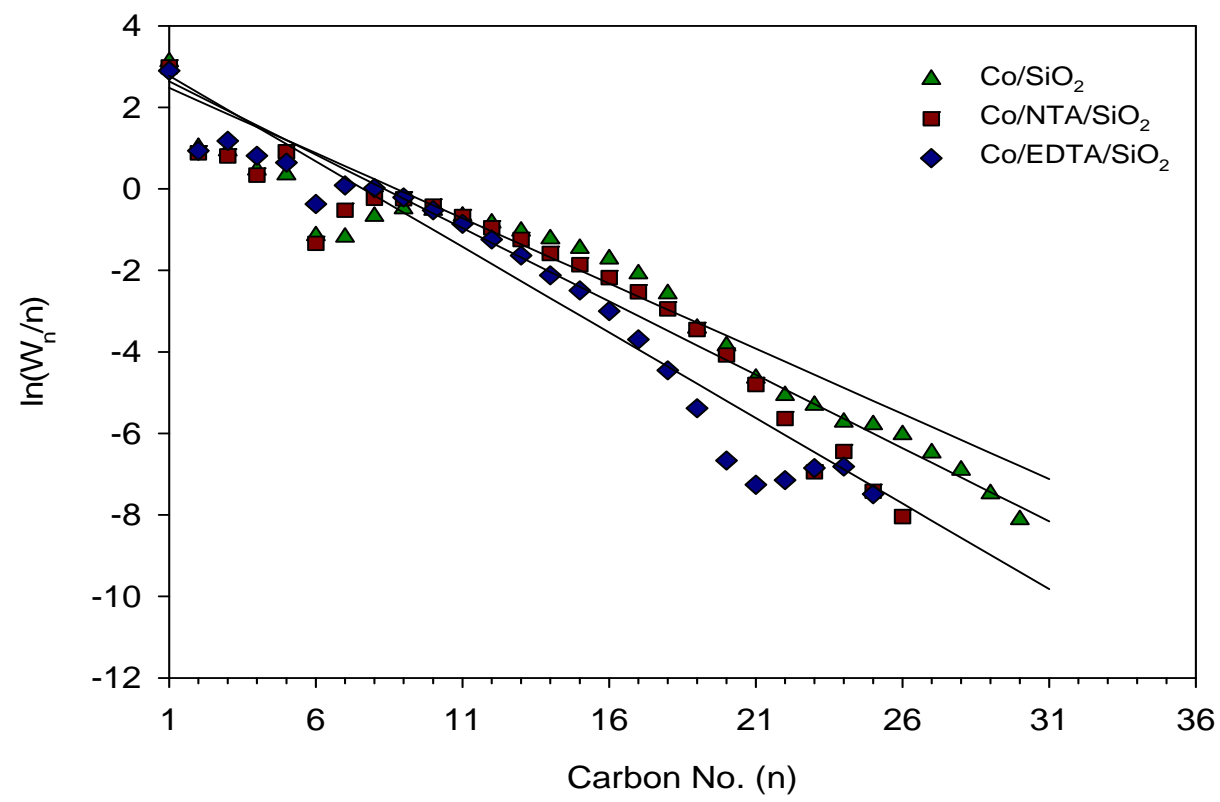

Figure 6.4 ASF distribution over cobalt catalysts at $\mathrm{T}=230^{\circ} \mathrm{C}$

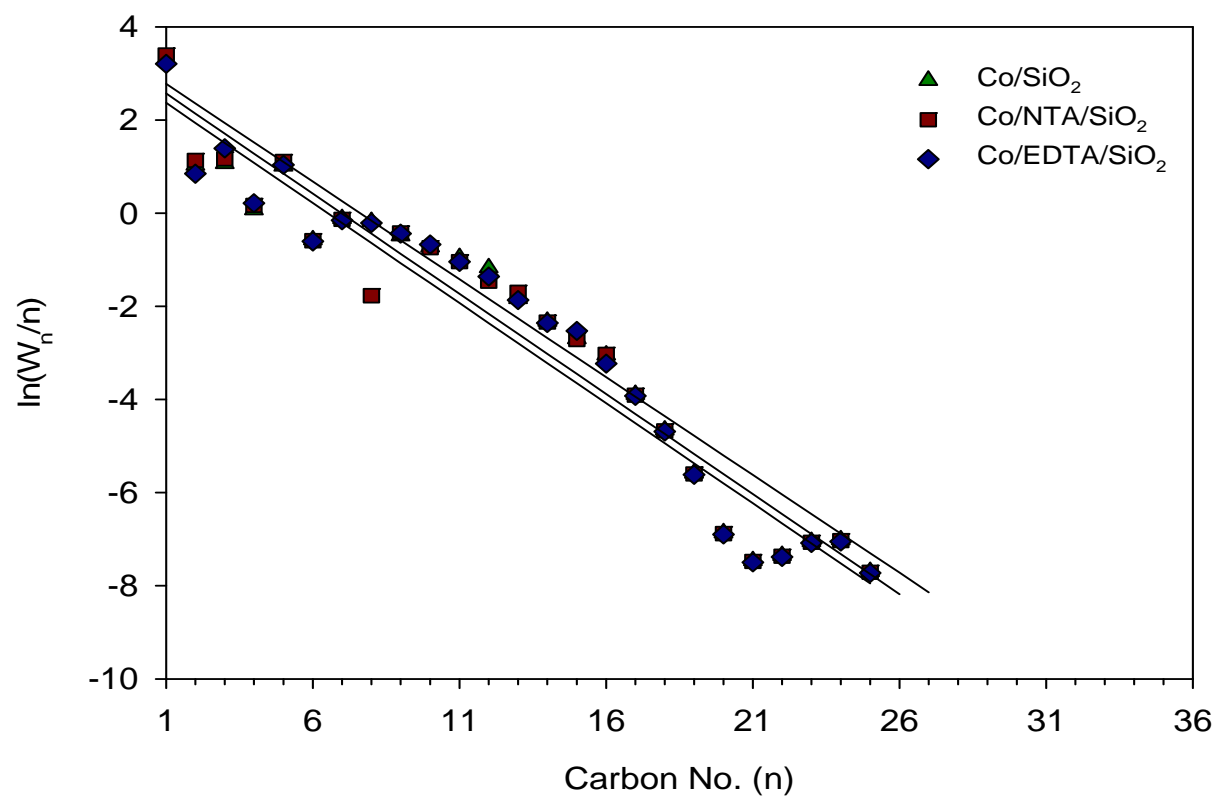

Figure 6.5 ASF distribution over cobalt catalysts at $\mathrm{T}=220^{\circ} \mathrm{C}$

Table $6.4 \alpha$ values of cobalt catalysts

\begin{tabular}{|c|c|c|c|c|c|c|}
\hline Catalyst & \multicolumn{2}{|c|}{$\mathrm{Co} / \mathrm{SiO}_{2}$} & \multicolumn{2}{|c|}{$\mathrm{Co} / \mathrm{NTA} / \mathrm{SiO}_{2}$} & \multicolumn{2}{|c|}{$\mathrm{Co} / \mathrm{EDTA} / \mathrm{SiO}_{2}$} \\
\hline Temperature, ${ }^{\circ} \mathrm{C}$ & 220 & 230 & 220 & 230 & 220 & 230 \\
\hline slope & -0.43 & -0.32 & -0.43 & -0.36 & -0.43 & -0.42 \\
\hline$\alpha$ & 0.65 & 0.73 & 0.65 & 0.70 & 0.65 & 0.66 \\
\hline
\end{tabular}




\subsubsection{Paraffin Selectivity}

The paraffin selectivities as a function of carbon numbers over three catalysts at 230 and $220^{\circ} \mathrm{C}$ are presented in Figure 6.6 and Figure 6.7, respectively. At both the temperatures, the maximum selectivity is at $C_{1}$ for all three catalysts. The selectivity drops thereafter with increasing carbon numbers before showing an increase at around $\mathrm{C}_{6}$. The selectivity progressively increases and reaches a secondary maximum before showing a further decrease for the higher carbon numbers. The secondary maximum for the base catalyst is around $\mathrm{C}_{10}$. For the CA-modified catalysts, the secondary maximum shifts towards $C_{9}$ for the NTA-modified catalyst and towards $\mathrm{C}_{7}$ for the EDTA-modified catalyst. In contrast, at $220{ }^{\circ} \mathrm{C}$, no noticeable shifts in paraffin selectivities are noted and all the three catalysts display similar trends with a secondary maximum around $\mathrm{C}_{7}$. Also, at $220^{\circ} \mathrm{C}$, the EDTA-modified catalyst shows a slightly higher paraffin selectivity between $C_{2}$ to $C_{6}$ compared to the NTA-modified and the base catalyst.

As mentioned earlier, the paraffins yields of the CA-modified catalysts are superior compared to the base catalyst (see Table 6.3). It is also evident that shifts in the selectivities are marginal for the CA-modified catalysts. As a result, the CA modification is said to be beneficial for achieving higher yields of the desired liquid products with the improved conversions.

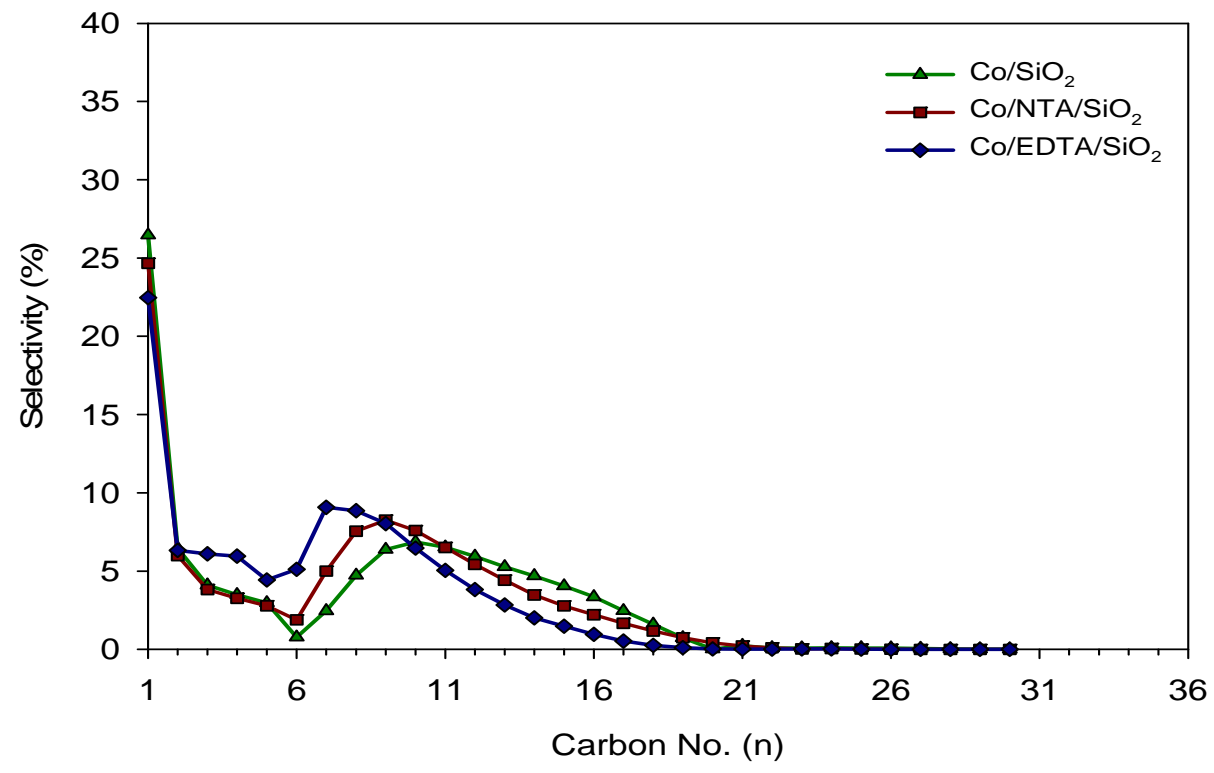

Figure 6.6 Paraffins selectivity as a function of carbon number over CA-modified catalysts (Experimental conditions: $\mathrm{T}_{\text {cat }}=230^{\circ} \mathrm{C} ; \mathrm{P}=20 \mathrm{bar} ; \mathrm{H}_{2} / \mathrm{CO}=2 ; \mathrm{GHSV}=9000 \mathrm{sccm} / \mathrm{h} / \mathrm{g}_{\text {cat }}$ ) 


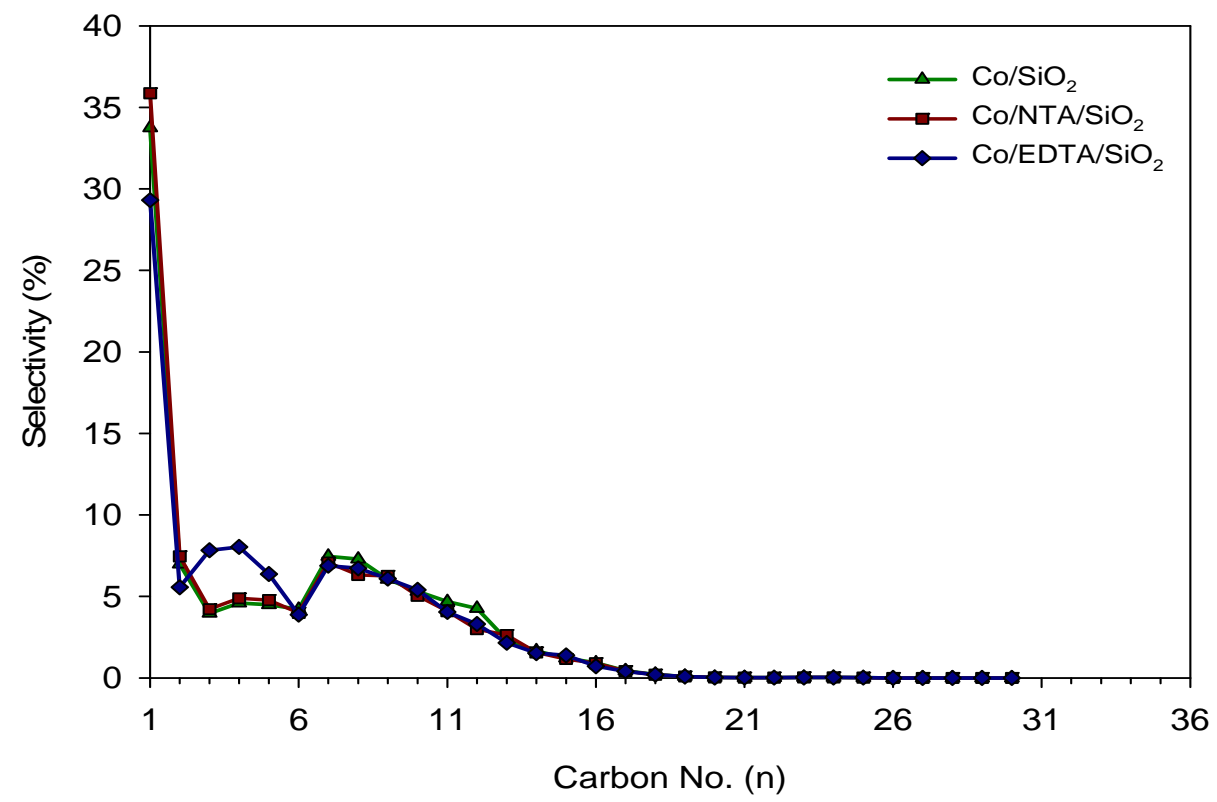

Figure 6.7 Paraffins selectivity as a function of carbon number over CA-modified catalysts (Experimental conditions: $\mathrm{T}_{\text {cat }}=220^{\circ} \mathrm{C} ; \mathrm{P}=20 \mathrm{bar} ; \mathrm{H}_{2} / \mathrm{CO}=2 ; \mathrm{GHSV}=9000 \mathrm{sccm} / \mathrm{h} / \mathrm{g}_{\text {cat }}$ )

\subsubsection{Olefin Selectivity}

Figure 6.8 and Figure 6.9 illustrate the olefin selectivities as a function of carbon numbers for the three catalysts at 230 and $220^{\circ} \mathrm{C}$, respectively. At $230{ }^{\circ} \mathrm{C}$, the base catalyst and the NTA-modified catalyst show increases in the olefin selectivity from $C_{2}$ to $C_{3}$ and thereafter show a drop in the selectivities with increasing carbon number till $C_{6}$. The EDTA-modified catalyst, however, shows a progressive drop from $C_{1}$ to $C_{6}$. After reaching the minimum at $C_{6}$, the olefin selectivities show increasing trend with the carbon number before reaching a secondary maximum. Thereafter, the selectivity drops for higher carbon number. Similar to the paraffin selectivities, for the CA-modified catalysts, the secondary maximum shifts to a lower carbon number. Also, both the CA-modified catalysts show better selectivities for the $C_{6}$ to $C_{14}$ olefins.

At $220^{\circ} \mathrm{C}$, the EDTA-modified catalyst shows increases from $C_{2}$ to $C_{3}$ and a progressive drop thereafter till $C_{6}$. The NTA-modified catalyst and the base catalyst, however, show a progressive drop from $C_{2}$ till $C_{6}$ and $C_{7}$, respectively. The selectivity trends for the higher carbon numbers are comparable for all the three catalysts, with a maximum around $\mathrm{C}_{8}$. 


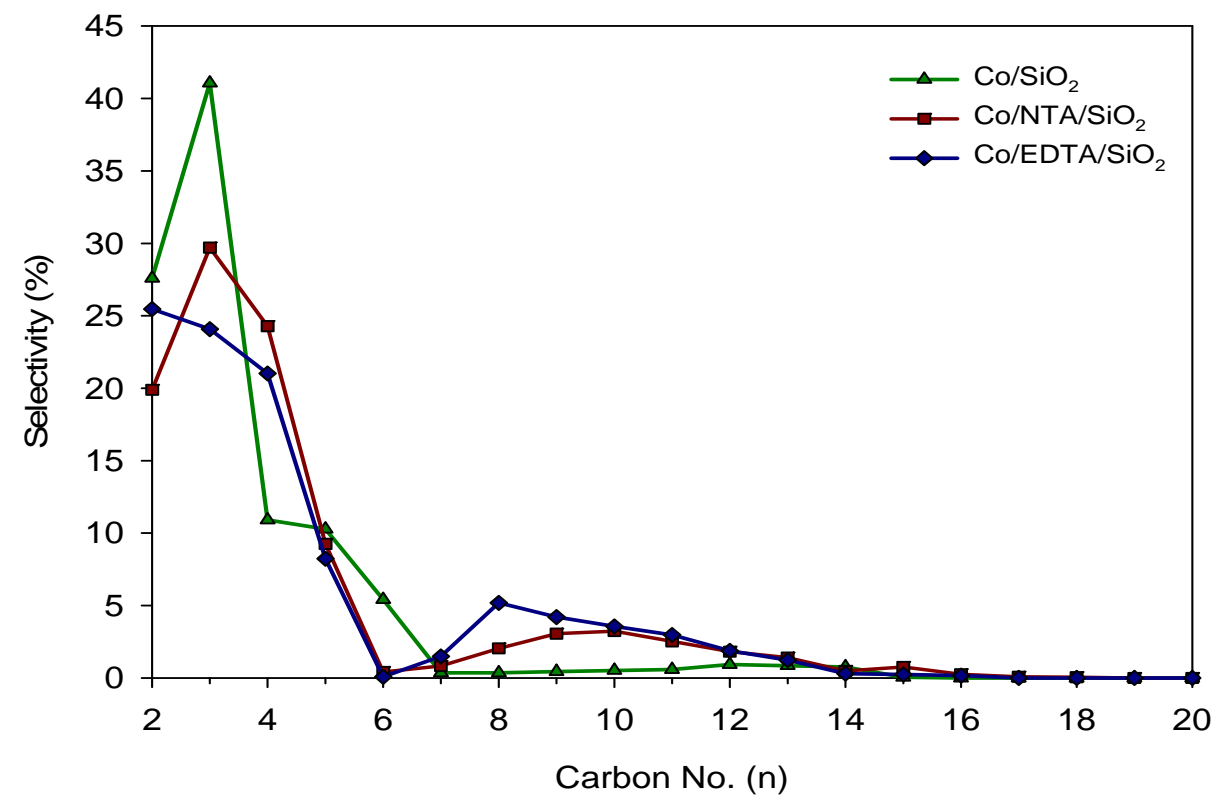

Figure 6.8 Olefin selectivity as a function of carbon number over CA-modified catalysts (Experimental conditions: $\mathrm{T}_{\text {cat }}=230^{\circ} \mathrm{C} ; \mathrm{P}=20 \mathrm{bar} ; \mathrm{H}_{2} / \mathrm{CO}=2 ; \mathrm{GHSV}=9000 \mathrm{sccm} / \mathrm{h} / \mathrm{g}_{\text {cat }}$ )

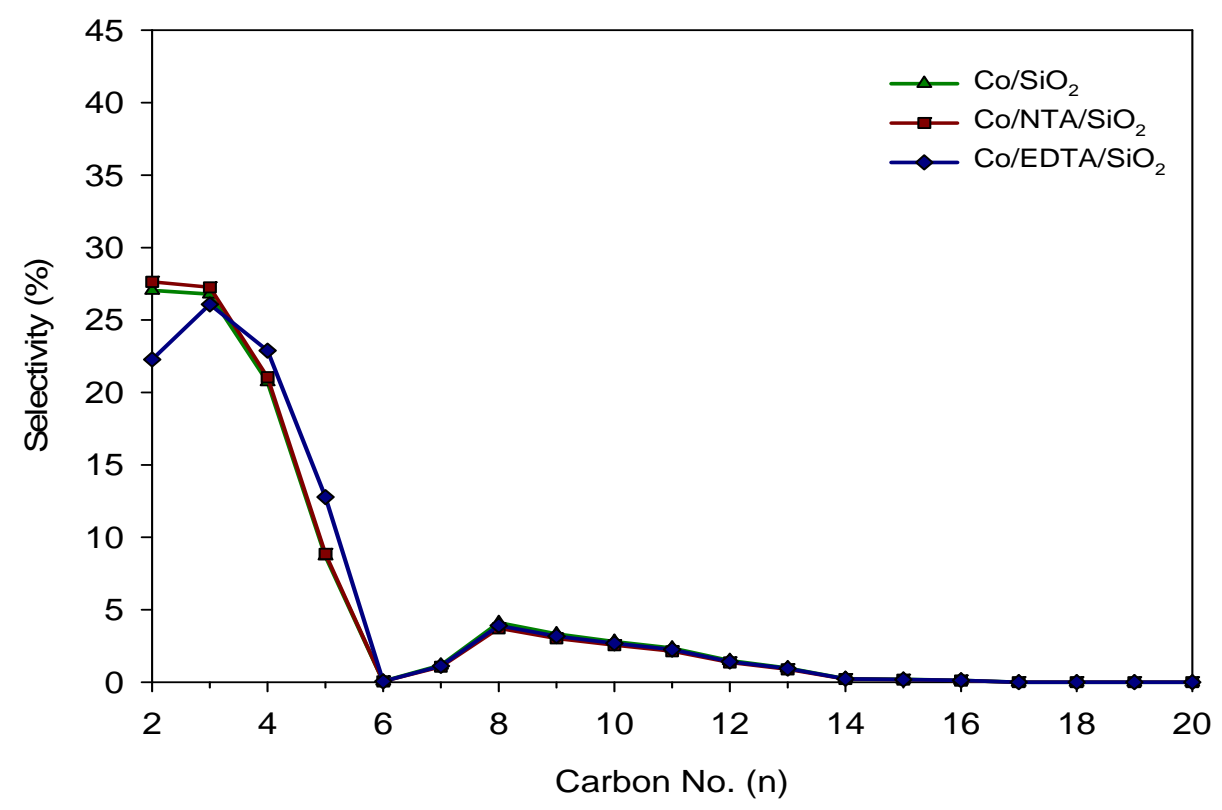

Figure 6.9 Olefin selectivity as a function of carbon number over CA-modified catalysts (Experimental conditions: $\mathrm{T}_{\text {cat }}=220^{\circ} \mathrm{C} ; \mathrm{P}=20 \mathrm{bar} ; \mathrm{H}_{2} / \mathrm{CO}=2 ; \mathrm{GHSV}=9000 \mathrm{sccm} / \mathrm{h} / \mathrm{g}_{\text {cat }}$ ) 
Therefore, the CA modification is said to have caused higher olefin yields (see Table 6.3), with a slight shift in the selectivity at $230{ }^{\circ} \mathrm{C}$ and no shift at $220^{\circ} \mathrm{C}$.

For the CA-modified catalysts at $230{ }^{\circ} \mathrm{C}$, the secondary maximum in the paraffin and olefin selectivities shifts slightly to the lower carbon numbers, compared to the base catalyst. These trends are consistent with the lower values of $\alpha$ for both the CA-modified catalysts at 230 ${ }^{\circ} \mathrm{C}$.

\subsubsection{Alcohol Selectivity}

The alcohol selectivities as a function of carbon numbers are compared in Figure 6.10 and Figure 6.11 for the three catalysts at 230 and $220{ }^{\circ} \mathrm{C}$, respectively. The selectivities of alcohols with carbon number is qualitatively the same at both the temperatures over all the three catalysts, showing an increasing trend from $C_{1}$ to $C_{2}$ and then decreasing selectivities for the higher alcohols from $\mathrm{C}_{2}$ onwards. Therefore, ethanol is the dominant alcohol in the aqueous phase of the products. The alcohol yields of the CA-modified catalysts are higher than those of the base catalyst. It can be said that the CA modification results in higher alcohol yields (see Table 6.3) without significantly changing the alcohol selectivities.

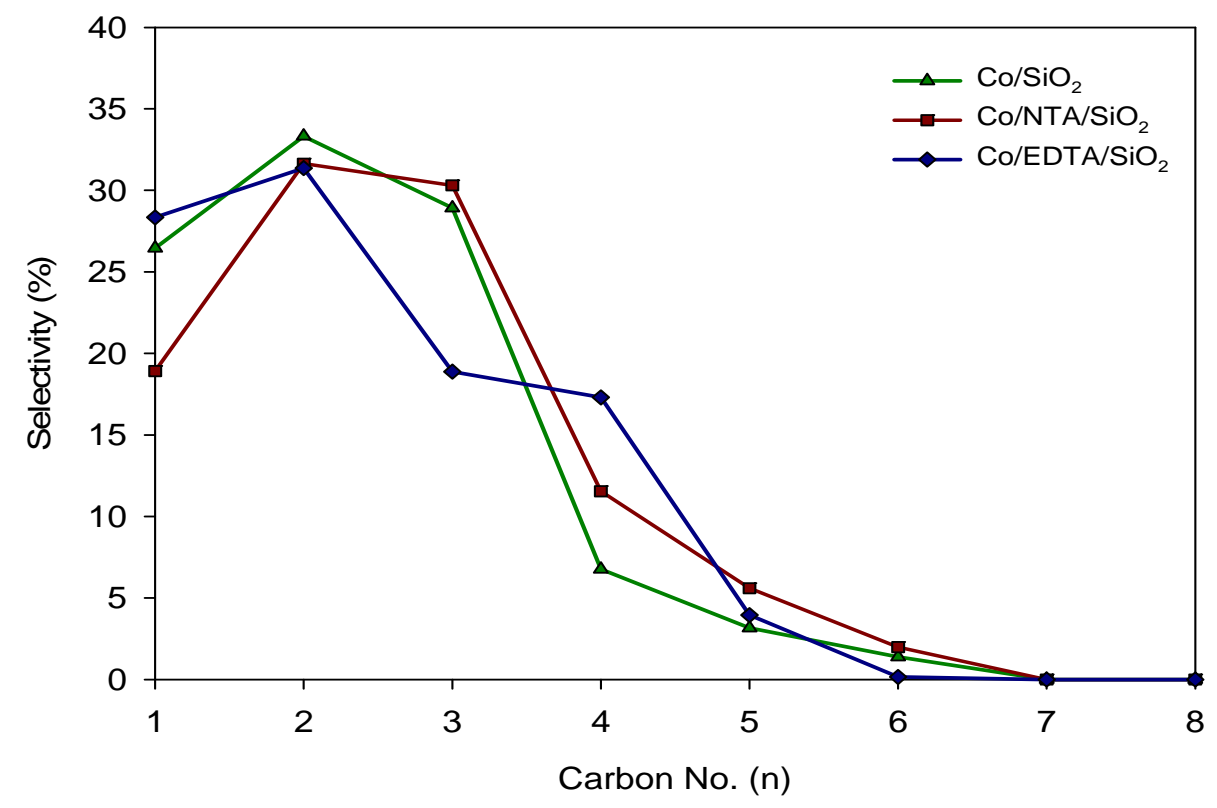

Figure 6.10 Alcohol selectivity as a function of carbon number over CA-modified catalysts (Experimental conditions: $\mathrm{T}_{\text {cat }}=230^{\circ} \mathrm{C} ; \mathrm{P}=20 \mathrm{bar} ; \mathrm{H}_{2} / \mathrm{CO}=2 ; \mathrm{GHSV}=9000 \mathrm{sccm} / \mathrm{h} / \mathrm{g}_{\text {cat }}$ ) 


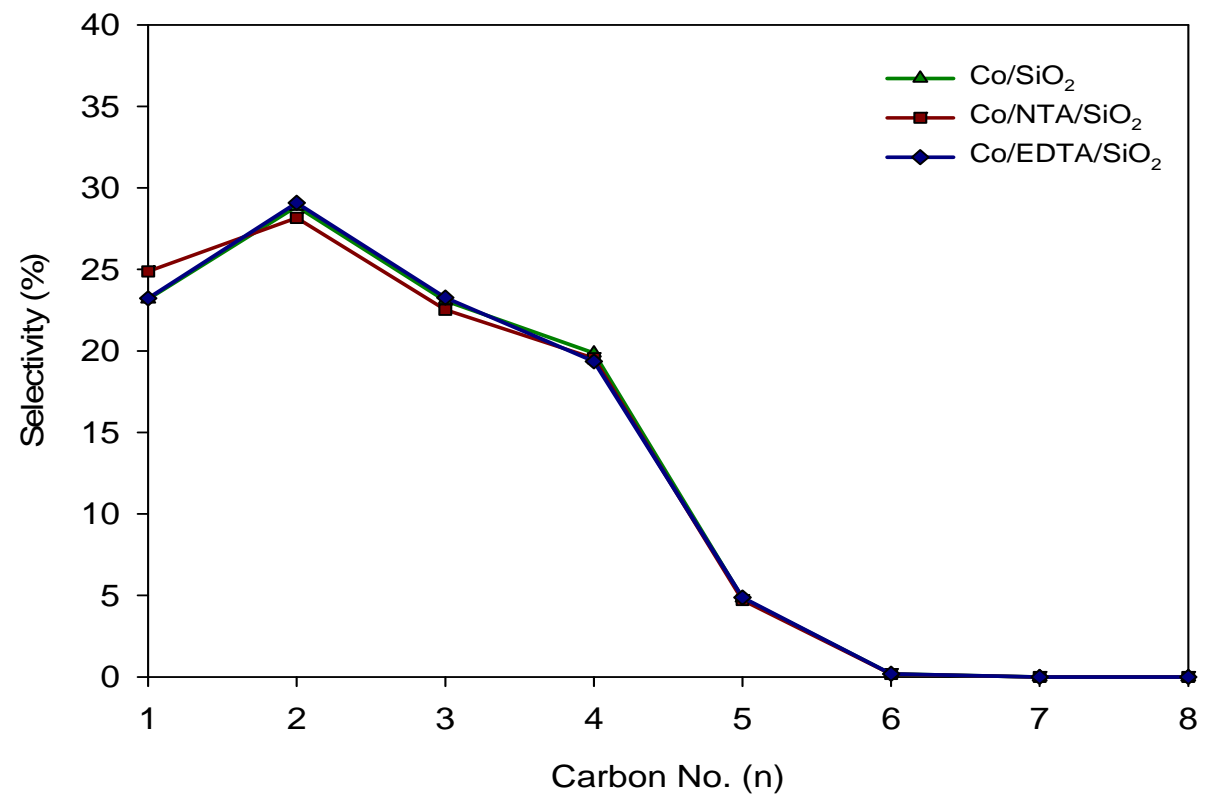

Figure 6.11 Alcohol selectivity as a function of carbon number over CA-modified catalysts (Experimental conditions: $\mathrm{T}_{\text {cat }}=220^{\circ} \mathrm{C} ; \mathrm{P}=20$ bar; $\mathrm{H}_{2} / \mathrm{CO}=2 ; \mathrm{GHSV}=9000 \mathrm{sccm} / \mathrm{h} / \mathrm{g}_{\text {cat }}$ )

\subsubsection{Discussion}

Surface modification by CA forms a larger number of $\mathrm{CO}$ adsorption sites, as evident by the improved CO conversions. The CA modification of silica forms stable chelate-Co complexes and a more-highly dispersed active metallic phase on the surface of the cobalt catalyst. This has been confirmed by the results from the XPS study in Section 4.3.4, indicating higher $I_{\mathrm{Co}} / I_{\mathrm{Si}}$ ratios for fresh CA-modified catalysts. Also, the dispersion measured by hydrogen chemisorption is higher for both the CA-modified catalysts than for the base catalyst. The TOFs for the base catalyst and the EDTA-modified catalysts are comparable. On the other hand, the NTA-modified catalyst shows lowest value of TOFs. As the site density increases, especially in the case of CAmodified catalysts, the probability of $\alpha$-olefin readsoprtion increases, leading to higher yields of longer-chain hydrocarbons. In addition, Iglesia et al. $^{20}$ have reported that a structural characteristic of the support and a high site density within catalyst pellets increases the residence time and the readsoprtion probability of $\alpha$-olefin intermediates. Subsequently, the higher readsoprtion of the intermediates results in the formation of the longer-chain hydrocarbons and hence the higher $C_{5+}$ yields. 
As reported in the literature ${ }^{68}$, alcohols are produced under FTS condition by two possible routes: hydroformylation of olefins, and CO insertion of adsorbed intermediates. Also, the alcohol contribution to the overall products formed in FTS is less than $5 \%$ in all cases. Therefore, it is unwise to comment about the effect of the higher site density of CA-modified catalysts on alcohol yield.

The addition of NTA and EDTA to cobalt catalyst has been reported ${ }^{17,105}$ to impart additional acidic sites on the catalyst surface which could result in a lower-chain growth probability and higher selectivity to lighter hydrocarbons. However, in the present case, the observed selectivities for CA-modified catalyst are nearly similar to the base catalyst. It must be remembered that the molar ratio (i.e. CA to Co) used for catalysts synthesis in this study was unity and may not be sufficient to impart any additional acidic sites.

The post-reaction characterizations of these catalysts were performed to understand the effect of FT conditions on the structure of the catalysts. The results of the characterization study are presented in Chapter 9.

\subsection{Summary}

The CA-modified catalysts show improved CO conversions and the product yields compared to the base catalyst. In fact, the EDTA-modified catalyst shows the highest conversions and the product yield. The product selectivities of all the catalysts are comparable at various temperatures. The TOFs for the base catalyst and the EDTA-modified catalysts are comparable. On the other hand, the NTA-modified catalyst shows lowest value of TOFs. The enhanced activity of CA-modified catalysts can be attributed to the higher metal dispersions and hence the higher number of catalytic sites. The results from physical characterization are in good agreement with the FT activity and selectivity evaluation. Therefore, CA-modification of the support is confirmed to improve the performance of the FT catalysts. 


\section{CHAPTER 7}

\section{DETERMINATION OF KINETIC PARAMETERS AND MASS- TRANSFER LIMITATIONS FOR FT SYNTHESIS}

\subsection{Introduction}

In Chapter 7, the effects of catalyst bed temperature and syngas space velocity on FT performance are presented. It must also be noted that, the effect of temperature on $\mathrm{CO}$ conversion has been reported ${ }^{2}$ to be more severe than the effect of operating pressure, and hence investigation with pressure variation is eliminated in this study. The results from the temperature variation experiment are used to estimate kinetic parameters, such as the rate

constant, $k$, the activation energy, $E_{a}$, and the reaction rates, $r_{C O}$, for the base-case cobalt catalyst. In addition, $k$ and $E_{a}$ are determined for CA-modified catalysts. The absence of mass-transfer limitations is also evaluated by space velocity variation.

As mentioned earlier, at this point, the purchase of premixed syngas cylinders was no longer an option. Hence, we operated the remaining FT runs with separate cylinders having $\mathrm{H}_{2}$ and $\mathrm{CO}$ with their respective internal standards, 5 mol\% $\mathrm{He}$ and $5 \mathrm{~mol} \% \mathrm{Ar}$, respectively. Further, using two MFCs (instead of one MFC for the premixed cylinder) required the total syngas flow rate to be increased to $225 \mathrm{sccm}$ from $150 \mathrm{sccm}$. Therefore, the gas hourly space velocity (GHSV) for the rest of the work is $13,500 \mathrm{sccm} / \mathrm{h} / \mathrm{g}_{\text {cat }}$.

\subsection{Effect of Reaction Temperature}

In order to estimate the kinetic parameters, the catalyst bed temperature was varied within the proximity of the commonly used bed temperature of $230{ }^{\circ} \mathrm{C}$ for $\mathrm{Co} / \mathrm{SiO}_{2}$ catalysts. Therefore, bed temperatures of 215,230 and $245^{\circ} \mathrm{C}$ were selected.

Initially, the CO conversions were recorded at $215{ }^{\circ} \mathrm{C}$ for $24 \mathrm{~h}$. In the next step, the temperature of the bed was increased to $230{ }^{\circ} \mathrm{C}$. Once again, the instantaneous $\mathrm{CO}$ conversion was measured for $24 \mathrm{~h}$ and the average value was obtained. Finally, the bed temperature was further increased to $245{ }^{\circ} \mathrm{C}$ and $\mathrm{CO}$ conversion was recorded as before. This procedure varies 
somewhat from that used in previous chapters for which each run contained a $24 \mathrm{~h}$ settling period at the temp of interest. However, the settling is less important for conversion.

For each step, an average value of conversions and TOFs are shown in Table 7.1.

Table 7.1 Effect of temperature on average CO conversion and TOF

\begin{tabular}{|c|c|c|c|c|c|}
\hline $\begin{array}{c}\text { TOS } \\
(\mathrm{h})\end{array}$ & $\begin{array}{c}\mathrm{T} \\
\left({ }^{\circ} \mathrm{C}\right)\end{array}$ & $\begin{array}{c}\mathrm{T} \\
(\mathrm{K})\end{array}$ & $\begin{array}{c}1000 / \mathrm{T} \\
\left(\mathrm{K}^{-1}\right)\end{array}$ & $\begin{array}{c}\mathrm{X}_{\mathrm{CO}} \\
\%\end{array}$ & $\begin{array}{c}\mathrm{TOF} \\
\left(\mathrm{s}^{-1}\right)\end{array}$ \\
\hline $0-24$ & 215 & 488 & 2.05 & 12.0 & 0.0068 \\
\hline $24-48$ & 230 & 503 & 1.99 & 26.8 & 0.0151 \\
\hline $48-72$ & 245 & 518 & 1.93 & 41.8 & 0.0236 \\
\hline
\end{tabular}

\subsubsection{Determination of Rate Constants}

The data from Table 7.1 were analyzed to determine the rate constant, $k$.

The rate expressions proposed for FT cobalt catalysts in the literature range from simple power-law expressions to fairly complex Langmuir-Hinshelwood expressions of various forms ${ }^{6}$. Zennaro et al. ${ }^{98}$ have proposed a kinetic model for FT cobalt (11.7 w\%) catalyst from their work with a differential fixed-bed reactor over a wide range of operating conditions at 20 bar, 180$240{ }^{\circ} \mathrm{C}$ and $\mathrm{H}_{2} / \mathrm{CO}$ feed ratios of 1.0-4.0. In their study, the space velocity was varied between 3000-5000 $\mathrm{h}^{-1}$. In addition, the partial pressures of $\mathrm{H}_{2}$ and $\mathrm{CO}$ were also varied from 4-14 and 26 bar respectively. The TOF values were between 0.0071 and $0.095 \mathrm{~s}^{-1}$. These are close to the conditions used in the present work. The power-law rate expression of Zennaro et al. can be represented as:

$$
r_{\mathrm{CO}}=k \cdot p_{\mathrm{H}_{2}}^{0.74} \cdot p_{\mathrm{CO}}^{-0.24}
$$

where, $r_{C O}$ is the rate of $\mathrm{CO}$ consumption $\left[\mathrm{mol} / \mathrm{h} / \mathrm{g}_{\mathrm{cat}}\right], p_{\mathrm{H}_{2}}$ and $p_{C O}$ are the partial pressures of reactants [Pa], and $k$ is the rate constant and has the unit $\left[\mathrm{mol} \mathrm{CO} / \mathrm{h} / \mathrm{Pa}^{0.5} / \mathrm{g}_{\text {cat }}\right]$.

The concentration of $\mathrm{CO}, C_{C O}$, can be expressed in terms of conversions, $X_{C O}$, as,

$$
C_{C O}=\frac{C_{C O, i n}\left(1-X_{C O}\right)}{\left(1+\varepsilon X_{C O}\right)}
$$

where, the expansion factor, $\varepsilon$, accounts for the change in total molar volume. Also, $\varepsilon$ is negative in the present case due to reduction in total molar volume during the reaction. 
The inlet molar ratio of $\mathrm{H}_{2}$ to CO, i.e., $\mathrm{M}$, is 2.0 in the present study. Therefore, based on the reaction stoichiometry,

$$
\text { [ } \left.\text { mol of } \mathrm{H}_{2} \text { reacted }\right]=2 \times[\text { mol of CO reacted }]
$$

Similar to Eq. (7.2), the concentration of $\mathrm{H}_{2}, C_{\mathrm{H}_{2}}$, can be expressed in terms of $X_{\mathrm{CO}}$ as,

$$
C_{H_{2}}=\frac{C_{C O, \text { in }}\left(M-2 X_{C O}\right)}{\left(1+\varepsilon X_{C O}\right)}
$$

Using Eq. (7.2) and Eq. (7.4), simplified Eq.(7.1) can be written as,

$$
r_{C O}=2^{0.74} k C_{C O, i n} 0.5 \sqrt{\frac{\left(1-X_{C O}\right)}{\left(1+\varepsilon X_{C O}\right)}}
$$

Therefore, a design equation for a fixed-bed reactor becomes,

$$
v_{0} C_{C O} \frac{d X_{C O}}{d W_{c a t}}=2^{0.74} k C_{C O, i n} 0.5 \sqrt{\frac{\left(1-X_{C O}\right)}{\left(1+\varepsilon X_{C O}\right)}}
$$

where, $W_{c a t}$ is the weight of the catalyst $\left[g_{\text {cat }}\right]$ and $v_{0}$ is the volumetric flow rate $\left(\mathrm{m}^{3} / \mathrm{h}\right)$. Integrating,

$$
\int_{0}^{X_{C O, \text { out }}} \sqrt{\frac{\left(1+\varepsilon X_{C O}\right)}{\left(1-X_{C O}\right)}} d X_{C O}=\frac{2^{0.74} k}{v_{0} C_{C O, \text { in }}{ }^{0.5}} \int_{0}^{W_{\text {cat }}} d W_{\text {cat }}=\frac{2^{0.74} k W_{c a t}}{v_{0} C_{C O, \text { in }}{ }^{0.5}}
$$

The solution for the integral in Eq.(7.7) can be determined by comparing with the following integral,

$$
\int \sqrt{\frac{(p x+q)}{(a x+b)}} d x=\frac{\sqrt{(a x+b)(p x+q)}}{a}+\frac{(a q-b p)}{2 a} \int \frac{1}{\sqrt{(a x+b)(p x+q)}} d x
$$

Comparing Eq.(7.7) and (7.8), we get; $p=\varepsilon, q=1, a=-1$, and $b=1$

$$
\begin{aligned}
& \int_{0}^{X_{C O}, \text { out }} \sqrt{\frac{\left(1+\varepsilon X_{C O}\right)}{\left(1-X_{C O}\right)}} d X_{C O}=-\sqrt{\left(1-X_{C O}\right)\left(1+\varepsilon X_{C O}\right)} \\
& +\frac{(-1-\varepsilon)}{-2} \times \int \frac{1}{\sqrt{\left(1-X_{C O}\right)\left(1+\varepsilon X_{C O}\right)}} d X_{C O}
\end{aligned}
$$

The integral in Eq. (7.9) can be further simplified by using,

$$
\int \frac{1}{\sqrt{(a x+b)(p x+q)}} d x=\frac{2}{\sqrt{a p}} \ln [\sqrt{a(p x+q)}+\sqrt{p(a x+b)}]
$$


Comparing Eq.(7.9) and (7.10), we get; $a=-1, b=1, p=\varepsilon$ and $q=1$.

Therefore, the solutions of the integral in Eq.(7.9) can be written as,

$$
\begin{aligned}
& \int_{0}^{X_{C O} \text { out }} \sqrt{\frac{\left(1+\varepsilon X_{C O}\right)}{\left(1-X_{C O}\right)}} d X_{C O}= \\
& \left(-\sqrt{\left(1-X_{C O}\right)\left(1+\varepsilon X_{C O}\right)}+\frac{(-1-\varepsilon)}{-2} \times \frac{2}{\sqrt{-\varepsilon}} \ln \left[\sqrt{-\left(1+\varepsilon X_{C O}\right)}+\sqrt{\varepsilon\left(1-X_{C O}\right)}\right]\right)_{0}^{X_{C O, \text { out }}}
\end{aligned}
$$

Therefore, after solving Eq.(7.11) we get,

$$
\begin{aligned}
& \int_{0}^{X_{C O, \text { out }}} \sqrt{\frac{\left(1+\varepsilon X_{C O}\right)}{\left(1-X_{C O}\right)}} d X_{C O}= \\
& \left(1-\sqrt{\left(1-X_{C O, \text { out }}\right)\left(1+\varepsilon X_{C O, \text { out }}\right)}+\frac{(1+\varepsilon)}{\sqrt{-\varepsilon}} \ln \left[\frac{\sqrt{\left(1+\varepsilon X_{C O, \text { out }}\right)}+\sqrt{-\varepsilon\left(1-X_{C O, \text { out }}\right)}}{1+\sqrt{-\varepsilon}}\right]\right)
\end{aligned}
$$

Using Eq.(7.12), Eq.(7.7) becomes,

$$
\left(1-\sqrt{\left(1-X_{\text {CO, out }}\right)\left(1+\varepsilon X_{\text {CO,out }}\right)}+\frac{(1+\varepsilon)}{\sqrt{-\varepsilon}} \ln \left[\frac{\sqrt{\left(1+\varepsilon X_{C O, \text { out }}\right)}+\sqrt{-\varepsilon\left(1-X_{C O, \text { out }}\right)}}{1+\sqrt{-\varepsilon}}\right]\right)=\frac{2^{0.74} k W_{\text {cat }}}{v_{0} C_{C O, \text { in }}}
$$

Therefore, the value of $k$ can be calculated from Eq. (7.13).

As mentioned earlier, the products of FTS include paraffins, olefins and alcohols. However, in Chapter 6 it has been confirmed that the paraffins are the most-favored products among others, especially for cobalt catalyst. The value of $\varepsilon$ can be determined by considering the paraffin formation reaction (see Eq. (2.1)) as a representative one. Therefore, the average value of $\varepsilon$ is calculated to be -0.67 for carbon number (n) from 1 to 40 . The lower paraffins $(n<5)$ are assumed to be gaseous and higher paraffins $(n>5)$ are assumed to be liquid for calculation of $\varepsilon$.

Accordingly, the values of $k$ were calculated for each bed temperature. The values for the reaction rates were obtained from average CO conversion over $24 \mathrm{~h}$. The values of the rate 
constant and reaction rates for the base catalyst are presented in Table 7.2. The values for the rate constants are comparable to the reported values (e.g., $2.1 \times 10^{-2} \mathrm{~mol} / \mathrm{h} / \mathrm{Pa}^{0.5} / \mathrm{g}_{\text {cat }}$ at 200 $\left.{ }^{\circ} \mathrm{C}\right)^{68,69,98}$.

Table 7.2 Rate constant for the base-case cobalt catalyst

\begin{tabular}{|c|c|c|c|}
\hline $\begin{array}{c}\mathrm{T} \\
\left({ }^{\circ} \mathrm{C}\right)\end{array}$ & $\begin{array}{c}\mathrm{X}_{\mathrm{CO}} \\
\%\end{array}$ & $\begin{array}{c}\mathrm{k} \\
\left(\mathrm{mol} / \mathrm{h} / \mathrm{Pa}^{0.5} / \mathrm{g}_{\mathrm{cat}}\right)\end{array}$ & $\begin{array}{c}r_{\mathrm{CO}} \\
{\left[\mathrm{mol} / \mathrm{h} / \mathrm{g}_{\text {cat }}\right]}\end{array}$ \\
\hline 215 & 12.0 & $0.70 \mathrm{E}-02$ & 0.027 \\
\hline 230 & 26.8 & $1.69 \mathrm{E}-02$ & 0.058 \\
\hline 245 & 41.8 & $2.59 \mathrm{E}-02$ & 0.095 \\
\hline
\end{tabular}

Using

$$
k=k_{0} \exp \left(\frac{-E_{a}}{R T}\right)
$$

An Arrhenius plot obtained from Eq.(7.14) is shown in Figure 7.1. From the slope, the activation energy, $E_{a c t}$, is determined to be,

$$
E_{\text {act }}=85 \mathrm{KJ} / \mathrm{mol}
$$

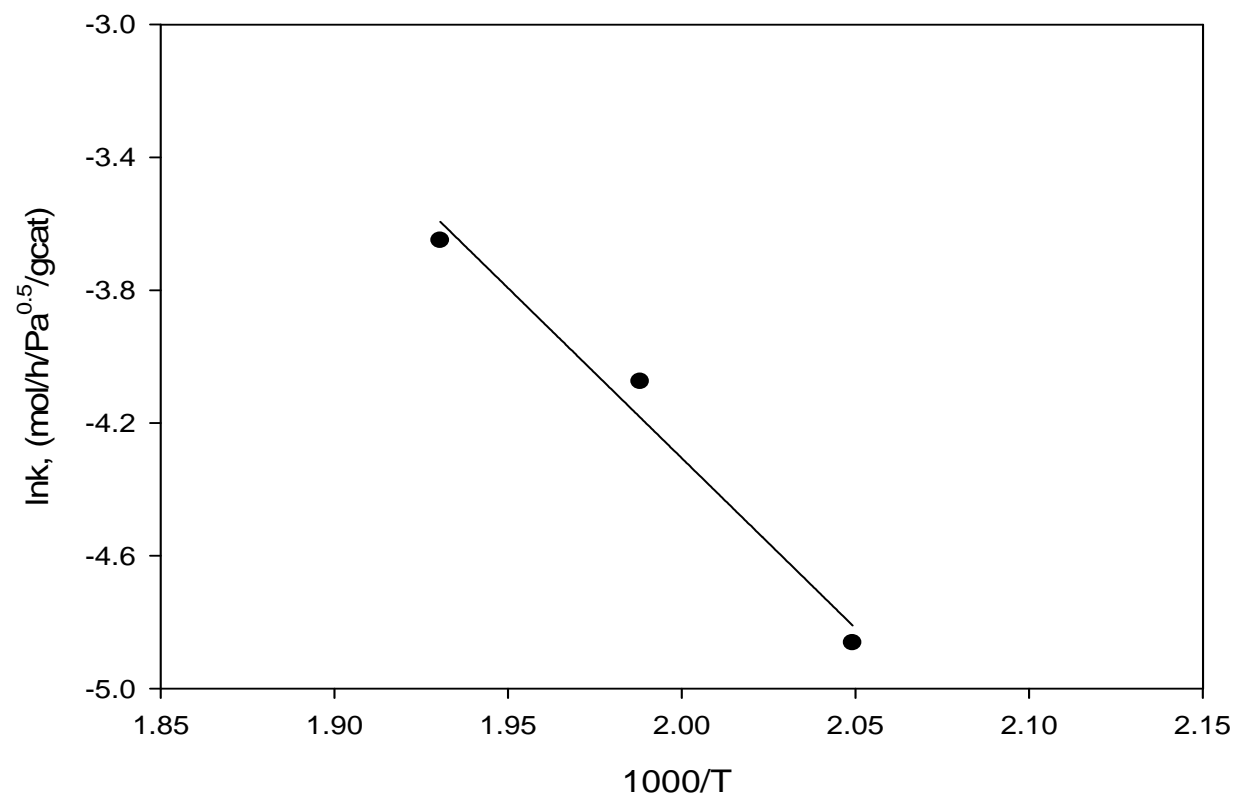

Figure 7.1 Arrhenius-plot of $\mathrm{CO}$ conversion for the base catalyst (Experimental conditions: $\mathrm{P}=20$ bar; $\mathrm{H}_{2} / \mathrm{CO}$ inlet molar ratio $=2 ; \mathrm{GHSV}=13,500 \mathrm{sccm} / \mathrm{h} / \mathrm{g}_{\text {cat }}$ ) 
The calculated of $E_{a c t}$ is well within the range of 63 to $132 \mathrm{KJ} / \mathrm{mol}$, as reported for cobalt catalysts under similar FTS conditions ${ }^{6,98}$.

The constant bed temperature of $230^{\circ} \mathrm{C}$ will be selected for the rest of the present work unless otherwise mentioned.

\subsubsection{Rate Constant and Reaction Rates of CA-modified Catalysts}

For CA-modified catalysts, the values of rate constants and reaction rates are calculated based on Eq.(7.13) and (7.5), and are presented in Table 7.3. The EDTA-modified catalyst shows highest conversions as confirmed in Chapter 6 . This is consistent with the highest reaction rate and the rate constants, calculated for the EDTA-modified catalyst.

Table 7.3 Rate constant and reaction rates of CA-modified catalysts

\begin{tabular}{|l|c|c|c|c|c|}
\hline & $\begin{array}{c}\mathrm{T} \\
\left({ }^{\circ} \mathrm{C}\right)\end{array}$ & $\begin{array}{c}\mathrm{X}_{\mathrm{CO}} \\
\%\end{array}$ & $\begin{array}{c}k \\
\left(\mathrm{~mol} / \mathrm{h} / \mathrm{Pa}^{0.5} / \mathrm{g}_{\mathrm{cat}}\right)\end{array}$ & $\begin{array}{c}r_{\mathrm{CO}} \\
{\left[\mathrm{mol} / \mathrm{h} / \mathrm{g}_{\mathrm{cat}}\right]}\end{array}$ & $\begin{array}{c}\mathrm{TOF} \\
\left(\mathrm{s}^{-1}\right)\end{array}$ \\
\hline $\mathrm{Co} / \mathrm{NTA} / \mathrm{SiO}_{2}$ & 230 & 32.0 & $2.01 \mathrm{E}-02$ & 0.072 & 0.0052 \\
\hline $\mathrm{Co} / \mathrm{EDTA} / \mathrm{SiO}_{2}$ & 230 & 66.7 & $3.96 \mathrm{E}-02$ & 0.151 & 0.0107 \\
\hline
\end{tabular}

\subsection{Mass-Transfer Limitations}

It is important to verify whether the kinetic parameters in the previous section were determined in the absence of any mass-transfer limitation. Therefore, in the next step, space velocity was varied to study the effect on conversion ${ }^{6}$.

The effect of space velocity on the CO conversion was studied by varying the flow rate of syngas at constant reaction temperature and constant total pressure. At first, the total inlet flow rate of syngas was set at $200 \mathrm{sccm}$ and the CO conversions were recorded for $24 \mathrm{~h}$. In the next step, the flow rate was increased to $225 \mathrm{scccm}$ and the data were recorded for the next 24-h interval. In the last $24-\mathrm{h}$ interval, the flow rate was raised to $250 \mathrm{sccm}$, and the corresponding conversion data were recorded.

The observed CO conversions are plotted in Figure 7.2 with respect to TOS. The CO conversion is observed to be strongly influenced by the space velocity since it corresponds to inverse of residence time. 


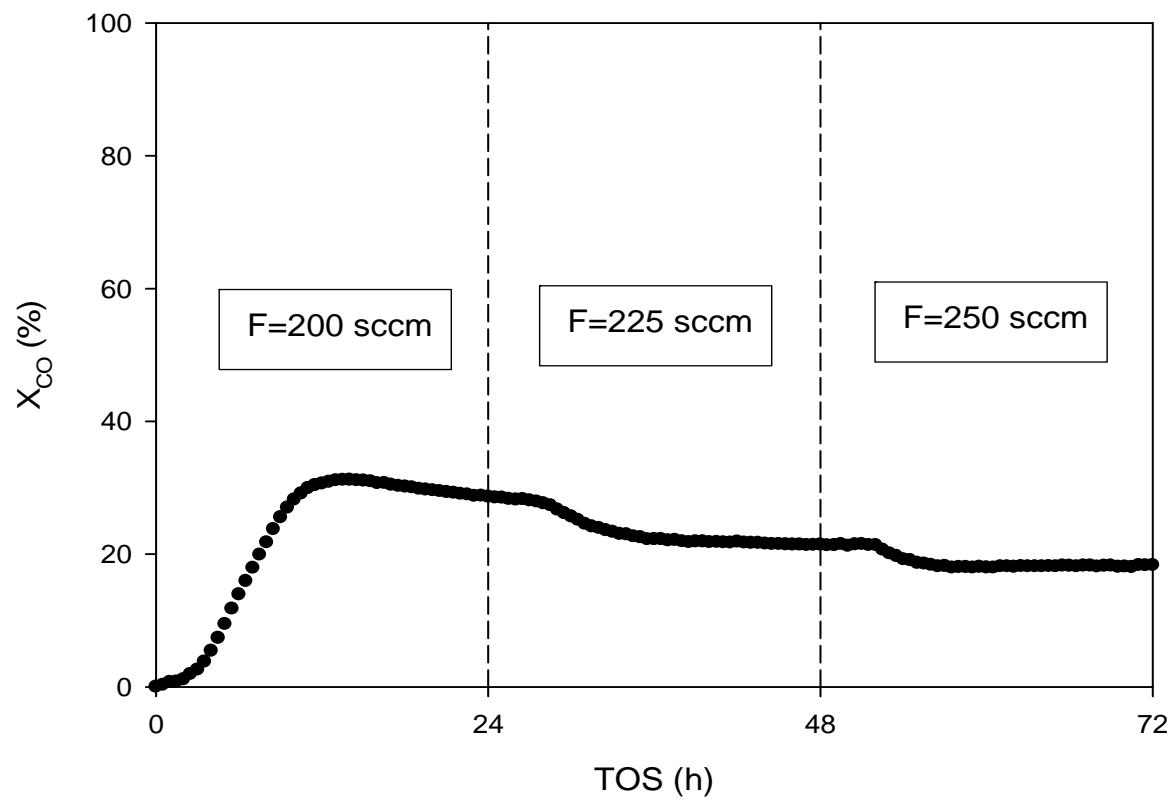

Figure 7.2 CO conversion as a function of TOS (h) for the base catalyst at flow rates of 200, 225 and $250 \mathrm{sccm}$ (experimental conditions: $\mathrm{T}=230^{\circ} \mathrm{C} ; \mathrm{P}=20 \mathrm{bar} ; \mathrm{H}_{2} / \mathrm{CO}$ inlet molar ratio $=2$ )

In addition, Table 7.4 provides the averaged CO data and TOF with varying space velocity. In general, CO conversion and TOF decreases with increased space velocity or decreased space-time.

Quantitatively, the plot for CO conversion (\%) vs. space velocity $\left(\mathrm{sccm} / \mathrm{h} / \mathrm{g}_{\text {cat }}\right)$ is a straight line as shown in Figure 7.3. Therefore, it can be confirmed ${ }^{98}$ that there is an absence of any external mass-transfer limitations within operating conditions for $20-40$ mesh $\mathrm{Co} / \mathrm{SiO}_{2}$ catalyst particles.

Table 7.4 Effect of GHSV on CO conversion and TOF of the base catalyst

\begin{tabular}{|c|c|c|c|}
\hline Flow Rate & GHSV $\left(\mathrm{sccm} / \mathrm{h} / \mathrm{g}_{\text {cat }}\right)$ & $\mathrm{X}_{\mathrm{CO}} \%$ & $\mathrm{TOF}\left(\mathrm{s}^{-1}\right)$ \\
\hline 200 & 12000 & 29.83 & 0.0141 \\
\hline 225 & 13500 & 23.01 & 0.0057 \\
\hline 250 & 15000 & 18.63 & 0.0050 \\
\hline
\end{tabular}




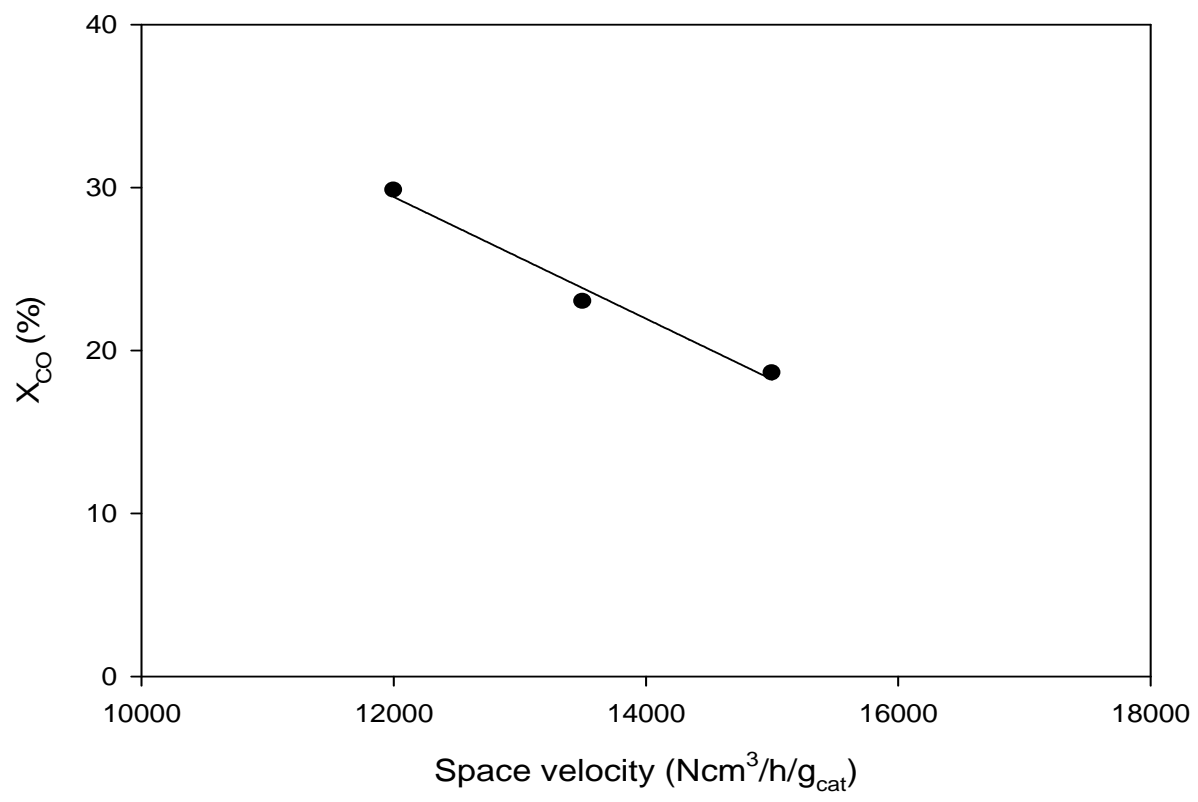

Figure 7.3 Plot of CO conversion vs. space velocity for the base catalyst (Experimental conditions: $\mathrm{T}=230^{\circ} \mathrm{C} ; \mathrm{P}=20$ bar; $\mathrm{H}_{2} / \mathrm{CO}$ inlet molar ratio $=2$ )

\subsection{Summary}

The prepared cobalt catalyst showed acceptable performance and confirmed absence of any external-mass-transfer limitations. The measured rate constant, TOF and the activation energy values are in good agreement with the reported values for cobalt catalysts.

The study of the temperature and space velocity variations assisted in a better understanding of catalyst activity within the proximity of operating conditions. It provides a strong basis for understanding the catalyst performance when syngas with sulfur impurities (poisons) are introduced into the FT reactor. The results from the poisoning study will be discussed in the next chapter. 


\section{CHAPTER 8}

\section{EFFECT OF SULFUR IMPURITIES IN THE INLET SYNGAS ON THE PERFORMANCE OF FT CATALYST}

\subsection{Introduction}

Sulfur-based impurities, mainly $\mathrm{H}_{2} \mathrm{~S}$ and organic sulfur, are formed during the gasification process from the sulfur present in the coal or biomass. The concentration of these impurities in the coal or biomass is not uniform and even average values vary based on the carbon source. Many industrially used catalysts are sensitive to sulfur poisoning and are severely affected by even very low concentrations of impurities.

In this study, the aim is first to develop the strategy to introduce the organic sulfur impurities into the catalyst zone and to evaluate catalyst performance during in-situ poisoning. In order to carry out poisoning studies, a suitable organic sulfur compound and a solvent are selected. The selection is justified by preliminary experimental runs under relevant conditions. For the base catalyst, the activity and the product selectivities are compared in the presence of different sulfur concentrations. On the other hand, the poisoning study of CA-modified catalysts is performed under one sulfur impurity level. Furthermore, the effect of sulfur poisoning on the performance of the catalyst is carefully determined by comparing catalyst activity and product selectivity during the pre-poisoning, poisoning and post-poisoning stages.

\subsection{Selection of Solvent and Organic Sulfur}

As mentioned in Chapter 3, sulfur-poisoning runs require some modifications to the equipment and procedure. The BenchCat unit, shown in Figure 3.1, incorporates a liquiddelivery system consisting of a syringe pump followed by an evaporator and a volume expander. This setup can therefore be used to introduce sulfur impurities in the inlet syngas. The experimental plan involves the use of a liquid solvent that can dissolve a liquid organic sulfur compound, and then the mixture can be vaporized. The vapor formed in the evaporator enters the volume expander which serves to maintain a desired concentration and pressure of 
vapor before mixing with the inlet syngas. Both the evaporator and expander operate at temperatures well above the boiling point of both the liquids.

Paraffins $\left(\mathrm{C}_{n} \mathrm{H}_{2 n+2}\right)$ with $\mathrm{n}$ greater than 5 , are available as liquids at normal conditions. The low boiling points of $C_{5}$ to $C_{7}$ paraffins make handling difficult when exposed to the atmosphere. Therefore, paraffins with carbon number 8 or higher were potentially considered for use as a solvent. Inspecting the inherent paraffinic distribution of FT products (Figure 5.5a), the percentage of higher hydrocarbons (i.e., $\mathrm{C}_{20}$ onwards) is on the low side, and the use of these longer-chain paraffins as solvent was considered not to affect the quantification of other paraffins. A longer-chain non-paraffinic hydrocarbon such as squalene, $\mathrm{C}_{30} \mathrm{H}_{50}$, with a boiling point of $285^{\circ} \mathrm{C}$, was also considered as a solvent. However, the selection of a $\mathrm{C}_{20+}$ hydrocarbon as a solvent was overruled by the maximum operating temperature of the evaporator and the volume expander, i.e., $230{ }^{\circ} \mathrm{C}$. The longer-chain hydrocarbons would necessitate a higher operating temperature. Non-uniform vaporization of a longer-chain hydrocarbon could result in a channeling effect, leading to a non-uniform distribution of the sulfur compound in the catalyst bed. The highly viscous liquid-phase solvent with long-chain hydrocarbon could also accumulate into bends and elbows of the unit, and could result in a buildup of back-pressure.

On the other hand, a lower-chain hydrocarbon, such as with carbon number 8 , offers the advantages of a relatively lower boiling point and a lower viscosity. Of course, if used as a solvent, this paraffin, i.e., n-octane, would interfere with $C_{8}$ peaks of FT products. However, the quantification issues could be resolved by performing some additional calibration runs. The resolution of these operational issues resulted in the selection of $n$-octane as the solvent.

The alkanethiols, i.e., R-SH, were then considered to represent the organic sulfur impurities normally present in raw syngas. The lower boiling point of ethanethiol (b.p. of $35^{\circ} \mathrm{C}$ ) poses handling issues in normal conditions. Butanethiol, on the other hand, has a boiling point of $98{ }^{\circ} \mathrm{C}$ and can be handled with proper precautions. In addition, butanethiol forms a homogeneous mixture with n-octane. Therefore, butanethiol $\left(\mathrm{C}_{4} \mathrm{H}_{10} \mathrm{~S}\right)$ was selected as the sulfur carrier, and n-octane $\left(\mathrm{n}-\mathrm{C}_{8} \mathrm{H}_{18}\right)$ as the organic solvent.

In summary, the selection of these two components, n-octane and butanethiol, was primarily influenced by the ease of operation, boiling point, and the limitations of the existing 
reactor setup. The important physical properties of n-octane and butanethiol are listed in Table 8.1.

Table 8.1 Physical properties of the solvent and sulfur carrier ${ }^{106}$

\begin{tabular}{|l|c|c|}
\hline & n-Octane & Butanethiol \\
\hline Molecular formula & $\mathrm{C}_{8} \mathrm{H}_{18}$ & $\mathrm{C}_{4} \mathrm{H}_{10} \mathrm{~S}$ \\
\hline Molecular weight (g/mol) & 114.3 & 90.2 \\
\hline Color & colorless & colorless \\
\hline Boiling point $\left({ }^{\circ} \mathrm{C}\right)$ & 126 & 98.4 \\
\hline Specific gravity & 0.84 & 0.73 \\
\hline Viscosity (cP) & 0.54 & 0.51 \\
\hline
\end{tabular}

\subsection{Activity of n-Octane under FT Conditions}

Initially, the syringe pump was made operational and was calibrated. At first, the pump was filled with DI water from a 500-ml reservoir to ensure the functional reliability of the various components. In this setup, water from the syringe pump was passed through the evaporator and the volume expander, both preheated to $140{ }^{\circ} \mathrm{C}$. The steam exiting the expander was mixed with the inert gas and the mixture was subsequently passed through the empty reactor at different operating pressures. The steam was allowed to condense in the downstream condenser and was recovered at the end of the run. The preliminary blank run performed with DI water provided useful directions (e.g., deciding liquid flow rates) in developing the approach for the subsequent n-octane and sulfur introduction runs.

In the next step, pure n-octane from a new 500-ml reservoir was used to flush out the water from all the setup lines. The flushing cycles were repeated until the recovered $n$-octane showed no trace of water. Trace water, if present, can potentially affect the accuracy of the data from a real FT run and hence the repeated flushing with n-octane was necessary.

Next, runs were performed to find the activity of n-octane solvent under FT conditions (T, $230{ }^{\circ} \mathrm{C} ; \mathrm{P}, 20$ bar; GHSV, 13,500 sccm/h/g $\left./ \mathrm{g}_{\text {cat }}\right)$. A low flow rate of n-octane $(0.01 \mathrm{cc} / \mathrm{min}$ of liquid) was selected, in order to limit the n-octane quantity in the condensed products. In the first scenario, the reactor tube was loaded with the base $\mathrm{Co} / \mathrm{SiO}_{2}$ catalyst, similar to a routine FT run. An inert He gas was used as the primary feed, instead of syngas. Once the desired conditions were reached, the n-octane from the syringe pump was introduced at a liquid flow rate of $0.01 \mathrm{cc} / \mathrm{min}$. The gases exiting the unit were continuously analyzed by the online GC and 
showed no measurable TCD or FID products. Therefore, it can be confirmed that the cobalt catalyst under relevant FT conditions and inert He atmosphere does not show any activity with respect to the n-octane.

In the second scenario, the experiment was designed to evaluate the non-catalytic activity of n-octane and syngas under FT conditions. The reactor was loaded with only quartz chips and no catalyst. The inert He gas was replaced with syngas. The other operating conditions were the same as mentioned in the first scenario. The outlet gases were analyzed by the online GC. The CO conversion data and the inlet and the outlet CO molar flow rates are shown in Figure 8.1.

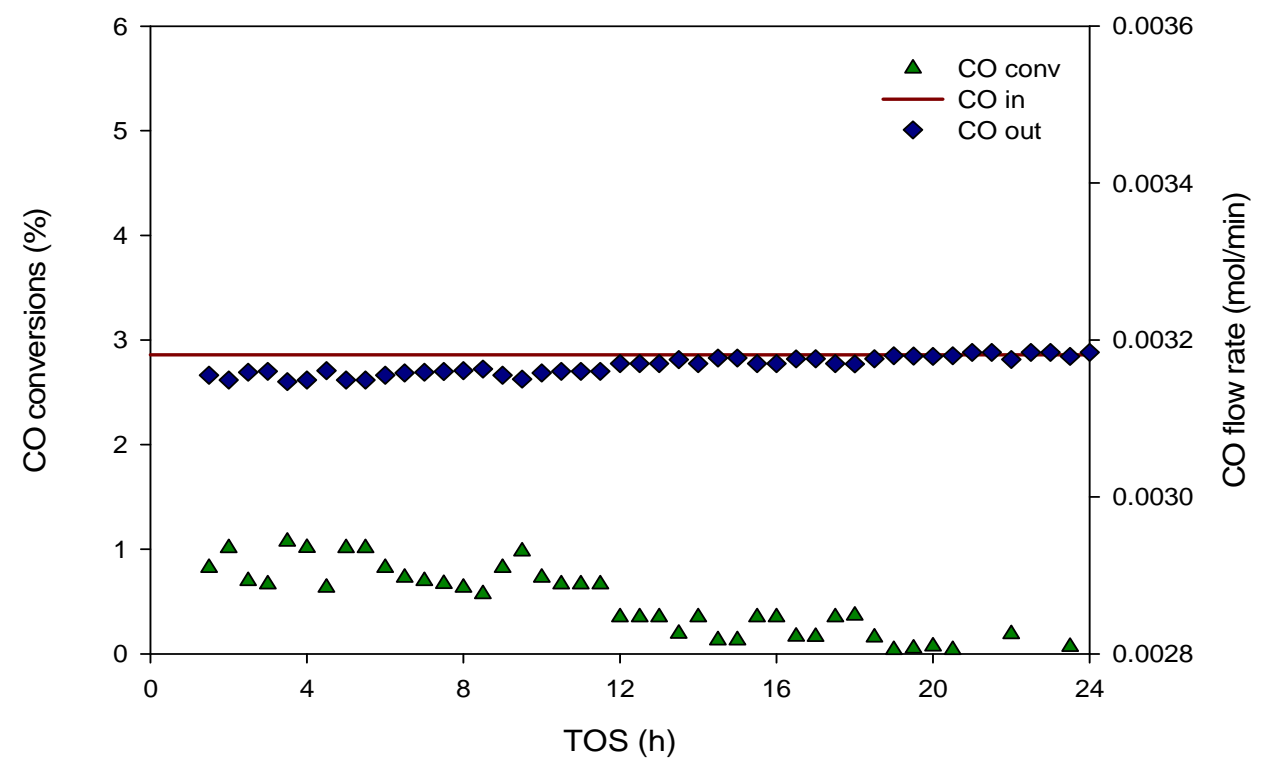

Figure 8.1 CO conversion and molar inlet and outlet CO flow rates for a blank run with n-octane, syngas and quartz chips

(Experimental conditions: $\mathrm{T}=230^{\circ} \mathrm{C} ; \mathrm{P}=20$ bar; $\mathrm{GHSV}=13,500 \mathrm{sccm} / \mathrm{h} / \mathrm{g}_{\text {cat }}$ )

The CO conversion, in the presence of n-octane and in the absence of the cobalt catalyst, was measured to be below $1 \%$. The FID showed only traces of $\mathrm{CH}_{4}$ during first few hours of the run, after which $\mathrm{CH}_{4}$ was seen to disappear. In addition, product analysis showed insignificant CO conversion (less than $1 \%$ ) after the initial few hours. Such a small extent of conversion could be attributed to the activity of quartz chips used for filling the reactor, that of 
the SS wall of the reactor and the tubing, or to measurement errors from GC quantification. The numbers are similar to the situation when the synthesis gas was run in the absence of n-octane and the catalyst, i.e., below $1 \%$ as shown in Figure 5.2. The product analysis once again confirmed the absence of any effect of n-octane.

Therefore, after studying the activity under two scenarios as explained above, n-octane was determined to be effectively inactive towards the catalyst, syngas and other components of the reactor separately. The next experimental strategy was developed to evaluate the activity of n-octane in the presence of the Co catalyst and syngas under normal FT conditions.

\subsection{Performance of the Cobalt Catalyst in the Presence of n-Octane Only}

In the next step, a FT run was planned with the addition of only n-octane to the syngas feed. In this case, the reactor was loaded with the $\mathrm{Co} / \mathrm{SiO}_{2}$ catalyst and syngas was used as a primary feed. All other operating conditions were similar to the one used in the routine FT run.

The total time on stream (TOS) was $72 \mathrm{~h}$. Similar to previous runs, the outlet gases were analyzed every $30 \mathrm{~min}$ with an online GC. During the initial $24 \mathrm{~h}$, the syngas alone was in the feed, to allow the catalyst to reach a stable activity. A liquid sample was recovered at the end of this $24 \mathrm{~h}$ period. At the beginning of the next $24 \mathrm{~h}$ period, n-octane was introduced in the inlet syngas through the syringe pump. The flow rate of $n$-octane was kept constant at $0.01 \mathrm{cc} / \mathrm{min}$ $15 \mathrm{~h}$. After $15 \mathrm{~h}$, only syngas was fed to the reactor. Similar to the first $24 \mathrm{~h}$ period, a liquid sample was collected at the end of $48 \mathrm{~h}$. Finally, in the last $24 \mathrm{~h}$ period, again only pure syngas was allowed to pass through the reactor, and a liquid sample was recovered at the end of $72 \mathrm{~h}$.

The CO conversions for the runs with only syngas and with syngas plus n-octane are shown in Figure 8.2. In both the cases, the CO conversion slowly increases in the initial period. Furthermore, the CO conversions in both cases remain constant during entire run. In the case of the run with n-octane addition, during the second period of solvent addition (i.e., TOS from 24 to $48 \mathrm{~h}$ ), there is no noticeable effect on CO conversion. In fact, the CO conversion remains steady at ca. $18 \%$ during the entire $72 \mathrm{~h}$ operation, even after the $\mathrm{n}$-octane flow is stopped. Therefore, the addition of n-octane during the FT run does not appear to have any effect on the CO conversion. 
It must be stressed here that the n-octane was added to the inlet feed only after the catalyst reached some steady-state activity. The approach adopted here is effective in estimating the actual change in CO conversion due to the addition of n-octane. Also, the adopted approach can be considered to represent the changes in conversion more precisely compared to a situation where solvent is introduced in the feed from the beginning of the run and without attaining the steady-state conversions.

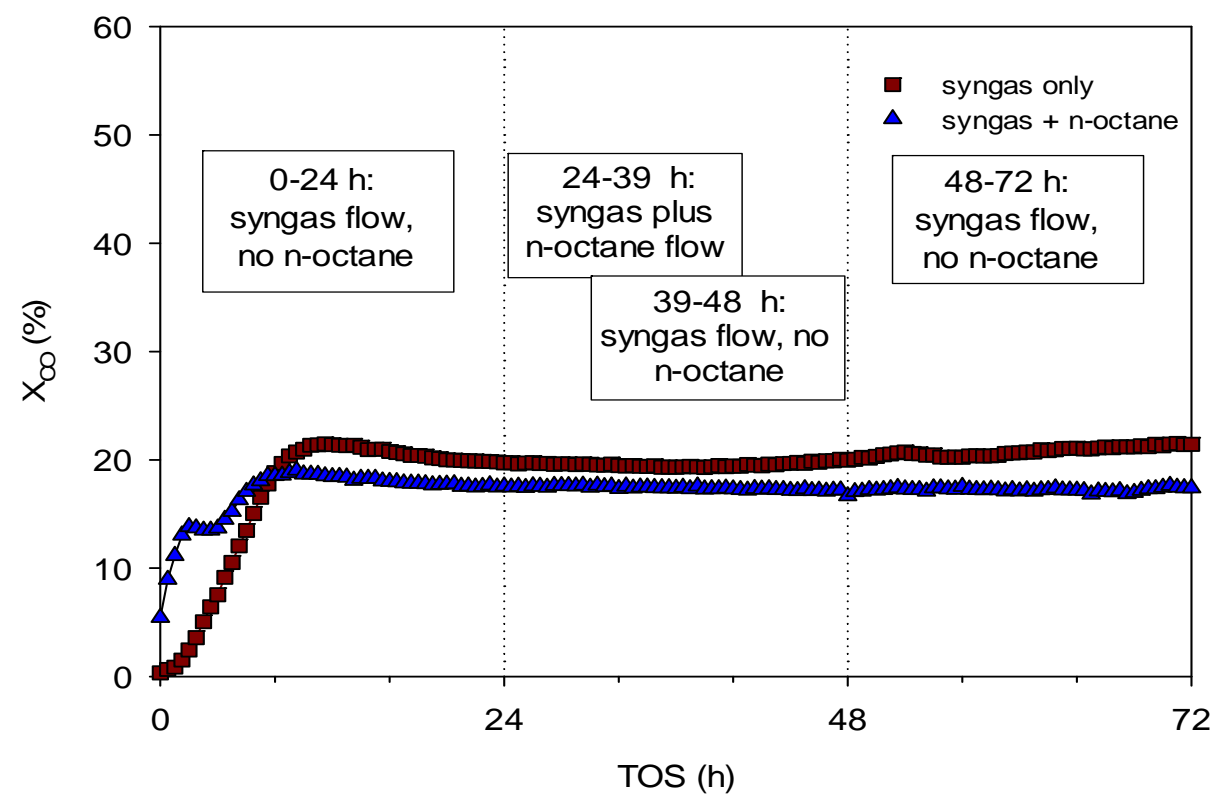

Figure $8.2 \mathrm{CO}$ conversion for $\mathrm{Co} / \mathrm{SiO}_{2}$ catalyst during a dry run ("normal" run) and with n-octane (Experimental conditions: $\mathrm{T}=230^{\circ} \mathrm{C} ; \mathrm{P}=20 \mathrm{bar} ; \mathrm{GHSV}=13,500 \mathrm{sccm} / \mathrm{h} / \mathrm{g}_{\text {cat }}$ )

\subsubsection{Revised Procedure for Paraffin Product Analysis}

For the run discussed above, the liquid samples collected every $24 \mathrm{~h}$ were analyzed by an offline GC. As discussed earlier, the only difference between this run and the normal FT run is the addition of n-octane during the operation. For the run where n-octane is added, the oil product recovered is expected to have anomalies in the paraffin distribution, because n-octane is also one of the paraffin products of FT reaction. Therefore, the original approach is revised to quantify the n-octane from FT product as discussed below.

The paraffin weight distribution for the oil sample collected at the end of $48 \mathrm{~h}$ and $72 \mathrm{~h}$ is shown in Figure $8.3 \mathrm{a}$ and $\mathrm{b}$, respectively. 

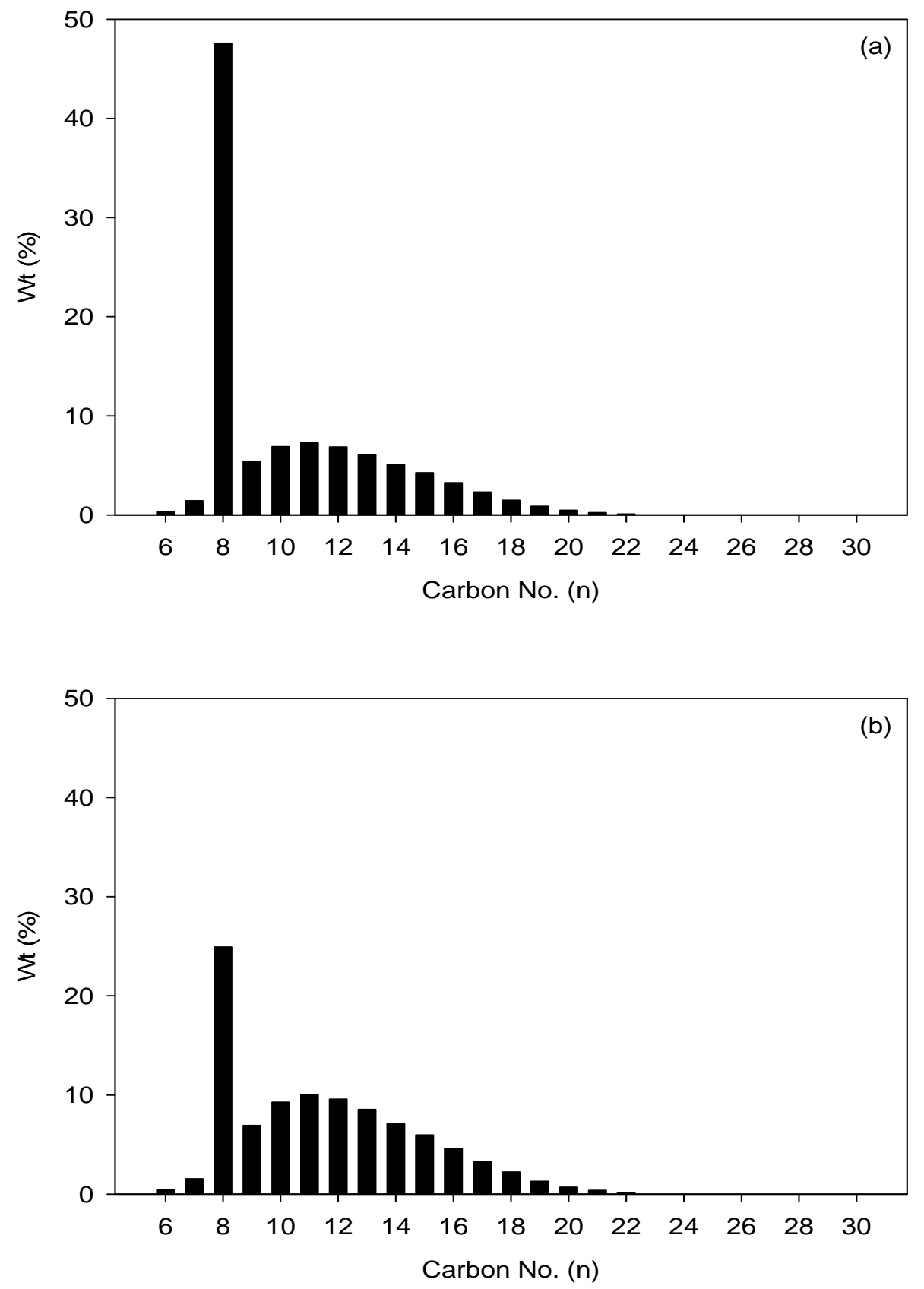

Figure 8.3 Weight distribution of paraffins as a function of carbon numbers over a $\mathrm{Co} / \mathrm{SiO}_{2}$ catalyst (a) for 24-48 $\mathrm{h}$ and (b) for $48-72 \mathrm{~h}$

The sample collected at the end of $48 \mathrm{~h}$ exhibits a paraffin distribution with carbon numbers from 6 to 28 with a maximum (not counting $C_{8}$ ) around $C_{11}$ as shown in Figure 8.3a. This paraffin distribution (not counting $C_{8}$ ) is consistent with the one from the run without $n$ - 
octane addition, as shown in Figure 5.5a. Of course, due to the additional n-octane passed during this segment, a strong peak for $\mathrm{C}_{8}$ is noticed. Further, the liquid sample collected at the end of $72 \mathrm{~h}$, shown in Figure 8.3b, also contains a $\mathrm{C}_{8}$ peak but with a lower intensity than the one in Figure 8.3a. This clearly suggests the presence of vaporized n-octane traces in the lines, even after the n-octane flow is terminated. This could be due to the time required for the vaporized $n$-octane to flush out of the unit under high pressure.

The difference between the mass flow rate of $C_{8}$ recovered during the run with $C_{8}$, syngas and no catalyst (see Figure 8.1) and the $C_{8}$ collected during the FT run between 24-48 $\mathrm{h}$ with $\mathrm{C}_{8}$ introduced into the feed, is used to determine the mass flow rate of $\mathrm{C}_{8}$ present in the FT products alone. Quantitatively, the total amount of $\mathrm{C}_{8}$ collected during the FT run with n-octane addition is $1.45 \mathrm{gC} /$ day. The amount of $\mathrm{C}_{8}$ collected during the run with $\mathrm{C}_{8}$, syngas and no catalyst is $1.26 \mathrm{gC} /$ day. Therefore, the amount of $\mathrm{C}_{8}$ in the actual FT product is estimated to be the difference of these two numbers, i.e., $0.19 \mathrm{gC} /$ day. With the corrected mass flow rate of $\mathrm{C}_{8}$, the weight distribution of the paraffins is re-calculated. The corrected distribution is shown in Figure 8.4.

In addition, the amount of $\mathrm{C}_{7}$ in the $\mathrm{FT}$ product is $0.05 \mathrm{gC} /$ day and the amount of $\mathrm{C}_{9}$ is $0.17 \mathrm{gC} /$ day. The corrected $C_{8}$ amount is expected to be between the $C_{7}$ and $C_{9}$ amounts; however, the corrected value of $\mathrm{C}_{8}(0.19 \mathrm{gC} /$ day $)$ is higher than $\mathrm{C}_{9}$. These deviations are attributed to experimental measurement errors. Due to the very large volume (liters) of the reactor and the condensers of the BenchCat unit, it is difficult to recover the relatively small quantity of $n$-octane that is injected during the run. The deviations in the estimation of $C_{8}$ are within an acceptable range, especially when products are lumped. Therefore, the approach developed can be applied for the estimation of $C_{8}$ in the remaining runs involving sulfur poisoning. 


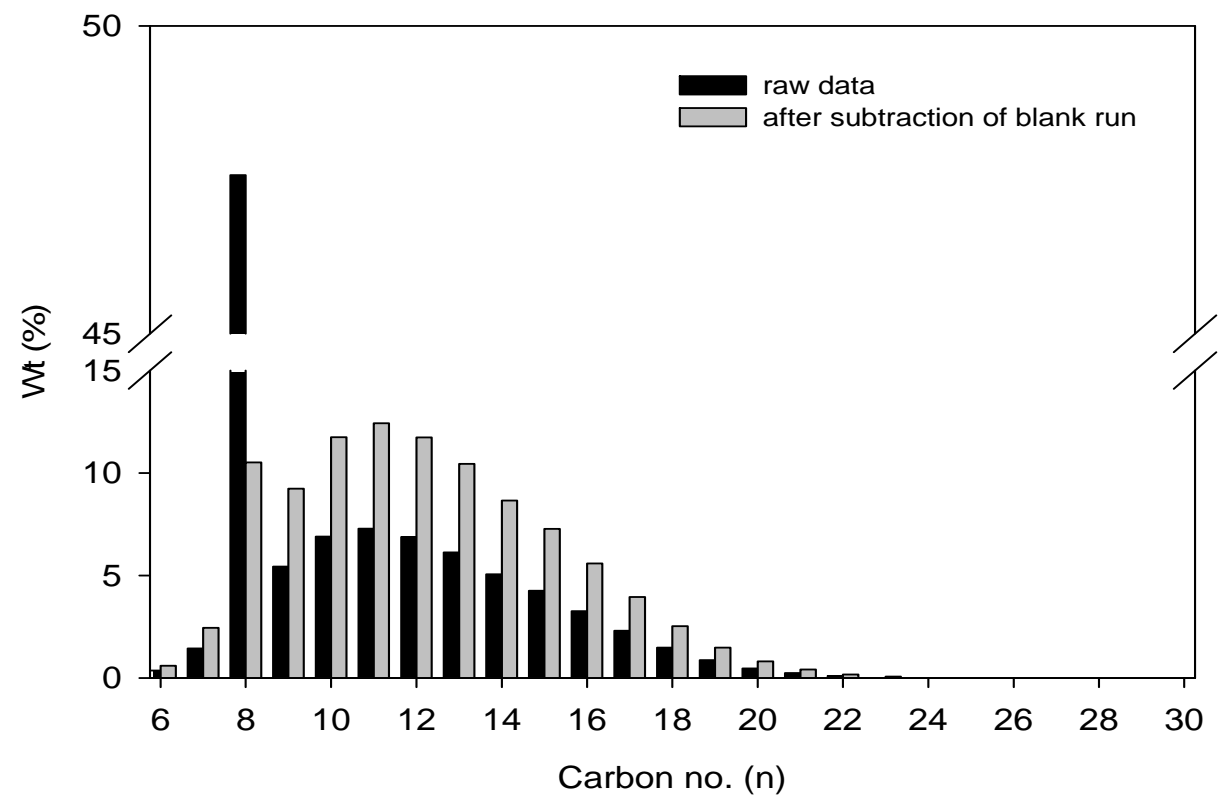

Figure 8.4 Weight distribution of paraffins collected at the end of $48 \mathrm{~h}$ after subtracting the blank run data for $\mathrm{C}_{8}$

\subsection{Syngas with Organic Sulfur Impurities}

After sufficient confidence was developed in the use of n-octane as an organic solvent, runs were initiated to study the poisoning effect of organic sulfur on the FT catalyst. The organic sulfur was introduced in the inlet syngas by pumping the liquid mixture of butanethiol and n-octane through the syringe pump and vaporizing the mixture in the evaporator before entering the volume expander. The mixture was kept in the volume expander until the vapor reached system pressure (20 bar). Then the check valve opened and the mixture was added to the inlet syngas.

\subsubsection{Preparation of Butanethiol and n-Octane Mixture}

The mixture of butanethiol and n-octane was prepared inside the fume hood using hand gloves, a lab coat, an ear-loop face mask and safety glasses as personal protective equipment (PPE). The precaution is necessary to avoid direct exposure of the butanethiol to the operator and other laboratory users. The mixture was prepared by mixing the desired quantity of butanethiol into n-octane. The prepared mixture of butanethiol and n-octane was subsequently loaded into the syringe pump. 
Two mixtures of butanethiol and n-octane were prepared for the poisoning study. The solutions contained butanethiol such that, when $0.01 \mathrm{cc} / \mathrm{min}$ of the liquid was evaporated and mixed with $225 \mathrm{sccm}$ of syngas for $15 \mathrm{~h}$, the sulfur concentration in the syngas was either 10 ppmv or 50 ppmv.

\subsubsection{Organic Sulfur Impurities in the Syngas}

The base case $\mathrm{Co} / \mathrm{SiO}_{2}$ catalyst was subjected to two inlet sulfur concentrations of 10 ppm and 50 ppm. On the other hand, the EDTA- and NTA-modified catalysts were subjected to only 10 ppm sulfur.

The following nomenclature will be used to simplify further discussion,

I. Pre-poisoning stage: TOS $=0$ to $24 \mathrm{~h}$; only syngas

II. Poisoning stage: $\quad$ TOS $=24$ to $48 \mathrm{~h}$; syngas along with butanethiol and $\mathrm{n}$-octane for the first $15 \mathrm{~h}$, only syngas for the remainder

III. Post-poisoning: TOS $=48$ to $72 \mathrm{~h}$; only syngas

It must be stressed that, during the poisoning stage, the sulfur introduction was initiated at the end of $24 \mathrm{~h}$ and was continued for the next $15 \mathrm{~h}$ before being terminated; however, the liquid products were collected only at the end of $48 \mathrm{~h}$. The catalyst activity and selectivity could only be evaluated for the entire $24 \mathrm{~h}$ to $48 \mathrm{~h}$, although the sulfur introduction was terminated at $39 \mathrm{~h}$ by switching off the syringe pump. The check valve was allowed to stay open until the outlet pressure drop below 20 bar. Therefore, the entire 24-to-48 h TOS interval is referred to as a poisoning stage.

The effect of sulfur impurities on the performance of the different catalysts was evaluated. The performance is compared based on the change in the catalyst activity and the product selectivity due to addition of sulfur. The results from the study are discussed in the following section. 


\subsection{Effect of Organic Sulfur Impurities on CO Conversion and FT Rate}

\subsubsection{CO Conversions of Base Case Catalyst}

The effect of addition of 10 and $50 \mathrm{ppm}$ sulfur on the $\mathrm{CO}$ conversion of $\mathrm{Co} / \mathrm{SiO}_{2}$ is shown in Figure 8.5. In both cases, the operating conditions in the first $24 \mathrm{~h}$ remain essentially the same. The average CO conversions are ca. $19 \%$ and ca. $18 \%$, identical within experimental error, as expected.

With the addition of $10 \mathrm{ppm}$ sulfur, a small drop in conversion is noted for the first $8 \mathrm{~h}$ of the poisoning stage. In the next $8 \mathrm{~h}$ of the poisoning stage, the conversion slips to ca. $16 \%$, and in the remaining $8 \mathrm{~h}$ of the poisoning stage, the conversion further drops to ca. $9 \%$. In the post-poisoning stage, in the presence of pure syngas, the average CO conversion is only ca. $5 \%$ and tends to reach a steady value toward the end of $72 \mathrm{~h}$. Therefore, with $10 \mathrm{ppm}$ sulfur poison in the feed, the conversion drops from the initial value of ca. $19 \%$ to ca. $5 \%$ at the end of the run. It is evident that the catalyst does not regain the lost activity for at least $24 \mathrm{~h}$ even after the removal of sulfur poison in the feed. Hence the poisoning can be considered to result in the permanent and at least partial loss of activity.

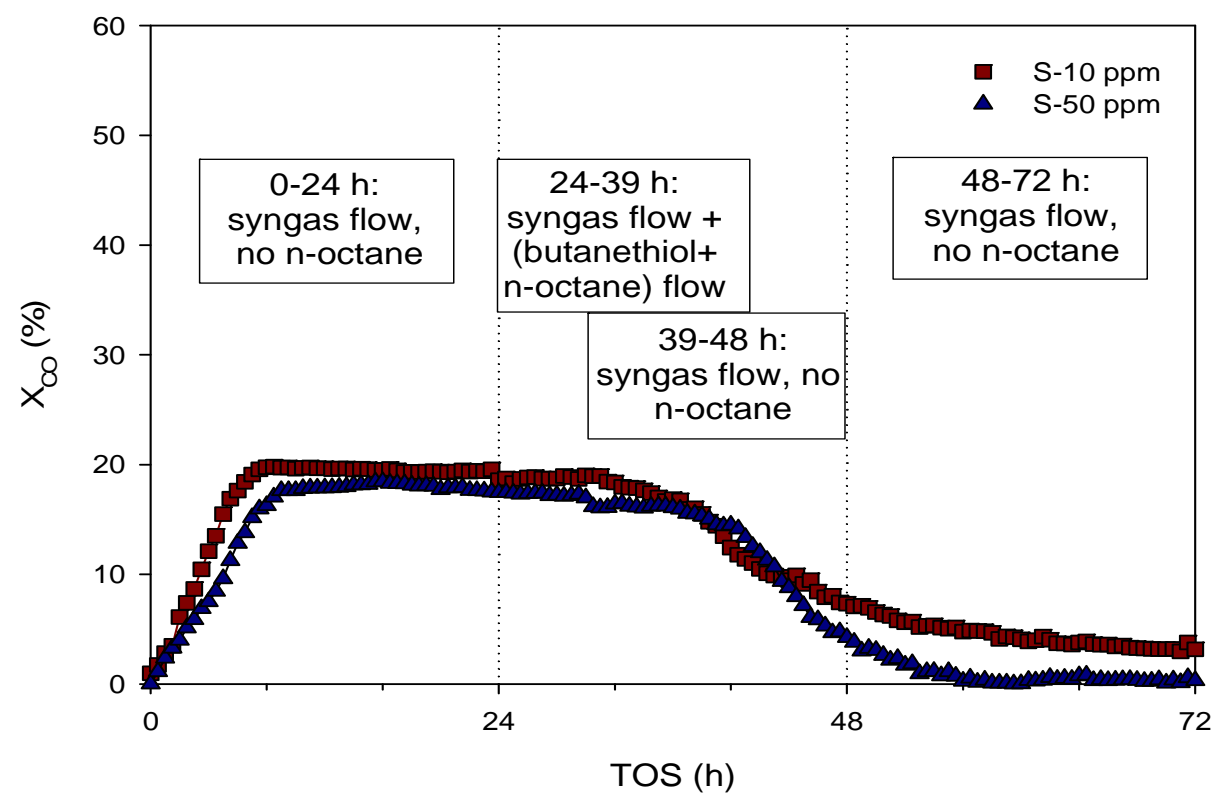

Figure $8.5 \mathrm{CO}$ conversion data for $\mathrm{Co} / \mathrm{SiO}_{2}$ catalyst with addition of 10 and $50 \mathrm{ppm}$ sulfur

(Experimental conditions: $\mathrm{T}=230^{\circ} \mathrm{C} ; \mathrm{P}=20$ bar; $\mathrm{GHSV}=13,500 \mathrm{sccm} / \mathrm{h} / \mathrm{g}_{\text {cat }}$ ) 
After the introduction of sulfur, the CO conversion remains unaltered for the first few hours in the poisoning stage. This may be because the sulfur is introduced at a relatively low flow rate and needs time to fill up the large system volume of the evaporator and the expander before reaching the desired pressure. In addition, the outlet gases are analyzed by the online $\mathrm{GC}$ only after the stream passes through the downstream condensers, under high pressure. The response-lags for introduction to the evaporator and expander, shown in Appendix I, are approximately $555 \mathrm{~min}$, assuming the ideal-gas behavior in the expander and plug flow through the vaporizer.

For the next run, the inlet sulfur concentration was increased from $10 \mathrm{ppm}$ to $50 \mathrm{ppm}$. Addition of $50 \mathrm{ppm}$ sulfur results in considerable changes in the performance of the catalyst, as shown in Figure 8.5. In the first $8 \mathrm{~h}$ of the poisoning stage, the CO conversion drops slightly from ca. $18 \%$ to ca. $16 \%$; in the next $8 \mathrm{~h}$, the Co conversion drops to ca. $14 \%$. In the remaining $8 \mathrm{~h}$ of the poisoning stage, the conversion drops rapidly to ca. $6 \%$. In the post-poisoning stage, the $\mathrm{CO}$ conversion shows a progressive drop as the deactivation becomes more severe at higher sulfur concentration. At the end of $72 \mathrm{~h}$, the catalyst shows virtually no activity. As shown later, there are no measurable products of GC analysis. As the catalyst did not regain activity even after the sulfur was not being added, the $50 \mathrm{ppm}$ sulfur present in the feed can be considered to have poisoned all the catalyst sites and hence can be said to result in a permanent and total loss in the activity.

The average CO conversions for each of the three stages for runs with different inlet streams are plotted in Figure 8.6 for the $\mathrm{Co} / \mathrm{SiO}_{2}$ catalyst. The operating conditions during the pre-poisoning stage (i.e., the first $24 \mathrm{~h}$ ) are essentially similar for all the four experimental runs, Figure 8.6(a) through (d), and the conversions are expected to be comparable. The small deviations with the measured data can be attributed to experimental error. As discussed earlier, the n-octane addition is found to have no effect on the CO conversions. Therefore, in both the "normal" FT run and the one with pure n-octane (Figure 8.6(a) and (b), respectively), the average CO conversions for all the three stages are nearly the same. On the other hand, the addition of $10 \mathrm{ppm}$ sulfur results in a drop in the CO conversion during both the poisoning and the post-poisoning stage. The addition of $50 \mathrm{ppm}$ of $\mathrm{S}$ shows an even more detrimental effect 
and results in virtually a complete loss in activity at the end of $72 \mathrm{~h}$. Therefore, it can be confirmed that organic sulfur impurities present in the syngas causes unfavorable changes in the activity of FT catalysts.

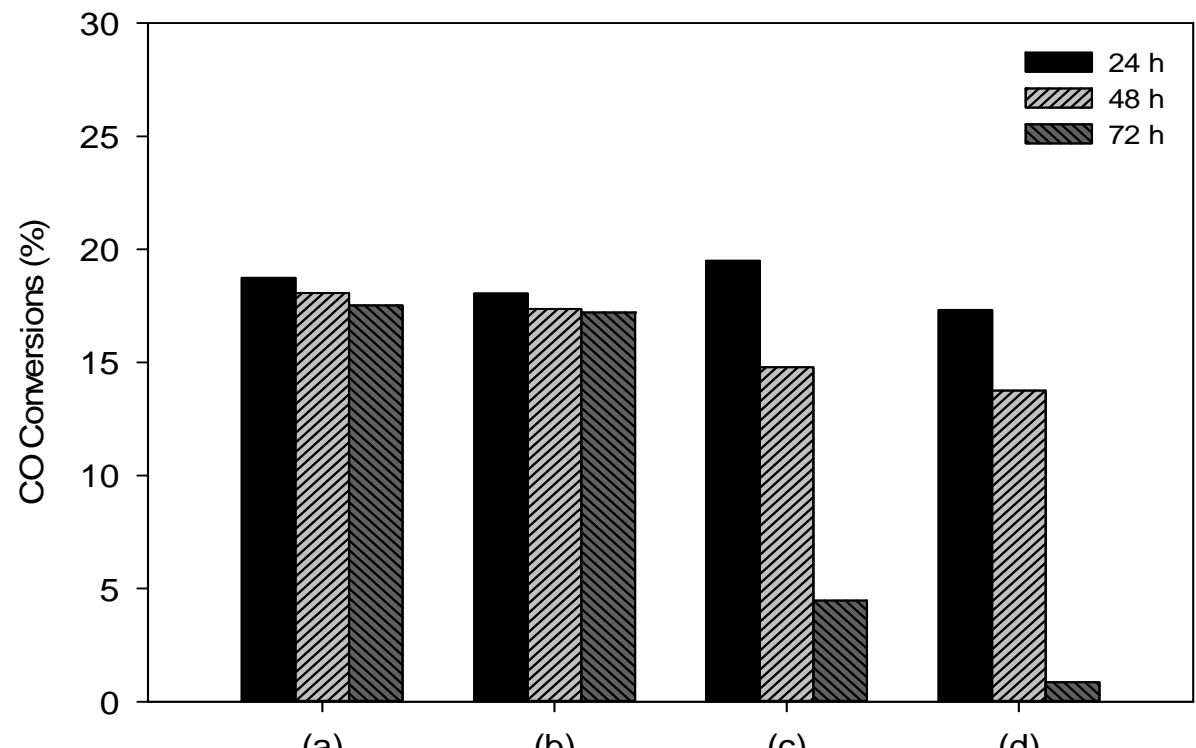

(a)

(b)

(c)

(d)

Figure 8.6 $\mathrm{CO}$ conversion for the $\mathrm{Co} / \mathrm{SiO}_{2}$ catalyst with different inlet: (a) "normal" run with syngas feed, (b) run with syngas and n-octane feed, (c) syngas with 10 ppmv S equivalent, and (d) syngas with 50 ppmv $S$ equivalent

(Experimental conditions: $\mathrm{T}=230^{\circ} \mathrm{C} ; \mathrm{P}=20 \mathrm{bar} ; \mathrm{GHSV}=13,500 \mathrm{sccm} / \mathrm{h} / \mathrm{g}_{\text {cat }}$ )

\subsubsection{CO Conversions of CA-modified Catalysts}

In the next step, the CA-modified catalysts are subjected to sulfur poisoning during FT operation. Since the use of $50 \mathrm{ppm}$ sulfur results in complete deactivation, runs with the CAmodified catalysts were carried out with $10 \mathrm{ppm}$ sulfur only. All the operating conditions were kept similar to the one mentioned earlier.

The trend of CO conversions vs. TOS is plotted for the EDTA- and NTA-modified catalyst in Figure 8.7. Similar to the case of the base catalyst, the CO conversions drop for both the CAmodified catalysts during the poisoning stage. In particular, for the EDTA-modified catalyst, in the first $8 \mathrm{~h}$ of the poisoning stage, the conversion drops from ca. $51 \%$ to ca. $48 \%$. In the next 8 $\mathrm{h}$ of the poisoning stage, the conversion drops only marginally to ca. $47 \%$. In the last $8 \mathrm{~h}$ of the 
poisoning stage, the conversion drops to ca. $37 \%$. In the post-poisoning stage, the EDTAmodified catalyst shows a progressive drop in the conversion and reaches value of ca. $31 \%$.

In the case of the NTA-modified catalyst, in the first $8 \mathrm{~h}$ of the poisoning stage, the conversion drops from ca. $23 \%$ to ca. $20 \%$. In the next $8 \mathrm{~h}$ of the poisoning stage, the conversion marginally drops to ca. $19 \%$. In the last $8 \mathrm{~h}$ of the poisoning stage, the conversion further drops to ca. $17 \%$. In the post-poisoning stage, the conversion shows signs of reaching a steady value of ca. $13 \%$.

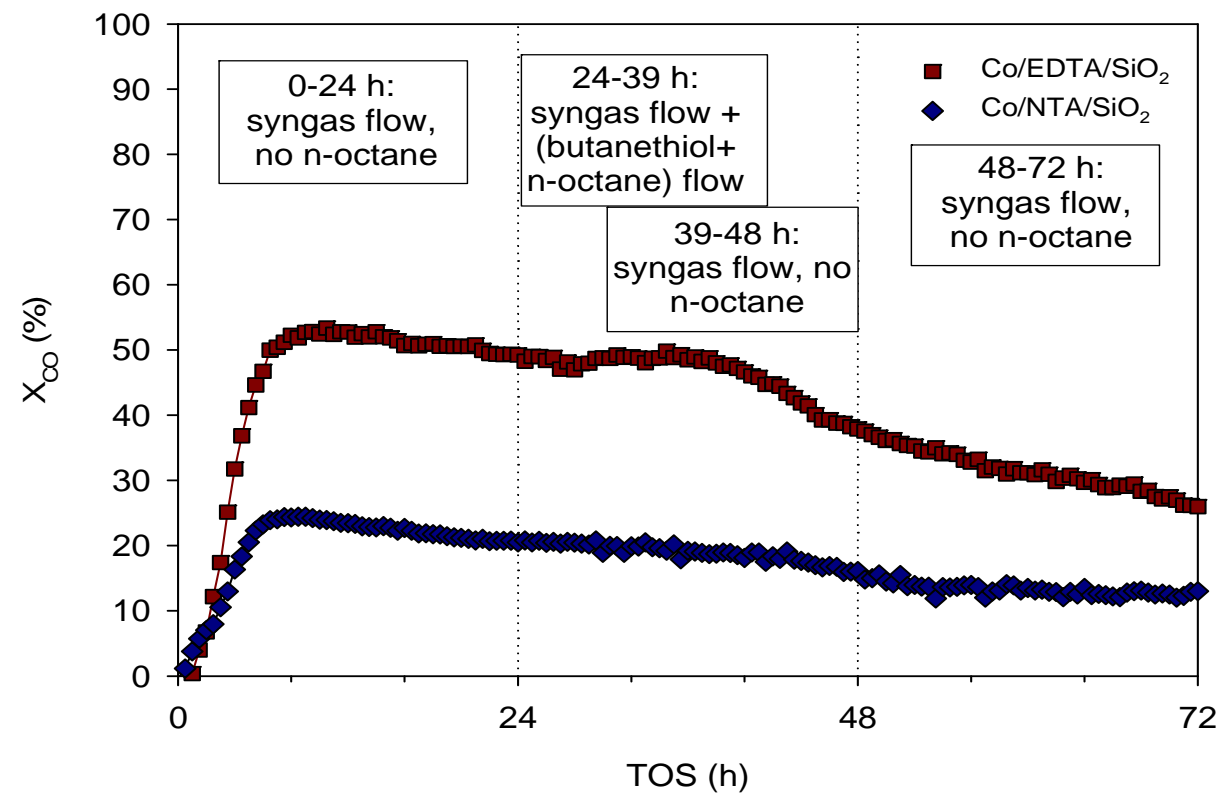

Figure $8.7 \mathrm{CO}$ conversion data for $\mathrm{Co} / \mathrm{EDTA} / \mathrm{SiO}_{2}$ and $\mathrm{Co} / \mathrm{NTA} / \mathrm{SiO}_{2}$ catalyst in presence of 10 ppm sulfur

(Experimental conditions: $\mathrm{T}=230^{\circ} \mathrm{C} ; \mathrm{P}=20$ bar; $\mathrm{GHSV}=13,500 \mathrm{sccm} / \mathrm{h} / \mathrm{g}_{\text {cat }}$ )

The behaviors of the NTA- and EDTA-modified catalyst are also compared in the presence and absence of sulfur in Figure 8.8. It must be noted that the runs in the absence of sulfur for both the catalysts were performed at a space velocity of $9000 \mathrm{sccm} / \mathrm{h} / \mathrm{g}_{\text {cat, }}$, whereas a space velocity of $13,500 \mathrm{sccm} / \mathrm{h} / \mathrm{g}_{\mathrm{cat}}$ was used for the sulfur poisoning runs. This was due to the use of an additional MFC for separate gas cylinders during the poisoning study. The change in the space velocity accounts for the difference in the conversion during the first $24 \mathrm{~h}$ between Figure 8.8(a) and (b), and between Figure 8.8(c) and (d). The comparison is shown merely to understand the conversion trend for these catalysts in the absence of sulfur. 
In the case of $\mathrm{Co} / \mathrm{EDTA} / \mathrm{SiO}_{2}$, the average conversion drops from ca. $51 \%$ in the prepoisoning stage to ca. $46 \%$ in the poisoning stage. The conversion shows a further drop and reached to ca. $31 \%$ in the post-poisoning stage. The $\mathrm{Co} / \mathrm{NTA} / \mathrm{SiO}_{2}$ catalyst, on the other hand, shows ca. $23 \%$ conversion during the poisoning stage with a drop of $3 \%$ from the prepoisoning stage. The conversion further drops to ca. $13 \%$ in the post-poisoning stage.

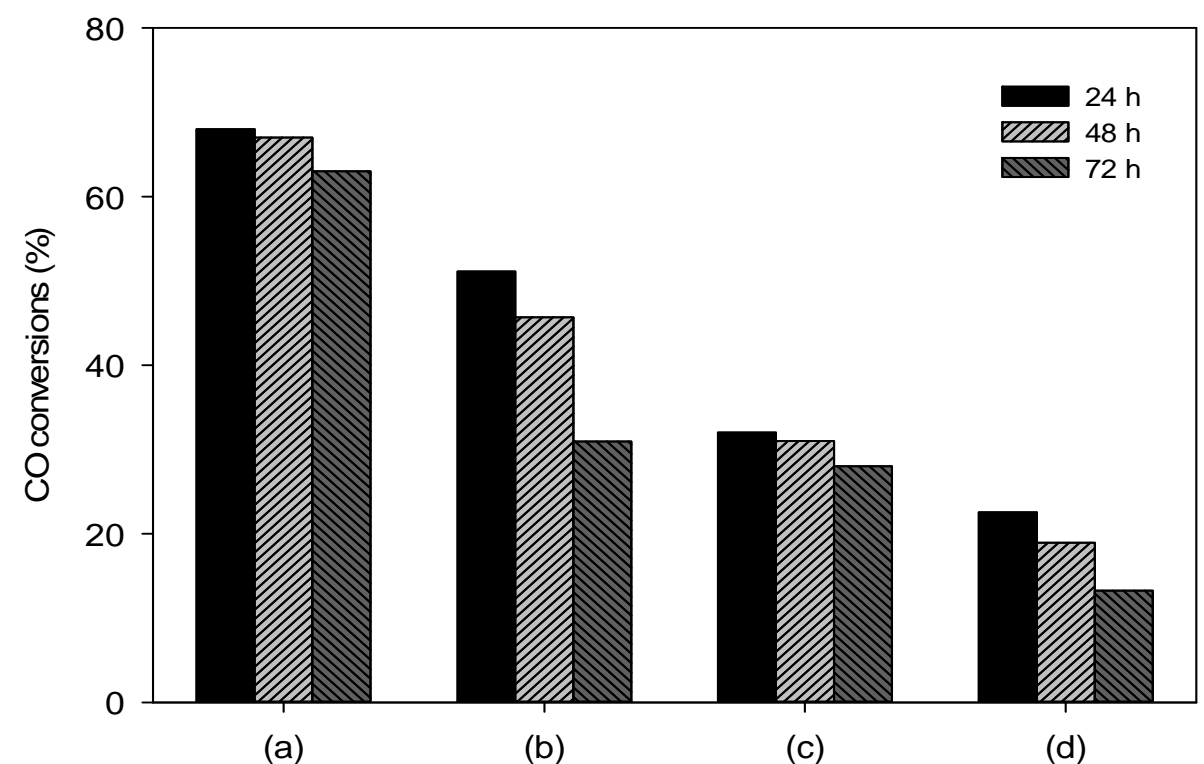

Figure $8.8 \mathrm{CO}$ conversions data for CA-modified catalyst: (a) Co/EDTA/SiO ${ }_{2}$ at $\mathrm{GHSV}=9000$ $\mathrm{sccm} / \mathrm{h} / \mathrm{g}_{\mathrm{cat}}$ and no S, (b) Co/EDTA $/ \mathrm{SiO}_{2}$ at GHSV $=13,500 \mathrm{sccm} / \mathrm{h} / \mathrm{g}_{\mathrm{cat}}$ with $10 \mathrm{ppmv} \mathrm{S}$ equivalent, (c) $\mathrm{Co} / \mathrm{NTA} / \mathrm{SiO}_{2}$ at $\mathrm{GHSV}=9000 \mathrm{sccm} / \mathrm{h} / \mathrm{g}_{\mathrm{cat}}$ and no $\mathrm{S}$, and (d) $\mathrm{Co} / \mathrm{NTA} / \mathrm{SiO}_{2}$ at GHSV $=13,500 \mathrm{sccm} / \mathrm{h} / \mathrm{g}_{\text {cat }}$ with $10 \mathrm{ppmv} S$ equivalent (Experimental conditions: $\mathrm{T}=230^{\circ} \mathrm{C} ; \mathrm{P}=20$ bar)

\subsubsection{Reaction Rates, TOF and Percent Site Lost due to Poisoning}

The average reaction rates calculated for the pre-poisoning, poisoning and postpoisoning stages are compared in Table 8.2. In addition, the values TOF for all the catalysts are listed for pre-poisoning stage in Table 8.2. For the poisoning and the post-poisoning stage, the percent sites lost due to sulfur are calculated relative to TOF values in the pre-poisoning stage on percent basis. 
Table 8.2 Reaction rates, TOF and percent sites lost by poisoning of cobalt catalysts

\begin{tabular}{|c|c|c|c|c|c|c|c|c|}
\hline & \multicolumn{3}{|c|}{ Reaction Rate $\left(\mathbf{m o l} / \mathbf{h} / g_{\text {cat }}\right)$} & \multicolumn{3}{c|}{ TOF (s ${ }^{-1}$ ) } & \multicolumn{2}{c|}{ \% Sites lost by poisoning } \\
\cline { 2 - 9 } & $0-24 \mathrm{~h}$ & $24-48 \mathrm{~h}$ & $48-72 \mathrm{~h}$ & $0-24 \mathrm{~h}$ & $24-48 \mathrm{~h}$ & $48-72 \mathrm{~h}$ & $24-48 \mathrm{~h}$ & $48-72 \mathrm{~h}$ \\
\hline $\mathrm{Co} / \mathrm{SiO}_{2} ;$ normal run & 0.039 & 0.035 & 0.033 & 0.0106 & 0.0102 & 0.0099 & 3.6 & 6.5 \\
\hline $\mathrm{Co} / \mathrm{SiO}_{2} ; \mathrm{n}$-octane run & 0.035 & 0.033 & 0.033 & 0.0102 & 0.0098 & 0.0097 & 3.7 & 4.6 \\
\hline $\mathrm{Co} / \mathrm{SiO}_{2} ; 10 \mathrm{ppm} \mathrm{S}$ & 0.037 & 0.028 & 0.009 & 0.0110 & 0.0083 & 0.0025 & 24.2 & 77.1 \\
\hline $\mathrm{Co} / \mathrm{SiO}_{2} ; 50 \mathrm{ppm} \mathrm{S}$ & 0.033 & 0.026 & 0.002 & 0.0098 & 0.0078 & 0.0005 & 20.5 & 95.1 \\
\hline $\mathrm{Co} / \mathrm{EDTA} / \mathrm{SiO}_{2} ; 10 \mathrm{ppm} \mathrm{S}$ & 0.098 & 0.087 & 0.059 & 0.0130 & 0.0116 & 0.0078 & 10.6 & 39.5 \\
\hline $\mathrm{Co} / \mathrm{NTA} / \mathrm{SiO}_{2} ; 10 \mathrm{ppm} \mathrm{S}$ & 0.043 & 0.036 & 0.025 & 0.0059 & 0.0049 & 0.0034 & 16.1 & 41.2 \\
\hline
\end{tabular}


For the "normal" run, the reaction rate drops by $15.4 \%$ during $72 \mathrm{~h}$ TOS. In the case of the n-octane run, the reaction rate drops only by $5.7 \%$ during $72 \mathrm{~h}$ TOS. In the presence of 10 ppm sulfur, due to the poisoning effect, the rate drops by $24.3 \%$ in the poisoning stage and further drops by $75.7 \%$ (relative to the initial rate) in the post-poisoning stage. The rate drop is even more significant in the presence of $50 \mathrm{ppm}$ sulfur. The rate drops by $21.2 \%$ in the poisoning stage and drops further by as high as $93.9 \%$ (relative to the initial rate) in the postpoisoning stage, indicating the extent of poisoning. For the EDTA-modified catalyst, the extents of rate drop are relatively smaller; $11.2 \%$ in the poisoning stage and $39.8 \%$ in the postpoisoning stage (relative to the initial rate). In the case of the NTA-modified catalyst, the rate drops by $16.3 \%$ in the poisoning stage and drops further by $41.9 \%$ (relative to the initial rate) in the post-poisoning stage. It is evident that the post-poisoning reaction rates of the CAmodified catalysts are higher than that of the base catalyst.

In the poisoning stage for the base catalyst, the $10 \mathrm{ppm}$ sulfur results in $24.2 \%$ drop in TOF values, whereas the 50 ppm results in $20.5 \%$ drop in TOF. Further, in the post-poisoning stage, $95.1 \%$ drop in TOF values suggest most of the active sites are poisoned due to sulfur. In case of the CA-modified catalyst, 10 ppm sulfur results in ca. $40 \%$ drop in the TOF values.

\subsubsection{Discussion}

For both 10 and $50 \mathrm{ppm}$ sulfur in the feed, the $\mathrm{Co} / \mathrm{SiO}_{2}$ catalyst shows irreversible poisoning and a significant drop in the CO conversions. This suggests that the sulfur poisoning decreases the adsorption of reactants on the active sites of the catalyst, as evident by drop in TOF. In the post-poisoning stages, the catalyst does not recover from its lost activity during poisoning. Therefore, the organic sulfur adsorbs irreversibly on the catalyst and causes permanent loss in the number of active sites and in the activity of cobalt catalyst. However, the observed trend of permanent loss in activity may be opposite to other studies. For example, the sulfur poisoning studies by Borg et al. ${ }^{107}$ show a slight positive step increase in the catalyst activity after removal of sulfur from the inlet. The work of Pansare and Allison ${ }^{69}$ suggests that $50 \mathrm{ppb}$ of sulfur may be the limiting concentration in syngas, with sulfur starting to have a having detrimental effect above this value. 
Sulfur molecules are known to adsorb strongly on the active metal sites with stoichiometry values (ratio of $S$ to metal) from 0.5 to as high as $3^{108}$. Therefore, even small levels of sulfur can markedly affect the catalyst performance. The performances of the CAmodified catalysts during the poisoning and post-poisoning stages are clearly superior to that of the base-case cobalt catalyst (within TOS, 72 h), even in the absence of sulfur. The physical characterizations of the fresh CA-modified catalysts show the existence of a well-dispersed cobalt phase and a larger number of catalytic sites, relative to the base case. The interaction of sulfur with catalytic sites results in a loss of activity for those specific sites. However, due to the availability of a larger number of catalytic sites, the CO-hydrogenation reactions can still proceed on the un-poisoned sites. Therefore, a well-dispersed phase may be the reason for the higher activity of CA-modified catalysts.

The evaluation of product selectivities, presented below, is expected to provide further insights into the sulfur susceptibilities of cobalt catalyst.

\subsection{Effect of Sulfur Poisoning on Product Selectivities}

\subsubsection{Hydrocarbon Selectivity of the Base Catalyst}

During the FT process, products containing $C_{1}$ to $C_{5}$ hydrocarbons appear in the gaseous form, and those above $C_{5}$ hydrocarbon are condensed. The overall hydrocarbon selectivities for base case catalysts are listed in Table 8.3 in lumps $C_{1}, C_{2}-C_{5}, C_{5+}$ and $C_{10}-C_{20}$ (FT diesel, a subset of $\mathrm{C}_{5+}$ ). The results are compared based on the changes in the selectivity among the prepoisoning, poisoning and post-poisoning stages. The results from the "normal" run and the noctane run are presented for the purpose of comparison. It must be remembered that there is no sulfur addition for the "normal" run and the n-octane run. 
Table 8.3 Overall HC selectivity of cobalt catalyst for different sulfur concentration

\begin{tabular}{|c|c|c|c|c|c|c|c|c|c|c|c|c|}
\hline & \multicolumn{3}{|c|}{$\mathrm{Co} / \mathrm{SiO}_{2}$; normal run } & \multicolumn{3}{|c|}{$\mathrm{Co} / \mathrm{SiO}_{2} ;$ n-octane } & \multicolumn{3}{|c|}{$\mathrm{Co} / \mathrm{SiO}_{2} ; 10$ ppm S } & \multicolumn{3}{|c|}{$\mathrm{Co} / \mathrm{SiO}_{2} ; 50$ ppm S } \\
\hline Selectivity \% & $0-24 h$ & $24-48 h$ & $48-72 \mathrm{~h}$ & $0-24 h$ & $24-48 h$ & $48-72 \mathrm{~h}$ & $0-24 h$ & $24-48 h$ & $48-72 \mathrm{~h}$ & $0-24 h$ & $24-48 \mathrm{~h}$ & $48-72 \mathrm{~h}$ \\
\hline $\mathrm{C}_{1}$ & 21.5 & 22.8 & 22.0 & 15.8 & 22.4 & 22.2 & 13.9 & 21.0 & 31.4 & 11.8 & 18.5 & 25.6 \\
\hline $\mathrm{C}_{2}-\mathrm{C}_{5}$ & 12.6 & 14.5 & 14.0 & 8.3 & 12.7 & 14.2 & 11.8 & 12.3 & 13.7 & 11.1 & 8.0 & 41.0 \\
\hline $\mathrm{C}_{5+}$ & 65.9 & 62.7 & 64.0 & 75.9 & 64.9 & 63.6 & 74.3 & 66.7 & 54.9 & 77.1 & 73.5 & 33.4 \\
\hline $\begin{array}{c}\text { FT Diesel } \\
\mathrm{C}_{10}-\mathrm{C}_{20}\end{array}$ & 47.5 & 42.5 & 44.5 & 54.5 & 41.2 & 37.7 & 59.4 & 46.1 & 34.1 & 53.3 & 52.9 & 0.0 \\
\hline
\end{tabular}


For the "normal" run, in the first $24 \mathrm{~h}$ TOS, the catalyst shows selectivity of $21.5 \%$ towards $C_{1}, 12.6 \%$ towards $C_{2}-C_{5}$ and $65.9 \%$ towards $C_{5+}$. In the next $24 \mathrm{~h}$, the selectivity toward $\mathrm{C}_{1}$ and $\mathrm{C}_{2}-\mathrm{C}_{5}$ slightly increases to $22.8 \%$ and $14.5 \%$, respectively. On the other hand, the $\mathrm{C}_{5+}$ selectivity drops to $62.7 \%$. In the last $24 \mathrm{~h}$ of TOS, the change in product selectivity is insignificant. Furthermore, the selectivity towards the $C_{10}-C_{20}$ fraction drops initially from 47.5 $\%$ to $42.5 \%$, and reaches $44.5 \%$ towards the end. For the n-octane run, the selectivities of $C_{1}$ and $\mathrm{C}_{2}-\mathrm{C}_{5}$ in the first $24 \mathrm{~h}$ are lower compared to the normal run. However, during the 24-48 $\mathrm{h}$ interval, the selectivities of $\mathrm{C}_{1}, \mathrm{C}_{2}-\mathrm{C}_{5}$ and $\mathrm{C}_{5+}$ selectivities are $22.4 \%, 12.7 \%$ and $64.9 \%$, respectively; which are comparable to the selectivities observed under the "normal" run in the same period. Further, for the n-octane run during 48-72 h TOS, the $C_{1}, C_{2}-C_{5}$, and $C_{5+}$ selectivities do not show any significant changes from the $24-48 \mathrm{~h}$ interval.

For a run with the $10 \mathrm{ppm}$ sulfur in the inlet, the selectivities of $C_{1}$ and $C_{2}-C_{5}$ in the poisoning stage are higher compared to those in the pre-poisoning stage. The poisoning-stage selectivity toward $\mathrm{C}_{5+}$ also drops from the pre-poisoning stage value. As mentioned earlier, the sulfur injection is terminated before the start of post-poisoning stage. Therefore, during the post-poisoning period, the FT catalyst should encounters only pure syngas. Interestingly, in the post-poisoning, the $C_{1}$ and $C_{2}-C_{5}$ selectivities continue to increase. The increased selectivity towards lower hydrocarbons also means a drop in the selectivity for $\mathrm{C}_{5+}$ hydrocarbons. The selectivity for $\mathrm{C}_{10}-\mathrm{C}_{20}$ progressively drops from the pre-poisoning stage to the post-poisoning stage.

For $50 \mathrm{ppm}$ sulfur in the inlet, the trends in the selectivity change are mostly similar to the case of 10 ppm sulfur. The $C_{1}$ selectivity increases from $11.8 \%$ in the pre-poisoning stage to $18.5 \%$, in the poisoning stage. On the other hand, the $C_{2}-C_{5}$ selectivity drops from $11.1 \%$ to $8.0 \%$ in the poisoning stage. The $\mathrm{C}_{5+}$ selectivity also drops in the poisoning stage. The $\mathrm{C}_{10^{-}}$ $\mathrm{C}_{20}$ selectivity, however, drops only marginally in the poisoning stage. During the postpoisoning stage, the $C_{1}$ selectivity further increases to $25.6 \%$ and $C_{2}-C_{5}$ increases to $41 \%$. The $\mathrm{C}_{5+}$ selectivity drops to an even lower value of $33.4 \%$. The $\mathrm{C}_{10}-\mathrm{C}_{20}$ selectivity is severely affected by the sulfur poisoning and completely disappears in the post-poisoning stage. 
In general, due to the presence of the sulfur impurities in the inlet, the catalyst poisoning results in a shift in the product selectivities. In both the poisoning and the postpoisoning stages, the product selectivities shift towards short-chain hydrocarbons; with an equivalent drop in the $C_{5+}$ selectivity. The $C_{10}-C_{20}$ selectivity also drops due to sulfur poisoning. Therefore, the sulfur poisoning can be said to have caused undesired shifts in the product selectivity. In addition, even after removal of the inlet sulfur in the post-poisoning stage, the trend in product selectivity does not show signs of approaching the initial selectivity observed during the pre-poisoning stage. Therefore, as the catalyst fails to recover from its lost selectivity, the sulfur poisoning can be said to have resulted in the permanent loss in the catalyst selectivity.

\subsubsection{Hydrocarbon Selectivity of the CA-modified Catalysts}

The hydrocarbon selectivities of the CA-modified catalysts in the presence of $10 \mathrm{ppm}$ sulfur are compared in Table 8.4. For the EDTA-modified catalyst, the $C_{1}$ selectivity in the poisoning stage increases to $21.3 \%$ from the $15.8 \%$ in the pre-poisoning stage. Also, the $\mathrm{C}_{2^{-}}$ $C_{5}$ selectivity increases to $18.4 \%$ in the poisoning stage. Further, the $C_{5+}$ as well as $C_{10}-C_{20}$ selectivity drops during the poisoning stage. Similarly, for the case of the NTA-modified catalyst, the selectivity towards $C_{1}$ and $C_{2}-C_{5}$ increases in the poisoning stage, whereas the selectivity towards $\mathrm{C}_{5+}$ drops in the poisoning stage. The trend in the selectivity shifts for the poisoning stage is nearly similar to the one observed for the base catalyst at 10 and $50 \mathrm{ppm}$ sulfur. In the post-poisoning stage, for the EDTA-modified catalyst, the $C_{1}$ and $C_{2}-C_{5}$ selectivities drop to $20.7 \%$ and $13.0 \%$, respectively. On the other hand, the $\mathrm{C}_{5+}$ selectivity improves to $66.3 \%$ in the post-poisoning stage. In the case of the NTA-modified catalyst, the selectivities of $C_{1}, C_{2}-C_{5}$, and $C_{5+}$ are comparable in both the poisoning and the post-poisoning stage. In addition, for both the CA-modified catalysts, the $\mathrm{C}_{10}-\mathrm{C}_{20}$ selectivities improve in the post-poisoning stage from that of the poisoning stage. 
Table 8.4 HC Selectivity for the CA-modified catalysts in the presence of $10 \mathrm{ppm}$ sulfur

\begin{tabular}{|c|c|c|c|c|c|c|c|c|c|}
\hline & \multicolumn{3}{|c|}{ Co/SiO } & \multicolumn{3}{c|}{ Co/EDTA/SiO } & \multicolumn{3}{c|}{ Co/NTA/SiO } \\
\hline
\end{tabular}


It is noteworthy that the selectivity trend in the post-poisoning stage shown by the CA-modified catalyst is opposite to the trend observed for the base-case catalyst. For CAmodified catalysts, the selectivity towards higher hydrocarbon in the post-poisoning stage either slightly improves or steadies near the poisoning values, opposite to the trend observed for the base catalyst. It must be further noted that, even in the post-poisoning stage, the selectivity towards higher hydrocarbons is still low compared to the one in the pre-poisoning stage. It is therefore clear that, even for the CA-modified catalysts, similar to the base catalyst, the sulfur poisoning results in a permanent drop in selectivity towards higher hydrocarbon and an increase in the selectivity for lower hydrocarbons. In the context of selectivity towards higher hydrocarbons, the post-poisoning performance of the CA-modified catalysts is clearly superior in comparison to the base catalyst.

\subsection{3 $\mathrm{CO}_{2}$ Selectivity of the Base Catalyst}

The $\mathrm{CO}_{2}$ selectivity of the base catalyst in the presence of the sulfur impurities is shown in Figure 8.9. For the "normal" run, the $\mathrm{CO}_{2}$ selectivity in the first $24 \mathrm{~h}$ TOS is $13 \%$; it drops to $12.2 \%$ in the next $24 \mathrm{~h}$ and finally reaches $11.2 \%$ in the last $24 \mathrm{~h}$. Similarly for the $\mathrm{n}$ octane run, the $\mathrm{CO}_{2}$ selectivity starts with $13.7 \%$, slightly higher than the normal run; it drops to $13 \%$ in the next $24 \mathrm{~h}$ and finally reaches $12.5 \%$ in the last $24 \mathrm{~h}$.

In the presence of $10 \mathrm{ppm}$ sulfur, the $\mathrm{CO}_{2}$ selectivity in the poisoning stage increases to $12.9 \%$ from that of $11.2 \%$ in the pre-poisoning stage. The $\mathrm{CO}_{2}$ selectivity further increases to $15.5 \%$ in the post-poisoning stage. In the case of $50 \mathrm{ppm}$ sulfur, the $\mathrm{CO}_{2}$ selectivity increases from $10.9 \%$ in the pre-poisoning stage to $13.0 \%$ in the poisoning stage. However, the selectivity drops to $11.9 \%$ in the post-poisoning stage, opposite to the trend observed in earlier cases. The difference can be attributed to the error in GC measurement at very low CO conversions in the post-poisoning stage for the $50 \mathrm{ppm}$ case. 


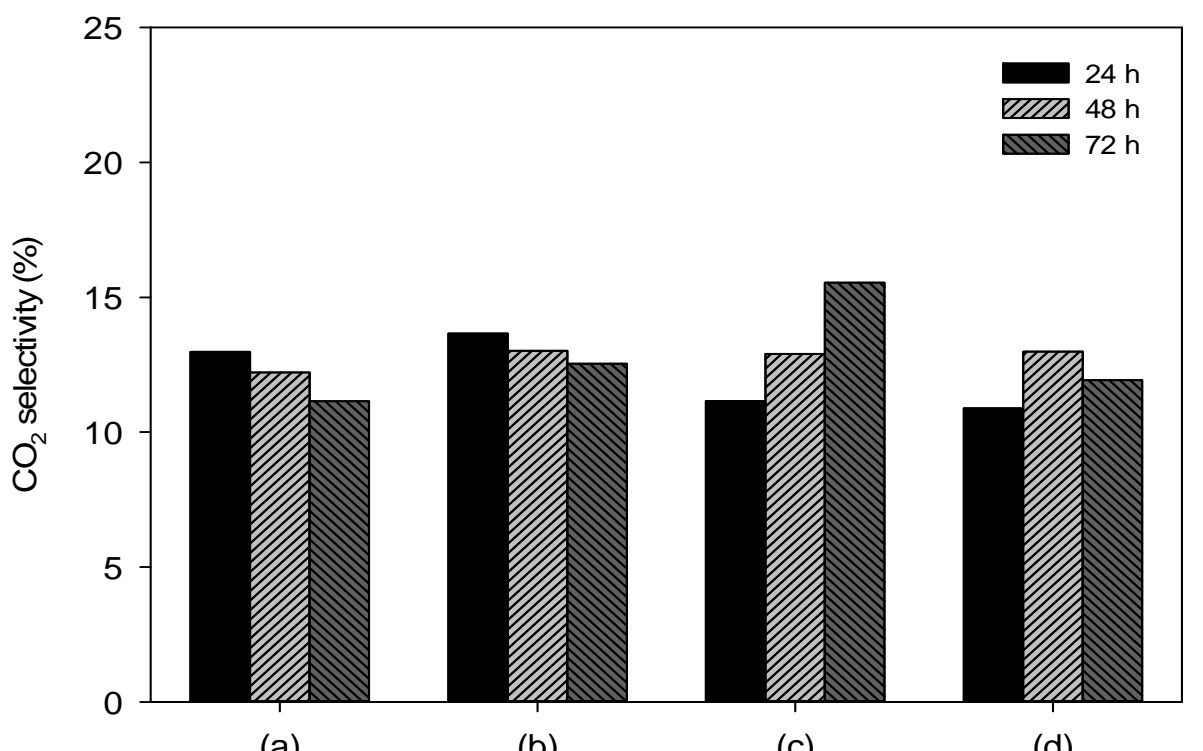

(a)

(b)

(c)

(d)

Figure $8.9 \mathrm{CO}_{2}$ selectivity for the $\mathrm{Co} / \mathrm{SiO}_{2}$ catalyst with different inlet: (a) "normal" run with syngas feed, (b) run with syngas and n-octane feed, (c) syngas with 10 ppmv S equivalent, and (d) syngas with 50 ppmv $S$ equivalent

(Experimental conditions: $\mathrm{T}, 230^{\circ} \mathrm{C} ; \mathrm{P}, 20$ bar and syngas $\mathrm{SV}, 13,500 \mathrm{sccm} / \mathrm{h} / \mathrm{g}_{\text {cat }}$ )

\subsection{4 $\mathrm{CO}_{2}$ Selectivity of the CA-modified Catalysts}

The $\mathrm{CO}_{2}$ selectivities of the CA-modified catalyst in the presence of the $10 \mathrm{ppm}$ sulfur impurity are compared in Figure 8.10. For the EDTA-modified catalyst, the pre-poisoning $\mathrm{CO}_{2}$ selectivity of $14.9 \%$ increases to $16.1 \%$ in the poisoning stage. The selectivity reaches $18.0 \%$ in the post-poisoning stage. In the case of the NTA-modified catalyst, similar to the EDTAmodified catalyst, the selectivity starts at $9.6 \%$, increases to $10.3 \%$ in the poisoning stage and finally reaches $11.3 \%$ in the post-poisoning stage.

In general, due to the presence of inlet sulfur, the $\mathrm{CO}_{2}$ selectivity for the CA-modified catalysts increases both in the poisoning and the post-poisoning stage. The observed shifts in the in the $\mathrm{CO}_{2}$ selectivity trends due to sulfur poisoning are similar for the base catalyst as well as the CA-modified catalyst. 


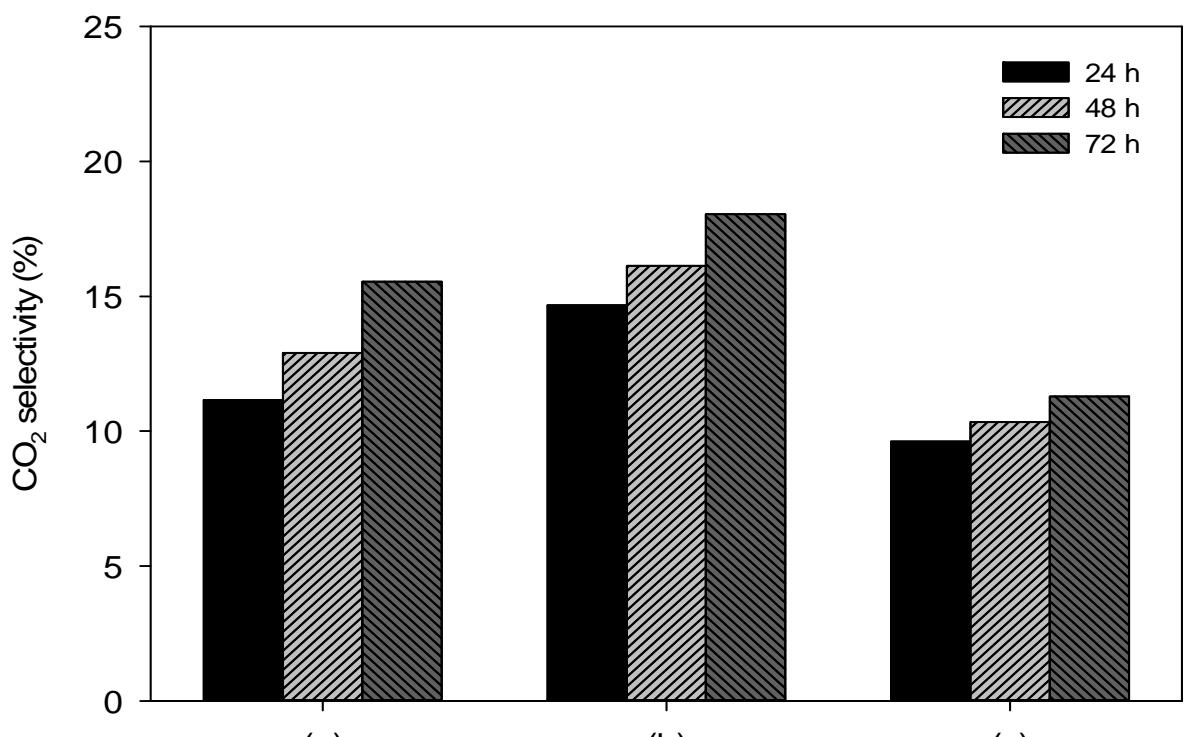

(a)

(b)

(c)

Figure $8.10 \mathrm{CO}_{2}$ selectivity for the catalyst in the presence of $10 \mathrm{ppmv} \mathrm{S}$ equivalent: (a) $\mathrm{Co} / \mathrm{SiO}_{2}$ catalyst, (b) $\mathrm{Co} / \mathrm{EDTA} / \mathrm{SiO}_{2}$ catalyst, and (c) $\mathrm{Co} / \mathrm{NTA} / \mathrm{SiO}_{2}$ catalyst (Experimental conditions: $\mathrm{T}, 230^{\circ} \mathrm{C} ; \mathrm{P}, 20$ bar and syngas SV, 13,500 sccm/h/g $/ \mathrm{g}_{\text {cat }}$ )

\subsubsection{Discussion}

Madon and Shaw ${ }^{63}$ have presented a detailed review of the sulfur effect on FT catalyst. Low concentrations of $\mathrm{H}_{2} \mathrm{~S}$ and $\mathrm{CS}_{2}$ have been reported to have a promotional effect on the FT catalysts. Such species are said to have a beneficial effect on the catalyst lifetime and the selectivity towards hydrocarbons. For example, Anderson et al. ${ }^{71}$ report higher wax and lower gasoline contents in the products for the sulfur-poisoned catalyst than the unpoisoned catalyst. For pre-poisoned $\mathrm{Co} / \mathrm{TiO}_{2}$ catalysts, $\mathrm{Li}$ and Coville ${ }^{57}$ have reported no change in the activity and selectivity upto 200 ppm S, while 500 ppm S results in a significant drop in activity. However, in the present investigations, within the impurity range studied, no such beneficial effects are observed. In contrast, the sulfur impurity is found to have caused an undesired effect as it results in the drop in CO conversion and shifts the product selectivity towards short-chain hydrocarbons.

The adsorption phenomenon of the organic sulfur (e.g., C-S) and the inorganic sulfur (e.g., $\mathrm{H}_{2} \mathrm{~S}$ ) may be significantly different and must be realized while drawing any parallel conclusions. In some cases ${ }^{63,64,71}, \mathrm{H}_{2} \mathrm{~S}$ interactions with the FT catalyst have been proposed to 
form new catalytically active surface sites leading to the enhanced activity. However, the present study, with organic sulfur, contradicts any favorable changes in the activity.

Sulfur impurities present in the syngas have been reported to block the catalytic sites physically and possibly to cause the electronic modification of the neighboring sites ${ }^{67,99,108}$. Sulfur interaction with active metal to form new catalytic sites on the surface can also lead to enhanced activity. Therefore, for the cobalt catalyst in this study, poisoning by the organic sulfur in the form of butanethiol appears more like a physical blockage of sites than an electronic modification.

It is also possible that the physical blocking of the catalytic sites by the sulfur can further induce diffusion limitations to certain extent. Therefore, besides influencing the catalytic activity, additional diffusion limitations caused due to sulfur poison can also alter the product selectivity. In fact, it has also been reported ${ }^{109}$ that the sulfur atom adsorbed on alumina-supported cobalt catalyst poisons more than two cobalt atoms. Therefore, it is possible that a small concentration of sulfur can potentially cover a significant numbers of sites on the surface of the catalyst, leading to diffusion limitations. Consequently, such limitations on the transport processes could limit the readsoprtion probabilities of the reaction intermediates and may eventually cause shifts in the product selectivities.

It is also evident from the shifts in the hydrocarbon selectivities that the sulfur decreases the ability of the catalyst to form C-C bonds to produce longer-chain hydrocarbons. Zhao-Tie et al. ${ }^{70}$ have reported that, due to sulfur poisoning in the form of COS for iron catalyst, the fraction of $\mathrm{C}_{1}$ and $\mathrm{C}_{2}-\mathrm{C}_{4}$ hydrocarbons in the product increases, while decreasing the $\mathrm{C}_{5+}$ fraction. The work clearly suggests the shift in product distribution to favor lighter hydrocarbons. In another study, Curtis et al. ${ }^{65}$ have reported that sulfur inhibits CO adsorption onto the surface of Co catalysts for all sulfur concentrations studied (100-200 ppm). This may be because of site blockage and/or inhibited reduction due to the sulfur poison on the pre-sulfided catalysts. Likewise, in the present work of in-situ poisoning, physical blockage by sulfur can be considered to have resulted in reduced $\mathrm{CO}$ adsorption on the Co catalysts. It is also evident that, both the sites responsible for $\mathrm{CO}$ adsorptions as well as the sites for chain growth processes are poisoned in the in-situ poisoning experiment. 
The CA-modified catalysts show relatively better performance compared to the base catalyst in the poisoning and the post-poisoning stage. The higher activity of the CA-modified catalysts can be attributed to the greater availability of the accessible catalyst sites. The higher readsorption probability of the reaction intermediates on these highly dispersed catalysts can lead to the formation of longer-chain hydrocarbons. The higher $\mathrm{C}_{5+}$ selectivities of CA-modified catalysts in the post-poisoning stage also suggest that the sites responsible for the polymerization of the adsorbed intermediate are still present in sufficient numbers even after the sulfur poisoning.

The trends observed here for $\mathrm{CO}_{2}$ selectivity are similar to those previously reported. Visconti et al. ${ }^{68}$ have reported increased $\mathrm{CO}_{2}$ selectivity for $\mathrm{Co} / \mathrm{Al}_{2} \mathrm{O}_{3}$ catalyst due to sulfur poisoning. According to Zhao-Tie et al. ${ }^{70}$, WGS is enhanced for iron catalyst during initial stages of COS poisoning. According to Madon and Shaw ${ }^{63}$, the sulfur poison may influence consumption of CO via the WGS (Eq.3, Table 2.1) or the Boudouard reaction (Eq.7, Table 2.1), leading to the formation of $\mathrm{CO}_{2}$. However, the direct poisoning effect of sulfur on to enhance $\mathrm{CO}_{2}$ selectivity is not entirely clear. Sulfur poisoning on the cobalt catalyst may be expected to increase the number of sites responsible for WGSR and/or Boudouard reaction. At this point, there is no concrete proof to support this argument.

In the present study, the interaction between sulfur and the FT metal is explained based on the observed changes in the activity and the product selectivity. The real-time observation of microstructural changes due to interaction between organic sulfur and cobalt is challenging, but can be effective if used to gain a clear understanding of the observed changes.

\subsection{Effect of Sulfur Poisoning on the Product Yield and Distribution}

After evaluating the poisoning effect on the activity and the selectivity, the product yields of different catalysts are compared. The total product yield is calculated by adding the rates of formation of paraffins, olefins and alcohols in the product on a $\mathrm{gC} / \mathrm{kg}_{\text {cat }} / \mathrm{h}$ basis. In addition, the percent product distribution is calculated from the contribution of paraffin, olefin and alcohol yields. The results are discussed in the following sections. 


\subsubsection{Product Yield and Percent Product Distribution of the Base Catalyst}

The product yields and the percent product distributions for the base catalyst are compared in Table 8.5, for different levels of sulfur concentrations. For the "normal" run, in the first $24 \mathrm{~h}$ of TOS, the product yield of base catalyst contains $242.4 \mathrm{gC}$ of paraffin, $24.7 \mathrm{gC}$ of olefins and $9.9 \mathrm{gC}$ of alcohols; the total product yield, therefore, is $277 \mathrm{gC}$. The total product yield slightly drops to $274.8 \mathrm{gC}$ in the next $24 \mathrm{~h}$, and finally reaches $262.5 \mathrm{gC}$ in the last $24 \mathrm{~h}$. Similarly, for the n-octane run, the total product yield initially is $279.2 \mathrm{gC}$, drops marginally to $259.6 \mathrm{gC}$ in the next $24 \mathrm{~h}$, and finally drops to $248.6 \mathrm{gC}$ in the last $24 \mathrm{~h}$. As expected, the paraffin yield, compared to olefins and alcohol yields, of cobalt catalysts is the highest throughout the $72 \mathrm{~h}$ TOS.

In the presence of $10 \mathrm{ppm}$ sulfur, during the poisoning stage, the paraffin yield drops from $247.4 \mathrm{gC}$ to $137.2 \mathrm{gC}$. The olefin yield is also suppressed due to poisoning. However, alcohol yield increases during the poisoning stage. The total product yield during the poisoning stage is $179.9 \mathrm{gC}$, with a drop of $36.7 \%$. In the post-poisoning stage, the paraffin yield is only $21.6 \mathrm{gC}$, suggesting the severity of the poisoning. Both the olefin yields and the alcohol yield drop in the post-poisoning as well. The total product yield drops by another 79.9 $\%$ and is noted to be $36.1 \mathrm{gC}$. It is evident that even $10 \mathrm{ppm}$ sulfur can greatly suppress the product yields of cobalt catalyst due to severe poisoning.

For $50 \mathrm{ppm}$ inlet sulfur, the total product yield drops from $269.7 \mathrm{gC}$ in the prepoisoning stage to $191.5 \mathrm{gC}$ in the poisoning stage. The paraffin yield and the olefin yield drop, whereas the alcohol yield increases in the poisoning stage. Further, in the postpoisoning stage, the total product yield is merely $0.2 \mathrm{gC}$ dropping by $99.9 \%$. The extent of drop in the product yield clearly suggests that the sulfur, even at such low concentrations, can lead to extensive loss of the catalyst productivity. 
Table 8.5 Summary of the product yield and the product distribution of $\mathrm{Co} / \mathrm{SiO}_{2}$ catalyst under different sulfur concentrations

\begin{tabular}{|c|c|c|c|c|c|c|c|c|c|c|c|c|}
\hline & \multicolumn{3}{|c|}{$\mathrm{Co} / \mathrm{SiO}_{2}$; normal run } & \multicolumn{3}{|c|}{$\mathrm{Co} / \mathrm{SiO}_{2} ;$ n-octane } & \multicolumn{3}{|c|}{$\mathrm{Co} / \mathrm{SiO}_{2} ; 10$ ppm S } & \multicolumn{3}{|c|}{$\mathrm{Co} / \mathrm{SiO}_{2} ; 50$ ppm S } \\
\hline & $0-24$ & $24-48$ & $48-72$ & $0-24$ & $24-48$ & $48-72$ & $0-24$ & $24-48$ & $48-72$ & $0-24$ & $24-48$ & $48-72$ \\
\hline & $\mathrm{h}$ & $\mathrm{h}$ & $\mathrm{h}$ & $\mathrm{h}$ & $\mathrm{h}$ & $\mathrm{h}$ & $\mathrm{h}$ & $\mathrm{h}$ & $\mathrm{h}$ & $\mathrm{h}$ & $\mathrm{h}$ & $\mathrm{h}$ \\
\hline & \multicolumn{12}{|c|}{ Product Yield (gC/ $\left./ \mathrm{Kg}_{\text {cat }} / \mathrm{h}\right)$} \\
\hline Paraffin & 242.4 & 238.1 & 234.2 & 249.7 & 225.2 & 217.2 & 247.4 & 137.2 & 21.6 & 234.7 & 158.6 & 0.2 \\
\hline Olefin & 24.7 & 26.8 & 22.1 & 20.2 & 27.4 & 25.0 & 27.8 & 23.5 & 8.4 & 23.0 & 18.1 & 0.0 \\
\hline Alcohol & 9.9 & 9.9 & 8.1 & 9.2 & 7.0 & 6.4 & 8.8 & 19.2 & 6.1 & 12.0 & 14.8 & 0.0 \\
\hline \multirow[t]{2}{*}{ Total } & 277.0 & 274.8 & 262.5 & 279.1 & 259.6 & 248.6 & 284.0 & 179.9 & 36.1 & 269.7 & 191.5 & 0.2 \\
\hline & \multicolumn{12}{|c|}{ \% Product Distribution } \\
\hline Paraffin & 87.5 & 86.6 & 88.6 & 89.4 & 86.7 & 87.4 & 87.1 & 76.3 & 59.9 & 87.0 & 82.8 & 88.1 \\
\hline Olefin & 8.9 & 9.8 & 8.4 & 7.3 & 10.6 & 10.0 & 9.8 & 13.1 & 23.3 & 8.5 & 9.5 & 11.9 \\
\hline Alcohol & 3.6 & 3.6 & 3.0 & 3.3 & 2.7 & 2.6 & 3.1 & 10.7 & 16.8 & 4.4 & 7.7 & 0.0 \\
\hline
\end{tabular}


The percent product distribution provides a further interesting fact of the effect of catalyst poisoning. In the first $24 \mathrm{~h}$, the percent product distribution for the "normal" run includes $87.5 \%$, paraffins, $8.9 \%$ olefins and $3.6 \%$, alcohols. In the next $24 \mathrm{~h}$, the paraffin percent slightly drops and olefins percent in the product increases. In the last $24 \mathrm{~h}$, the paraffin percent increases slightly and olefin percent drops. However, the changes in the percent product distribution are relatively insignificant and the percent product distribution is considered to be comparable for $72 \mathrm{~h}$ TOS. Similar trends are observed for the case of the $\mathrm{n}$ octane run and smaller deviations in the percent product distribution can be neglected.

Interestingly, for $10 \mathrm{ppm}$ inlet sulfur, the paraffin percent drops from $87.1 \%$ in the prepoisoning stage to $76.3 \%$ in the poisoning stage. The olefin percent, on the other hand, increases from $9.8 \%$ in the pre-poisoning stage to $13.1 \%$ in the post-poisoning stage. Similarly, the alcohol percent also increases from $3.1 \%$ to $10.7 \%$. In the post-poisoning stage, the paraffin percent further drops to $59.9 \%$, whereas the olefin and alcohol percent increase to $23.3 \%$ and $16.8 \%$, respectively.

In the case of $50 \mathrm{ppm}$ sulfur, in the poisoning stage, the paraffin percent drop and the olefin and alcohol percent increase. The trends are consistent to the one observed for the 10 ppm case. In the post-poisoning stage, the catalyst productivity is insignificant.

Therefore, due to sulfur poisoning, it can be said that the paraffin percent in the product decreases, and the olefin and the alcohol percent increases.

\subsubsection{Product Yield and Percent Product Distribution of the CA-modified Catalysts}

The product yield and the percent product distribution of the CA-modified catalysts, in the presence of $10 \mathrm{ppm}$ sulfur, are compared in Table 8.6. The total product yields of the NTAmodified catalysts are larger than those of the base catalyst, in the poisoning as well as the post-poisoning stage, and the total product yields of the EDTA-modified catalyst are larger still. 
Table 8.6 Product yield and percent product distribution of CA-modified catalysts in the presence of $10 \mathrm{ppm}$ sulfur

\begin{tabular}{|c|c|c|c|c|c|c|c|c|c|}
\hline & \multicolumn{3}{|c|}{$\mathrm{Co} / \mathrm{SiO}_{2} ; 10$ ppm S } & \multicolumn{3}{|c|}{ Co/EDTA/SiO $2 ; 10$ ppm S } & \multicolumn{3}{|c|}{$\mathrm{Co} / \mathrm{NTA} / \mathrm{SiO}_{2} ; 10 \mathrm{ppm} \mathrm{S}$} \\
\hline & $\begin{array}{c}0-24 \\
h\end{array}$ & $\begin{array}{c}24-48 \\
h\end{array}$ & $\begin{array}{c}48-72 \\
h\end{array}$ & $\begin{array}{c}0-24 \\
h\end{array}$ & $\begin{array}{c}24-48 \\
h\end{array}$ & $\begin{array}{c}48-72 \\
h\end{array}$ & $\begin{array}{c}0-24 \\
h\end{array}$ & $\begin{array}{c}24-48 \\
h\end{array}$ & $\begin{array}{c}48-72 \\
\mathrm{~h}\end{array}$ \\
\hline & \multicolumn{9}{|c|}{ Product Yield (gC/ $\left./ \mathrm{Kg}_{\text {cat }} / \mathrm{h}\right)$} \\
\hline Paraffin & 247.4 & 137.2 & 21.6 & 735.7 & 567.8 & 379.9 & 365.7 & 255.6 & 195.4 \\
\hline Olefin & 27.8 & 23.5 & 8.4 & 79.4 & 139.5 & 140.4 & 26.1 & 21.9 & 8.5 \\
\hline Alcohol & 8.8 & 19.2 & 6.1 & 36.2 & 55.3 & 18.9 & 5.6 & 5.7 & 4.6 \\
\hline \multirow[t]{2}{*}{ Total } & 284.0 & 179.9 & 36.1 & 851.3 & 762.6 & 413.2 & 397.4 & 283.2 & 208.5 \\
\hline & \multicolumn{9}{|c|}{ \% Product Distribution } \\
\hline Paraffin & 87.1 & 76.3 & 59.9 & 86.4 & 74.5 & 70.5 & 92.0 & 90.3 & 93.7 \\
\hline Olefin & 9.8 & 13.1 & 23.3 & 9.3 & 18.3 & 26.0 & 6.6 & 7.7 & 4.1 \\
\hline Alcohol & 3.1 & 10.7 & 16.8 & 4.3 & 7.2 & 3.5 & 1.4 & 2.0 & 2.2 \\
\hline
\end{tabular}


The EDTA-modified catalyst shows the highest paraffin yield in the pre-poisoning stage. The value drops by ca. $22 \%$ in the poisoning stage to 568 gC, with a further drop of ca. $48.4 \%$ (relative to initial yield) during the post-poisoning stage to $379.9 \mathrm{gC}$. The NTA-modified catalyst follows the similar trend. During the poisoning stage, the paraffin yield drops by ca. $30 \%$, with another drop of ca. $46.6 \%$ in the post-poisoning stage. In general, the CA-modified catalysts display better paraffin yields in the poisoning and the post-poisoning stage than that of the base catalyst.

For the percent product distributions of the CA-modified catalysts, similar conclusions to the case of the base catalysts can be drawn. For the EDTA-modified catalyst, the paraffin percent in the product drops from $86.4 \%$ in the pre-poisoning stage to $74.5 \%$ during the poisoning period and further drops to $70.5 \%$ in the post-poisoning stage. The olefin percent increase from $9.3 \%$ in the pre-poisoning stage to $18.3 \%$ in the poisoning stage and further increases to $26.0 \%$ in the post-poisoning stage. The alcohol percent, however, increases from $4.3 \%$ in the pre-poisoning stage to $7.2 \%$ in the poisoning stage, but drops to $3.5 \%$ in the postpoisoning stage.

For the NTA-modified catalyst, the paraffin percent drops to $90.3 \%$ in the poisoning stage from that of $92.0 \%$ in the pre-poisoning stage, but increases to $93.7 \%$ in the postpoisoning stage. The olefin percent increase from $6.6 \%$ in the pre-poisoning stage to $7.7 \%$ in the poisoning stage, then drops to $4.1 \%$ in the post-poisoning stage. The alcohol contents progressively increase from $1.4 \%$ in the pre-poisoning stage to $2.0 \%$ in the poisoning stage and further to $2.2 \%$ in the post-poisoning stage. The trend for the NTA-modified catalyst in the post-poisoning stage is somewhat different from that of the other cases.

In general, the trends observed for the CA-modified catalysts in the presence of $10 \mathrm{ppm}$ sulfur are comparable to the trends observed for the base catalyst in the presence of 10 and 50 ppm sulfur. Therefore, the sulfur poisoning can be said to suppress the total product yield of the FT catalysts and to increase the olefins and the alcohols in the products.

\subsubsection{Discussion}

Different active sites on the same catalyst may catalyze different reactions in various ways. The sulfur compounds can preferentially adsorb on certain catalytic sites and can thus 
inhibit the reactions that normally occur on those sites. Therefore, the selective blocking of sulfur can alter the product distribution of FT synthesis. It is generally believed that the olefin appears in the FT products due to desorption of the reaction intermediates and incomplete hydrogenation ${ }^{110}$. In general, FT catalysts are comprised of the sites responsible for the solely of hydrogenation. The increase in the olefin content due to sulfur poisoning can be attributed to a drop in the hydrogenation ability of the catalysts. Bartholomew et al. ${ }^{111}$ have suggested that sulfur blocking can effectively reduce the adsorption probability of $\mathrm{H}_{2}$ and hence the products may desorb before the hydrogenation step. Visconti et al. ${ }^{68}$ have also postulated that sulfur adsorption can lead to the poisoning of the sites responsible for the $\mathrm{CO}$ adsorption and the hydrogenation. Visconti et al. evaluated the hydrogenation capabilities of the pre-poisoned cobalt catalyst in the propylene-to-propane hydrogenation reaction. They claimed that the hydrogenation capability of the catalyst significantly decreases with increasing sulfur loading. The changes observed in the product distribution for all the catalysts are consistent with this, showing higher olefin content in the products during the poisoning and the post-poisoning stage. However, other studies ${ }^{69}$ have suggested that the sulfur can form a surface cobalt sulfide which is known to have hydrogenation ability. This would mean more paraffin in the products and less olefins, contrary to the findings of this study.

Similar to the observation of increased olefin content due to sulfur poisoning, the alcohol content also increases in the products due to the poisoning effect. However, the alcohol contribution to overall FT products is less than $7 \%$ in most cases. Therefore, it would not be possible to comment on the change in alcohol distribution due to sulfur poisoning.

The trend presented here for the paraffin yield correlates well with the drop in CO conversion discussed earlier. Further, it is confirmed that the sulfur poisoning not only reduces the paraffin yield but also shifts the selectivity towards the lighter hydrocarbons. Overall, the CA-modified catalysts show the better paraffin yield in the post-poisoning stage, compared to the base-case catalyst. 


\subsection{Kinetic Modeling of the Deactivation}

The deactivation data are processed to determine the poisoning rate constant, $k_{d}$, for the base catalyst. The derivation of the kinetic expression is explained below.

For an isothermal differential reactor, the mass balance of CO can be written as,

$$
v_{0} C_{C O} 0 \frac{d X_{C O}}{d W_{C a t}}=r_{C O}
$$

where, $C_{C O}$ is the concentration of $\mathrm{CO}\left[\mathrm{mol} / \mathrm{m}^{3}\right], v_{0}$ is the volumetric flow rate $\left[\mathrm{m}^{3} / \mathrm{h}\right]$, and $r_{C O}$ is the rate of reaction of $\mathrm{CO}\left[\mathrm{mol} / \mathrm{h} / \mathrm{g}_{\mathrm{cat}}\right]$

The rate of deactivation of the cobalt catalyst by sulfur poison is proportional to the unpoisoned fraction of active sites on the catalyst. This can be expressed as,

$$
\frac{d a}{d t}=-k_{d} a
$$

where, $t$ is the time under deactivation $[\mathrm{h}], k_{d}$ is the poisoning rate constant $\left[\mathrm{h}^{-1}\right]$ and $a$ is the activity function accounting for the deactivation due to sulfur expressed as,

$$
a=\frac{r_{C O}}{r_{C O^{0}}}
$$

where ${ }_{\mathrm{CO}^{0}}$ is the rate of the reaction before the initiation of sulfur poisoning $\left[\mathrm{mol} / \mathrm{h} / \mathrm{g}_{\mathrm{cat}}\right]$, Therefore, on integration of eq. (8.2) we get,

$$
a=\exp \left(-k_{d}(t-24)\right)
$$

As mentioned earlier, sulfur is introduced at the end of first $24 \mathrm{~h}$. Therefore the term, $(t-24)$, in Eq. (8.4) represents onset of deactivation due to sulfur poisoning. The mass balance of $\mathrm{CO}$, during the poisoning process, has to be modified to include the activity,

$$
v_{0} C_{C O} 0 \frac{d X_{C O}}{d W_{c a t}}=r_{C O} \times a
$$

where, $X_{C O}$ is the conversion of CO given in terms of the inlet concentration $C_{C O \text {,in }}$. From Eq. (7.5),

$$
r_{C O}=2^{0.74} k C_{C O, i n} 0.5 \sqrt{\frac{\left(1-X_{C O}\right)}{\left(1+\varepsilon X_{C O}\right)}}
$$


Therefore using Eq.(8.6), Eq.(8.5) becomes,

$$
v_{0} C_{C O} 0 \frac{d X_{C O}}{d W_{\text {cat }}}=2^{0.74} k C_{C O, \text { in }} 0.5 \sqrt{\frac{\left(1-X_{C O}\right)}{\left(1+\varepsilon X_{C O}\right)}} \times a
$$

Using the solution in Eq. (7.11), Eq (8.7) can be written as,

$$
\begin{aligned}
& \left.\left(1-\sqrt{\left(1-X_{C O, \text { out }}\right)\left(1+\varepsilon X_{C O, \text { out }}\right.}\right)+\frac{(1+\varepsilon)}{\sqrt{-\varepsilon}} \ln \left[\frac{\left.\sqrt{\left(1+\varepsilon X_{C O, \text { out }}\right)}+\sqrt{-\varepsilon\left(1-X_{C O, \text { out }}\right.}\right)}{1+\sqrt{-\varepsilon}}\right]\right) \\
& =\frac{2^{0.74} k W_{\text {cat }}}{v_{0} C_{C O, \text { in }} 0.5} \times a=\frac{2^{0.74} k W_{\text {cat }}}{v_{0} C_{C O, \text { in }} 0.5} \times \exp \left(-k_{d}(t-24)\right)
\end{aligned}
$$

On simplification,

$$
\begin{aligned}
& \ln \left(1-\sqrt{\left(1-X_{\text {CO,out }}\right)\left(1+\varepsilon X_{C O, \text { out }}\right)}+\frac{(1+\varepsilon)}{\sqrt{-\varepsilon}} \ln \left[\frac{\left.\sqrt{\left(1+\varepsilon X_{C O, \text { out }}\right)}+\sqrt{-\varepsilon\left(1-X_{C O, \text { out }}\right.}\right)}{1+\sqrt{-\varepsilon}}\right]\right) \\
& =\ln \left(\frac{2^{0.74} k W_{\text {cat }}}{v_{0} C_{C O, \text { in }} 0.5}\right)+\left(-k_{d}(t-24)\right)
\end{aligned}
$$

From Eq. (8.9), $k_{d}$ can be determined by plotting $f\left(X_{C O}\right)$ vs. $(t-24)$, as presented in the following section.

\subsubsection{Determination of Deactivation Constant and Half-life of Catalysts}

The plots of $f\left(X_{C O}\right)$ vs. $(t-24)$ for the base-case cobalt catalyst are shown in Figure 8.11 and Figure 8.12 for 10 and 50 ppm sulfur poisoning run, respectively. The data for EDTAand NTA-modified catalyst in presence of 10 ppm S is shown in Figure 8.13 and Figure 8.14, respectively. Clearly, from Eq.(8.9) the slope of these graphs is the deactivation constant, $k_{d}$, for the catalyst under given sulfur impurity levels.

In addition, the half-life of the catalyst, $t_{1 / 2}$, can be defined as:

$$
t_{1 / 2}=\frac{-\ln (0.5)}{k_{d}}
$$

The calculated values of the $k_{d}$ and $t_{1 / 2}$ are presented in Table 8.7 for the cobalt catalysts under different sulfur levels. Also, the calculated values of the intercept in Eq.(8.9) are compared with experimental values in Table 8.7. 


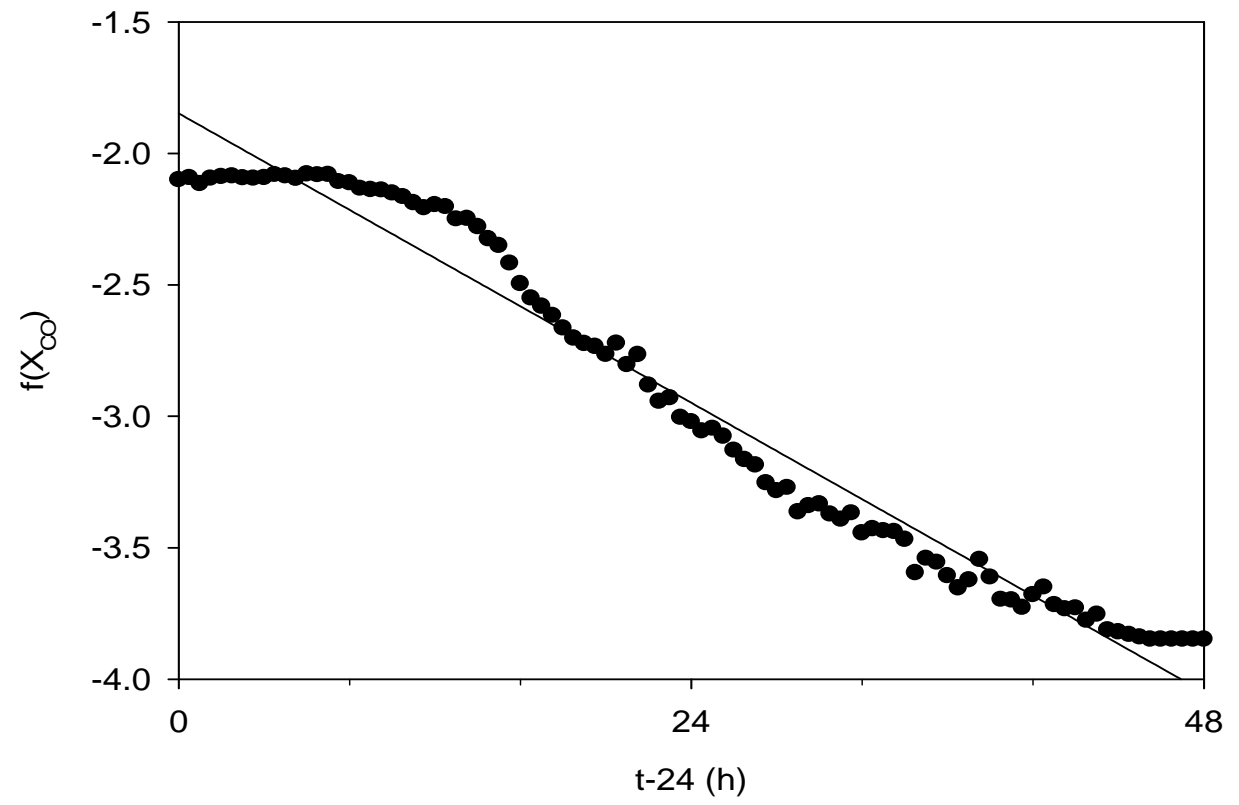

Figure 8.11 Plot of $f\left(X_{C O}\right)$ vs. $(t-24)$ for the $10 \mathrm{ppm}$ sulfur poisoning run for $\mathrm{Co} / \mathrm{SiO}_{2}$ catalyst

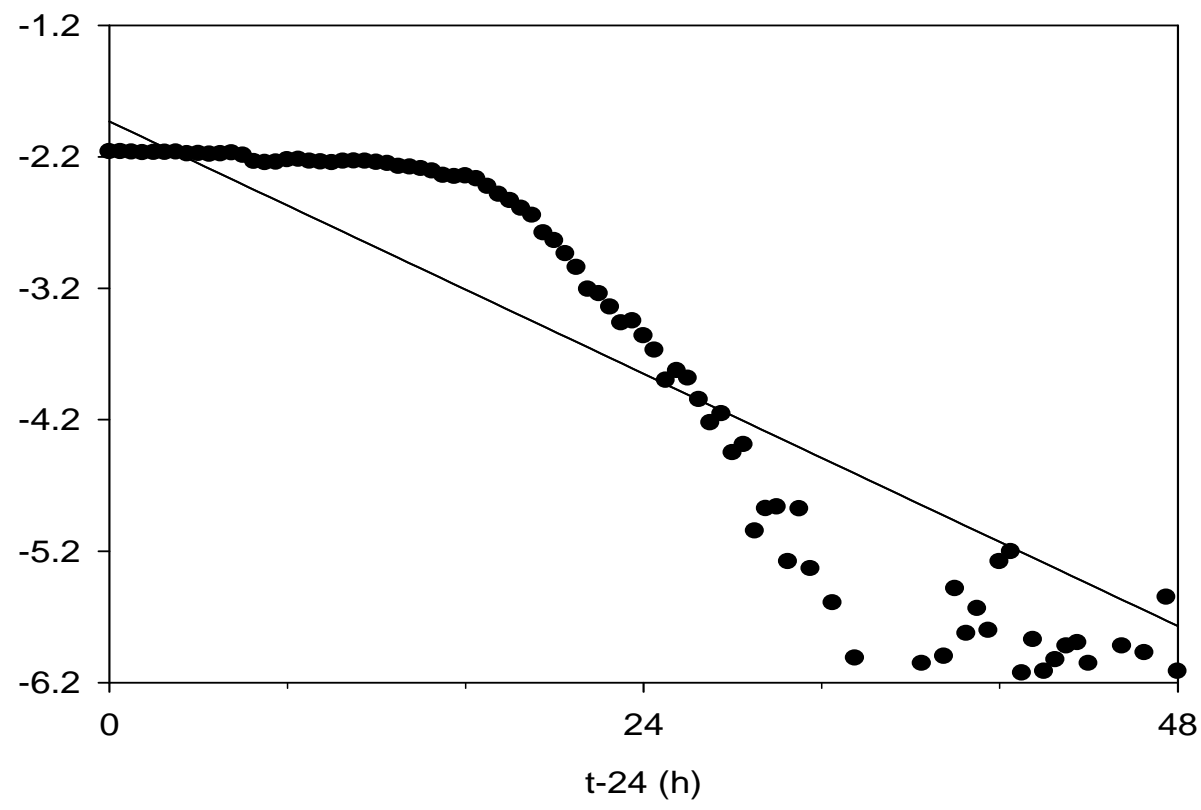

Figure 8.12 Plot of $f\left(X_{C O}\right)$ vs. $(t-24)$ for the $50 \mathrm{ppm}$ sulfur poisoning run for $\mathrm{Co} / \mathrm{SiO}_{2}$ catalyst 


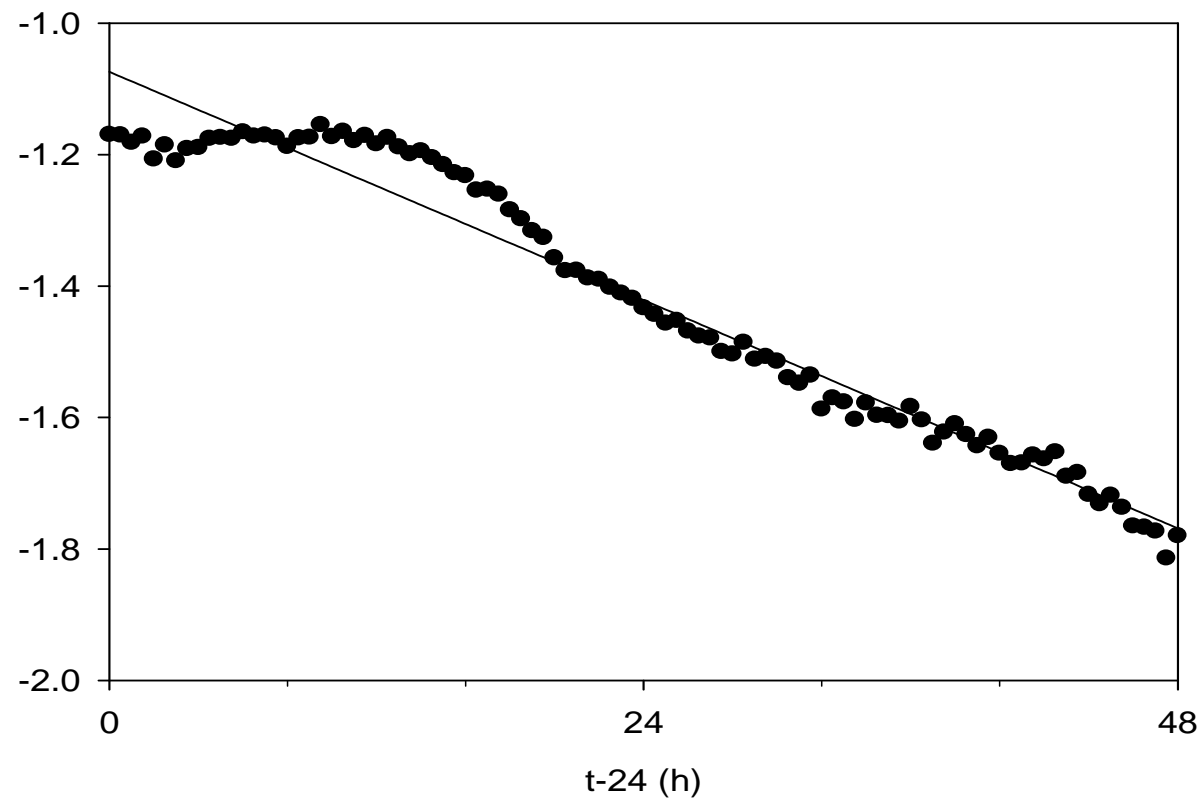

Figure 8.13 Plot of $f\left(X_{C O}\right)$ vs. $(t-24)$ for the 10 ppm sulfur poisoning run on Co/EDTA/SiO 2 catalyst

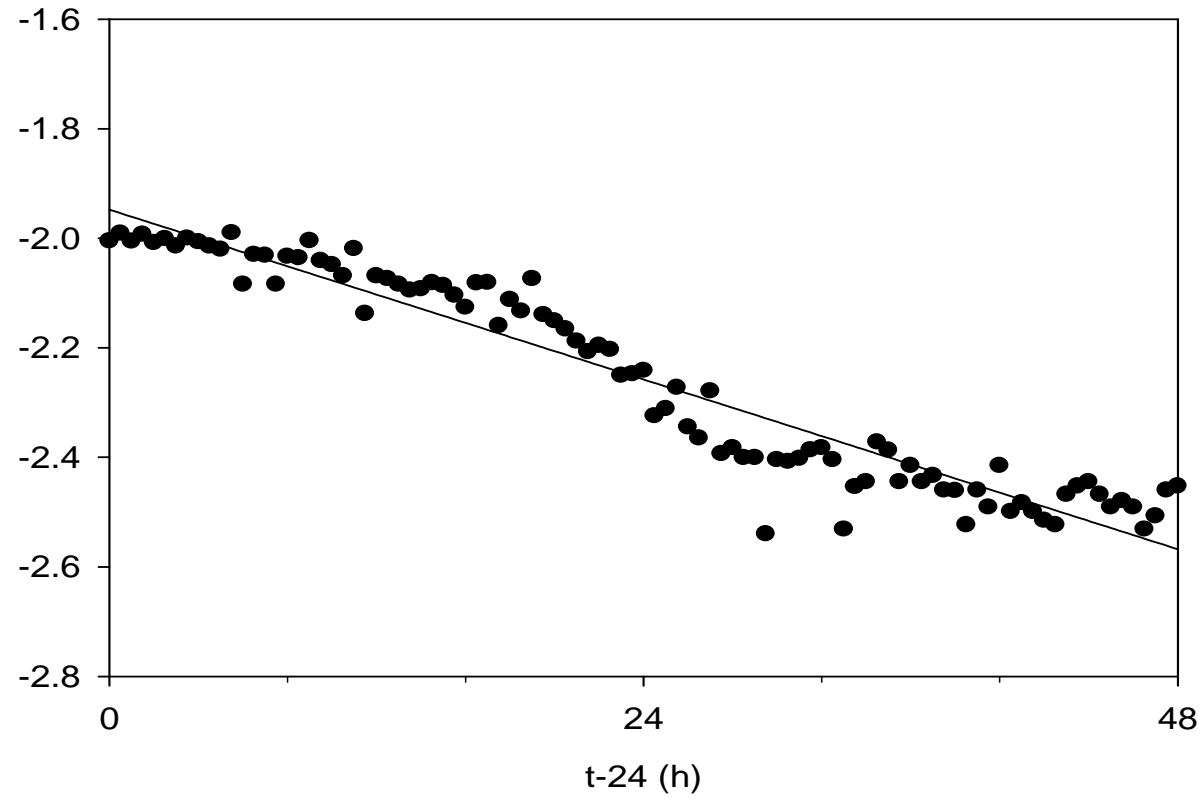

Figure 8.14 Plot of $f\left(X_{C O}\right)$ vs. $(t-24)$ for the $10 \mathrm{ppm}$ sulfur poisoning run on $\mathrm{Co} / \mathrm{NTA} / \mathrm{SiO}_{2}$ catalyst 
Table 8.7 Deactivation constant, half-life and intercept of FT catalysts under sulfur poison

\begin{tabular}{|c|c|c|c|c|}
\hline \multirow[t]{2}{*}{ Catalyst } & \multirow[t]{2}{*}{$\begin{array}{c}k_{d} \\
\left(\mathbf{h}^{-1}\right)\end{array}$} & \multirow[t]{2}{*}{$\begin{array}{r}t_{1 / 2} \\
\text { (h) }\end{array}$} & $\begin{array}{l}\text { Intercept ir } \\
\ln \left(\frac{2^{0.74}}{v_{0} C_{C C}}\right.\end{array}$ & $\begin{array}{l}\text { Eq.(8.9) } \\
\frac{W_{\text {cat }}}{0.5} \\
\text {,in }\end{array}$ \\
\hline & & & Experimental & Calculated \\
\hline $\mathrm{Co} / \mathrm{SiO}_{2} ; 10 \mathrm{ppm} \mathrm{S}$ & 0.045 & 15.4 & -1.84 & -1.76 \\
\hline $\mathrm{Co} / \mathrm{SiO}_{2} ; 50 \mathrm{ppm} \mathrm{S}$ & 0.270 & 2.57 & -1.93 & -1.76 \\
\hline Co/EDTA/SiO $2 ; 10$ ppm S & 0.014 & 49.5 & -1.07 & -0.90 \\
\hline $\mathrm{Co} / \mathrm{NTA} / \mathrm{SiO}_{2} ; 10 \mathrm{ppm} \mathrm{S}$ & 0.013 & 53.3 & -1.94 & -1.58 \\
\hline
\end{tabular}

The value of $k_{d}$ for $10 \mathrm{ppm}$ sulfur run is $0.045 \mathrm{~h}^{-1}$ and for $50 \mathrm{ppm}$ run is $0.270 \mathrm{~h}^{-1}$. As expected, the value of the deactivation constant is higher for $50 \mathrm{ppm}$ than $10 \mathrm{ppm}$ sulfur in the feed. The reported ${ }^{69}$ values of the deactivation constant for similar cobalt catalyst in presence of $0.6 \mathrm{ppm}$ and $1.1 \mathrm{ppm}$ sulfur are, 0.017 and $0.023 \mathrm{~h}^{-1}$, respectively. In addition, for the CAmodified catalysts with larger active sites, the values of deactivation constant are smaller.

The half-life of the base catalyst in the presence of $10 \mathrm{ppm}$ sulfur is determined to be $15.4 \mathrm{~h}$ and in presence of $50 \mathrm{ppm}$ sulfur is $2.57 \mathrm{~h}$. Therefore, as mentioned earlier, the severity of poisoning is higher in presence of $50 \mathrm{ppm}$ sulfur. The half-life values of the CA-modified catalysts are higher than that of the base catalyst. This is consistent with the higher conversion noted for CA-modified than the base catalyst in the post-poisoning stage.

The experimental values of the intercepts are comparable to the calculated values of the intercept, and can be said to confirm the validity of the derived kinetic expressions, Eq.(7.13) and Eq.(8.9).

\subsection{Summary}

The presence of sulfur in the inlet syngas acts as a poison as it shows the detrimental effect on the conversion and product selectivity of the cobalt catalyst. In fact, the cobalt catalyst is observed to be sensitive even at the inlet sulfur concentration of 10 and $50 \mathrm{ppm}$. The sulfur adsorption on the cobalt catalyst is confirmed to be irreversible.

The performances of the CA-modified catalysts during the poisoning and post-poisoning stages are clearly superior to that of the base-case cobalt catalyst. A well-dispersed cobalt may 
be the reason for the higher activity of the CA-modified catalysts. Within the impurity range studied, no beneficial effects of sulfur poisoning are observed. In contrast, the sulfur impurity is found to have caused an undesired effect as it results in the drop in CO conversion and shifts the product selectivity towards shorter-chain hydrocarbons. Additional diffusion limitations caused due to sulfur poisoning is thought to alter the product selectivity. It is also evident from the shifts in the selectivity that the sulfur decreases the ability of the catalyst to form $\mathrm{C}-\mathrm{C}$ bonds to produce longer-chain hydrocarbons. The selective blocking of sulfur is thought to affect the hydrogenation ability on the catalyst, resulting in more olefins in the product after sulfur poisoning. The sulfur poisoning on the cobalt catalyst is expected to cause an increase in the number of sites responsible for WGS or to influence the Boudouard reaction, resulting in the higher $\mathrm{CO}_{2}$ selectivity.

The deactivation constant determined by the derived kinetic expression is in good agreement with the reported values for similar catalysts. The value of the deactivation rate constant is $0.045 \mathrm{~h}^{-1}$ in the presence of $10 \mathrm{ppm}$ sulfur and is $0.27 \mathrm{~h}^{-1}$ for $50 \mathrm{ppm}$ sulfur. The halflife value for base catalyst is $15.4 \mathrm{~h}$ in the presence of $10 \mathrm{ppm}$ sulfur and is $2.57 \mathrm{~h}$ in the presence of $50 \mathrm{ppm}$ sulfur. In addition, the higher half-life values confirm that the severity of poisoning is more in the presence of $50 \mathrm{ppm}$ sulfur than the $10 \mathrm{ppm}$ sulfur. Furthermore, the half-life values of the CA-modified catalysts are higher than that of the base catalyst. This is consistent to higher conversion noted for CA-modified than the base catalyst in the postpoisoning stage. The experimental and calculated values of the intercept confirm the validity of derived kinetic expression. 


\section{CHAPTER 9}

\section{POST-REACTION CHARACTERIZATION OF THE CATALYSTS}

\subsection{Introduction}

The FT catalyst after $72 \mathrm{~h}$ TOS was recovered from the reactor for post-reaction characterizations. The catalyst particles were physically separated from the quartz chips used as a diluent. The spent catalysts were characterized by SEM, EDS, $\mathrm{N}_{2}$-physisorption and XPS. The spent catalyst is expected to provide information about the structural changes on the catalysts during the FTS. First, the characterization results of the spent catalyst, the performance of which is discussed in Chapter 6, are discussed. As mentioned earlier, these catalysts were evaluated using only syngas. In the next step, the characterization results of the spent catalysts subjected to sulfur poisoning are discussed.

\subsection{Characterization of the Spent Catalysts Subjected to Pure Syngas}

The physical characterizations of the fresh catalysts, $\mathrm{Co} / \mathrm{SiO}_{2}, \mathrm{Co} / \mathrm{EDTA} / \mathrm{SiO}_{2}$ and $\mathrm{Co} / \mathrm{NTA} / \mathrm{SiO}_{2}$ are discussed in Section 4.3.2-4.3.4. In the following sections, the results from the BET measurements and the XPS analysis of the spent catalysts are discussed.

\subsubsection{BET Measurements}

The measured pore size distribution, BET surface area and pore volume of the spent catalysts are presented in Table 9.1. The analogous results for the fresh catalysts (before the FTS run) can be found in Table 4.1. The isotherms for $\mathrm{N}_{2}$ adsorption and the pore size distribution for the base catalyst and the CA-modified catalysts are shown in Figure 9.1 and Figure 9.2, respectively. From comparison of the fresh and spent catalysts, it is clear that there is a drop of ca. $20 \%$ in the surface area and the pore volume during FT synthesis for all the catalysts. This drop can be attributed to the fact that the heavy products formed during FT may partially block the pores of catalyst. In addition, the inspection of the isotherm for the spent catalysts reveals an absence of any noticeable hysteresis. Therefore, it can be said that the reaction intermediates could effectively access the majority of the active sites available on the catalyst during FTS. In addition, all the catalysts display unchanged values for the pore diameter 
even after the $72 \mathrm{~h}$ under FTS conditions. Therefore, it can be said that the catalysts prepared in this study did not undergo any structural collapse and retained their structural integrity during the high-temperature and high-pressure FT operation.

Table 9.1 BET Results of spent catalysts

\begin{tabular}{|l|c|c|c|}
\hline \multirow{2}{*}{} & \multicolumn{3}{|c|}{ Spent Catalyst } \\
\cline { 2 - 4 } & $\begin{array}{c}\text { Surface area } \\
\left(\mathrm{m}^{2} / \mathrm{g}\right)\end{array}$ & $\begin{array}{c}\text { Pore volume } \\
\left(\mathrm{cm}^{3} / \mathrm{g}\right)\end{array}$ & $\begin{array}{c}\text { Pore diameter } \\
(\mathrm{nm})\end{array}$ \\
\hline $\mathrm{Co} / \mathrm{SiO}_{2}$ & 134 & 0.53 & 12.0 \\
\hline $\mathrm{Co} / \mathrm{NTA}_{\mathrm{SiO}}{ }_{2}$ & 149 & 0.57 & 11.9 \\
\hline $\mathrm{Co} / \mathrm{EDTA} / \mathrm{SiO}_{2}$ & 135 & 0.54 & 12.6 \\
\hline
\end{tabular}

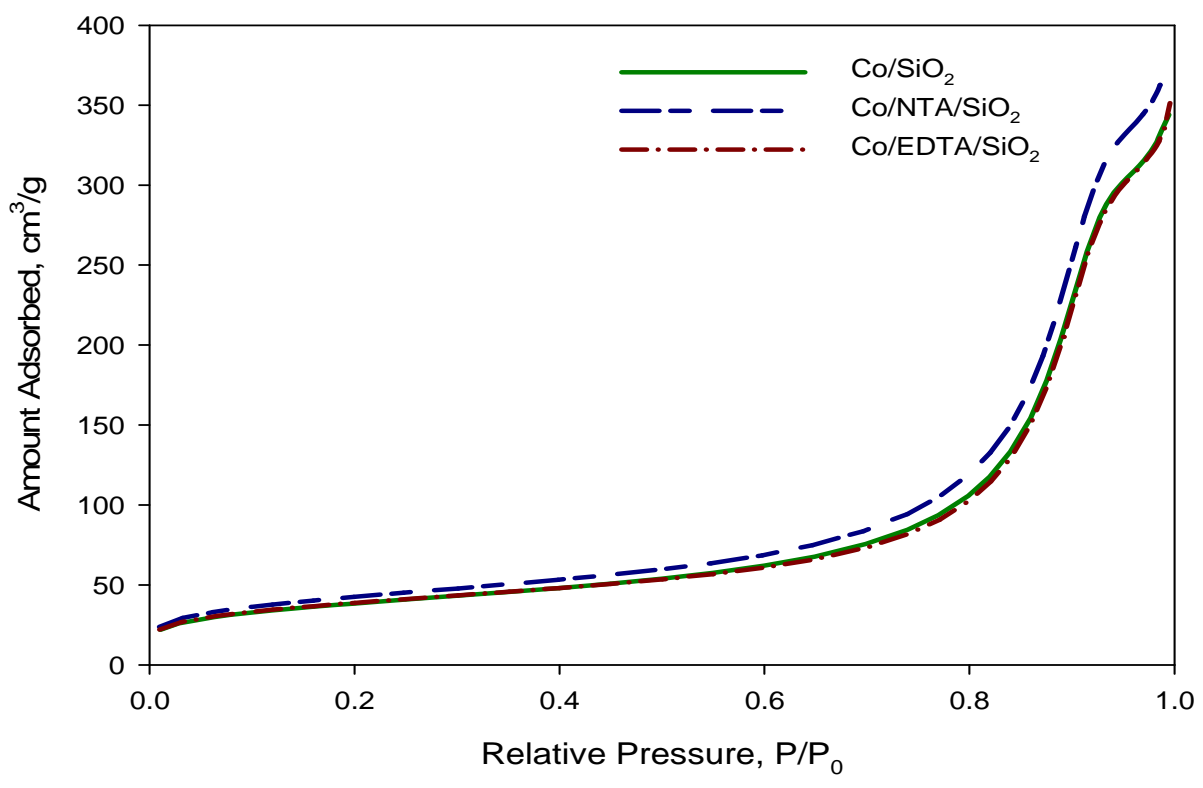

Figure 9.1 Nitrogen adsorption (BET) isotherms for the spent cobalt catalysts 


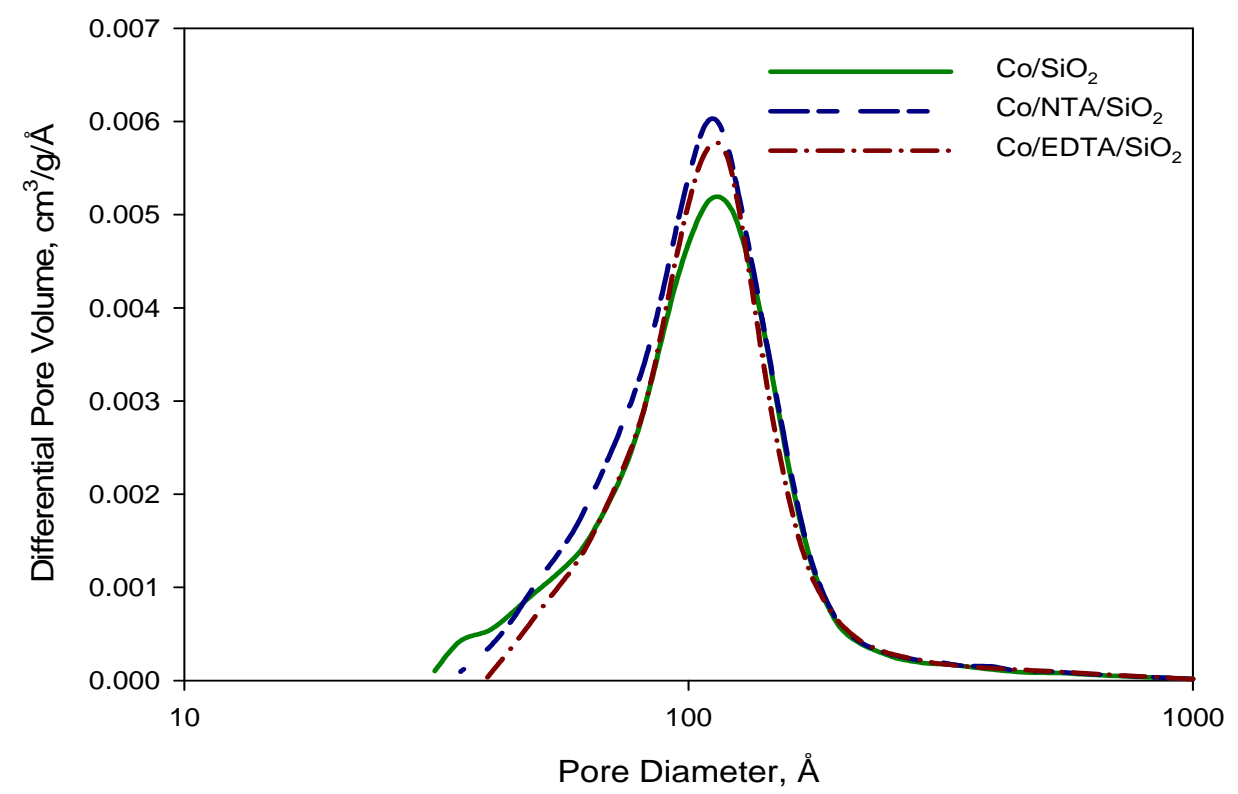

Figure 9.2 Pore size distribution curves (PSD) for the spent cobalt catalysts

\subsubsection{XPS Analysis}

The spent catalysts recovered from the run were subjected to XPS analysis. The binding energies of the Co $2 p$ peaks are compared for all three catalysts in Figure 9.3. The binding energies of $\mathrm{CO}^{\prime \prime \prime}, \mathrm{CO}^{\prime \prime}$ and Co" satellite after peak decomposition are listed in Table 9.2. The intensity ratios $\left(I_{c_{0}} / I_{s_{i}}\right)$ for the spent catalysts are also listed in Table 9.2. The XPS results with fresh catalysts are presented in Table 4.4.

For a spent base catalyst, the lower intensity of the Co $2 p$ results in very broad Co $2 p$ peaks, and hence the peak decomposition is difficult. The heavy products formed during FTS can cover the surface of the catalyst and hence it is difficult to perform XPS over the spent catalyst. Therefore, the binding energies of Co $2 \mathrm{p} 3 / 2$ and Co $2 \mathrm{p} 1 / 2$ are not tabulated in Table 9.2. The relatively lower intensities of the Co" satellite peak in the spent catalyst (see Figure 9.3) as compared to fresh catalysts (see Table 4.4), suggest the possibility of the cobalt sites being masked by FT products.

It is also clear that the intensity ratios, i.e. $\mathrm{I}_{\mathrm{co}} / \mathrm{I}_{\mathrm{s}}$, are lower for all spent catalysts than for the fresh ones, further indicating masking of exposed catalytic sites. Interestingly, both the spent CA-modified catalysts show higher intensity ratios, compared to the base catalyst. The 
higher intensity ratios of the fresh CA-modified catalysts relative to the base catalyst are also confirmed previously. This indicates that there are larger numbers of accessible catalytic sites available on the CA-modified catalysts than the base catalyst. These findings are well supported by the higher syngas conversion observed at the end of $72 \mathrm{~h}$ for CA-modified catalysts (refer to Figure 6.1).

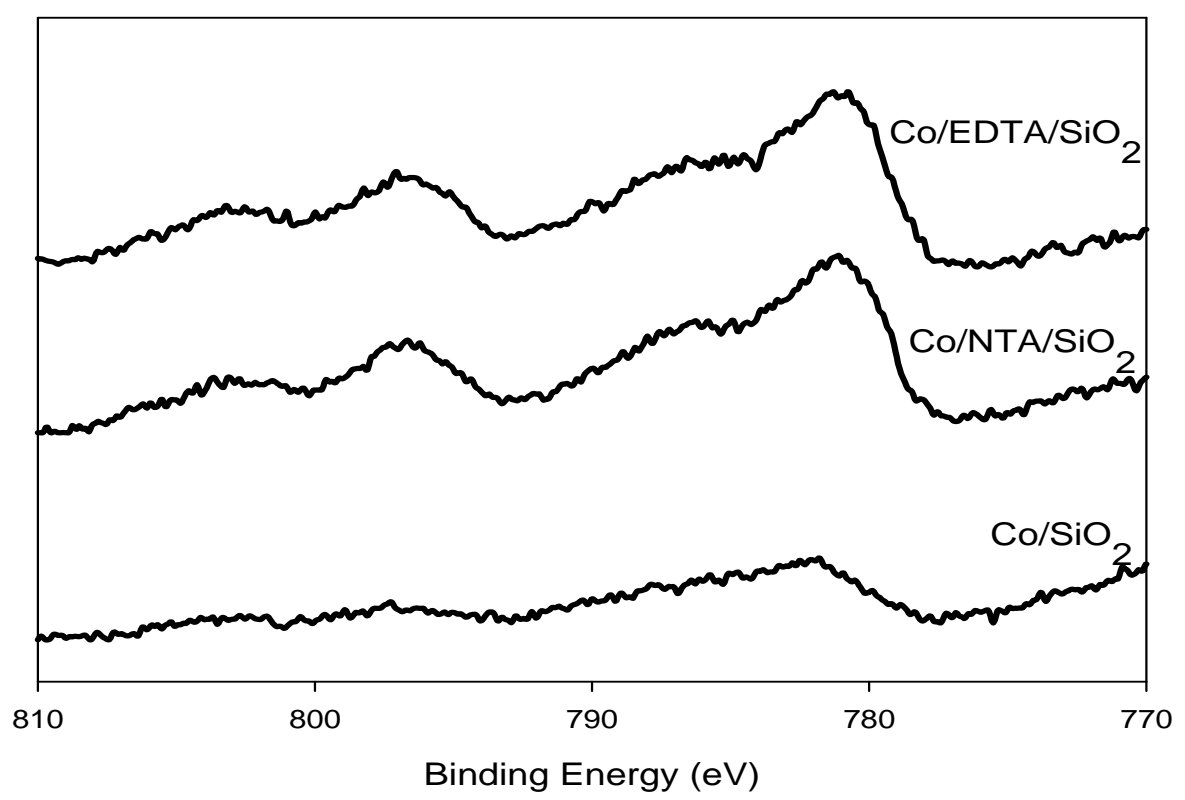

Figure 9.3 Comparison between the $\mathrm{Co} 2 p$ XPS spectra of $\mathrm{Co}_{3} \mathrm{O}_{4}$ for spent catalyst

Table 9.2 Binding energies of $\mathrm{Co} 2 \mathrm{p} 3 / 2$ and $\mathrm{Co} 2 \mathrm{p} 1 / 2$ for the $\mathrm{CO}_{3} \mathrm{O}_{4}$ phase of spent catalysts

\begin{tabular}{|c|c|c|c|c|c|c|c|}
\hline \multirow[t]{2}{*}{ Catalyst } & \multicolumn{3}{|c|}{ Binding Energy Co2p3/2 (eV) } & \multicolumn{3}{|c|}{ Binding Energy Co2p1/2 (eV) } & \multirow[t]{2}{*}{$\mathrm{I}_{\mathrm{Co}} / \mathrm{I}_{\mathrm{Si}}$ ratio } \\
\hline & $\mathrm{Co}^{\mathrm{III}}$ & Co" & Co" satellite & Co"I & $\mathrm{Co}^{\prime \prime}$ & Co" satellite & \\
\hline $\mathrm{Co} / \mathrm{SiO}_{2}$ & - & - & - & - & - & - & 0.3 \\
\hline Co/NTA/ & 780.7 & 782.3 & 787.1 & 795.9 & 797.4 & 801.5 & 0.8 \\
\hline $\mathrm{Co} / \mathrm{EDTA} / \mathrm{SiO}_{2}$ & 780.6 & 782.9 & 787.9 & 795.8 & 797.8 & 801.9 & 0.7 \\
\hline
\end{tabular}

\subsection{Characterization of the Spent Catalysts Subjected to Sulfur Impurities}

The spent catalysts were characterized by SEM and EDS analysis. The elemental composition of the fresh and the spent $\mathrm{Co} / \mathrm{SiO}_{2}$ catalysts by EDS is presented in Figure 9.4. The fresh catalyst (Figure 9.4a) shows peaks of $\mathrm{Co}, \mathrm{Si}, \mathrm{O}$ and $\mathrm{C}$, as expected from the catalyst composition. The appearance of the Ag peak is due to the use of the Ag-coating during the sample preparation stage, as mentioned earlier. The EDS spectra of the spent cobalt catalyst with the n-octane run (Figure 9.4b) show spectra similar to the fresh catalyst. The 
characterizations of the spent catalyst from the $10 \mathrm{ppm}$ and $50 \mathrm{ppm}$ sulfur poisoning runs are shown in Figure 9.4c and Figure 9.4d, respectively. The appearance of the sulfur on the EDS spectra confirms the sulfur uptake by the cobalt catalysts during the poisoning stage. Also note that the intensity of the $S$ peak for the $50 \mathrm{ppm}$ sulfur poisoning run is higher than that for the 10 ppm sulfur poisoning run.

Similarly, the spent CA-modified catalysts were subjected to the EDS analysis, and the results are presented in Figure 9.5. The spent EDTA- and NTA-modified catalysts both show the uptake of sulfur introduced during the poisoning stage of the FT run. It must be stressed that all the catalyst particles in the bed may not receive the same sulfur dosing during the poisoning stage. Therefore, the intensity of sulfur may vary for particles; see especially Figure 9.5c and d. The appearance of $\mathrm{Al}$ and Fe peaks in some spectra can be attributed to the traces present in the silica support. 

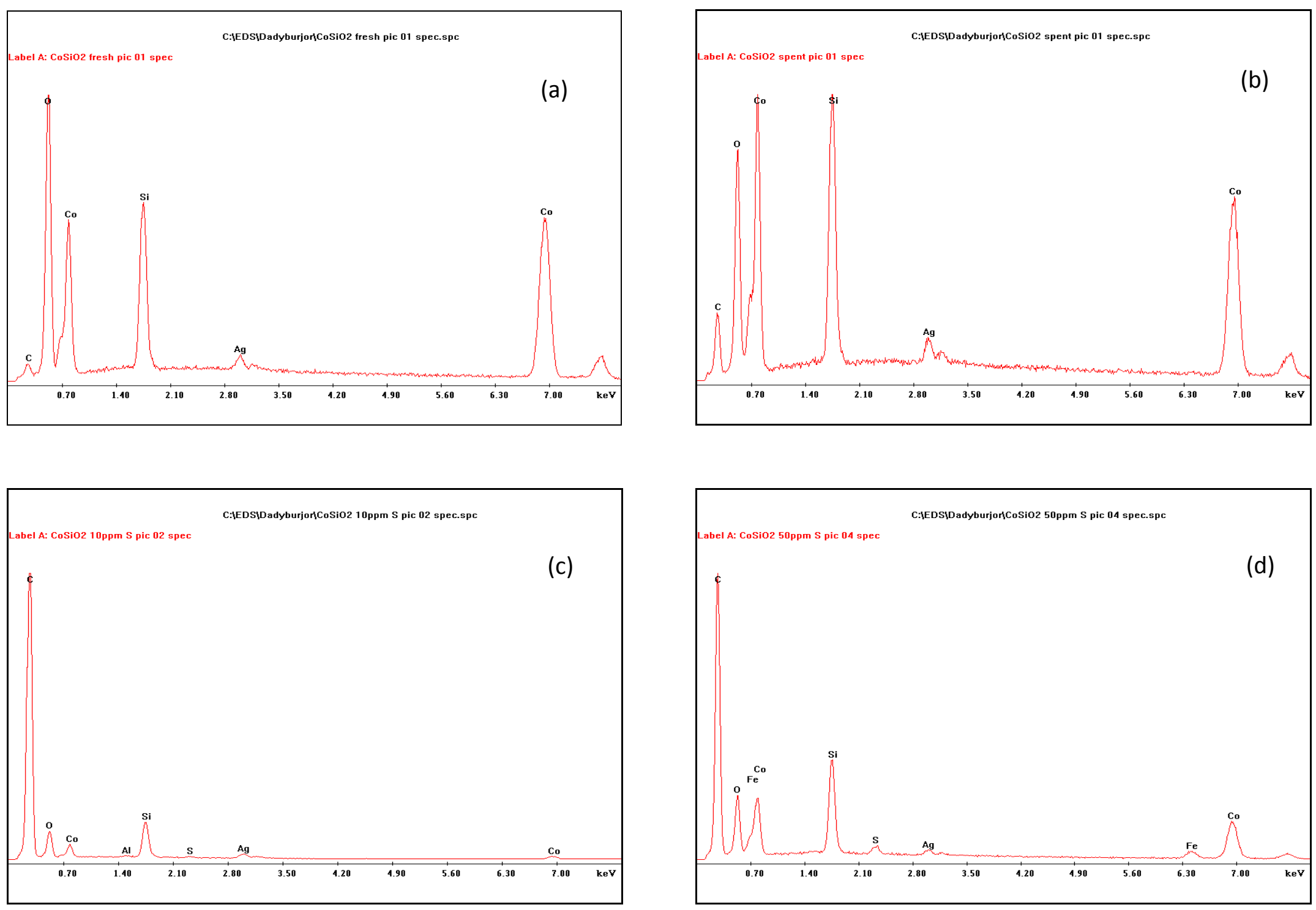

Figure 9.4 EDS analysis of $\mathrm{Co} / \mathrm{SiO}_{2}$ catalyst (a) fresh sample, (b) spent catalyst with pure-n-octane run, (c) spent catalyst with 10 ppm sulfur run and (d) spent catalyst with $50 \mathrm{ppm}$ sulfur run 

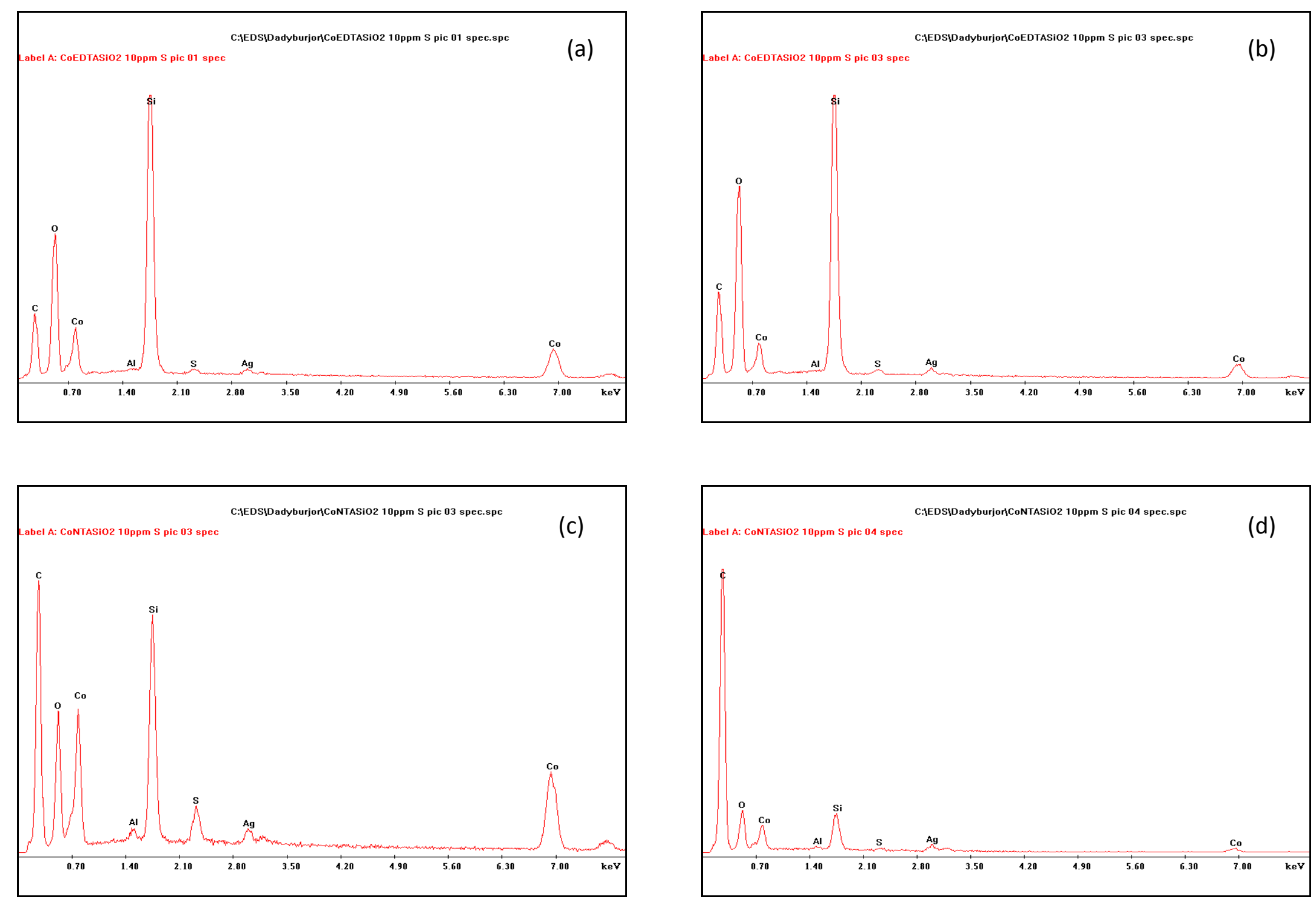

Figure 9.5 EDS analysis of the spent CA-modified catalyst with $10 \mathrm{ppm}$ sulfur in the feed (a), (b) different particles of Co/EDTA/SiO ${ }_{2}$; (c), (d) different particles of spent Co/NTA/SiO 


\subsection{Summary}

The surface area and pore volume of the spent catalysts are smaller than the corresponding values for the fresh catalysts. The drop can be attributed to pore blocking by the heavy products formed during the reaction. Also, the characterization confirms that most of the active sites are available during FTS, and that the catalyst particles retain their structural integrity. The lower intensities of the Co2p peaks, in case of the spent catalyst compared to the fresh catalysts, suggest the possibility of catalytic sites being masked by FT products. The higher intensity ratios for the spent CA-modified catalysts compared to the spent base-case catalyst indicate the greater availability of accessible catalytic sites.

The characterization of the spent catalysts subjected to the sulfur impurity study confirms sulfur uptake during the poisoning stage. However, it is not necessarily true that, the intensity of the sulfur peak in the $50 \mathrm{ppm}$ sulfur is higher compared to the one in $10 \mathrm{ppm}$ sulfur run, as different particles may not experience uniform sulfur exposure during the poisoning. 


\section{CHAPTER 10 \\ CONCLUSIONS AND FUTURE RECOMMENDATIONS}

\subsection{Conclusions}

The study of the modification of the silica support by a chelating agent concluded the following:

- Slow temperature rise during the calcination assisted in minimizing the material disintegration.

- Calcination step completely decomposes the nitrate precursor and $\mathrm{Co}_{3} \mathrm{O}_{4}$ is confirmed to the dominant phase on calcined catalysts.

- CA modification alters the particle size, reduction behavior and metal-support interaction of the cobalt catalyst.

- Physical characterization studies confirm the presence of smaller $\mathrm{Co}_{3} \mathrm{O}_{4}$ crystallites and the higher dispersion for the CA-modified catalysts.

- Both the CA-modified catalysts display higher CO conversions at 220 and $230{ }^{\circ} \mathrm{C}$, compared to the base catalyst.

- Total hydrocarbon yield of the CA-modified catalysts is higher than that of the base catalyst at both the temperatures.

- The higher site density for the CA-modified catalyst causes a higher readsoprtion probability of the reaction intermediates, leading to a higher yield of the desired long-chain hydrocarbons.

- CA modification does not significantly change the hydrogenation rate of olefins.

- Kinetic parameters and TOF are well within the reported values for similar cobalt catalysts.

- Characterization of the spent catalyst confirms that all the catalysts retain their structural integrity the after FT synthesis. Due to the deposition of FT products inside the pores, the surface area and pore volume is decreased after the reaction.

Therefore, the structure-activity relationship established for the catalysts is well supported by the findings from the physical characterization and the performance evaluation in FTS. 
In order to study the in-situ sulfur poisoning, an approach based on the use of a liquid solvent and organic sulfur carrier was developed with the available setup. For the poisoning study, n-octane and butanethiol were selected as the liquid solvent and the sulfur carrier, respectively. A series of blank runs were performed to confirm the negligible activity of $n$ octane. The quantification procedure was revised to estimate the actual n-octane in the FT products.

The investigation of the effect of sulfur poisoning of cobalt catalysts reveals the following observations:

- The presence of sulfur in the inlet syngas has a detrimental effect on the conversion and product selectivity of the cobalt catalyst. In fact, the cobalt catalyst is observed to be sensitive even at the inlet sulfur concentration of 10 and $50 \mathrm{ppm}$. The sulfur adsorption on the cobalt catalyst is confirmed to be irreversible.

- Within the impurity range studied, no beneficial effects of sulfur poisoning are observed. In contrast, the sulfur results in a drop in $\mathrm{CO}$ conversion and shifts the product selectivity towards shorter-chain hydrocarbons. Additional diffusion limitations caused by sulfur poisoning may alter the product selectivity.

- It is also evident from the shifts in the selectivity that the sulfur decreases the ability of the catalyst to form C-C bonds to produce longer-chain hydrocarbons.

- The selective blocking of sites by sulfur affects the hydrogenation ability of the catalyst, resulting in more olefins in the product after sulfur poisoning.

- The sulfur poisoning on the cobalt catalyst may increase the number of sites responsible for WGS or influence the Boudouard reaction, resulting in the higher $\mathrm{CO}_{2}$ selectivity.

- The product yield of the CA-modified catalysts is higher than that of the base catalyst in the poisoning as well as the post-poisoning stage.

- A well-dispersed phase is reasoned for the superior performance of CA-modified catalysts in the post-poisoning stage.

- The deactivation constant and the half-life values confirm that the severity of poisoning is more in the presence of $50 \mathrm{ppm}$ sulfur than the $10 \mathrm{ppm}$ sulfur. 
- The experimental and calculated values of the intercept in the derived kinetic expressions are comparable. This is said to confirm the validity of the derived expression for the deactivation process.

- The EDS analysis of spent catalysts shows sulfur uptake on the surface of catalyst and confirms the drop in the catalyst activity is due to the sulfur poisoning.

- The EDTA-modified catalyst performed well compared to other two catalysts. Hence, the EDTA-modified catalyst can be used to develop the sulfur-tolerant catalyst in the next phase of the project.

\subsection{Future Recommendation}

- The approach based on the use of solvent and the organic sulfur for impurity study worked satisfactorily in the present study. Based on the similar approach, alkali and chloride impurities can be injected into the unit to study the poisoning effect with these species.

- The hydrogenation ability of the spent catalysts can be evaluated by propylene-to-propane reactions studies. The current setup with Micromeritics 2950, at NETL, can be modified to perform the hydrogenation reactions.

- In addition, the bed temperature can be varied in the presence of different levels of sulfur impurity. This can potentially assist in the development of a detailed model for the sulfur poison.

- The EDTA-modified catalyst shows superior performance among all the catalyst and can be used to develop the sulfur tolerant catalyst in the future. Accordingly, the design of a sulfurtolerant catalyst (e.g., alkali promoted) can be based on the EDTA-modified catalyst developed in this study. 


\section{REFERENCES}

1. D. Xiaoping, Y. C., and L. Ranjia, Chinese Journal of Catalysis 2007, 1047.

2. Dry, M. E., High quality diesel via the Fischer-Tropsch process - a review. Journal of Chemical Technology and Biotechnology 2002, 77 (1), 43-50.

3. Dalai, A. K.; Davis, B., Fischer-Tropsch synthesis: A review of water effects on the performances of unsupported and supported cobalt catalysts. Abstracts of Papers of the American Chemical Society 2005, 229, 120-PETR.

4. Anderson, R. B.; Seligman, B.; Shultz, J. F.; Kelly, R.; Elliott, M. A., Fischer-Tropsch synthesis. Some important variables of -the synthesis on iron catalysts. Industrial \& Engineering Chemistry 1952, 44 (2), 391-397.

5. Anderson, R. B.; Seligman, B.; Shultz, J. F.; Kelly, R.; Elliott, M. A., Fischer-Tropsch Synthesis. Some Important Variables of the Synthesis on Iron Catalysts. Industrial \& Engineering Chemistry 2002, 44 (2), 391-397.

6. Van der Laan, G. P.; Beenackers, A., Kinetics and selectivity of the Fischer-Tropsch synthesis: A literature review. Catalysis Reviews-Science and Engineering 1999, 41 (3-4), 255318.

7. Adesina, A. A., Hydrocarbon synthesis via Fischer-Tropsch reaction: travails and triumphs. Applied Catalysis A: General 1996, 138 (2), 345-367.

8. Davis, B. H., Fischer-Tropsch conversion of gas to liquid. Applied Catalysis A: General 1997, 155 (1), N4-N7.

9. Saxena, S. C., Bubble-column reactors and Fisher-Tropsch synthesis. Catalysis ReviewsScience and Engineering 1995, 37 (2), 227-309; Saxena, S. C.; Rosen, M.; Smith, D. N.; Ruether, J. A., Mathematical-modeling of fischer-tropsch slurry bubble column reactors. Chemical Engineering Communications 1986, 40 (1-6), 97-151.

10. Chaumette, P.; Courty, P.; Kiennemann, A.; Ernst, B., Higher alcohol and paraffin synthesis on cobalt-based catalysts - comparison of mechanistic aspects. Topics in Catalysis 1995, 2 (1-4), 117-126. 
11. Lox, E. S.; Marin, G. B.; Degrave, E.; Bussiere, P., Characterization of a promoted precipitated iron catalyst for Fischer-Tropsch synthesis. Applied Catalysis 1988, 40 (1-2), 197218.

12. Novak, S.; Madon, R. J.; Suhl, H., Models of hydrocarbon product distributions in FischerTropsch synthesis .1. Journal of Chemical Physics 1981, 74 (11), 6083-6091; Novak, S.; Madon, R. J.; Suhl, H., Secondary effects in the Fischer-Tropsch synthesis. Journal of Catalysis 1982, 77 (1), 141-151.

13. Davis, B. H., Fischer-Tropsch synthesis: current mechanism and futuristic needs. Fuel Processing Technology 2001, 71 (1-3), 157-166.

14. Dry, M. E.; Oosthuizen, G. J., The correlation between catalyst surface basicity and hydrocarbon selectivity in the Fischer-Tropsch synthesis. Journal of Catalysis 1968, 11 (1), 1824.

15. Iglesia, E.; Reyes, S. C.; Madon, R. J.; Soled, S. L., Selectivity control and catalyst design in the Fischer-Tropsch synthesis - sites, pellets, and reactors. Advances in Catalysis, Vol 39 1993, 39, 221-302.

16. Iglesia, E., Fischer-Tropsch synthesis on cobalt catalysts: Structural requirements and reaction pathways. Natural Gas Conversion Iv 1997, 107, 153-162.

17. Khodakov, A. Y.; Chu, W.; Fongarland, P., Advances in the Development of Novel Cobalt Fischer-Tropsch Catalysts for Synthesis of Long-Chain Hydrocarbons and Clean Fuels. Chemical Reviews 2007, 107 (5), 1692-1744.

18. Vannice, M. A., Catalytic synthesis of hydrocarbons from H2-CO mixtures over group-viii metals .4. Kinetic-behavior of co hydrogenation over Ni catalysts. Journal of Catalysis 1976, 44 (1), 152-162.

19. Vannice, M. A., Catalytic synthesis of hydrocarbons from $\mathrm{H} 2-\mathrm{CO}$ mixtures over group 8 metals .5. Catalytic behavior of silica-supported metals. Journal of Catalysis 1977, 50 (2), 228236.

20. Iglesia, E.; Soled, S. L.; Fiato, R. A., Fischer-Tropsch synthesis on cobalt and ruthenium metal dispersion and support effects on reaction-rate and selectivity. Journal of Catalysis 1992, $137(1), 212-224$. 
21. Iglesia, E.; Soled, S. L.; Fiato, R. A.; Via, G. H., Bimetallic synergy in cobalt ruthenium Fischer-Tropsch synthesis catalysts. Journal of Catalysis 1993, 143 (2), 345-368.

22. Madon, R. J.; Reyes, S. C.; Iglesia, E., Primary and secondary reaction pathways in ruthenium-catalyzed hydrocarbon synthesis. Journal of Physical Chemistry 1991, 95 (20), 77957804.

23. Li, J. L.; Xu, L. G.; Keogh, R.; Davis, B., Fischer-Tropsch synthesis. Effect of CO pretreatment on a ruthenium promoted Co/TiO2. Catalysis Letters 2000, 70 (3-4), 127-130.

24. Madon, R. J.; Iglesia, E., Hydrogen and CO intrapellet diffusion effects in rutheniumcatalyzed hydrocarbon synthesis. Journal of Catalysis 1994, 149 (2), 428-437.

25. Soled, S. L.; Baumgartner, J. E.; Reyes, S. C.; Iglesia, E., Preparation and catalytic behavior of eggshell cobalt catalysts for the Fischer-Tropsch synthesis. Abstracts of Papers of the American Chemical Society 1994, 207, 85-CATL.

26. Li, J. L.; Jacobs, G.; Das, T.; Zhang, Y. Q.; Davis, B., Fischer-Tropsch synthesis: effect of water on the catalytic properties of a Co/SiO2 catalyst. Applied Catalysis a-General 2002, 236 (1-2), 67-76.

27. Diehl, F.; Khodakov, A. Y., Promotion of Cobalt Fischer-Tropsch Catalysts with Noble metals: a Review. Oil \& Gas Science and Technology-Revue De L Institut Francais Du Petrole 2009, 64 (1), 11-24.

28. Dry, M. E., The Fischer-Tropsch process: 1950-2000. Catalysis Today 2002, 71 (3-4), 227241.

29. Vannice, M. A., Catalytic synthesis of hydrocarbons from carbon-monoxide and hydrogen. Catalysis Reviews-Science and Engineering 1976, 14 (2), 153-191.

30. Zhang, Q.; Kang, J.; Wang, Y., Development of Novel Catalysts for Fischer-Tropsch Synthesis: Tuning the Product Selectivity. ChemCatChem 2010, 2 (9), 1030-1058.

31. Saib, A. M.; Moodley, D. J.; Ciobîcă, I. M.; Hauman, M. M.; Sigwebela, B. H.; Weststrate, C. J.; Niemantsverdriet, J. W.; van de Loosdrecht, J., Fundamental understanding of deactivation and regeneration of cobalt Fischer-Tropsch synthesis catalysts. Catalysis Today 2010, 154 (3-4), 271-282. 
32. Koizumi, N.; Murai, K.; Ozaki, T.; Yamada, M., Development of sulfur tolerant catalysts for the synthesis of high quality transportation fuels. Catalysis Today 2004, 89 (4), 465-478.

33. Mochizuki, T.; Hara, T.; Koizumi, N.; Yamada, M., Surface structure and Fischer-Tropsch synthesis activity of highly active $\mathrm{Co} / \mathrm{SiO} 2$ catalysts prepared from the impregnating solution modified with some chelating agents. Applied Catalysis A: General 2007, 317 (1), 97-104.

34. Koizumi, N.; Mochizuki, T.; Yamada, M., Preparation of highly active catalysts for ultraclean fuels. Catalysis Today 2009, 141 (1-2), 34-42.

35. Steen, E. v.; Sewell, G. S.; Makhothe, R. A.; Micklethwaite, C.; Manstein, H.; de Lange, M.; O'Connor, C. T., TPR Study on the Preparation of Impregnated $\mathrm{Co} / \mathrm{SiO}_{2}$ Catalysts. Journal of Catalysis 1996, 162 (2), 220-229.

36. Sun, S.; Tsubaki, N.; Fujimoto, K., The reaction performances and characterization of Fischer-Tropsch synthesis Co/SiO2 catalysts prepared from mixed cobalt salts. Applied Catalysis A: General 2000, 202 (1), 121-131.

37. Mochizuki, T.; Hara, T.; Koizumi, N.; Yamada, M., Novel preparation method of highly active $\mathrm{Co} / \mathrm{SiO} 2$ catalyst for Fischer-Tropsch synthesis with chelating agents. Catalysis Letters 2007, 113 (3-4), 165-169.

38. Mochizuki, T.; Hongo, D.; Satoh, T.; Koizumi, N.; Yamada, M., Improvement of the Fischer-Tropsch Synthesis Activity of Co/SiO2 Catalyst by the Stepwise Impregnation Method with Chelating Agents. Catalysis Letters 2008, 121, 52-57.

39. Raveendran, K.; Ganesh, A.; Khilar, K. C., Influence of mineral matter on biomass pyrolysis characteristics. Fuel 1995, 74 (12), 1812-1822.

40. Herguido, J.; Corella, J.; Gonzalezsaiz, J., Steam gasification of lignocellulosic residues in a fluidized-bed at a small pilot scale - effect of the type of feedstock. Industrial \& Engineering Chemistry Research 1992, 31 (5), 1274-1282.

41. Ciferno, J.; Marano, J. Benchmarking Biomass Gasification Technologies for Fuels, Chemical and Hydrogen Production; US Department of Energy, National Energy Technology Laboratory: June 2002; pp 1-52.

42. Wang, T.; Chang, J.; Lv, P., Synthesis Gas Production via Biomass Catalytic Gasification with Addition of Biogas. Energy \& Fuels 2005, 19 (2), 637-644. 
43. Maschio, G.; Lucchesi, A.; Stoppato, G., Production of syngas from biomass. Bioresource Technology 1994, 48 (2), 119-126.

44. Gil, J.; Aznar, M. P.; Caballero, M. A.; Frances, E.; Corella, J., Biomass Gasification in Fluidized Bed at Pilot Scale with Steam-Oxygen Mixtures. Product Distribution for Very Different Operating Conditions. Energy \& Fuels 1997, 11 (6), 1109-1118.

45. Lv, P.; Yuan, Z.; Wu, C.; Ma, L.; Chen, Y.; Tsubaki, N., Bio-syngas production from biomass catalytic gasification. Energy Conversion and Management 2007, 48 (4), 1132-1139.

46. Asadullah, M.; Miyazawa, T.; Ito, S.-i.; Kunimori, K.; Yamada, M.; Tomishige, K., Gasification of different biomasses in a dual-bed gasifier system combined with novel catalysts with high energy efficiency. Applied Catalysis A: General 2004, 267 (1-2), 95-102.

47. Torres, W.; Pansare, S. S.; Goodwin, J. G., Hot Gas Removal of Tars, Ammonia, and Hydrogen Sulfide from Biomass Gasification Gas. Catalysis Reviews: Science and Engineering 2007, 49 (4), 407-456.

48. Chaudhari, S. T.; Dalai, A. K.; Bakhshi, N. N., Production of Hydrogen and/or Syngas (H2 + CO) via Steam Gasification of Biomass-Derived Chars. Energy \& Fuels 2003, 17 (4), 1062-1067.

49. Gil, J.; Corella, J.; Aznar, M. P.; Caballero, M. A., Biomass gasification in atmospheric and bubbling fluidized bed: Effect of the type of gasifying agent on the product distribution. Biomass and Bioenergy 1999, 17 (5), 389-403.

50. Könemann, J.-W.; Zwart, R., Jan-Willem Könemann; Robin Zwart, OLGA Tar Removal Technology - biomass gasification to electricity. In POWER-GEN International Conference, New Orleans, 2007.

51. Wright, I. G.; Gibbons, T. B., Recent developments in gas turbine materials and technology and their implications for syngas firing. International Journal of Hydrogen Energy 2007, 32 (16), 3610-3621.

52. Lamb, C.; Soelberg, N.; Dellinger, B.; Quapp, B. IT3'03, Orlando, Florida, Orlando, Florida, May 12-16, 2003.

53. Bain, R. An Overview of Biomass Gasification; National Renewable Energy Laboratory: Golden, Colorado, USA, 2005. 
54. Boerrigter, H.; Calis, H.; Slort, D.; Bodenstaff, H., Gas Cleaning for Integrated Biomass Gasification (BG) and Fischer-Tropsch (FT) Systems; Experimental Demonstration of BG-FT Systems. In 2nd World Conference and Technology Exposition on Biomass for Energy, Industry and Climate Protection, Rome, Italy, May 10-14, 2004.

55. Gulyurtlu, I.; Pinto, F.; Lopes, H.; Andre, R. N.; Crujeira, A.; Teresa, D. M.; Cabrita, I. In Comparison of Contaminants in Gas and Solid Wastes from Co-gasification of Sewage Sludge with Coal and with Biomass, Proceedings of 19th FBC Conf. Part 1, Vienna, Austria, Vienna, Austria, May 21-24, 2006.

56. Kuramochi, H.; Wu, W.; Kawamoto, K., Prediction of the behaviors of $\mathrm{H} 2 \mathrm{~S}$ and $\mathrm{HCl}$ during gasification of selected residual biomass fuels by equilibrium calculation. Fuel 2005, 84 (4), 377387.

57. Li, J.; Coville, N. J., Effect of boron on the sulfur poisoning of Co/TiO2 Fischer-Tropsch catalysts. Applied Catalysis A: General 2001, 208 (1-2), 177-184.

58. Spivey, J. J., Catalysis in the development of clean energy technologies. Catalysis Today 2005, 100 (1-2), 171-180.

59. Berg, M.; Koningen, J.; Sjostrom, K.; Waldheim, L., Development in Thermochemical Biomass Conversion. Blackie Academic \& Professional: London, UK, 1997; p 1117.

60. Karn, F. S.; Schultz, J. F.; Kelly, R. E.; Anderson, R. B., Fischer-Tropsch Synthesis. Poisoning of Iron Catalysts by H2S in Synthesis Gas. I\&EC Product Research and Development 2002, 2 (1), 43-47.

61. Fischer, F.; Tropsch, H., Brennst. Chem. 1923, 4, 276.

62. Wood, B. J.; Isakson, W. E.; Wise, H., Kinetic Studies of Catalyst Poisoning during Methanol Synthesis at High Pressures. Industrial \& Engineering Chemistry Product Research and Development 2002, 19 (2), 197-204.

63. Madon, R. J.; Seaw, H., Effect of Sulfur on the Fischer-Tropsch Synthesis. Catalysis Reviews: Science and Engineering 1977, 15 (1), 69-106.

64. Chaffee, A. L.; Campbell, I.; Valentine, N., Sulfur Poisoning of Fischer-Tropsch Synthesis Catalysts in a Fixed-Bed Reactor. Applied Catalysis 1989, 47 (2), 253-276. 
65. Curtis, V.; Nicolaides, C. P.; Coville, N. J.; Hildebrandt, D.; Glasser, D., The effect of sulfur on supported cobalt Fischer-Tropsch catalysts. Catalysis Today 1999, 49 (1-3), 33-40.

66. Ma, Y.; Ge, Q.; Li, W.; Xu, H., Study on the sulfur tolerance of catalysts for syngas to methanol. Catalysis Communications 2008, 10 (1), 6-10.

67. Bartholomew, C. H.; Bowman, R. M., Sulfur poisoning of cobalt and iron fischer-tropsch catalysts. Applied Catalysis 1985, 15 (1), 59-67.

68. Visconti, C. G.; Lietti, L.; Forzatti, P.; Zennaro, R., Fischer-Tropsch synthesis on sulphur poisoned Co/Al2O3 catalyst. Applied Catalysis A: General 2007, 330, 49-56.

69. Pansare, S. S.; Allison, J. D., An investigation of the effect of ultra-low concentrations of sulfur on a Co/[gamma]-Al2O3 Fischer-Tropsch synthesis catalyst. Applied Catalysis A: General 2010, 387 (1-2), 224-230.

70. Zhao-Tie, L.; Jing-Lai, Z.; Bi-Jiang, Z., Poisoning of iron catalyst by COS in syngas for Fischer--Tropsch synthesis. Journal of Molecular Catalysis 1994, 94 (2), 255-261.

71. Anderson, R. B.; Karn, F. S.; Shultz, J. F., Factors in sulfur poisoning of iron catalysts in Fischer-Tropsch synthesis. Journal of Catalysis 1965, 4 (1), 56-63.

72. Iglesia, E., Design, synthesis, and use of cobalt-based Fischer-Tropsch synthesis catalysts. Applied Catalysis a-General 1997, 161 (1-2), 59-78.

73. Bayer, J.; Stein, K. C.; Hofer, L. J. E.; Anderson, R. B., Effect of preadsorbed sulfur compounds on chemisorption of CO and CO2 on iron catalysts. Journal of Catalysis 1964, 3 (2), 145-155.

74. Madikizela-Mnqanqeni, N. N.; Coville, N. J., The effect of sulfur addition during the preparation of Co/Zn/TiO2 Fischer-Tropsch catalysts. Applied Catalysis A: General 2008, 340 (1), 7-15.

75. Feller, A.; Claeys, M.; Steen, E. v., Cobalt Cluster Effects in Zirconium Promoted Co/SiO2 Fischer-Tropsch Catalysts. Journal of Catalysis 1999, 185 (1), 120-130.

76. Iglesia, E.; Soled, S. L.; Fiato, R. A.; Via, G. H., Dispersion, support, and bimetallic effects in Fischer-Tropsch synthesis on cobalt catalysts. Abstracts of Papers of the American Chemical Society 1994, 207, 71-CATL. 
77. Tavasoli, A.; Mortazavi, Y.; Khodadadi, A.; Karimi, A.; Sadagiani, K.; Azizi, A.; Jam, S., Fischer-Tropsch synthesis: characterization, catalytic properties and deactivation of $\mathrm{Ru}$ and $\mathrm{Re}$ promoted cobalt catalyst. In 7th World Congress of Chemical Engineering, SECC, Glasgow, Scotland, 10-14 July, 2005.

78. Visconti, C. G.; Lietti, L.; Tronconi, E.; Forzatti, P.; Zennaro, R.; Finocchio, E., FischerTropsch synthesis on a $\mathrm{Co} / \mathrm{Al} 2 \mathrm{O} 3$ catalyst with $\mathrm{CO} 2$ containing syngas. Applied Catalysis A: General 2009, 355 (1-2), 61-68.

79. Zhang, J.; Guo, X.; Cao, W., Effect of Several Anions on Fe-Based Catalyst for FischerTropsch Synthesis. Journal of Natural Gas Chemistry 2007, 16 (4), 377-381.

80. Wu, B.; Bai, L.; Xiang, H.; Li, Y.-W.; Zhang, Z.; Zhong, B., An active iron catalyst containing sulfur for Fischer-Tropsch synthesis. Fuel 2004, 83 (2), 205-212.

81. High Surface Area Catalyst Carrier. http://www.norpro.saint-gobain.com/hsa-catalystcarriers.aspx.

82. Perego, C.; Villa, P., Catalyst preparation methods. Catalysis Today 1997, 34 (3-4), 281305.

83. Khodakov, A. Y., Enhancing Cobalt Dispersion in Supported Fischer-Tropsch Catalysts Via Controlled Decomposition of Cobalt Precursors. Brazilian Journal of Physics 2009, 39 (1A), 171175.

84. Choi, J. G.; Choi, H. K.; Jung, M. K.; Oh, H. G.; Choi, J. O., Characterization of Supported Cobalt Catalysts by TPR and TPD. Journal of Industrial and Engineering Chemistry 1997, 3 (3), 235-246.

85. Ernst, B.; Hilaire, L.; Kiennemann, A., Effects of highly dispersed ceria addition on reducibility, activity and hydrocarbon chain growth of a $\mathrm{Co} / \mathrm{SiO} 2$ Fischer-Tropsch catalyst. Catalysis Today 1999, 50 (2), 413-427; Ernst, B.; Libs, S.; Chaumette, P.; Kiennemann, A., Preparation and characterization of Fischer-Tropsch active Co/SiO2 catalysts. Applied Catalysis A: General 1999, 186 (1-2), 145-168; Castner, D. G.; Watson, P. R.; Chan, I. Y., X-ray absorption spectroscopy, x-ray photoelectron spectroscopy, and analytical electron microscopy studies of cobalt catalysts. 1. Characterization of calcined catalysts. The Journal of Physical Chemistry 1989, 93 (8), 3188-3194. 
86. Sexton, B. A.; Hughes, A. E.; Turney, T. W., An XPS and TPR study of the reduction of promoted cobalt-kieselguhr Fischer-Tropsch catalysts. Journal of Catalysis 1986, 97 (2), 390406.

87. Mochizuki, T.; Koizumi, N.; Hamabe, Y.; Hara, T.; Takizawa, H.; Yamada, M., Preparation of Highly Active Co/SiO2 Fischer-Tropsch Synthesis Catalyst with Chelating Agents: Effect of Chelating Agents on Structure of Co Species during Preparation Steps. Journal of the Japan Petroleum Institute 2007, 50 (5), 262-271.

88. Girardon, J. S.; Quinet, E.; Griboval-Constant, A.; Chernavskii, P. A.; Gengembre, L.; Khodakov, A. Y., Cobalt dispersion, reducibility, and surface sites in promoted silica-supported Fischer-Tropsch catalysts. Journal of Catalysis 2007, 248 (2), 143-157.

89. Martínez, A.; López, C.; Márquez, F.; Díaz, I., Fischer-Tropsch synthesis of hydrocarbons over mesoporous Co/SBA-15 catalysts: the influence of metal loading, cobalt precursor, and promoters. Journal of Catalysis 2003, 220 (2), 486-499.

90. Lund, C. R. F.; Dumesic, J. A., Strong oxide-oxide interactions in silica-supported magnetite catalysts. 2. The core/shell nature of the interaction. The Journal of Physical Chemistry 1982, $86(1), 130-135$.

91. Lira, E.; López, C. M.; Oropeza, F.; Bartolini, M.; Alvarez, J.; Goldwasser, M.; Linares, F. L.; Lamonier, J.-F.; Pérez Zurita, M. J., HMS mesoporous silica as cobalt support for the FischerTropsch Synthesis: Pretreatment, cobalt loading and particle size effects. Journal of Molecular Catalysis A: Chemical 2008, 281 (1-2), 146-153.

92. Xiong, H.; Zhang, Y.; Liew, K.; Li, J., Ruthenium promotion of Co/SBA-15 catalysts with high cobalt loading for Fischer-Tropsch synthesis. Fuel Processing Technology 2009, 90 (2), 237246.

93. Shi, L.; Li, D.; Hou, B.; Wang, Y.; Sun, Y., The modification of SiO2 by various organic groups and its influence on the properties of cobalt-based catalysts for Fischer-Tropsch synthesis. Fuel Processing Technology In Press, Corrected Proof.

94. Puskas, I.; Fleisch, T. H.; Full, P. R.; Kaduk, J. A.; Marshall, C. L.; Meyers, B. L., Novel aspects of the physical chemistry of $\mathrm{Co} / \mathrm{SiO} 2$ Fischer-Tropsch catalyst preparations: The 
chemistry of cobalt silicate formation during catalyst preparation or hydrogenation. Applied Catalysis A: General 2006, 311, 146-154.

95. Shi, L.; Li, D.; Hou, B.; Wang, Y.; Sun, Y., The modification of SiO2 by various organic groups and its influence on the properties of cobalt-based catalysts for Fischer-Tropsch synthesis. Fuel Processing Technology 2010, 91 (4), 394-398.

96. Sharma, B. K.; Sharma, M. P.; Kumar, S.; Roy, S. K.; Roy, S. K.; Badrinarayanan, S.; Sainkar, S. R.; Mandale, A. B.; Date, S. K., Studies on cobalt-based Fischer-Tropsch catalyst and characterization using SEM and XPS techniques. Applied Catalysis A: General 2001, 211 (2), 203211.

97. Iglesia, E.; Soled, S. L.; Fiato, R. A.; Via, G. H., Dispersion, Support, and Bimetallic Effects in Fischer-Tropsch Synthesis on Cobalt Catalysts. Natural Gas Conversion li 1994, 81, 433-442.

98. Zennaro, R.; Tagliabue, M.; Bartholomew, C. H., Kinetics of Fischer-Tropsch synthesis on titania-supported cobalt. Catalysis Today 2000, 58 (4), 309-319.

99. Tsakoumis, N. E.; Rønning, M.; Borg, Ø.; Rytter, E.; Holmen, A., Deactivation of cobalt based Fischer-Tropsch catalysts: A review. Catalysis Today 2010, 154 (3-4), 162-182.

100. Soled, S. L.; Iglesia, E.; Fiato, R. A.; Baumgartner, J. E.; Vroman, H.; Miseo, S., Control of Metal Dispersion and Structure by Changes in the Solid-State Chemistry of Supported Cobalt Fischer-Tropsch Catalysts. Topics in Catalysis 2003, 26 (1), 101-109.

101. Soled, S. L.; Iglesia, E.; Fiato, R.; Baumgartner, J. E.; Vroman, H.; Miseo, S., Control of Fischer-Tropsch activity and selectivity by changes in the solid state chemistry of supported. Abstracts of Papers of the American Chemical Society 2002, 223, 034-PETR.

102. Khodakov, A. Y.; Griboval-Constant, A.; Bechara, R.; Zholobenko, V. L., Pore Size Effects in Fischer Tropsch Synthesis over Cobalt-Supported Mesoporous Silicas. Journal of Catalysis 2002, 206 (2), 230-241.

103. Reuel, R. C.; Bartholomew, C. H., Effects of support and dispersion on the CO hydrogenation activity/selectivity properties of cobalt. Journal of Catalysis 1984, 85 (1), 78-88.

104. Iglesia, E.; Soled, S. L.; Baumgartner, J. E.; Reyes, S. C., Synthesis and catalytic properties of eggshell cobalt catalysts for the Fischer-Tropsch synthesis. Topics in Catalysis 1995, 2 (1-4), 17-27. 
105. Bessell, S., Support effects in cobalt-based fischer-tropsch catalysis. Applied Catalysis A: General 1993, 96 (2), 253-268.

106. n-octane. $\quad \underline{\text { http://fscimage.fishersci.com/msds/17260.htm; }}$ 1-Butanethiol. http://fscimage.fishersci.com/msds/97105.htm.

107. Borg, Ø.; Hammer, N.; Enger, B. C.; Myrstad, R.; Lindvåg, O. A.; Eri, S.; Skagseth, T. H.; Rytter, E., Effect of biomass-derived synthesis gas impurity elements on cobalt Fischer-Tropsch catalyst performance including in situ sulphur and nitrogen addition. Journal of Catalysis 2011, $279(1), 163-173$.

108. Bartholomew, C. H.; Agrawal, P. K.; Katzer, J. R., Sulfur Poisoning of Metals. In Advances in Catalysis, D.D. Eley, H. P. a. P. B. W., Ed. Academic Press: 1982; Vol. Volume 31, pp 135-242. 109. Agrawal, P. K.; Katzer, J. R.; Manogue, W. H., Methanation over transition metal catalysts: III. CoAl2O3 in sulfur-poisoning studies. Journal of Catalysis 1981, 69 (2), 327-344.

110. Visconti, C. G.; Tronconi, E.; Lietti, L.; Zennaro, R.; Forzatti, P., Development of a complete kinetic model for the Fischer-Tropsch synthesis over Co/Al2O3 catalysts. Chemical Engineering Science 62 (18-20), 5338-5343; Hanlon, R. T.; Satterfield, C. N., Reactions of selected 1-olefins and ethanol added during the Fischer-Tropsch synthesis. Energy \& Fuels 1988, 2 (2), 196-204.

111. Bartholomew, C. H.; Weatherbee, G. D.; Jarvi, G. A., Sulfur poisoning of nickel methanation catalysts : I. in situ deactivation by $\mathrm{H} 2 \mathrm{~S}$ of nickel and nickel bimetallics. Journal of Catalysis 1979, $60(2), 257-269$. 


\section{APPENDIX A: CALIBRATION OF MASS-FLOW CONTROLLERS (MFCs)}

The BenchCat unit provides four mass flow controllers (MFCs) to feed various gases to the process manifold. The unit uses Brooks $5850 \mathrm{~S}$ mass flow controllers. During the calibration, the gas flow is preset to a fixed value and then the system is allowed to reach a steady state. At steady state, the outlet flow rate of gas is measured by a bubble flow meter. Similarly, gas flow rate is measured at different set points and a calibration curve is obtained. In addition, the ambient temperature and pressure is recorded at the time of measurement, to calculate the flow rates at STP conditions. Assuming ideal gas laws, the calculations can be explained as shown below.

$$
V_{S T P}=V \times\left(\frac{P}{P_{S T P}}\right)\left(\frac{T_{S T P}}{T}\right)
$$

where,

$\begin{array}{lll}\mathrm{V} & =\text { volumetric flow rate of gas measured by flow-meter } & (\mathrm{cc} / \mathrm{min}) \\ \mathrm{V}_{\text {STP }} & =\text { volumetric flow rate of gas at STP conditions } & (\mathrm{cc} / \mathrm{min} \text { or sccm }) \\ \mathrm{P} & =\text { atmospheric pressure } & (\mathrm{psi}) \\ \mathrm{P}_{\text {STP }} & =\text { pressure at STP conditions }(14.7 \mathrm{psi}) & (\mathrm{psi}) \\ \mathrm{T} & =\text { atmospheric temperature } & (\mathrm{K}) \\ \mathrm{T}_{\text {STP }} & =\text { temperature at STP conditions (273K) } & (\mathrm{K})\end{array}$

For example, a gas flow of $50 \mathrm{cc} / \mathrm{min}$ measured at $298 \mathrm{~K}$ and $14.3 \mathrm{psi}$, is equivalent to $44.6 \mathrm{cc} / \mathrm{min}$ (or sccm) at standard conditions of $273 \mathrm{~K}$ and $14.7 \mathrm{psi}$. The MFC calibration charts showing flow rate in sccm with set point are shown in Figure A.1-Figure A.4. 


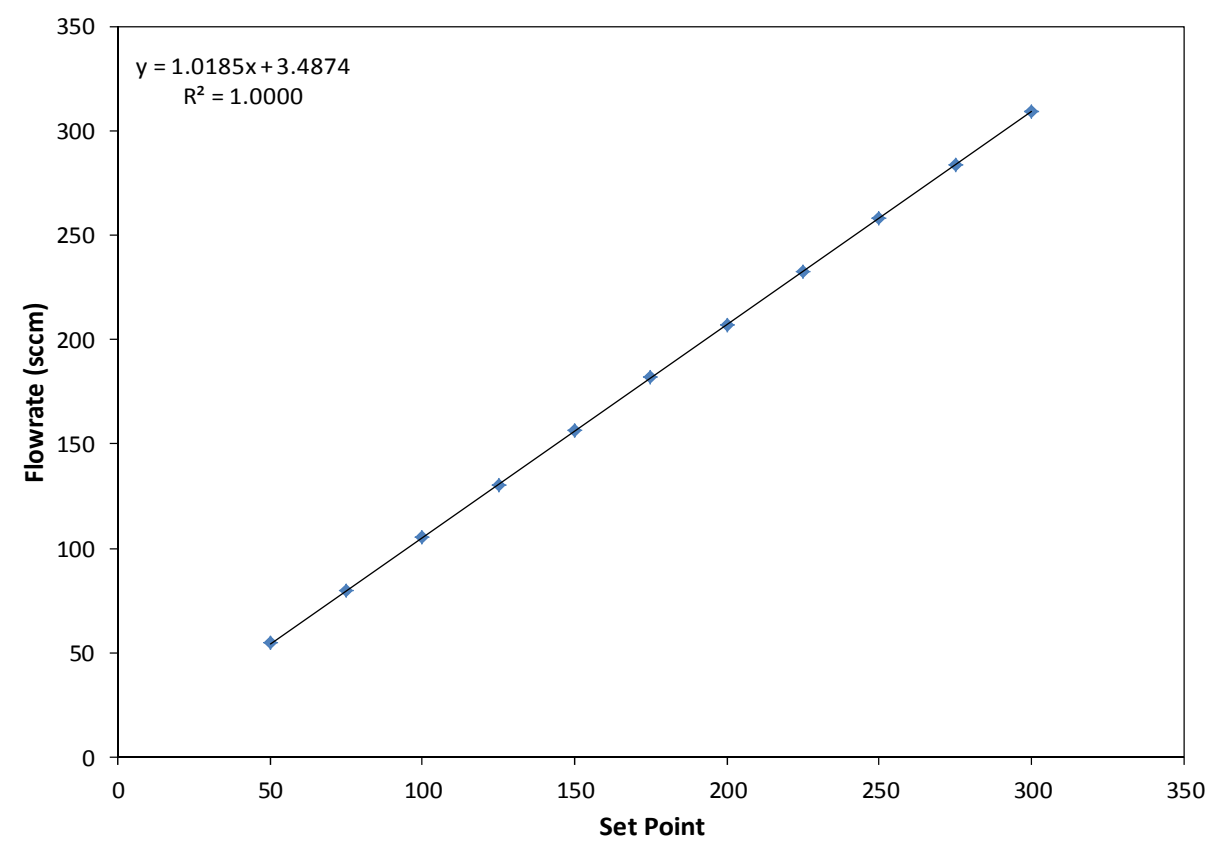

Figure A.1 $\mathrm{H}_{2}-\mathrm{MFC}$ calibrated with pure $\mathrm{H}_{2}$

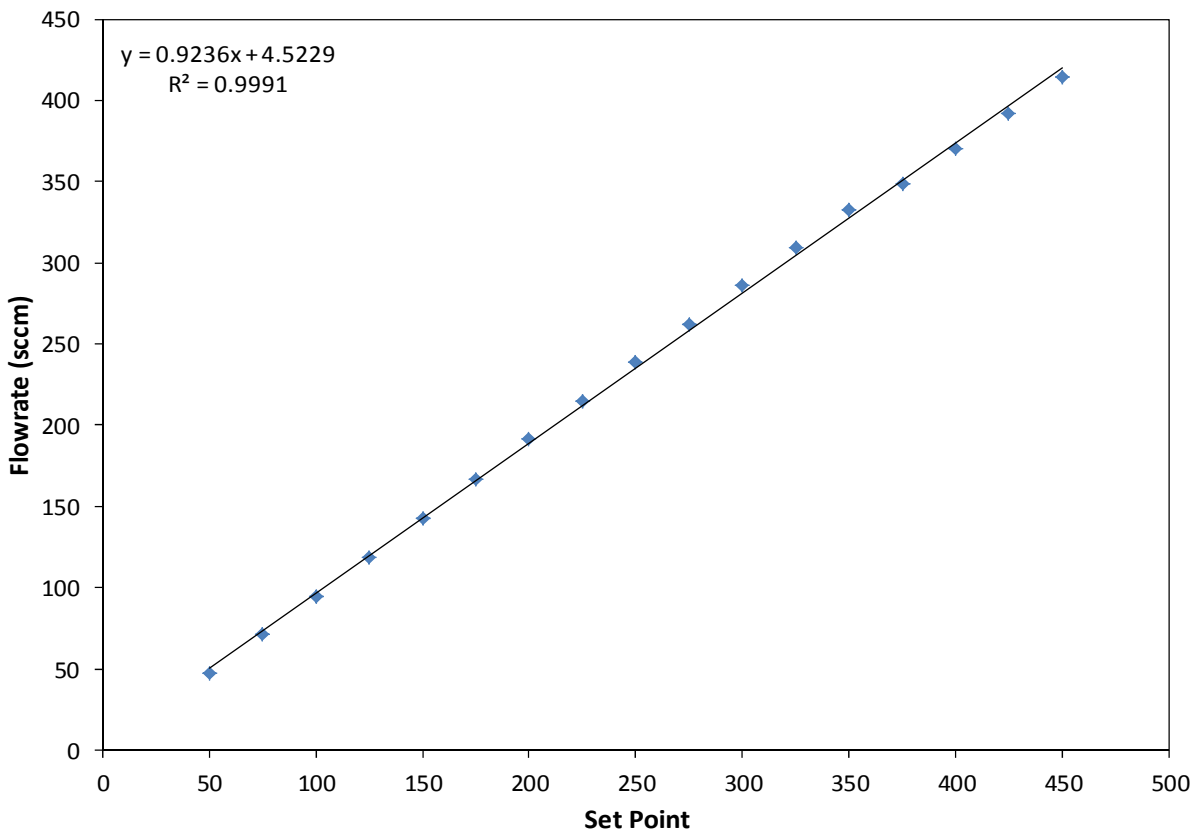

Figure A.2 CO-MFC calibrated with syngas mixture (He, $5 \%, \mathrm{H}_{2}, 60 \%$, Ar, $5 \%$, and CO, $30 \%$, mol basis) 


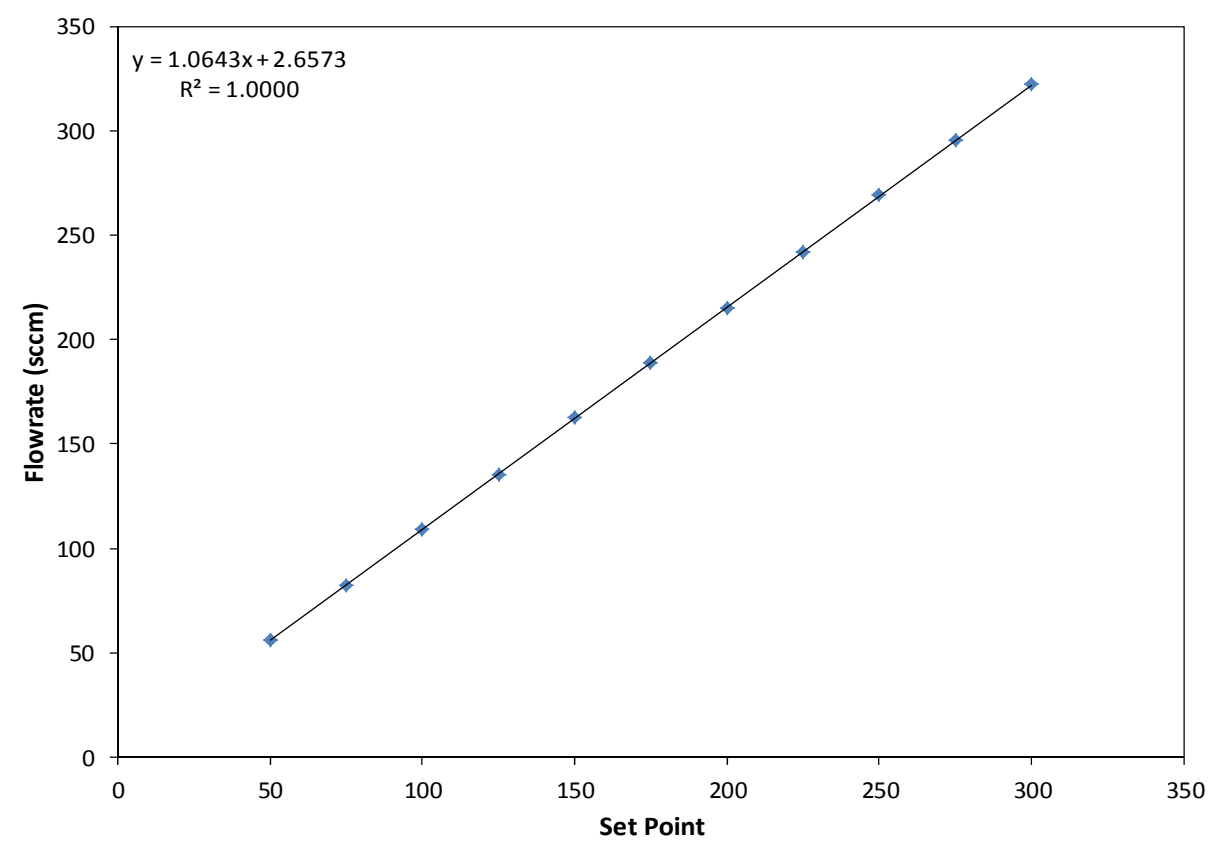

Figure A.3 He-MFC calibrated with pure He

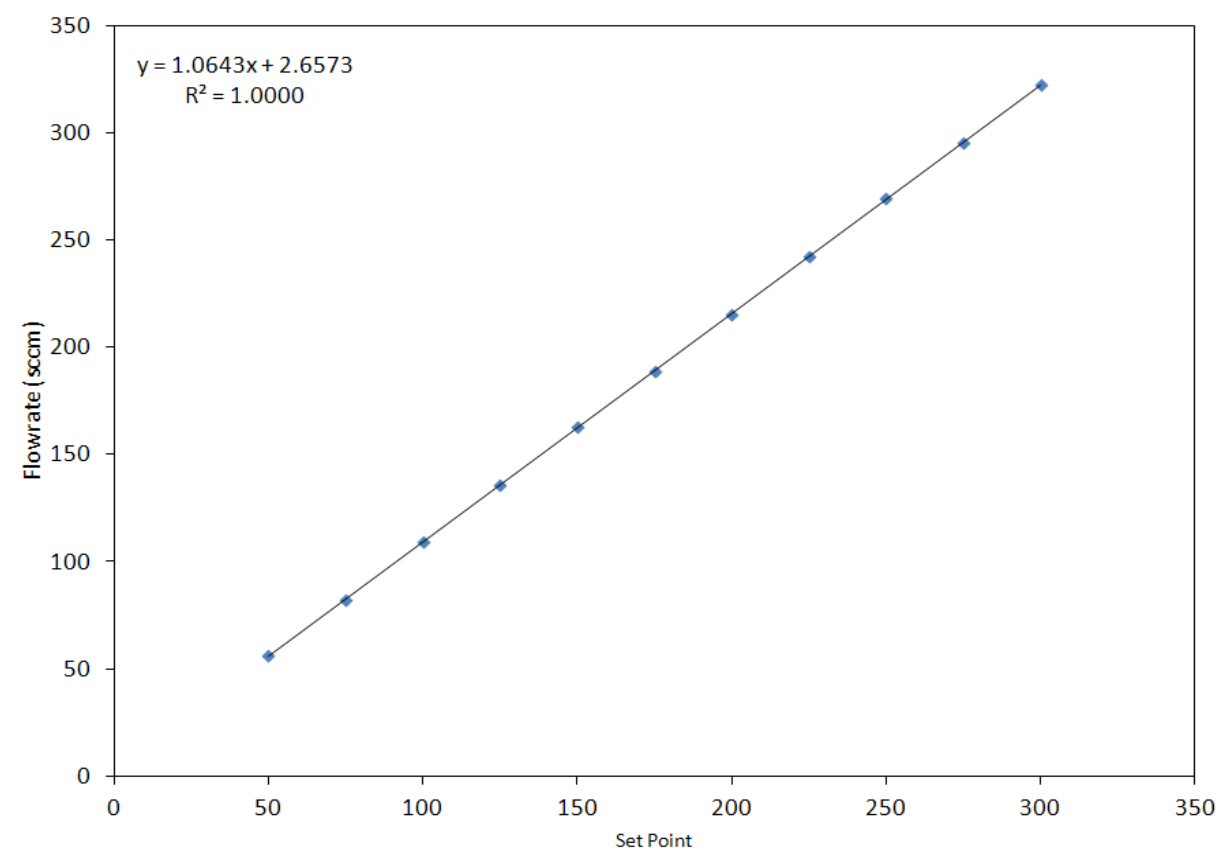

Figure A.4 $\mathrm{N}_{2}-$ MFC calibrated with pure $\mathrm{N}_{2}$ 


\section{APPENDIX B: ONLINE GAS-CHROMATOGRAPHY UNIT}

The product gases exiting the condensation stage of the BenchCat Unit are analyzed by the online Perkin-Elmer GC (Calurus 500). The GC contains of a HaySep packed column with a dual thermal-conductivity detector (TCD) and a capillary column with a flame-ionization detector (FID). The operating conditions for the GC are given below.

TCD

Temperature

Carrier Gas

Carrier Gas Supply Pressure

FID

Temperature

Carrier Gas

Carrier Gas Supply Pressure

Carrier Gas Flow

$\mathrm{H}_{2}$ flow

Air flow

Oven Temperature

Sample Injection $200^{\circ} \mathrm{C}$

$\mathrm{He}, \mathrm{N}_{2}$

90 psi

$250{ }^{\circ} \mathrm{C}$

$\mathrm{He}$

$30 \mathrm{psi}$

$36 \mathrm{ml} / \mathrm{min}$

$45 \mathrm{ml} / \mathrm{min}$

$450 \mathrm{ml} / \mathrm{min}$

$60^{\circ} \mathrm{C}$

$30 \mathrm{~min}$

\section{GC Columns}

18" RGAP, 1/8" Sf

17' RGA20, 1/8" Sf

7' RGAP 1/8" Sf

7" RGA, 1/8" Sf

7' HayeSep N 1/8" Sf

9' Molecular Sieve 13x 1/8" Sf

9' Molecular Sieve, 1/8" Sf

4' HayeSep T, 1/8" Sf for hydrocarbon

for hydrocarbon

for hydrocarbon

for hydrocarbon

for permanent gases

for permanent gases

for permanent gases

for permanent gases 


\section{APPENDIX C: CALIBRATION OF ONLINE GC}

\section{C.1 TCD Calibration}

The calibration charts for $\mathrm{He}, \mathrm{H}_{2}, \mathrm{CO}_{2}, \mathrm{Ar}, \mathrm{CH}_{4}$ and $\mathrm{CO}$ are shown in Figure A.5-Figure A.10. The slope from the calibration chart (i.e. GC area/mol) is used to calculate the relative response factors (rRF) for each component relative to the internal standard. Accordingly, He is assigned as an internal standard for the quantification of $\mathrm{H}_{2}$ and $\mathrm{CO}_{2}$. On the other hand, $\mathrm{Ar}$ is an internal standard for $\mathrm{CH}_{4}$ and $\mathrm{CO}$. Therefore, the rRF for $\mathrm{H}_{2}$ can be calculated from the slope of $\mathrm{H}_{2}$ and the slope of that internal standard $\mathrm{He}$.

$$
\text { relative response factor of component } X,(r R F)_{X}=\left(\frac{\frac{A_{X}}{C_{X}}}{\frac{A_{H e, A r}}{C_{H e, A r}}}\right)=\frac{\text { slope }_{X}}{\text { slope }_{H e, A r}}
$$

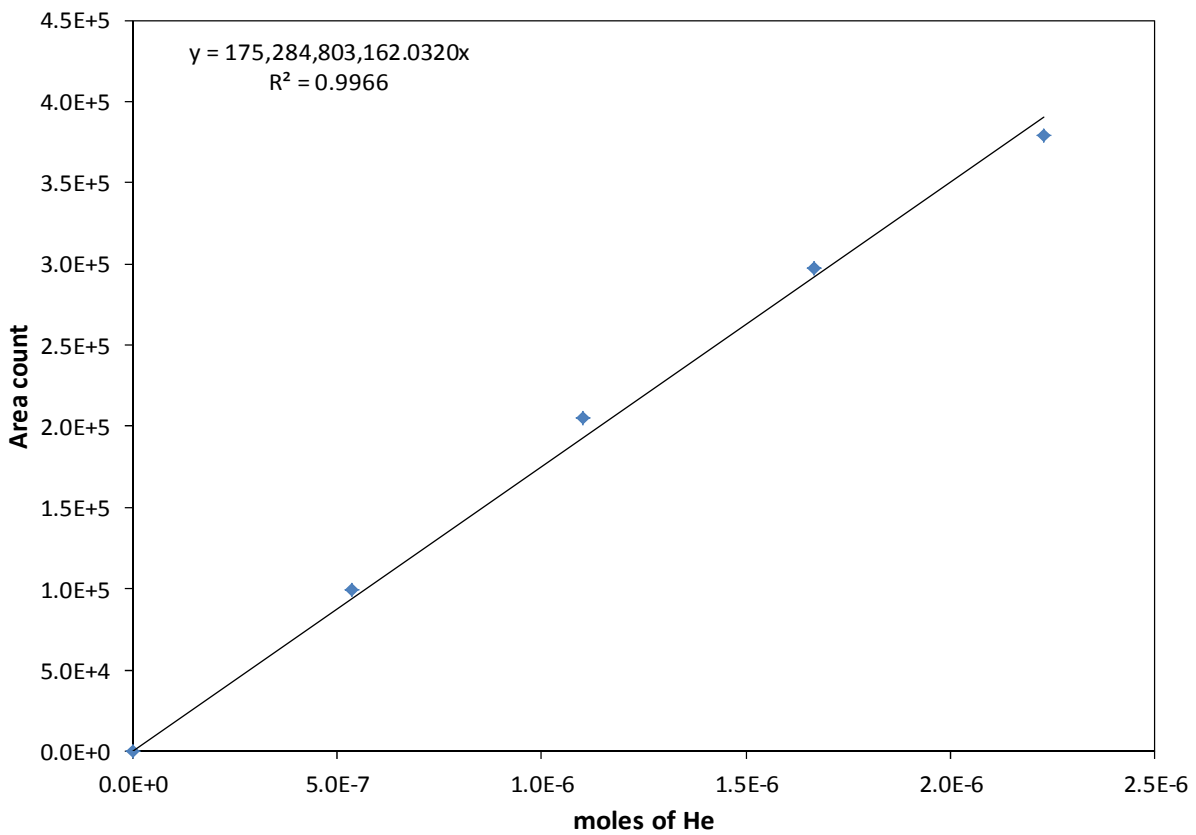

Figure A.5 GC calibration for He 


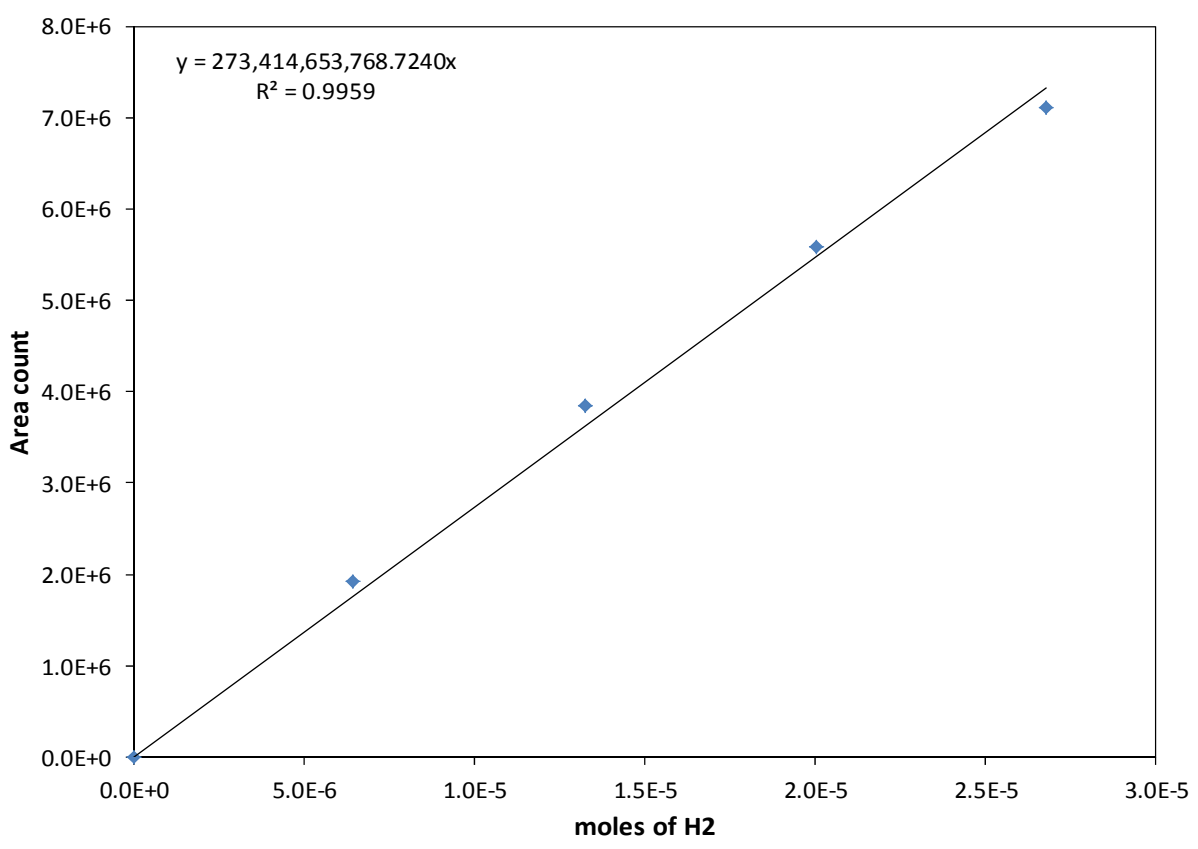

Figure A.6 GC calibration curve for $\mathrm{H}_{2}$

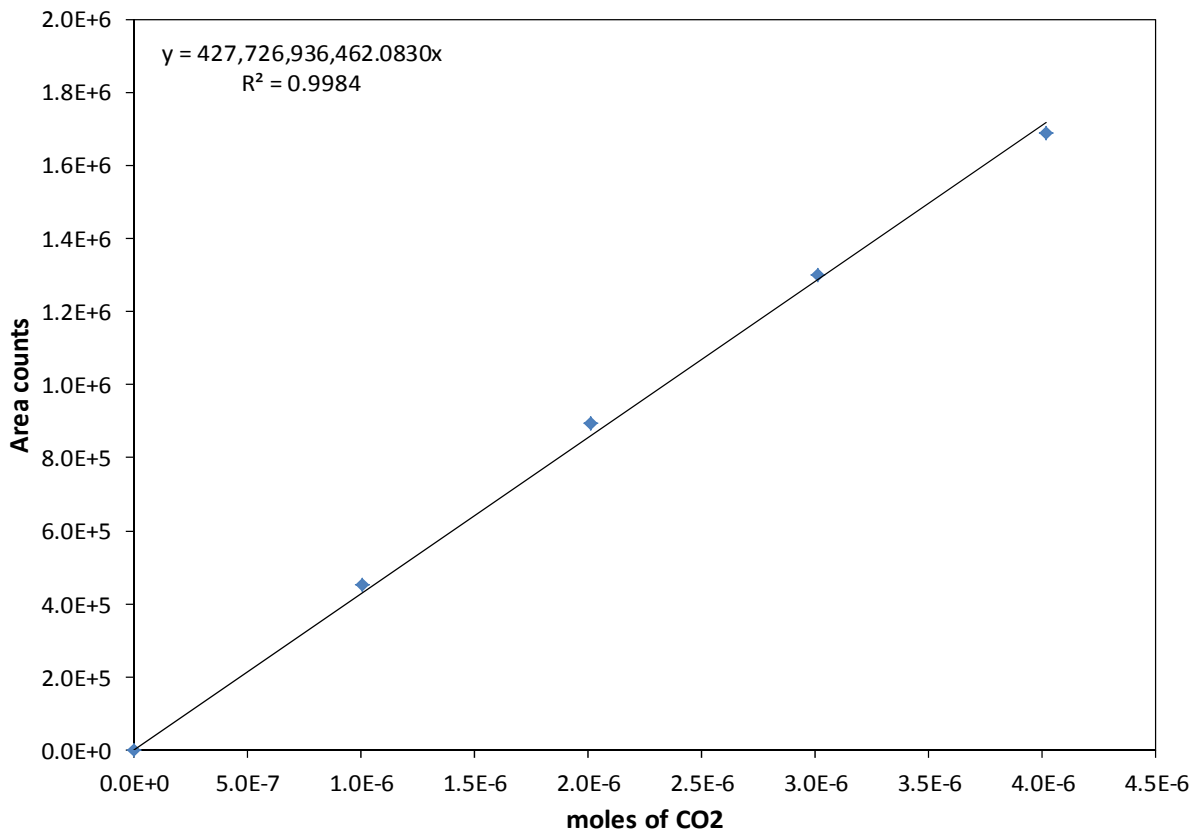

Figure A.7 GC calibration curve for $\mathrm{CO}_{2}$ 


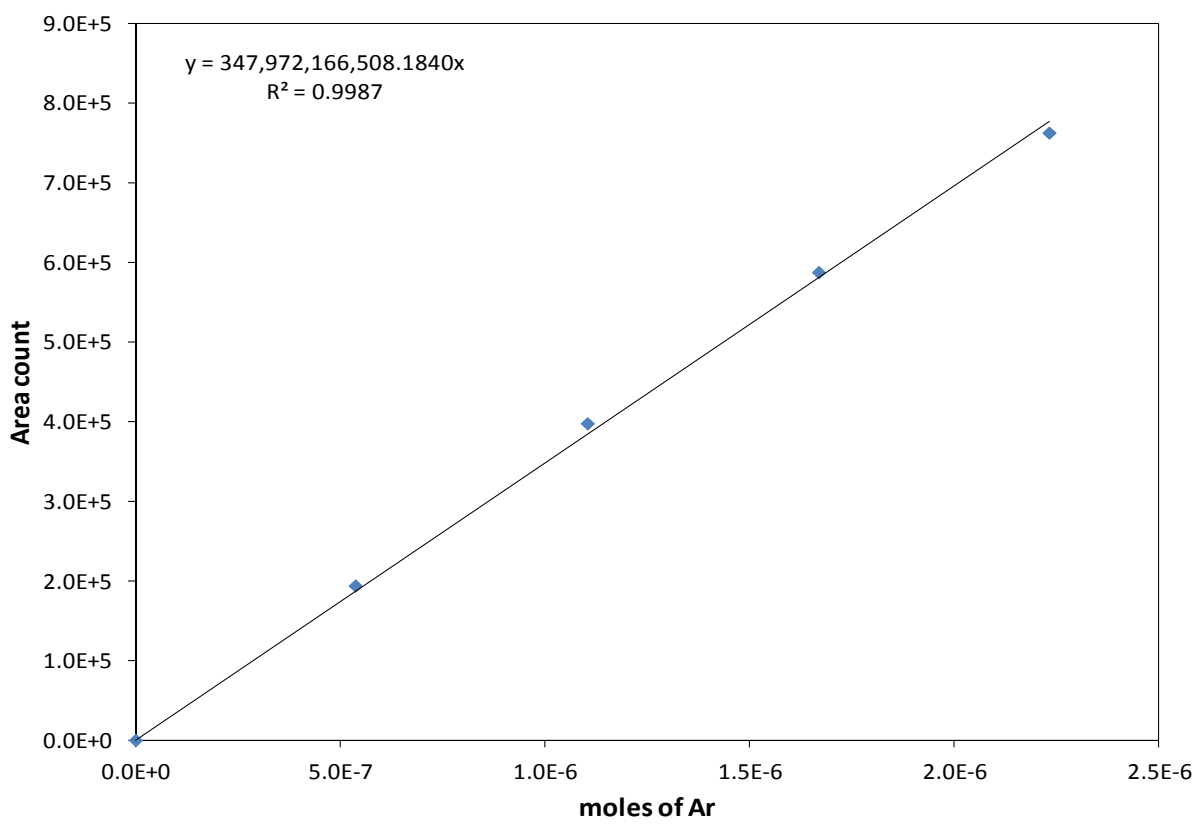

Figure A.8 GC calibration curve for $\mathrm{Ar}$

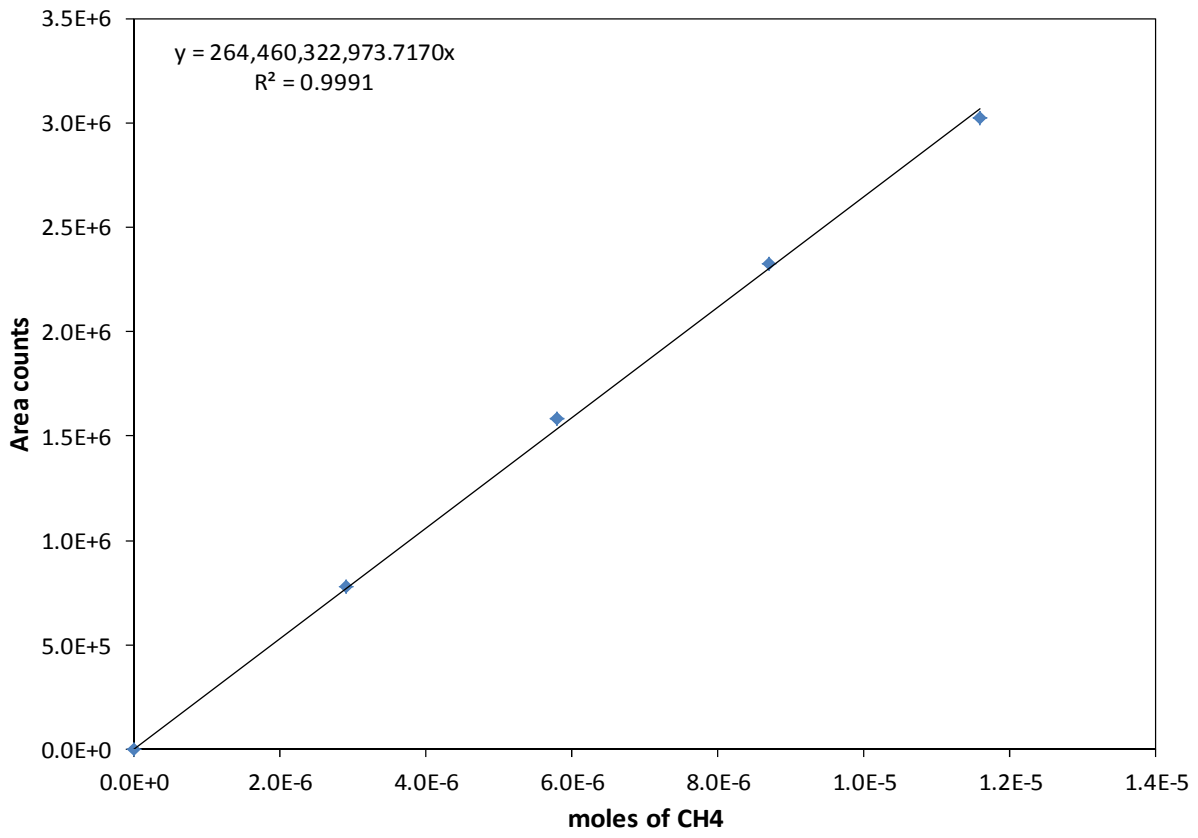

Figure A.9 GC calibration curve for $\mathrm{CH}_{4}$ 


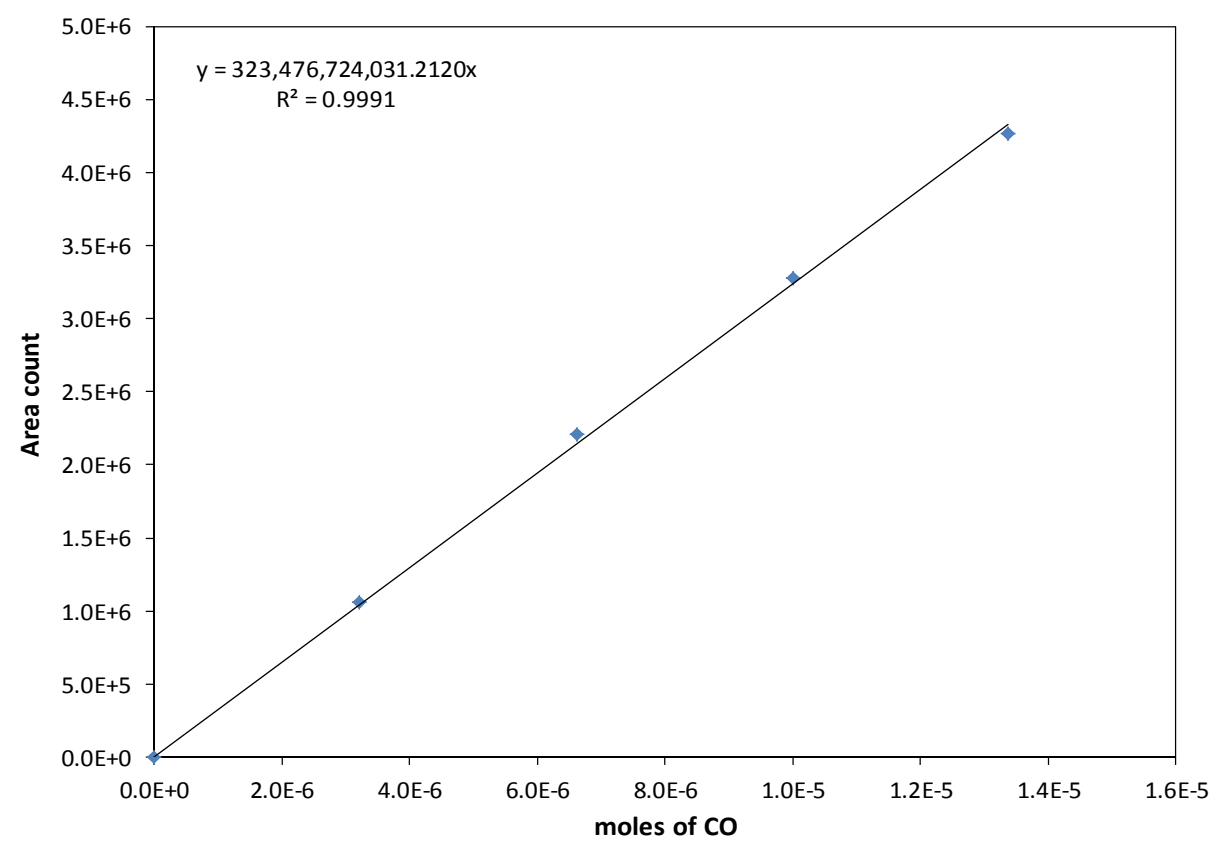

Figure A.10 GC calibration curve for CO

By definition, the rRF values of the internal standards are unity in Table A.1. In addition, the rRF values of other TCD components are also listed Table A.1.

Table A.1 rRF of TCD components of online GC

\begin{tabular}{|c|c|c|}
\hline Gas & Slopes & rRF \\
\hline $\mathrm{He}$ & $175,284,803,162$ & 1.00 \\
\hline $\mathrm{H}_{2}$ & $273,414,653,768$ & 1.56 \\
\hline $\mathrm{CO}_{2}$ & $427,726,936,462$ & 2.44 \\
\hline $\mathrm{Ar}$ & $347,972,166,508$ & 1.00 \\
\hline $\mathrm{N}_{2}$ & $306,487,860,300$ & 0.88 \\
\hline $\mathrm{CH}_{4}$ & $264,460,322,973$ & 0.76 \\
\hline $\mathrm{CO}$ & $323,476,724,031$ & 0.93 \\
\hline
\end{tabular}

\section{C.2 FID Calibration}

The $\mathrm{CH}_{4}$ in the product stream is analyzed by both TCD and FID and can be used as a tie component. Therefore, it is considered as an internal standard for hydrocarbon analysis from FID. Therefore, equation C.1 for FID analysis becomes: 


$$
\text { relative response factor of component } X,(r R F)_{X}=\left(\frac{\frac{A_{X}}{C_{X}}}{\frac{A_{C H_{4}}}{C_{C H_{4}}}}\right)=\frac{\text { slope }_{X}}{\operatorname{slope}_{C H_{4}}}
$$

The calculated rRF values for FID components are listed in Table A.2. By definition, the rRF for $\mathrm{CH}_{4}$ is unity.

Table A.2 rRF for FID components of online GC

\begin{tabular}{|c|c|c|}
\hline Gas & Slopes & rRF \\
\hline $\mathrm{C}_{5+}$ & $4.18646 \mathrm{E}+12$ & 10.20 \\
\hline $\mathrm{CH}_{4}$ & $4.10518 \mathrm{E}+11$ & 1.00 \\
\hline $\mathrm{C}_{2} \mathrm{H}_{6}$ & $7.81592 \mathrm{E}+11$ & 1.90 \\
\hline $\mathrm{C}_{2} \mathrm{H}_{4}$ & $7.81592 \mathrm{E}+11$ & 1.90 \\
\hline $\mathrm{C}_{3} \mathrm{H}_{8}$ & $1.15659 \mathrm{E}+12$ & 2.82 \\
\hline $\mathrm{C}_{3} \mathrm{H}_{6}$ & $1.1643 \mathrm{E}+12$ & 2.84 \\
\hline $\mathrm{i}-\mathrm{C}_{4} \mathrm{H}_{10}$ & $1.5231 \mathrm{E}+12$ & 3.71 \\
\hline $\mathrm{C}_{3} \mathrm{H}_{4}$ & $1.05729 \mathrm{E}+12$ & 2.58 \\
\hline $\mathrm{n}-\mathrm{C}_{4} \mathrm{H}_{10}$ & $1.56 \mathrm{E}+12$ & 3.81 \\
\hline $1-\mathrm{C}_{4} \mathrm{H}_{8}$ & $1.36 \mathrm{E}+12$ & 3.32 \\
\hline $\mathrm{t}-\mathrm{C}_{4} \mathrm{H}_{8}$ & $1.57 \mathrm{E}+12$ & 3.83 \\
\hline $1,3-\mathrm{C}_{4} \mathrm{H}_{6}$ & $1.539 \mathrm{E}+12$ & 3.75 \\
\hline $\mathrm{i}-\mathrm{C}_{5} \mathrm{H}_{12}$ & $1.878 \mathrm{E}+12$ & 4.57 \\
\hline $\mathrm{n}-\mathrm{C}_{5} \mathrm{H}_{12}$ & $1.01 \mathrm{E}+12$ & 2.46 \\
\hline
\end{tabular}




\section{APPENDIX D : OFFLINE GAS-CHROMATOGRAPHY UNIT}

The liquid products collected are analyzed by the offline GC (HP 3400). The GC used for liquid analysis is located in the ERB lab of WVU. The organic phase of the liquid samples is analyzed with a capillary column and $\operatorname{FID}(A)$, whereas the aqueous phase is analyzed by a Propak-Q packed column and FID(B). The unit is equipped with an auto injector operated by an air actuator. The operating conditions are listed in Table A.3.

Table A.3 Liquid GC Operating Conditions

\begin{tabular}{|c|c|c|}
\hline Detector Type & FID A & FID B \\
\hline Analysis & Oil phase hydrocarbon & Aqueous phase alcohol \\
\hline Column & $\begin{array}{l}\text { J and W scientific DB } 1 \\
\text { capillary column }\end{array}$ & $\begin{array}{c}\text { Restek packed column, TX-TA 80/100, } \\
\text { length: } 6 \mathrm{ft} \text {, ID: } 2.00 \mathrm{~mm} \text {, OD: } 1 / 8 \mathrm{in}, \text { SILCO } \\
\text { VAR } 3400\end{array}$ \\
\hline Carrier gas & $\mathrm{N}_{2}$ & $\mathrm{~N}_{2}$ \\
\hline $\begin{array}{l}\text { Carrier gas inlet } \\
\text { pressure (psig) }\end{array}$ & 6 & 82 \\
\hline $\begin{array}{l}\text { Period of analysis } \\
\text { (min) }\end{array}$ & 30 & 30 \\
\hline $\begin{array}{l}\text { Initial column } \\
\text { Temperature }\left({ }^{\circ} \mathrm{C}\right)\end{array}$ & 50 & 50 \\
\hline $\begin{array}{l}\text { Final column } \\
\text { Temperature }\left({ }^{\circ} \mathrm{C}\right)\end{array}$ & 290 & 300 \\
\hline $\begin{array}{l}\text { Column initial hold } \\
\text { time (min) }\end{array}$ & 0 & 0 \\
\hline $\begin{array}{l}\text { Column temperature } \\
\text { rate }\left({ }^{\circ} \mathrm{C} / \mathrm{min}\right)\end{array}$ & 5 & 10 \\
\hline $\begin{array}{l}\text { Initial injection } \\
\text { Temperature }\left({ }^{\circ} \mathrm{C}\right)\end{array}$ & 200 & 200 \\
\hline $\begin{array}{l}\text { Final injection } \\
\text { Temperature }\left({ }^{\circ} \mathrm{C}\right)\end{array}$ & 250 & 250 \\
\hline $\begin{array}{l}\text { Injection hold time } \\
\text { (min) }\end{array}$ & 1 & 0 \\
\hline $\begin{array}{l}\text { Injection temperature } \\
\text { rate }\left({ }^{\circ} \mathrm{C} / \mathrm{min}\right)\end{array}$ & 10 & 10 \\
\hline $\begin{array}{l}\text { Detector temperature } \\
\left({ }^{\circ} \mathrm{C}\right)\end{array}$ & 300 & 300 \\
\hline
\end{tabular}




\section{APPENDIX E: CALIBRATION OF OFFLINE GC}

\section{E.1 Oil Phase Analysis}

The retention times of paraffins were determined with the RESTEK D-2887 standard. Carbon disulfide is used as the solvent for preparation of the oil sample. The olefins present in the product are determined to elute before the paraffins with same carbon number. Also the FID response for the hydrocarbons is assumed to be linear with respect to number of carbon atoms in the molecule.

\section{E.2 Aqueous Phase Analysis}

For the aqueous phase analysis, the cyclohexanol is determined as an internal standard and de-ionized water is used as a solvent. The retention times for alcohol are determined by the reference standards (ACCUSTANDARD PS-111). For calibration purpose, each alcohol from the reference standard is added to a known quantity of cyclohexanol and water. The weight and FID area of each mixture of an alcohol from the reference standard, and cyclohexanol are listed in Table A.4.

Table A.4 FID Areas of reference standards and cyclohexanol

\begin{tabular}{|l|c|c|c|c|}
\hline \multicolumn{3}{|c|}{ Reference Standard } & \multicolumn{2}{c|}{ Cyclohexanol } \\
\hline Alcohol & $\mathrm{Wt}_{\text {ref }}(\mu \mathrm{g})$ & $\mathrm{A}_{\text {ref }}$ & $\mathrm{Wt}_{\text {cyclohex }}(\mu \mathrm{g})$ & $\mathrm{A}_{\text {cyclohex }}$ \\
\hline Methanol & 383.7 & 84286 & 22.2 & 19451 \\
\hline Ethanol & 225.6 & 82843 & 18.3 & 16693 \\
\hline 1-Propanol & 305.1 & 78959 & 19.5 & 16539 \\
\hline 1-Butanol & 391.4 & 82482 & 18.1 & 18344 \\
\hline 1-Pentanol & 388.3 & 77869 & 18.8 & 19888 \\
\hline
\end{tabular}




\section{F.1 Carbon Monoxide}

Source: www.airgas.com

\section{Material Safety Data Sheet}

Carbon Monoxide

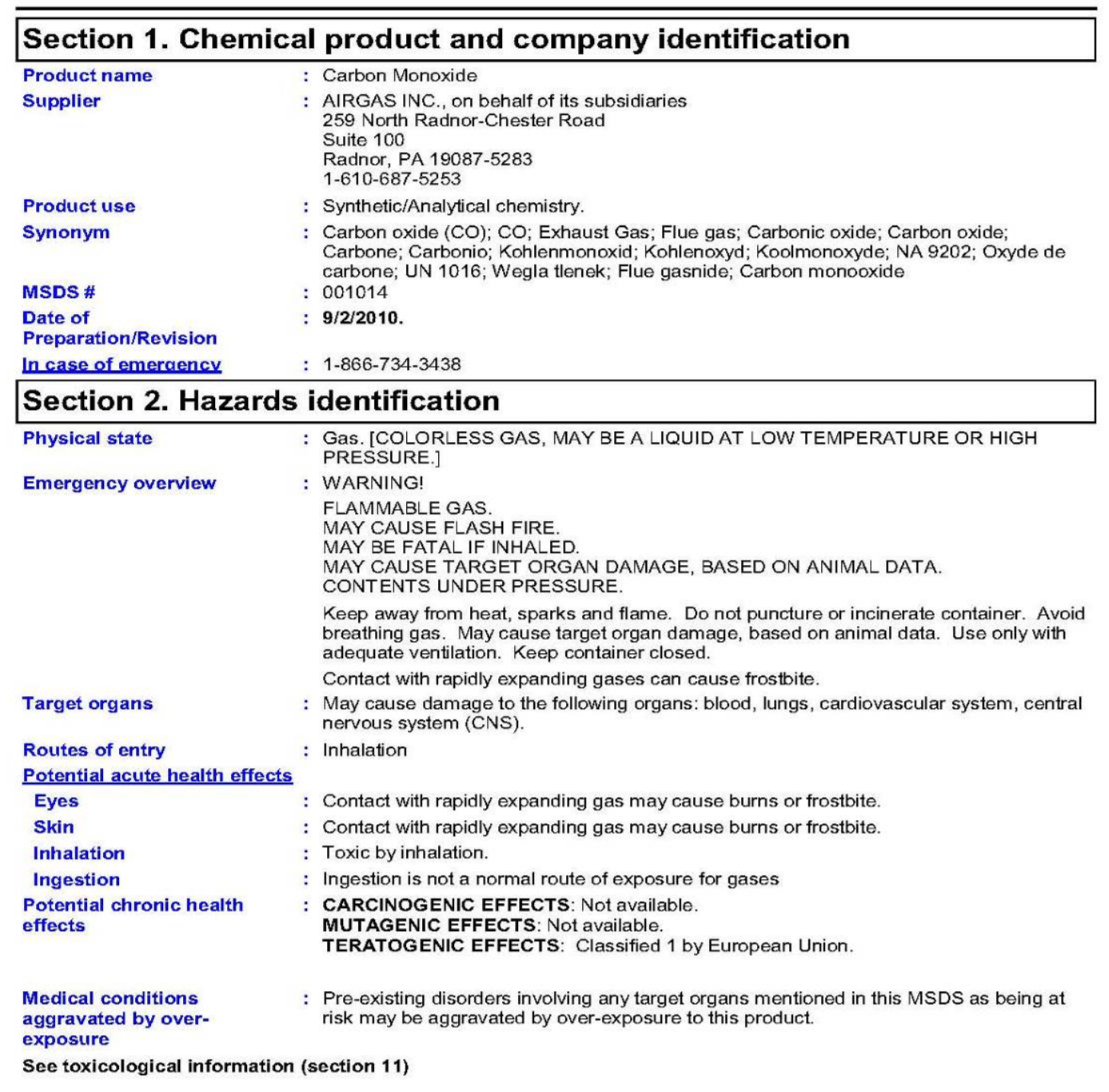




\section{F.2 Hydrogen}

Source: www.airgas.com

\section{Material Safety Data Sheet}

\section{Airgas}

Hydrogen

\begin{tabular}{|c|c|}
\hline \multicolumn{2}{|c|}{ Section 1. Chemical product and company identification } \\
\hline Product name & : Hydrogen \\
\hline Supplier & $\begin{array}{l}\text { : AIRGAS INC., on behalf of its subsidiaries } \\
259 \text { North Radnor-Chester Road } \\
\text { Suite } 100 \\
\text { Radnor, PA } 19087-5283 \\
\text { 1-610-687-5253 }\end{array}$ \\
\hline Product use & : Synthetic/Analytical chemistry. \\
\hline Synonym & $\begin{array}{l}\text { : Dihydrogen; o-Hydrogen; p-Hydrogen; Molecular hydrogen; H2; UN 1049; UN 1966; } \\
\text { Liquid hydrogen (LH2 or LH2) }\end{array}$ \\
\hline MSDS \# & : 001026 \\
\hline $\begin{array}{l}\text { Date of } \\
\text { Preparation/Revision }\end{array}$ & : 4/26/2010. \\
\hline In case of emergency & : 1-866-734-3438 \\
\hline \multicolumn{2}{|c|}{ Section 2. Hazards identification } \\
\hline Physical state & : Gas or Liquid. \\
\hline \multirow[t]{4}{*}{ Emergency overview } & : WARNING! \\
\hline & $\begin{array}{l}\text { GAS: } \\
\text { CONTENTS UNDER PRESURE. } \\
\text { Extremely flammable } \\
\text { Do not puncture or incinerate container. } \\
\text { Can cause rapid suffocation. } \\
\text { May cause severe frostbite. } \\
\text { LIQUID: } \\
\text { Extremely flammable } \\
\text { Extremely cold liquid and gas under pressure. } \\
\text { Can cause rapid suffocation. } \\
\text { May cause severe frostbite. }\end{array}$ \\
\hline & Do not puncture or incinerate container. \\
\hline & Contact with rapidly expanding gases or liquids can cause frostbite. \\
\hline Routes of entry & : Inhalation \\
\hline \multicolumn{2}{|c|}{ Potential acute health effects } \\
\hline Eyes & $\begin{array}{l}\text { : Contact with rapidly expanding gas may cause burns or frostbite. Contact with cryogenic } \\
\text { liquid can cause frostbite and cryogenic burns. }\end{array}$ \\
\hline Skin & $\begin{array}{l}\text { : Contact with rapidly expanding gas may cause burns or frostbite. Contact with cryogenic } \\
\text { liquid can cause frostbite and cryogenic burns. }\end{array}$ \\
\hline Inhalation & : Acts as a simple asphyxiant. \\
\hline Ingestion & $\begin{array}{l}\text { : Ingestion is not a normal route of exposure for gases Contact with cryogenic liquid can } \\
\text { cause frostbite and cryogenic burns. }\end{array}$ \\
\hline $\begin{array}{l}\text { Potential chronic health } \\
\text { effects }\end{array}$ & $\begin{array}{l}\text { : CARCINOGENIC EFFECTS: Not available. } \\
\text { MUTAGENIC EFFECTS: Not available. } \\
\text { TERATOGENIC EFFECTS: Not available. }\end{array}$ \\
\hline $\begin{array}{l}\text { Medical conditions } \\
\text { aggravated by over- } \\
\text { exposure }\end{array}$ & : Acute or chronic respiratory conditions may be aggravated by overexposure to this gas. \\
\hline See toxicological infor & \\
\hline
\end{tabular}




\section{F.3 Butanethiol}

Source: www.fishersci.com

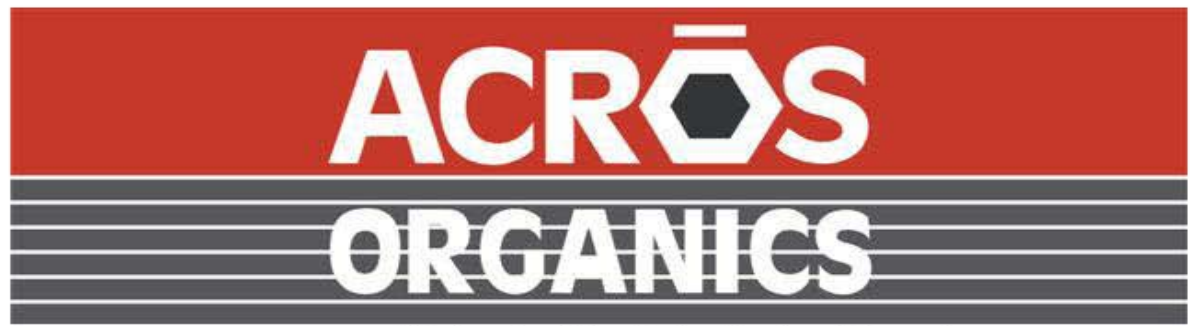

Creation Date 23-Apr-2010

Material Safety Data Sheet

Revision Number 1

\section{PRODUCT AND COMPANY IDENTIFICATION}

Product Name

Cat No.

Synonyms

Recommended Use

Compamy

Fisher Scientific

One Reagent Lane

Fair Lawn, NJ 07410

Tel: (201) 796-7100

1-Butanethiol

AC220620000; AC220620010; AC220620050; A C220620500; A C220622500

n-Butyl mercaptan

Laboratory chemicals

Entity /Business Name

Acros Organics

One Reagent Lane

Fair Lawn, NJ 07410
Emergency Telephone Number For information in the US, call: 800-ACROS-01 For information in Europe, call: +32145752

Emergency Number, Europe: +3214575299 Emergency Number, US: 201-796-7100

CHEMTREC Phone Number, US: 800-4249300

CHEMTREC Phone Number, Europe: 703$527-3887$

\section{HAZARDS IDENTIFICATION}

\section{DANGER!}

Emergency Overview

Flammable liquid and vapor. Harmful by inhalation and if swallowed. Irritating to eyes, respiratory system and skin Appearance Colorless

Physical State Liquid

odor Garlic-like, Stench

Target Organs

Eyes, Skin, Respiratory system

Potential Health Effects

Acute Effects

Page 1/8 


\title{
F.4 Cobalt Nitrate Hexahydrate
}

\section{Source: www.fishersci.com}

\author{
(F) Fisher Scientific \\ Material Safety Data Sheet \\ Cobalt(II) nitrate hexahydrate \\ MSDS\# 05290 \\ Section 1 - Chemical Product and Company Identification \\ MSDS \\ Name: \\ Catalog \\ Numbers: \\ AC213090000, AC213090010, AC213090050, AC213091000, AC213095000, AC219210000 \\ Synonyms: \\ AC219210000, AC219211000, AC219215000, AC423580000, AC423580025, AC423580050 \\ AC423580050, AC423581000, AC423585000, C378-500 \\ Nitric acid, cobalt $(2+)$ salt, hexahy drate; Cobaltous nitrate hexahydrate. \\ Company Identification: \\ Fisher Scientific \\ For information in the US, call: \\ One Reagent Lane \\ Fair Lawn, NJ 07410 \\ Emergency Number US: \\ 201-796-7100 \\ CHEM TREC Phone Number, US \\ 201-796-7100 \\ $800-424-9300$ \\ Section 2 - Composition, In formation on Ingredients \\ Risk Phrases:
CAS\#:
Chemical Name:
$\%$ :
EINECS\#:
Hazard Symbols:
Text for R-phrases: see Sect
Hazard Symbo \\ Risk Phrases: \\ 10026-22-9 \\ Cobalt(II) nitrate hexahydrate \\ $>98$ \\ unlisted \\ $\mathrm{TO}$

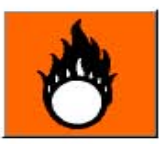 \\ $2236 / 37 / 384042 / 438$ \\ Section 3 - Hazards Identification \\ EMERGENCY OVERVIEW \\ Danger! Strong oxidizer. Contact with other material may cause a fire. Harmful if swallowed. Potential cancer hazard. May \\ cause allergic respiratory and skin reaction. Causes eye, skin, and respiratory tract irritation. Target Organs: Heart, 1 ungs, \\ respiratory system, red blood cells, reproductive system. \\ Potential Health Effects \\ Eye: Causes eye irritation. \\ Skin: Causes skin irritation. May cause skin sensitization, an allergic reaction, which becomes evident upon re- \\ exposure to this material. May be harmful if absorbed through the skin. \\ Ingestion: Harmful if swallowed. May cause irritation of the digestive tract. \\ Inhalation: Causes respiratory tract irritation. May be harmful if inhaled. May cause respiratory sensitization \\ Chronic: Repeated exposure may cause allergic respiratory reaction (asthma). Cobalt compounds may cause cancer \\ based up on animal studies.
}

\section{Section 4 - First Aid Measures}

Flush eyes with plenty of water for at least 15 minutes, occasionally lifting the upper and lower eyelids. Get 


\section{F.5 Silica}

Source:www.fishersci.com

http://fscimage. fishersci.com/msds/09890.htm

\section{Material Safety Data Sheet \\ Sand}

ACC\# 09890

\begin{tabular}{|c|c|c|c|}
\hline \multicolumn{4}{|c|}{ Section 1 - Chemical Product and Company Identification } \\
\hline \multicolumn{4}{|c|}{$\begin{array}{l}\text { MSDS Name: Sand } \\
\text { Catalog Numbers: AC370940000, AC370940010, AC370940050, AC370941000, AC393300000, } \\
\text { AC393300010, AC393302500, S80156, S801561, S93346, S23-3, S23-50, S25-10, S25-3, S25-500 } \\
\text { Synonyms: Quartz; Silicon dioxide; Silicon dioxide; Quartz; Sea Sand. } \\
\text { Company Identification: } \\
\quad \text { Fisher Scientific } \\
\quad \text { 1 Reagent Lane } \\
\quad \text { Fair Lawn, NJ 07410 } \\
\text { For information, call: } 201-796-7100 \\
\text { Emergency Number: } 201-796-7100 \\
\text { For CHEMTREC assistance, call: } 800-424-9300 \\
\text { For International CHEMTREC assistance, call: } 703-527-3887\end{array}$} \\
\hline \multicolumn{4}{|c|}{ Section 2 - Composition, Information on Ingredients } \\
\hline CAS\# & Chemical Name & Percent & EINECS/ELINCS \\
\hline $14808-60-7$ & jana & & \\
\hline
\end{tabular}

\section{Section 3 - Hazards Identification}

\section{EMERGENCY OVERVIEW}

Appearance: light beige to gray powder.

Warning! Cancer hazard. May cause eye, skin, and respiratory tract irritation.

Target Organs: Respiratory system, eyes, skin.

Potential Health Effects

Eye: Dust may cause mechanical irritation.

Skin: Dust may cause mechanical irritation.

Ingestion: May cause irritation of the digestive tract.

Inhalation: Dust is irritating to the respiratory tract.

Chronic: May cause cancer in humans. Prolonged exposure to respirable crystalline quartz may cause delayed lung injury/fibrosis (silicosis).

\section{Section 4 - First Aid Measures}

Eyes: Immediately flush eyes with plenty of water for at least 15 minutes, occasionally lifting the upper and lower eyelids. If irritation develo ps, get medical aid.

Skin: Immediately flush skin with plenty of water for at least 15 minutes while removing contaminated clothing and shoes. Get medical aid if irritation develops or persists. 


\title{
F.6 Nitrilotriacetic Acid (NTA)
}

\section{Source: www.fishersci.com}

\author{
(F) Fisher Scientific \\ Material Safety Data Sheet \\ Nitrilotriacetic Acid MSDS\# 90652 \\ Section 1 - Chemical Product and Company Identification \\ MSDS Name: Nitrilotriacetic Acid \\ Catalog Numbers: \\ Synonyms: $\quad$ Aminotriacetic Acid; N,N-Bis (Carboxymethyl)Glycine; Triglycine; Triglycollamic Acid; Chel NTA \\ Fisher Scientific UK \\ Bishop Meadow Road, Loughborough \\ Leics. LE11 5RG \\ For information in Europe, call: $\quad$ (01509) 231166 \\ Emergency Number, Europe: $\quad 01509231166$ \\ Section 2 - Composition, In formation on Ingredients \\ CAS\#: \\ 139-13-9 \\ Chemical Name: \\ Nitriloacetic Acid \\ 100 \\ 205-355-7 \\ EINECS\#: \\ $\mathrm{XN}$

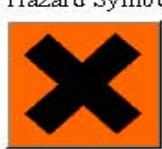 \\ Risk Phrases: \\ $20 / 21 / 2240$ \\ Section 3 - Hazards Identification \\ EMERGENCY OVERVIEW \\ Warning! May be harmful if swallowed. May cause kidney damage. May cause eye and skin irritation. May cause \\ respiratory and digestive tract irritation. May cause cancer based on animal studies. Potential cancer hazard. Target Organs \\ Kidneys, bladder. \\ Potential Health Effects \\ Eye: Dust may cause mechanical irritation. \\ Skin: Dust may cause mechanical irritation. \\ Ingestion. May cause gastrointestinal irritati on with nausea, vomiting and diarrhea. May cause kidney damage. May be \\ harmful if swallowed. \\ Inhalation: Dust is irritating to the respiratory tract. \\ Chronic: Possible cancer hazard based on tests with laboratory animals. May cause kidney injury.

$$
\text { Section } 4 \text { - First Aid Measures }
$$ \\ Eyes: Flush eyes with plenty of water for at least 15 minutes, occasionally lifting the upper and lower eyelids. Get \\ medical aid. \\ Skin: Get medical aid if irritation develops or persists. Wash cl othing before reuse. Flush skin with plenty of so ap \\ and water. \\ Ingestion: Do not induce vomiting. If victim is conscious and alert, give 2-4 cupfuls of milk or water. Never give \\ anything by mouth to an unconscious person. Get medical aid. \\ Remove from exposure and move to fresh air immediately. If not breathing, give artificial respiration. If \\ Inhalation: breathing is difficult, give oxygen. Get medical aid if cough or other symptoms appear. Do NOT use mouth- \\ Notes to \\ to-mouth resuscitation.
}

$\%$ : 


\section{F.7 Ethylenediaminetriacetic Acid (EDTA)}

Source:www.sigma-aldrich.com

SIGMA-ALDRICH

Material Safety Data Sheet Version 4.3 Print Date 12/13/2011

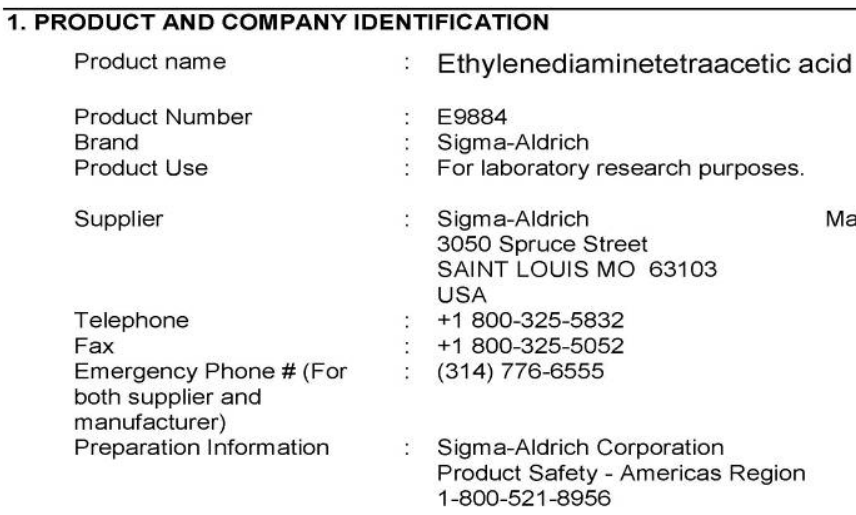

Product name

Product Number

Brand

Product Use

Supplier

Telephone

Fax

Emergency Phone \# (For

both supplier and

manufacturer)

Preparation Information

Ethylenediaminetetraacetic acid

E9884

Sigma-Aldrich

For laboratory research purposes.

Sigma-Aldrich 3050 Spruce Street SAINT LOUIS MO 63103

USA

$+1800-325-5832$

$+1800-325-5052$

(314) $776-6555$

Sigma-Aldrich Corporation

Product Safety - Americas Region

1-800-521-8956

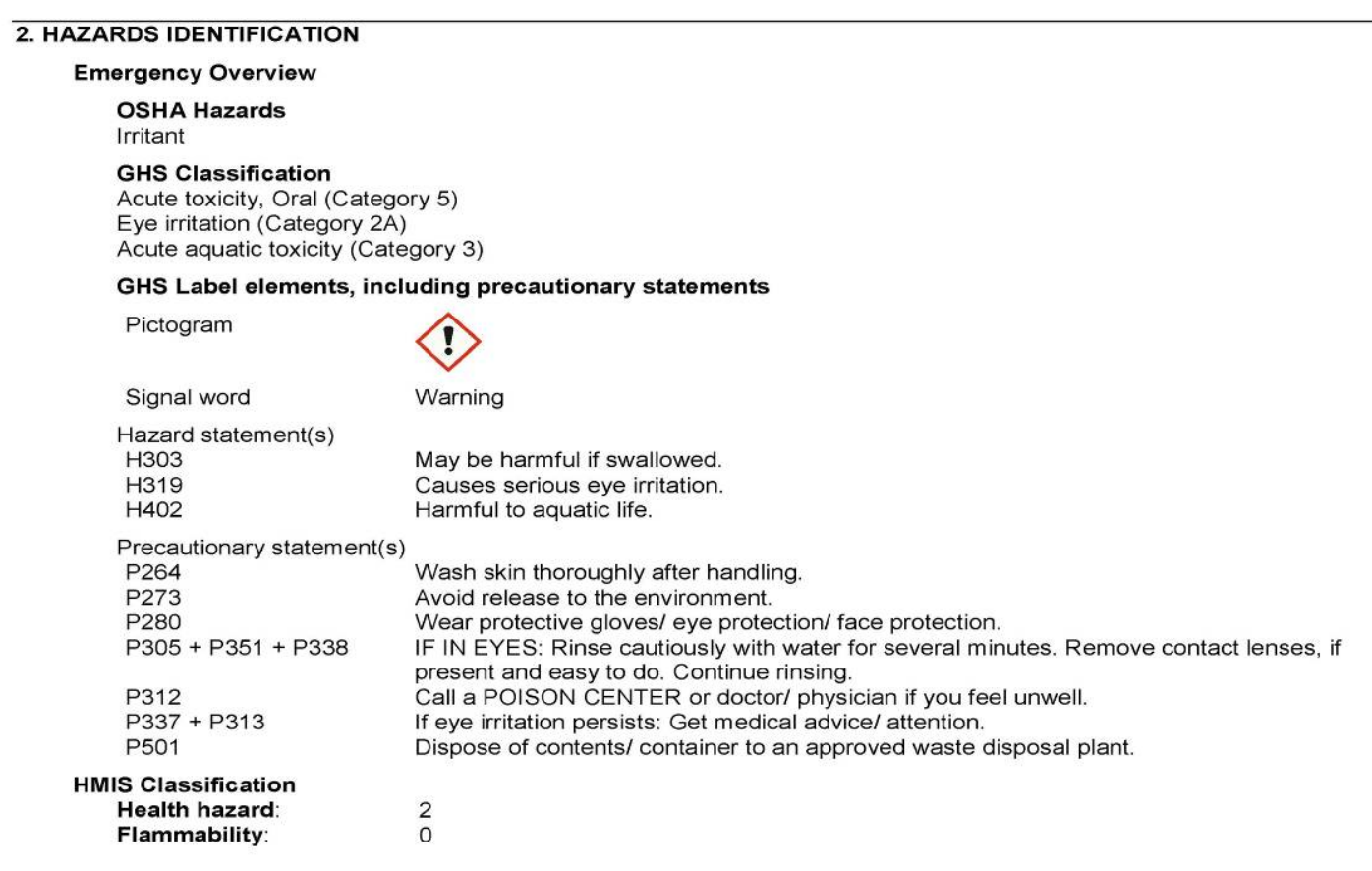

Sigma-Aldrich - E9884 


\section{APPENDIX G: PROPERTIES OF SILICA SUPPORT}

The properties of the $\mathrm{SiO}_{2}$ support, as received from Saint-Gobain NORPRO, are presented in Table A.5.

Table A.5 Physical properties of $\mathrm{SiO}_{2}$ support as received

\begin{tabular}{cc}
\hline \multicolumn{2}{c}{ Silica SS61138 } \\
\hline Size and Shape & $1.5 \mathrm{~mm}$ Pellets \\
Diameter, $\mathrm{mm}$ & 1.47 \\
Length, $\mathrm{mm}$ & 4.66 \\
Surface Area, $\mathrm{m}^{2} / \mathrm{gm}$ & 262 \\
Total Pore Volume, cc/gm & 0.99 \\
Chemistry $\mathrm{w} \%$ & + \\
$\mathrm{SiO}_{2}$ & $>99$ \\
$\mathrm{CaO}$ & 0.06 \\
$\mathrm{MgO}$ & 0.02 \\
$\mathrm{Na}_{2} \mathrm{O}$ & 0.07 \\
$\mathrm{Al}_{2} \mathrm{O}_{3}$ & 0.04 \\
$\mathrm{TiO}_{2}$ & 0.01 \\
$\mathrm{Fe}_{2} \mathrm{O}_{3}$ & 0.01 \\
\hline
\end{tabular}




\section{APPENDIX H: SAMPLE GAS CHROMATOGRAPHS}

Examples of TCD and FID chromatographs obtained for the online gas analysis are shown in Figure A.11 and Figure A.12, respectively. In addition, examples of FID chromatographs for an oil and an aqueous phase analysis are shown in Figure A.13 and Figure A.14, respectively. 

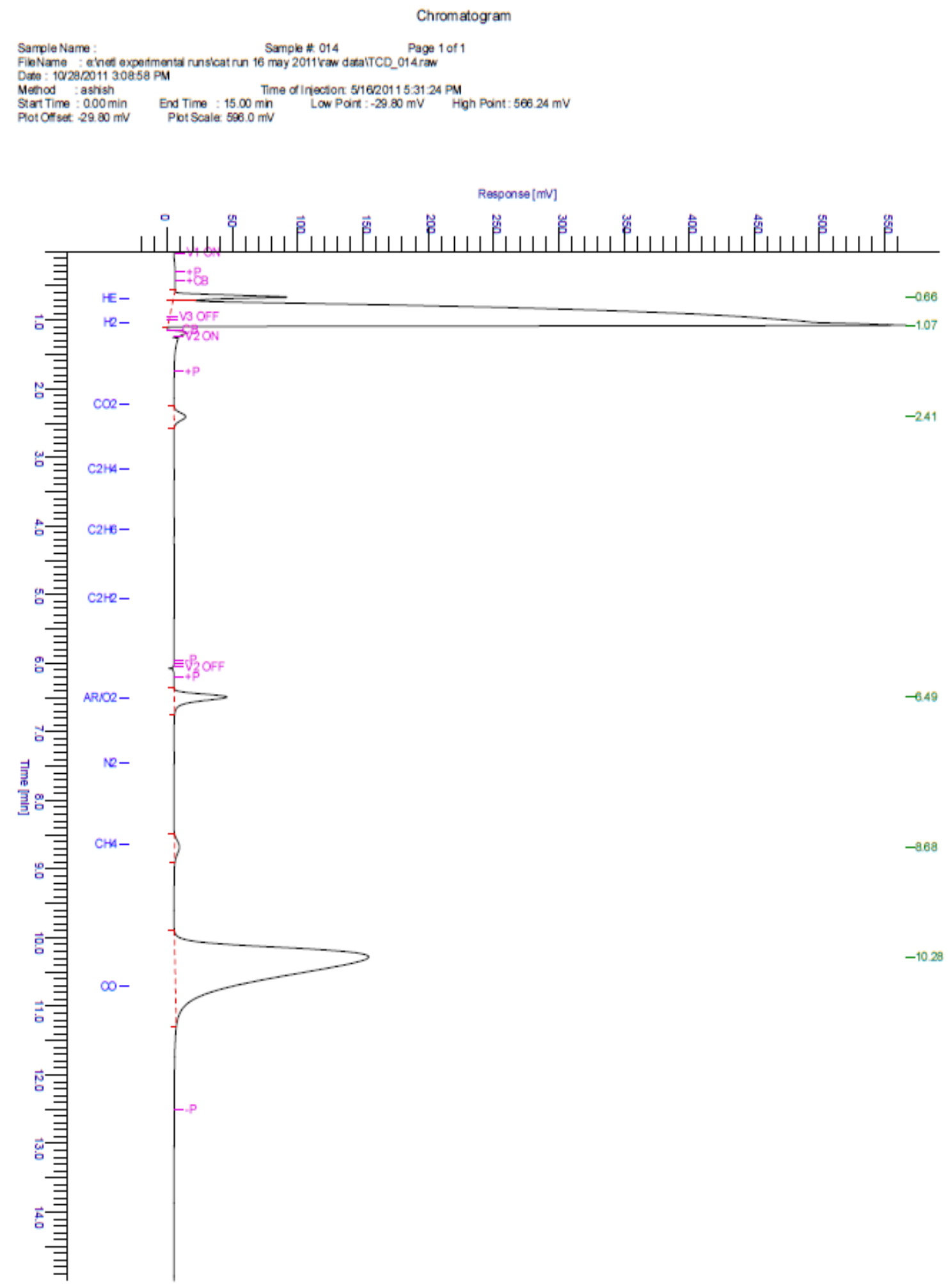

Figure A.11 TCD chromatograph of base catalyst on online GC 

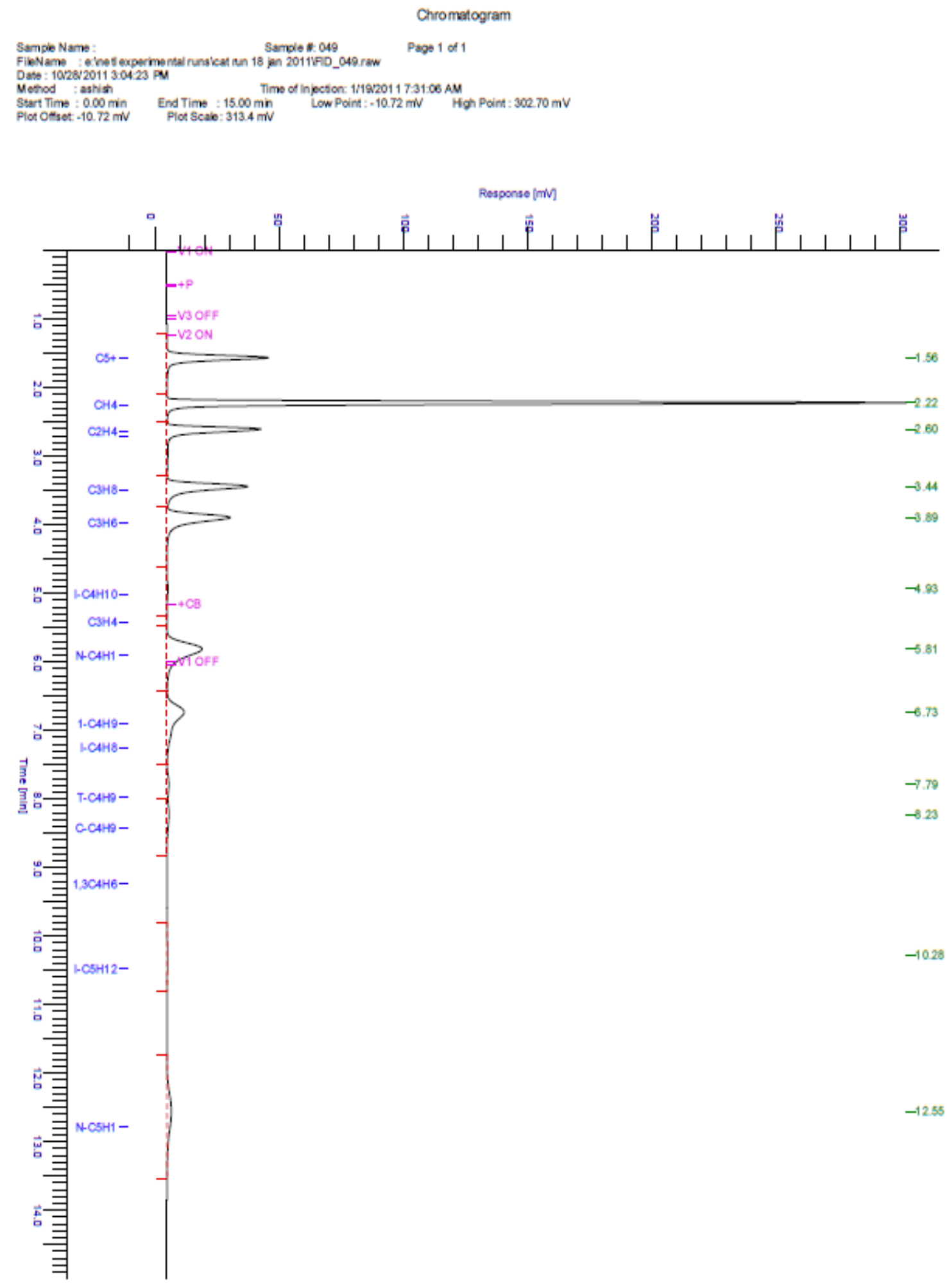

Figure A.12 FID chromatograph of base catalyst on online GC 
Title : Ashish Method- Oil Phase Analysis

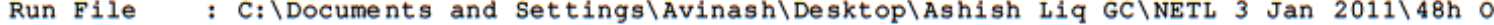

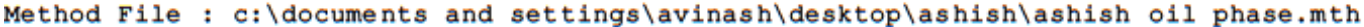

Sample ID : Manual Sample

Injection Date: 1/6/2011 2:48 PM Calculation Date: 1/6/2011 3:37 PM

Operator: Catalysis Lab

Workstation:

Instrument : Aqueous phase

Detector Type: ADCB (1 Volt)

Channel

: $\mathrm{A}=\mathrm{A}$

Bus Address: 16

Sample Rate : $10.00 \mathrm{~Hz}$

Run Time : $29.002 \mathrm{~min}$

** Star Chromatography Workstation (Demo) Version 5.50** 05000-1A68-DA2-3BE9 **

Chart Speed $=0.72 \mathrm{~cm} / \mathrm{min} \quad$ Attenuation $=521 \quad$ Zero offset $=2 \%$

Start Time $=0.000$ min End Time $=29.002 \mathrm{~min}$ Min $/$ Tick $=1.00$

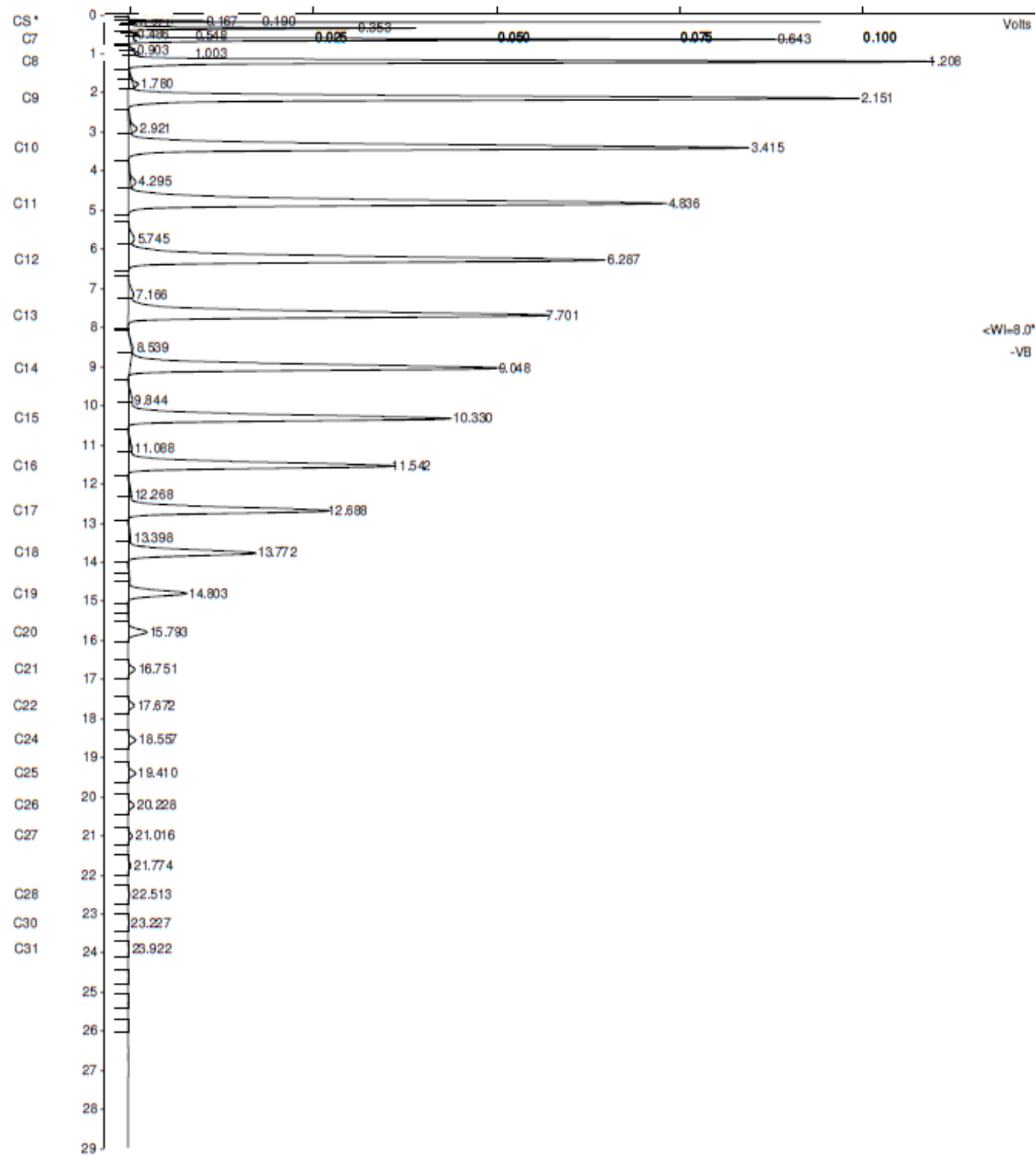

Figure A.13 FID chromatograph of oil phase of base catalyst on offline GC 
Title :

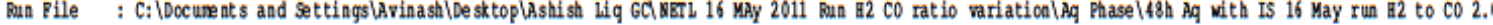
Wethod File: c: \documents and settings lavinashldesktoplashishlashish aq phase.nth

Sarple ID : Manual Sample

Injection Date: $5 / 21 / 2011$ 3:16 PM Calculation Date: 5/21/2011 3:36 PM

operator : Catalysis Lab

Norkstation:

Instrunent: Aqueous phase

Detector Type: ADCB (1 Volt)

Channel : B $=$ B

Bus Address : 16

Sample Rate : $10.00 \mathrm{~Hz}$

"t Star Chrouatogr aphy Workstation (Deano) Version 5.50 *t 05000-1A68-DA2-3BE9 *t

Chart Speed $=\quad 0.72 \mathrm{~cm} / \mathrm{min} \quad$ at tenuation $=207 \quad$ zero of fset $=-\mathbf{2 t}$

start Tine $=0.000$ nin Bad Tine $=29.002$ nin Min $/$ Tick $=1.00$

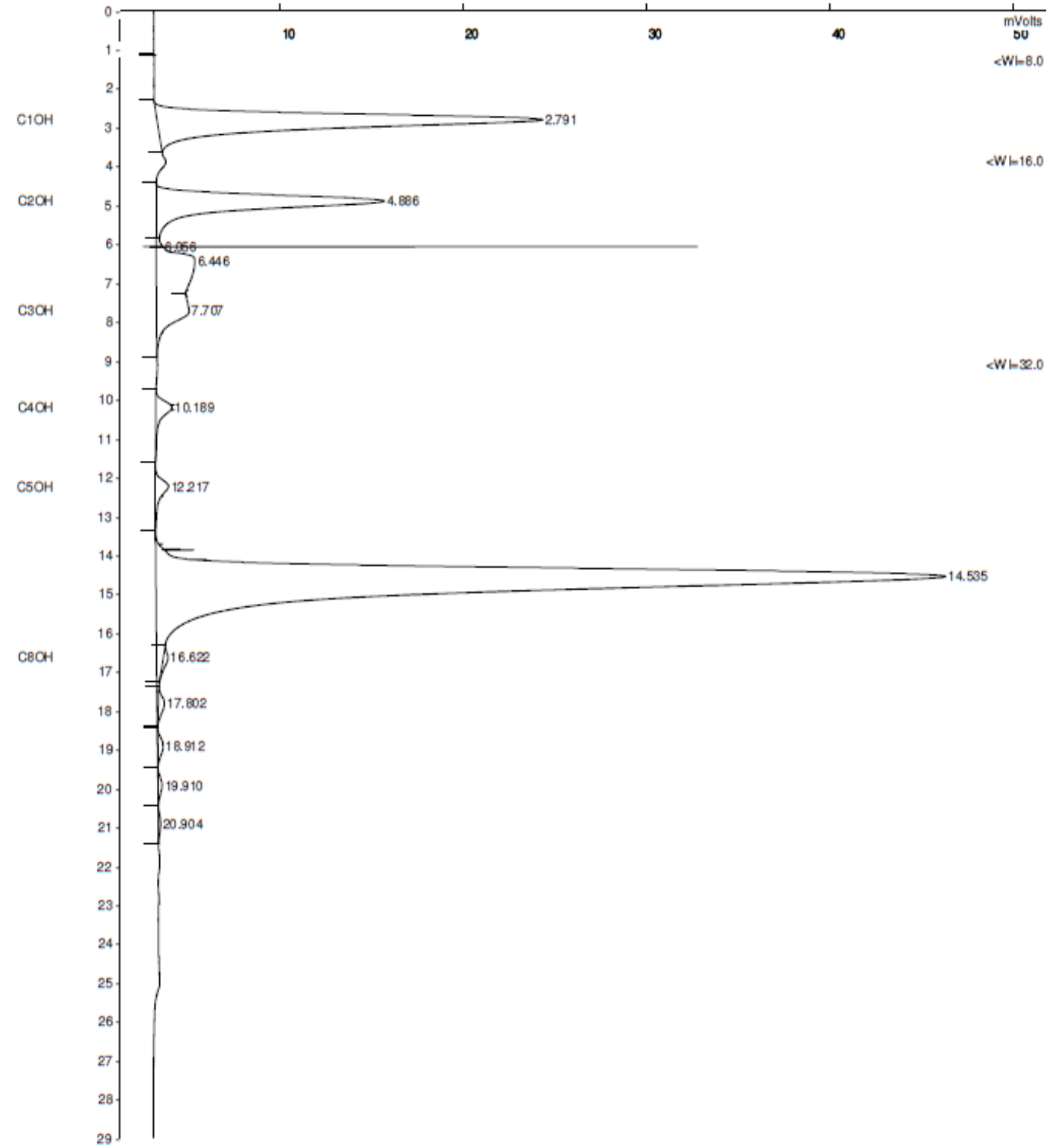

Figure A.14 FID chromatograph of aqueous phase of base catalyst on offline GC 


\section{APPENDIX I: CALCULATION PROCEDURE}

\section{I.1 Online Gas GC}

The products from the reactor outlet are analyzed by the TCD and FID of the online GC. The procedure to calculate the molar flow rate of products is outlined for each detector.

\section{I.1.1 TCD Products}

The TCD product includes $\mathrm{He}, \mathrm{H}_{2}, \mathrm{CO}_{2}, \mathrm{Ar}, \mathrm{CH}_{4}$ and $\mathrm{CO}$ gases, where $\mathrm{He}$ and $\mathrm{Ar}$ are internal standards. The internal standard is inert under the reaction conditions, and hence the inlet and outlet molar flow rates remain constant. The molar flow rates of the $\mathrm{F}_{\mathrm{He}, \mathrm{Ar} \text {,in internal }}$ standard are calculated from the total gas flow rates and the gas composition. Therefore, the molar flow rate of component $\mathrm{X}, \mathrm{F}_{\mathrm{X}}$, is determined by following expression,

$$
F_{X, \text { out }}\left(\frac{\mathrm{mol}}{\min }\right)=\frac{\left(A_{X, \text { out }}\right)}{\left(A_{\mathrm{He}, \text { Ar, out }}\right)} \div\left(r R F_{X}\right) \times F_{H e, A r, \text { in }}\left(\frac{\mathrm{mol}}{\mathrm{min}}\right)
$$

$A_{X}$ and $A_{H e, A r}$ are the measured TCD areas of component $X$ and the corresponding internal standard area $A_{\mathrm{He}, A r}$. The values of rRF for all the TCD components are listed in Table A.1.

\section{I.1.2 FID Products}

The gaseous hydrocarbon products formed during the reaction are analyzed by the FID on the online GC. In addition, $\mathrm{CH}_{4}$ is analyzed by TCD as well as FID. The molar flow rate of $\mathrm{CH}_{4}$ calculated from the TCD product analysis is used to calculate the molar flow rate of remaining FID components. Therefore, the molar flow rate of component $X$, i.e. $F_{X}$, is determined by following expression,

$$
F_{X, \text { out }}\left(\frac{\mathrm{mol}}{\min }\right)=\frac{\left(A_{X, \text { out }}\right)}{\left(A_{\mathrm{CH}_{4}, \text { out }}\right)} \div\left(r R F_{X}\right) \times F_{\mathrm{CH}_{4}, \text { out }}\left(\frac{\mathrm{mol}}{\mathrm{min}}\right)
$$

The $A_{X}$ and $A_{C H 4}$ are the measured FID areas of the component $X$ with corresponding $\mathrm{CH}_{4}$ area $A_{C H 4}$. The corresponding rRFs for all the FCD components are listed in Table A.2.

\section{I.2 Offline Liquid GC}


The liquid products collected from the run are separated into oil- and aqueous-phase products. The weight and the volume of each phase are noted before the GC analysis. The oil and aqueous phases are analyzed by the two FIDs on the offline GC. The calculation procedures for both product types are presented in the following section.

\section{I.2.1 FID Hydrocarbons}

The oil-phase product contains the paraffins, olefins and internal standard $\mathrm{CS}_{2}$. The FID response of the hydrocarbons is assumed to be linear with respect to the carbon number. Therefore, the GC areas of the hydrocarbons, excluding the area of internal standard, are proportional to the amount of hydrocarbon present in the sample. The weight percentage of component $\mathrm{X}$, i.e. $\mathrm{X}_{\mathrm{w}}$, can be calculated by following expression,

$$
X_{w} \%=\frac{A_{X}}{A_{\text {Total }}-A_{C S_{2}}}
$$

$A_{X}$ and $A_{C S 2}$ are the FID areas of component $X$ and the internal standard $C S_{2}$. $A_{\text {Total }}$ refers to the total FID area.

\subsubsection{FID Alcohols}

The aqueous phase contains alcohols and an internal standard cyclohexanol. The sample volume correction was performed with the internal standard. The peak area ratio of the component to the internal standard, in both the standard and the sample, was used for the volume correction. The amount of cylcohexanol present in the standard and the sample is known. Therefore, the amount of an alcohol in the product can be determined by knowing the corresponding peak area and the volume for alcohol in the reference standard. The corrected area for the component $\mathrm{X}$ can be calculated by,

$$
A_{X}^{\text {corr }}=A_{X}^{\text {sample }} \frac{\left(\begin{array}{c}
A_{\text {cyclohex }}^{\text {std }} \\
\text { sample }
\end{array}\right)\left(\begin{array}{l}
\text { sample } \\
w_{\text {cyclohex }}
\end{array}\right)}{\left(\begin{array}{c}
\text { suclohex } \\
\text { std }
\end{array}\right)}
$$

The corrected areas, $A_{X}^{\text {corr }}$, can now be used for determining the weight of component $\mathrm{X}$ in the GC sample.

$$
w_{X}=A_{X}^{c o r r} \times \frac{w_{X}^{s t d}}{A_{X}^{s t d}}
$$


The areas and the weight for the standards and cyclohexanol are listed in Table A.4. Similarly, the weight of remaining alcohols can be determined. 


\section{APPENDIX J: CALCULATION OF LAG TIME}

For the expander,

$$
\text { n-octane vapor }\left(\stackrel{\left.\mathrm{P}_{1}, \mathrm{~T}_{1}, \mathrm{u}_{1}, \mathrm{~V}_{1}\right)}{\longrightarrow \text { expander }} \begin{array}{l}
\text { At } \mathrm{t}=0,\left(\mathrm{P}_{0}, \mathrm{~T}_{0}, \mathrm{u}_{0}, \mathrm{E}_{0}, \mathrm{~m}_{0}\right) \\
\text { At } \mathrm{t},(\mathrm{P}, \mathrm{T}, \mathrm{u}, \mathrm{E}, \mathrm{m})
\end{array}\right.
$$

where,

$\mathrm{P}$ is pressure of the gas $(\mathrm{Pa})$,

$\mathrm{T}$ is temperature $(\mathrm{K})$,

$u$ is specific internal energy of the gas $(\mathrm{J} / \mathrm{g})$

$\mathrm{V}$ is volume of gas $\left(\mathrm{m}^{3}\right)$

$E$ is total energy $(\mathrm{J})$

$\mathrm{m}$ is the mass of the gas $(\mathrm{g})$

Change in total energy can be given as,

$$
\frac{d E}{d t}=h_{1} \frac{d m}{d t}
$$

$\mathrm{h}$ is enthalpy of the gas $(\mathrm{J} / \mathrm{g})$

On integration,

$$
E-E_{0}=h_{1}\left(m-m_{0}\right)
$$

Using

$$
\begin{aligned}
& H=U+P V \\
& m u=m_{0} u_{0}+\left(u_{1}+P_{1} V_{1}\right)\left(m-m_{0}\right)
\end{aligned}
$$

Using,

$$
\begin{aligned}
& P V=n R T \\
& u=C_{V}\left(T-T_{\text {ref }}\right)
\end{aligned}
$$

$R$ is universal gas constant $(\mathrm{J} / \mathrm{g} / \mathrm{K})$

$C_{V}$ is specific heat at constant volume $(\mathrm{J} / \mathrm{g} / \mathrm{K})$

Eq. (H.4) becomes,

$$
m C_{V}\left(T-T_{r e f}\right)=m_{0} C_{V}\left(T_{0}-T_{r e f}\right)+m\left\{C_{V}\left(T_{1}-T_{r e f}\right)+R T_{1}\right\}-m_{0}\left\{C_{V}\left(T_{1}-T_{r e f}\right)+R T_{1}\right\}
$$

On simplifying, 


$$
T=\frac{m_{0}\left(C_{v} T_{0}-C_{p} T_{1}\right)+m C_{p} T_{1}}{m C_{v}}
$$

Using Ideal Gas Law

$$
\begin{gathered}
P=\frac{R}{V C_{V}}\left(m_{0}\left(C_{V} T_{0}-C_{p} T_{1}\right)+m C_{p} T_{1}\right) \\
m=\frac{\left(\frac{P V C_{V}}{R}-m_{0}\left(C_{V} T_{0}-C_{p} T_{1}\right)\right)}{\left(C_{p} T_{1}\right)}
\end{gathered}
$$


For pump,

volume of line $=\frac{\pi}{4} D^{2} L=0.30 \mathrm{~cm}^{3}$

For n-octane,

mol wt. $=114 \frac{\mathrm{g}}{\mathrm{mol}}$
density $=0.84 \frac{\mathrm{g}}{\mathrm{mol}}$
flow rate $=0.01 \frac{\mathrm{cC}}{\mathrm{min}}$
time required, $t_{1}=\frac{0.30 \mathrm{~cm}^{3}}{0.01 \frac{\mathrm{CC}}{\mathrm{min}}}=30 \mathrm{~min}$
For evaporator,

volume of evaporator $=\frac{\pi}{4} D^{2} L=38.5 \mathrm{~cm}^{3}$

From Ideal Gas law,

flow rate $=\frac{n R T}{P}=2.79 \mathrm{~cm}^{3}$

time required, $t_{2}=\frac{38.5 \mathrm{~cm}^{3}}{2.79 \frac{\mathrm{CC}}{\mathrm{min}}}=13.8 \mathrm{~min}$
Based on the derived expression (J.10),

$m=\frac{\left(\frac{P V C_{V}}{R}-m_{0}\left(C_{v} T_{0}-C_{p} T_{1}\right)\right)}{\left(C_{p} T_{1}\right)}=4.29 \mathrm{~g}$

$m^{*}=0.01 \frac{c c}{\min } \times 0.84 \frac{g}{c c}=0.0084 \frac{g}{\min }$

time required, $t_{3}=\frac{m}{m^{*}}=\frac{4.29 \mathrm{~g}}{0.0084 \frac{\mathrm{g}}{\mathrm{min}}}=510.7 \mathrm{~min}$

Therefore,

Total time required, $t=t_{1}+t_{2}+t_{3}=554.5 \mathrm{~min}$ 


\section{APPENDIX $K$ : EXPERIMENTAL DATA}

\section{K.1 Data for CA-modified Catalyst Runs}

\begin{tabular}{|c|c|c|c|c|}
\hline & $\mathrm{Co} / \mathrm{SiO} 2$ at $230 \mathrm{C}$ & Co/NTA/SiO2 at $230 \mathrm{C}$ & Co/EDTA/SiO2 at $230 \mathrm{C}$ \\
\hline & & II & II & II \\
\hline Time & & $24-48$ & $24-48$ & $24-48$ \\
\hline CO in & g C/day & 34.64 & 34.64 & 34.64 \\
\hline CO out & g C/day & 25.64 & 23.56 & 11.54 \\
\hline Conversion & $\mathrm{X}_{\mathrm{CO} \%}$ & 26.00 & 32.01 & 66.69 \\
\hline Online & alysis & & & \\
\hline $\mathrm{C} 5+$ & g C/day & 0.4276 & 0.6808 & 0.9180 \\
\hline $\mathrm{CH} 4$ & g C/day & 0.8379 & 1.3321 & 2.7944 \\
\hline $\mathrm{C} 2 \mathrm{H} 6$ & g C/day & 0.2041 & 0.3234 & 0.7860 \\
\hline $\mathrm{C} 3 \mathrm{H} 8$ & g C/day & 0.1295 & 0.2062 & 0.7585 \\
\hline $\mathrm{C} 3 \mathrm{H} 6$ & g C/day & 0.1519 & 0.2416 & 0.7432 \\
\hline $\mathrm{i}-\mathrm{C} 4 \mathrm{H} 10$ & g C/day & 0.0004 & 0.0006 & 0.0190 \\
\hline $\mathrm{n}-\mathrm{C} 4 \mathrm{H} 10$ & g C/day & 0.1099 & 0.1756 & 0.7210 \\
\hline 1-C4H9 & g C/day & 0.0404 & 0.0643 & 0.5396 \\
\hline $\mathrm{i}-\mathrm{C} 4 \mathrm{H} 8$ & g C/day & 0.0000 & 0.0000 & 0.0000 \\
\hline $\mathrm{t}-\mathrm{C} 4 \mathrm{H} 9$ & g C/day & 0.0451 & 0.0720 & 0.0479 \\
\hline $\mathrm{c}-\mathrm{C} 4 \mathrm{H} 9$ & g C/day & 0.0383 & 0.0612 & 0.0611 \\
\hline $\mathrm{i}-\mathrm{C} 5 \mathrm{H} 12$ & g C/day & 0.0000 & 0.0000 & 0.0423 \\
\hline$n-\mathrm{C} 5 \mathrm{H} 12$ & g C/day & 0.0939 & 0.1504 & 0.5081 \\
\hline $\mathrm{CO} 2$ & g C/day & 0.8463 & 1.0526 & 2.7060 \\
\hline Offline Liqu & Analysis & & & \\
\hline Para & & & & \\
\hline C6 & g C/day & 0.0244 & 0.1017 & 0.6357 \\
\hline C7 & g C/day & 0.0779 & 0.2698 & 1.1282 \\
\hline C8 & g C/day & 0.1495 & 0.4078 & 1.1017 \\
\hline C9 & g C/day & 0.2020 & 0.4462 & 0.9984 \\
\hline $\mathrm{C} 10$ & g C/day & 0.2171 & 0.4098 & 0.8032 \\
\hline C11 & g C/day & 0.2064 & 0.3514 & 0.6260 \\
\hline C12 & g C/day & 0.1878 & 0.2931 & 0.4754 \\
\hline C13 & g C/day & 0.1666 & 0.2386 & 0.3534 \\
\hline C14 & g C/day & 0.1485 & 0.1875 & 0.2497 \\
\hline C15 & g C/day & 0.1282 & 0.1496 & 0.1836 \\
\hline C16 & g C/day & 0.1060 & 0.1190 & 0.1184 \\
\hline C17 & g C/day & 0.0781 & 0.0902 & 0.0653 \\
\hline C18 & g C/day & 0.0506 & 0.0629 & 0.0323 \\
\hline C19 & g C/day & 0.0230 & 0.0402 & 0.0135 \\
\hline $\mathrm{C} 2 \mathrm{O}$ & $\mathrm{g} \mathrm{C/day}$ & 0.0006 & 0.0225 & 0.0039 \\
\hline
\end{tabular}




\begin{tabular}{|c|c|c|c|c|}
\hline $\mathrm{C} 21$ & g C/day & 0.0074 & 0.0115 & 0.0023 \\
\hline $\mathrm{C} 22$ & g C/day & 0.0026 & 0.0052 & 0.0027 \\
\hline $\mathrm{C} 23$ & g C/day & 0.0024 & 0.0015 & 0.0038 \\
\hline $\mathrm{C} 24$ & g C/day & 0.0029 & 0.0025 & 0.0041 \\
\hline $\mathrm{C} 25$ & g C/day & 0.0028 & 0.0010 & 0.0021 \\
\hline $\mathrm{C} 26$ & g C/day & 0.0023 & 0.0006 & 0.0000 \\
\hline $\mathrm{C} 27$ & g C/day & 0.0015 & 0.0000 & 0.0000 \\
\hline $\mathrm{C} 28$ & g C/day & 0.0010 & 0.0000 & 0.0000 \\
\hline $\mathrm{C} 29$ & g C/day & 0.0006 & 0.0000 & 0.0000 \\
\hline $\mathrm{C} 30$ & g C/day & 0.0003 & 0.0000 & 0.0000 \\
\hline \multicolumn{2}{|c|}{ Olefins } & & & \\
\hline C6 & g C/day & 0.0006 & 0.0034 & 0.0020 \\
\hline $\mathrm{C7}$ & g C/day & 0.0009 & 0.0066 & 0.0455 \\
\hline $\mathrm{C} 8$ & g C/day & 0.0013 & 0.0166 & 0.1598 \\
\hline C9 & g C/day & 0.0016 & 0.0249 & 0.1296 \\
\hline $\mathrm{C} 10$ & g C/day & 0.0019 & 0.0263 & 0.1094 \\
\hline C11 & g C/day & 0.0021 & 0.0205 & 0.0917 \\
\hline $\mathrm{C} 12$ & g C/day & 0.0034 & 0.0147 & 0.0580 \\
\hline $\mathrm{C} 13$ & g C/day & 0.0031 & 0.0115 & 0.0379 \\
\hline C14 & g C/day & 0.0028 & 0.0038 & 0.0092 \\
\hline C15 & g C/day & 0.0002 & 0.0061 & 0.0073 \\
\hline $\mathrm{C} 16$ & g C/day & 0.0000 & 0.0020 & 0.0048 \\
\hline $\mathrm{C} 17$ & g C/day & 0.0000 & 0.0006 & 0.0000 \\
\hline $\mathrm{C} 18$ & g C/day & 0.0000 & 0.0004 & 0.0000 \\
\hline C19 & g C/day & 0.0000 & 0.0000 & 0.0000 \\
\hline $\mathrm{C} 20$ & g C/day & 0.0000 & 0.0000 & 0.0000 \\
\hline $\mathrm{C} 21$ & g C/day & 0.0000 & 0.0000 & 0.0000 \\
\hline $\mathrm{C} 22$ & g C/day & 0.0000 & 0.0000 & 0.0000 \\
\hline \multicolumn{2}{|c|}{ Alcohols } & & & \\
\hline $\mathrm{C} 1$ & g C/day & 0.1037 & 0.1667 & 0.2525 \\
\hline $\mathrm{C2}$ & g C/day & 0.1306 & 0.2788 & 0.2795 \\
\hline $\mathrm{C} 3$ & g C/day & 0.1134 & 0.2670 & 0.1683 \\
\hline $\mathrm{C4}$ & g C/day & 0.0265 & 0.1017 & 0.1542 \\
\hline $\mathrm{C} 5$ & g C/day & 0.0124 & 0.0493 & 0.0352 \\
\hline C6 & g C/day & 0.0054 & 0.0175 & 0.0013 \\
\hline $\mathrm{C7}$ & g C/day & 0.0000 & 0.0000 & 0.0000 \\
\hline $\mathrm{C} 8$ & g C/day & 0.0000 & 0.0000 & 0.0000 \\
\hline $\mathrm{C9}$ & g C/day & 0.0000 & 0.0000 & 0.0000 \\
\hline $\mathrm{C} 10$ & g C/day & 0.0000 & 0.0000 & 0.0000 \\
\hline
\end{tabular}




\begin{tabular}{|c|c|c|c|c|}
\hline & & $\mathrm{Co} / \mathrm{SiO} 2$ at $220 \mathrm{C}$ & $\mathrm{Co} / \mathrm{NTA} / \mathrm{SiO} 2$ at $220 \mathrm{C}$ & Co/EDTA/SiO2 at $220 \mathrm{C}$ \\
\hline \multirow[b]{2}{*}{ Time } & & II & II & II \\
\hline & & 48 & 48 & 48 \\
\hline $\mathrm{CO}$ in & g C/day & 34.64 & 34.64 & 34.64 \\
\hline CO out & g C/day & 28.11 & 27.77 & 20.06 \\
\hline Conversion & $\mathrm{Xco} \%$ & 18.86 & 19.84 & 20.06 \\
\hline \multicolumn{2}{|c|}{ Online Analysis } & & & \\
\hline $\mathrm{C} 5+$ & g C/day & 0.2761 & 0.4056 & 0.6947 \\
\hline $\mathrm{CH} 4$ & g C/day & 0.7375 & 1.0787 & 1.9551 \\
\hline $\mathrm{C} 2 \mathrm{H} 6$ & g C/day & 0.1527 & 0.2241 & 0.3706 \\
\hline $\mathrm{C} 3 \mathrm{H} 8$ & g C/day & 0.0864 & 0.1266 & 0.5224 \\
\hline $\mathrm{C} 3 \mathrm{H} 6$ & g C/day & 0.1512 & 0.2211 & 0.4338 \\
\hline i-C4H10 & g C/day & 0.0000 & 0.0000 & 0.0124 \\
\hline $\mathrm{n}-\mathrm{C} 4 \mathrm{H} 10$ & g C/day & 0.1004 & 0.1468 & 0.5231 \\
\hline 1-C4H9 & g C/day & 0.0771 & 0.1123 & 0.2932 \\
\hline $\mathrm{i}-\mathrm{C} 4 \mathrm{H} 8$ & g C/day & 0.0000 & 0.0000 & 0.0000 \\
\hline $\mathrm{t}-\mathrm{C} 4 \mathrm{H} 9$ & g C/day & 0.0197 & 0.0289 & 0.0397 \\
\hline $\mathrm{C}-\mathrm{C} 4 \mathrm{H} 9$ & g C/day & 0.0202 & 0.0295 & 0.0478 \\
\hline $\mathrm{i}-\mathrm{C} 5 \mathrm{H} 12$ & g C/day & 0.0000 & 0.0000 & 0.0000 \\
\hline $\mathrm{n}-\mathrm{C} 5 \mathrm{H} 12$ & g C/day & 0.0981 & 0.1434 & 0.4251 \\
\hline $\mathrm{CO} 2$ & g C/day & 0.8381 & 0.7132 & 1.3904 \\
\hline \multicolumn{2}{|c|}{ Offline Liquid Analysis } & & & \\
\hline \multicolumn{2}{|c|}{ Paraffins } & & & \\
\hline C6 & g C/day & 0.0918 & 0.1199 & 0.2586 \\
\hline $\mathrm{C} 7$ & g C/day & 0.1630 & 0.2128 & 0.4589 \\
\hline C8 & g C/day & 0.1592 & 0.0190 & 0.4482 \\
\hline $\mathrm{C} 9$ & g C/day & 0.1322 & 0.1883 & 0.4062 \\
\hline C10 & g C/day & 0.1160 & 0.1515 & 0.3600 \\
\hline C11 & g C/day & 0.1022 & 0.1230 & 0.2700 \\
\hline $\mathrm{C} 12$ & g C/day & 0.0930 & 0.0897 & 0.2200 \\
\hline C13 & g C/day & 0.0511 & 0.0789 & 0.1438 \\
\hline C14 & g C/day & 0.0361 & 0.0471 & 0.1016 \\
\hline C15 & g C/day & 0.0265 & 0.0346 & 0.0920 \\
\hline C16 & g C/day & 0.0200 & 0.0270 & 0.0482 \\
\hline C17 & g C/day & 0.0094 & 0.0123 & 0.0265 \\
\hline C18 & g C/day & 0.0047 & 0.0061 & 0.0131 \\
\hline C19 & g C/day & 0.0019 & 0.0025 & 0.0055 \\
\hline $\mathrm{C} 20$ & g C/day & 0.0006 & 0.0007 & 0.0016 \\
\hline
\end{tabular}




\begin{tabular}{|c|c|c|c|c|}
\hline $\mathrm{C} 21$ & g C/day & 0.0003 & 0.0004 & 0.0009 \\
\hline C22 & g C/day & 0.0004 & 0.0005 & 0.0011 \\
\hline $\mathrm{C} 23$ & g C/day & 0.0005 & 0.0007 & 0.0015 \\
\hline $\mathrm{C} 24$ & g C/day & 0.0006 & 0.0008 & 0.0017 \\
\hline $\mathrm{C} 25$ & g C/day & 0.0003 & 0.0004 & 0.0009 \\
\hline $\mathrm{C} 26$ & g C/day & 0.0000 & 0.0000 & 0.0000 \\
\hline $\mathrm{C} 27$ & g C/day & 0.0000 & 0.0000 & 0.0000 \\
\hline C28 & g C/day & 0.0000 & 0.0000 & 0.0000 \\
\hline $\mathrm{C} 29$ & g C/day & 0.0000 & 0.0000 & 0.0000 \\
\hline C30 & g C/day & 0.0000 & 0.0000 & 0.0000 \\
\hline \multicolumn{2}{|c|}{ Olefins } & & & \\
\hline C6 & g C/day & 0.0003 & 0.0004 & 0.0008 \\
\hline $\mathrm{C7}$ & g C/day & 0.0066 & 0.0086 & 0.0185 \\
\hline $\mathrm{C} 8$ & g C/day & 0.0231 & 0.0301 & 0.0650 \\
\hline C9 & g C/day & 0.0187 & 0.0244 & 0.0527 \\
\hline $\mathrm{C} 10$ & g C/day & 0.0158 & 0.0206 & 0.0445 \\
\hline C11 & g C/day & 0.0132 & 0.0173 & 0.0373 \\
\hline $\mathrm{C} 12$ & g C/day & 0.0084 & 0.0109 & 0.0236 \\
\hline $\mathrm{C} 13$ & g C/day & 0.0055 & 0.0072 & 0.0154 \\
\hline C14 & g C/day & 0.0013 & 0.0017 & 0.0037 \\
\hline C15 & g C/day & 0.0010 & 0.0014 & 0.0029 \\
\hline $\mathrm{C} 16$ & g C/day & 0.0007 & 0.0009 & 0.0019 \\
\hline C17 & g C/day & 0.0000 & 0.0000 & 0.0000 \\
\hline C18 & g C/day & 0.0000 & 0.0000 & 0.0000 \\
\hline C19 & g C/day & 0.0000 & 0.0000 & 0.0000 \\
\hline $\mathrm{C} 20$ & g C/day & 0.0000 & 0.0000 & 0.0000 \\
\hline $\mathrm{C} 21$ & g C/day & 0.0000 & 0.0000 & 0.0000 \\
\hline $\mathrm{C} 22$ & g C/day & 0.0000 & 0.0000 & 0.0000 \\
\hline \multicolumn{2}{|c|}{ Alcohols } & & & \\
\hline $\mathrm{C} 1$ & g C/day & 0.0210 & 0.0560 & 0.1200 \\
\hline $\mathrm{C} 2$ & g C/day & 0.0261 & 0.0634 & 0.1503 \\
\hline $\mathrm{C} 3$ & g C/day & 0.0209 & 0.0507 & 0.1202 \\
\hline $\mathrm{C} 4$ & g C/day & 0.0180 & 0.0440 & 0.1000 \\
\hline $\mathrm{C} 5$ & g C/day & 0.0044 & 0.0106 & 0.0251 \\
\hline C6 & g C/day & 0.0002 & 0.0004 & 0.0010 \\
\hline $\mathrm{C7}$ & g C/day & 0.0000 & 0.0000 & 0.0000 \\
\hline $\mathrm{C} 8$ & g C/day & 0.0000 & 0.0000 & 0.0000 \\
\hline $\mathrm{C9}$ & g C/day & 0.0000 & 0.0000 & 0.0000 \\
\hline C10 & g C/day & 0.0000 & 0.0000 & 0.0000 \\
\hline
\end{tabular}


K.2 Data for Sulfur Poisoning Runs

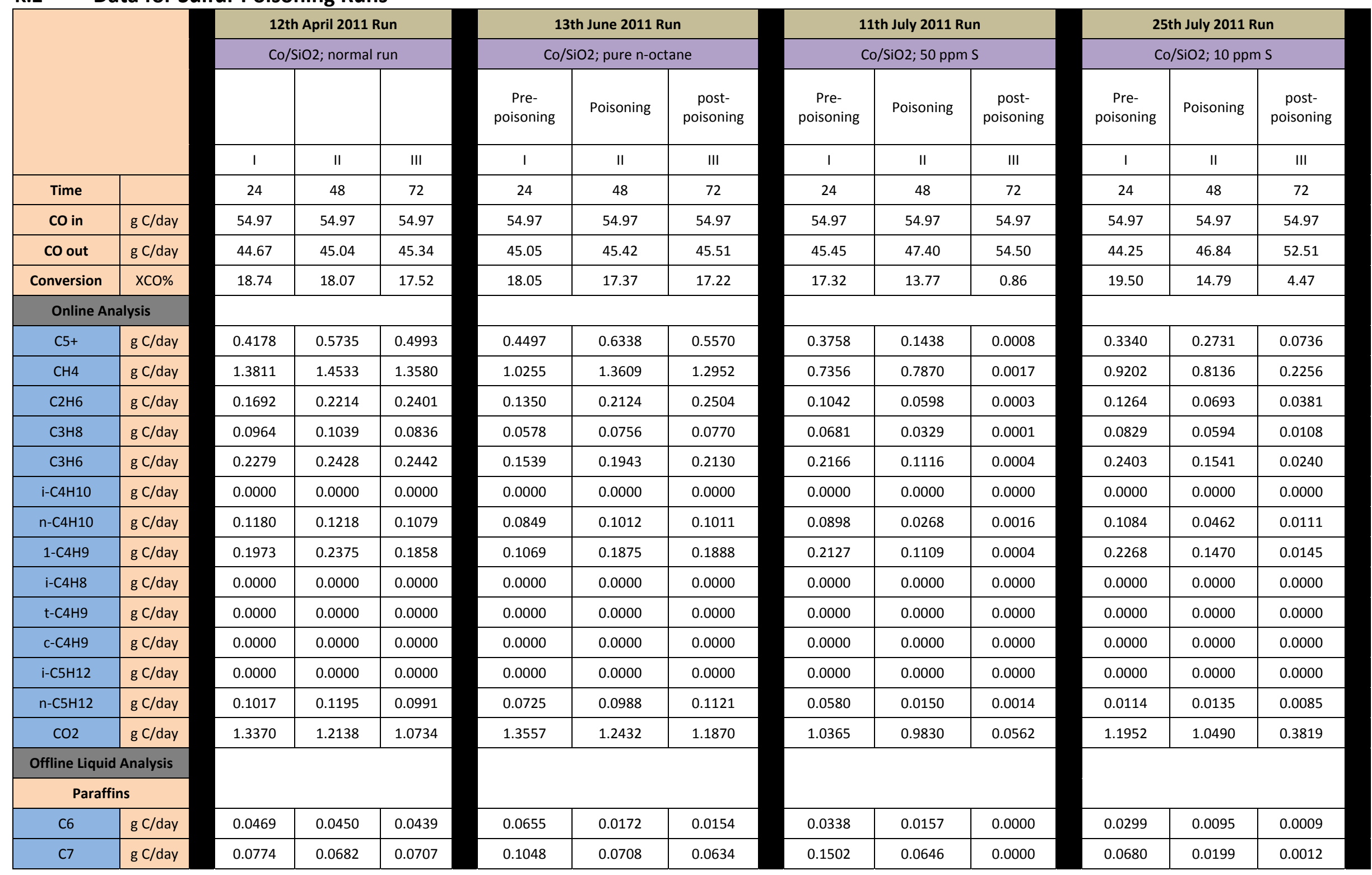




\begin{tabular}{|c|c|}
\hline C8* & $\mathrm{g} \mathrm{C} /$ day \\
\hline C9 & g C/day \\
\hline C10 & g C/day \\
\hline C11 & $\mathrm{g} \mathrm{C} /$ day \\
\hline C12 & $\mathrm{g} \mathrm{C} /$ day \\
\hline C13 & g C/day \\
\hline C14 & g C/day \\
\hline C15 & $\mathrm{g} \mathrm{C} /$ day \\
\hline C16 & g C/day \\
\hline C17 & g C/day \\
\hline C18 & g C/day \\
\hline C19 & $\mathrm{g} \mathrm{C} /$ day \\
\hline C20 & g C/day \\
\hline C21 & g C/day \\
\hline $\mathrm{C} 22$ & $\mathrm{~g} \mathrm{C/day}$ \\
\hline C23 & g C/day \\
\hline C24 & $\mathrm{g} \mathrm{C} /$ day \\
\hline C25 & g C/day \\
\hline C26 & $\mathrm{g} \mathrm{C} /$ day \\
\hline $\mathrm{C} 27$ & $\mathrm{~g} \mathrm{C} /$ day \\
\hline C28 & g C/day \\
\hline C29 & $\mathrm{g} \mathrm{C} / \mathrm{day}$ \\
\hline C30 & $\mathrm{g} \mathrm{C/day}$ \\
\hline \multicolumn{2}{|c|}{ Olefins } \\
\hline C6 & g C/day \\
\hline $\mathrm{C7}$ & g C/day \\
\hline $\mathrm{C} 8$ & $\mathrm{~g} \mathrm{C} /$ day \\
\hline C9 & $\mathrm{g}$ C/day \\
\hline $\mathrm{C} 10$ & $\mathrm{~g} \mathrm{C/day}$ \\
\hline C11 & g C/day \\
\hline
\end{tabular}

\begin{tabular}{|l|l|l|}
\hline 0.1848 & 0.1630 & 0.1689 \\
\hline 0.3303 & 0.2914 & 0.3019 \\
\hline 0.4394 & 0.3876 & 0.4016 \\
\hline 0.4742 & 0.4184 & 0.4335 \\
\hline 0.4512 & 0.3980 & 0.4124 \\
\hline 0.4002 & 0.3531 & 0.3658 \\
\hline 0.3379 & 0.2980 & 0.3088 \\
\hline 0.2760 & 0.2435 & 0.2523 \\
\hline 0.1935 & 0.1707 & 0.1769 \\
\hline 0.1270 & 0.1120 & 0.1161 \\
\hline 0.0756 & 0.0667 & 0.0691 \\
\hline 0.0388 & 0.0342 & 0.0355 \\
\hline 0.0211 & 0.0186 & 0.0193 \\
\hline 0.0121 & 0.0107 & 0.0111 \\
\hline 0.0089 & 0.0078 & 0.0081 \\
\hline 0.0075 & 0.0066 & 0.0068 \\
\hline 0.0073 & 0.0065 & 0.0067 \\
\hline 0.0073 & 0.0064 & 0.0067 \\
\hline 0.0068 & 0.0060 & 0.0062 \\
\hline 0.0061 & 0.0054 & 0.0055 \\
\hline 0.0043 & 0.0038 & 0.0040 \\
\hline 0.0000 & 0.0000 & 0.0000 \\
\hline 0.0000 & 0.0000 & 0.0000 \\
\hline & & \\
\hline 0.0010 & 0.0010 & 0.0009 \\
\hline 0.0014 & 0.0013 & 0.0010 \\
\hline 0.0022 & 0.0021 & 0.0013 \\
\hline 0.0084 & 0.0082 & 0.0051 \\
\hline 0.0172 & 0.0166 & 0.0103 \\
\hline 0.0225 & 0.0218 & 0.0135 \\
\hline
\end{tabular}

\begin{tabular}{|c|c|c|}
\hline 0.2774 & 0.3194 & 0.4917 \\
\hline 0.3972 & 0.2685 & 0.2401 \\
\hline 0.5051 & 0.3414 & 0.3054 \\
\hline 0.5342 & 0.3611 & 0.3229 \\
\hline 0.5045 & 0.3410 & 0.3050 \\
\hline 0.4495 & 0.3038 & 0.2717 \\
\hline 0.3723 & 0.2517 & 0.2251 \\
\hline 0.3127 & 0.2114 & 0.1891 \\
\hline 0.2400 & 0.1622 & 0.1451 \\
\hline 0.1699 & 0.1148 & 0.1027 \\
\hline 0.1088 & 0.0736 & 0.0658 \\
\hline 0.0637 & 0.0431 & 0.0385 \\
\hline 0.0344 & 0.0232 & 0.0208 \\
\hline 0.0176 & 0.0119 & 0.0106 \\
\hline 0.0071 & 0.0048 & 0.0043 \\
\hline 0.0028 & 0.0019 & 0.0017 \\
\hline 0.0000 & 0.0000 & 0.0000 \\
\hline 0.0000 & 0.0000 & 0.0000 \\
\hline 0.0000 & 0.0000 & 0.0000 \\
\hline 0.0000 & 0.0000 & 0.0000 \\
\hline 0.0000 & 0.0000 & 0.0000 \\
\hline 0.0000 & 0.0000 & 0.0000 \\
\hline 0.0000 & 0.0000 & 0.0000 \\
\hline 0.0009 & 0.0011 & 0.0008 \\
\hline 0.0026 & 0.0032 & 0.0023 \\
\hline 0.0055 & 0.0067 & 0.0048 \\
\hline 0.0063 & 0.0077 & 0.0055 \\
\hline 0.0287 & 0.0351 & 0.0251 \\
\hline 0.0308 & 0.0378 & 0.0270 \\
\hline
\end{tabular}

\begin{tabular}{|l|l|l|}
\hline 0.3267 & 0.3668 & 0.0000 \\
\hline 0.4955 & 0.2450 & 0.0000 \\
\hline 0.5838 & 0.3115 & 0.0000 \\
\hline 0.5800 & 0.3295 & 0.0000 \\
\hline 0.5200 & 0.3111 & 0.0000 \\
\hline 0.4396 & 0.2772 & 0.0000 \\
\hline 0.3436 & 0.2296 & 0.0000 \\
\hline 0.2637 & 0.1929 & 0.0000 \\
\hline 0.1795 & 0.1480 & 0.0000 \\
\hline 0.1092 & 0.1048 & 0.0000 \\
\hline 0.0607 & 0.0671 & 0.0000 \\
\hline 0.0335 & 0.0393 & 0.0000 \\
\hline 0.0223 & 0.0212 & 0.0000 \\
\hline 0.0189 & 0.0108 & 0.0000 \\
\hline 0.0161 & 0.0044 & 0.0000 \\
\hline 0.0121 & 0.0017 & 0.0000 \\
\hline 0.0074 & 0.0000 & 0.0000 \\
\hline 0.0032 & 0.0000 & 0.0000 \\
\hline 0.0010 & 0.0000 & 0.0000 \\
\hline 0.0020 & 0.0000 & 0.0000 \\
\hline 0.0000 & 0.0000 & 0.0000 \\
\hline 0.0000 & 0.0000 & 0.0000 \\
\hline 0.0000 & 0.0000 & 0.0000 \\
\hline & & \\
\hline 0.0010 & 0.0009 & 0.0000 \\
\hline 0.0012 & 0.0025 & 0.0000 \\
\hline 0.0038 & 0.0052 & 0.0000 \\
\hline 0.0101 & 0.0059 & 0.0000 \\
\hline 0.0159 & 0.0272 & 0.0000 \\
\hline 0.0186 & 0.0292 & 0.0000 \\
\hline
\end{tabular}

\begin{tabular}{|l|l|l|}
\hline 0.1898 & 0.2612 & 0.0113 \\
\hline 0.3290 & 0.1173 & 0.0093 \\
\hline 0.5536 & 0.2240 & 0.0157 \\
\hline 0.5737 & 0.2416 & 0.0229 \\
\hline 0.5303 & 0.2299 & 0.0192 \\
\hline 0.4639 & 0.2066 & 0.0159 \\
\hline 0.3830 & 0.1760 & 0.0139 \\
\hline 0.3210 & 0.1530 & 0.0107 \\
\hline 0.2447 & 0.1234 & 0.0122 \\
\hline 0.1695 & 0.0918 & 0.0092 \\
\hline 0.1081 & 0.0613 & 0.0045 \\
\hline 0.0679 & 0.0358 & 0.0030 \\
\hline 0.0504 & 0.0192 & 0.0000 \\
\hline 0.0498 & 0.0111 & 0.0000 \\
\hline 0.0499 & 0.0087 & 0.0000 \\
\hline 0.0525 & 0.0086 & 0.0000 \\
\hline 0.0527 & 0.0088 & 0.0000 \\
\hline 0.0387 & 0.0064 & 0.0000 \\
\hline 0.0189 & 0.0033 & 0.0000 \\
\hline 0.0068 & 0.0012 & 0.0000 \\
\hline 0.0024 & 0.0000 & 0.0000 \\
\hline 0.0000 & 0.0000 & 0.0000 \\
\hline 0.0000 & 0.0000 & 0.0000 \\
\hline & & \\
\hline 0.0008 & 0.0011 & 0.0006 \\
\hline 0.0022 & 0.0199 & 0.0026 \\
\hline 0.0043 & 0.0125 & 0.0071 \\
\hline 0.0062 & 0.0603 & 0.0338 \\
\hline 0.0224 & 0.0150 & 0.0066 \\
\hline 0.0215 & 0.0189 & 0.0134 \\
\hline
\end{tabular}




\begin{tabular}{|c|c|c|c|c|c|c|c|c|c|c|c|c|c|}
\hline $\mathrm{C} 12$ & g C/day & 0.0238 & 0.0231 & 0.0143 & 0.0316 & 0.0387 & 0.0277 & 0.0192 & 0.0300 & 0.0000 & 0.0224 & 0.0208 & 0.0152 \\
\hline $\mathrm{C} 13$ & g C/day & 0.0228 & 0.0221 & 0.0137 & 0.0292 & 0.0358 & 0.0256 & 0.0167 & 0.0277 & 0.0000 & 0.0238 & 0.0210 & 0.0157 \\
\hline C14 & g C/day & 0.0204 & 0.0198 & 0.0122 & 0.0158 & 0.0194 & 0.0139 & 0.0100 & 0.0150 & 0.0000 & 0.0227 & 0.0168 & 0.0121 \\
\hline C15 & g C/day & 0.0175 & 0.0170 & 0.0105 & 0.0219 & 0.0268 & 0.0192 & 0.0104 & 0.0207 & 0.0000 & 0.0213 & 0.0196 & 0.0116 \\
\hline C16 & g C/day & 0.0146 & 0.0142 & 0.0088 & 0.0189 & 0.0231 & 0.0165 & 0.0074 & 0.0179 & 0.0000 & 0.0206 & 0.0181 & 0.0142 \\
\hline C17 & g C/day & 0.0102 & 0.0099 & 0.0061 & 0.0148 & 0.0182 & 0.0130 & 0.0044 & 0.0140 & 0.0000 & 0.0153 & 0.0153 & 0.0126 \\
\hline $\mathrm{C} 18$ & g C/day & 0.0061 & 0.0059 & 0.0037 & 0.0101 & 0.0123 & 0.0088 & 0.0022 & 0.0095 & 0.0000 & 0.0095 & 0.0117 & 0.0100 \\
\hline C19 & g C/day & 0.0000 & 0.0000 & 0.0000 & 0.0054 & 0.0066 & 0.0047 & 0.0011 & 0.0051 & 0.0000 & 0.0051 & 0.0074 & 0.0015 \\
\hline $\mathrm{C} 20$ & g C/day & 0.0000 & 0.0000 & 0.0000 & 0.0024 & 0.0030 & 0.0021 & 0.0000 & 0.0023 & 0.0000 & 0.0026 & 0.0035 & 0.0028 \\
\hline $\mathrm{C} 21$ & g C/day & 0.0000 & 0.0000 & 0.0000 & 0.0000 & 0.0000 & 0.0000 & 0.0000 & 0.0000 & 0.0000 & 0.0000 & 0.0014 & 0.0028 \\
\hline $\mathrm{C} 22$ & g C/day & 0.0000 & 0.0000 & 0.0000 & 0.0000 & 0.0000 & 0.0000 & 0.0000 & 0.0000 & 0.0000 & 0.0000 & 0.0000 & 0.0000 \\
\hline \multicolumn{2}{|c|}{ Alcohols } & & & & & & & & & & & & \\
\hline $\mathrm{C} 1$ & g C/day & 0.0695 & 0.0696 & 0.0567 & 0.0648 & 0.0495 & 0.0449 & 0.0619 & 0.1040 & 0.0000 & 0.0610 & 0.1157 & 0.0160 \\
\hline $\mathrm{C} 2$ & g C/day & 0.0708 & 0.0709 & 0.0577 & 0.0660 & 0.0504 & 0.0457 & 0.0473 & 0.1060 & 0.0000 & 0.0529 & 0.1222 & 0.0102 \\
\hline C3 & g C/day & 0.0649 & 0.0650 & 0.0529 & 0.0605 & 0.0462 & 0.0419 & 0.0872 & 0.0971 & 0.0000 & 0.0172 & 0.0596 & 0.0580 \\
\hline $\mathrm{C} 4$ & g C/day & 0.0220 & 0.0220 & 0.0179 & 0.0205 & 0.0157 & 0.0142 & 0.0494 & 0.0329 & 0.0000 & 0.0166 & 0.0419 & 0.0054 \\
\hline C5 & g C/day & 0.0102 & 0.0102 & 0.0083 & 0.0095 & 0.0073 & 0.0066 & 0.0177 & 0.0153 & 0.0000 & 0.0181 & 0.0309 & 0.0286 \\
\hline $\mathrm{C} 6$ & g C/day & 0.0000 & 0.0000 & 0.0000 & 0.0000 & 0.0000 & 0.0000 & 0.0160 & 0.0000 & 0.0000 & 0.0177 & 0.0264 & 0.0076 \\
\hline $\mathrm{C7}$ & g C/day & 0.0000 & 0.0000 & 0.0000 & 0.0000 & 0.0000 & 0.0000 & 0.0049 & 0.0000 & 0.0000 & 0.0119 & 0.0238 & 0.0076 \\
\hline $\mathrm{C} 8$ & g C/day & 0.0000 & 0.0000 & 0.0000 & 0.0000 & 0.0000 & 0.0000 & 0.0025 & 0.0000 & 0.0000 & 0.0081 & 0.0177 & 0.0044 \\
\hline $\mathrm{C9}$ & g C/day & 0.0000 & 0.0000 & 0.0000 & 0.0000 & 0.0000 & 0.0000 & 0.0000 & 0.0000 & 0.0000 & 0.0051 & 0.0121 & 0.0041 \\
\hline $\mathrm{C} 10$ & g C/day & 0.0000 & 0.0000 & 0.0000 & 0.0000 & 0.0000 & 0.0000 & 0.0000 & 0.0000 & 0.0000 & 0.0030 & 0.0110 & 0.0037 \\
\hline
\end{tabular}




\begin{tabular}{|c|c|c|c|c|c|c|c|c|c|c|}
\hline & & \multicolumn{3}{|c|}{$\begin{array}{l}\text { 25th July } 2011 \text { Run } \\
\mathrm{Co} / \mathrm{SiO} 2 ; 10 \mathrm{ppm} \mathrm{S}\end{array}$} & \multicolumn{3}{|c|}{$\begin{array}{l}\text { 1st August } 2011 \text { Run } \\
\text { Co/EDTA/SiO2; } 10 \mathrm{ppm} \mathrm{S}\end{array}$} & \multicolumn{3}{|c|}{$\begin{array}{l}\text { 8th August } 2011 \text { Run } \\
\text { Co/NTA/SiO2; } 10 \text { ppm S }\end{array}$} \\
\hline & & $\begin{array}{c}\text { Pre- } \\
\text { poisoning }\end{array}$ & Poisoning & $\begin{array}{c}\text { post- } \\
\text { poisonin } \\
\mathrm{g}\end{array}$ & $\begin{array}{l}\text { Pre- } \\
\text { poisoning }\end{array}$ & Poisoning & $\begin{array}{c}\text { post- } \\
\text { poisoning }\end{array}$ & $\begin{array}{l}\text { Pre- } \\
\text { poisoning }\end{array}$ & Poisoning & $\begin{array}{c}\text { post- } \\
\text { poisoning }\end{array}$ \\
\hline & & 1 & II & III & 1 & II & III & 1 & II & III \\
\hline Time & & 24 & 48 & 72 & 24 & 48 & 72 & 24 & 48 & 72 \\
\hline Conversion & $x \mathrm{CCO} \%$ & 19.50 & 14.79 & 4.47 & 51.14 & 45.70 & 30.95 & 22.54 & 18.93 & 13.25 \\
\hline \multicolumn{11}{|c|}{ Online Analysis } \\
\hline $\mathrm{C} 5+$ & g C/day & 0.3340 & 0.2731 & 0.0736 & 1.9345 & 1.9850 & 1.1178 & 0.5227 & 0.4027 & 0.1046 \\
\hline $\mathrm{CH} 4$ & g C/day & 0.9202 & 0.8136 & 0.2256 & 3.1023 & 3.6196 & 2.5904 & 0.4031 & 0.5140 & 0.3853 \\
\hline $\mathrm{C} 2 \mathrm{H} 6$ & g C/day & 0.1264 & 0.0693 & 0.0381 & 0.6203 & 0.9163 & 0.4082 & 0.0554 & 0.0448 & 0.0515 \\
\hline 1-C4H9 & g C/day & 0.2268 & 0.1470 & 0.0145 & 0.5246 & 0.7169 & 0.3492 & 0.1129 & 0.1402 & 0.0973 \\
\hline $\mathrm{i}-\mathrm{C} 4 \mathrm{H} 8$ & g C/day & 0.0000 & 0.0000 & 0.0000 & 0.0000 & 0.0000 & 0.0000 & 0.0000 & 0.0000 & 0.0000 \\
\hline $\mathrm{t}-\mathrm{C} 4 \mathrm{H} 9$ & g C/day & 0.0000 & 0.0000 & 0.0000 & 0.0000 & 0.0000 & 0.0000 & 0.0000 & 0.0000 & 0.0000 \\
\hline c-C4H9 & g C/day & 0.0000 & 0.0000 & 0.0000 & 0.0000 & 0.0000 & 0.0000 & 0.0000 & 0.0000 & 0.0000 \\
\hline $\mathrm{i}-\mathrm{C} 5 \mathrm{H} 12$ & g C/day & 0.0000 & 0.0000 & 0.0000 & 0.0000 & 0.0000 & 0.0000 & 0.0000 & 0.0000 & 0.0000 \\
\hline $\mathrm{n}-\mathrm{C} 5 \mathrm{H} 12$ & g C/day & 0.0114 & 0.0135 & 0.0085 & 0.6848 & 0.9963 & 0.5187 & 0.0291 & 0.0362 & 0.0251 \\
\hline $\mathrm{CO} 2$ & g C/day & 1.1952 & 1.0490 & 0.3819 & 4.1256 & 4.0518 & 3.0700 & 1.1906 & 1.0748 & 0.8223 \\
\hline \multicolumn{11}{|c|}{ Offline Liquid Analysis } \\
\hline \multicolumn{11}{|c|}{ Paraffins } \\
\hline $\mathrm{C} 6$ & g C/day & 0.0299 & 0.0095 & 0.0009 & 0.0781 & 0.0829 & 0.0291 & 0.0463 & 0.0280 & 0.0242 \\
\hline
\end{tabular}




\begin{tabular}{|c|c|c|c|c|c|c|c|c|c|c|}
\hline C8* & g C/day & 0.1898 & 0.2612 & 0.0113 & 0.7817 & 0.7287 & 0.2912 & 0.6921 & 0.8186 & 0.4043 \\
\hline C9 & g C/day & 0.3290 & 0.1173 & 0.0093 & 1.1060 & 0.6514 & 0.4121 & 0.7213 & 0.4366 & 0.3778 \\
\hline C10 & g C/day & 0.5536 & 0.2240 & 0.0157 & 1.3177 & 0.5542 & 0.4910 & 0.9173 & 0.5553 & 0.4805 \\
\hline $\mathrm{C} 11$ & g C/day & 0.5737 & 0.2416 & 0.0229 & 1.2934 & 0.5439 & 0.4819 & 0.9700 & 0.5872 & 0.5081 \\
\hline C13 & g C/day & 0.4639 & 0.2066 & 0.0159 & 0.9582 & 0.4030 & 0.3570 & 0.8162 & 0.4941 & 0.4275 \\
\hline C14 & g C/day & 0.3830 & 0.1760 & 0.0139 & 0.7636 & 0.3211 & 0.2845 & 0.6761 & 0.4093 & 0.3542 \\
\hline C17 & g C/day & 0.1695 & 0.0918 & 0.0092 & 0.3782 & 0.1591 & 0.1409 & 0.3085 & 0.1868 & 0.1616 \\
\hline C18 & g C/day & 0.1081 & 0.0613 & 0.0045 & 0.2670 & 0.1123 & 0.0995 & 0.1976 & 0.1196 & 0.1035 \\
\hline C19 & g C/day & 0.0679 & 0.0358 & 0.0030 & 0.1713 & 0.0720 & 0.0638 & 0.1157 & 0.0700 & 0.0606 \\
\hline $\mathrm{C} 20$ & g C/day & 0.0504 & 0.0192 & 0.0000 & 0.1036 & 0.0436 & 0.0386 & 0.0625 & 0.0378 & 0.0327 \\
\hline $\mathrm{C} 21$ & g C/day & 0.0498 & 0.0111 & 0.0000 & 0.0747 & 0.0314 & 0.0278 & 0.0319 & 0.0193 & 0.0167 \\
\hline $\mathrm{C} 25$ & g C/day & 0.0387 & 0.0064 & 0.0000 & 0.1231 & 0.0518 & 0.0459 & 0.0000 & 0.0000 & 0.0000 \\
\hline $\mathrm{C} 26$ & g C/day & 0.0189 & 0.0033 & 0.0000 & 0.0881 & 0.0371 & 0.0328 & 0.0000 & 0.0000 & 0.0000 \\
\hline $\mathrm{C} 27$ & g C/day & 0.0068 & 0.0012 & 0.0000 & 0.0360 & 0.0151 & 0.0134 & 0.0000 & 0.0000 & 0.0000 \\
\hline $\mathrm{C} 28$ & g C/day & 0.0024 & 0.0000 & 0.0000 & 0.0098 & 0.0041 & 0.0037 & 0.0000 & 0.0000 & 0.0000 \\
\hline $\mathrm{C} 29$ & g C/day & 0.0000 & 0.0000 & 0.0000 & 0.0000 & 0.0000 & 0.0000 & 0.0000 & 0.0000 & 0.0000 \\
\hline C30 & g C/day & 0.0000 & 0.0000 & 0.0000 & 0.0000 & 0.0000 & 0.0000 & 0.0000 & 0.0000 & 0.0000 \\
\hline \multicolumn{11}{|c|}{ Olefins } \\
\hline $\mathrm{C} 6$ & g C/day & 0.0008 & 0.0011 & 0.0006 & 0.0018 & 0.0048 & 0.0060 & 0.0016 & 0.0012 & 0.0003 \\
\hline $\mathrm{C} 7$ & g C/day & 0.0022 & 0.0199 & 0.0026 & 0.0525 & 0.0233 & 0.0294 & 0.0047 & 0.0036 & 0.0009 \\
\hline $\mathrm{C} 8$ & g C/day & 0.0043 & 0.0125 & 0.0071 & 0.1111 & 0.0821 & 0.1039 & 0.0098 & 0.0074 & 0.0018 \\
\hline $\mathrm{C} 9$ & g C/day & 0.0062 & 0.0603 & 0.0338 & 0.1505 & 0.1586 & 0.2007 & 0.0112 & 0.0085 & 0.0021 \\
\hline
\end{tabular}




\begin{tabular}{|c|c|c|c|c|c|c|c|c|c|c|}
\hline C12 & g C/day & 0.0224 & 0.0208 & 0.0152 & 0.0655 & 0.2635 & 0.3335 & 0.0565 & 0.0427 & 0.0105 \\
\hline C13 & g C/day & 0.0238 & 0.0210 & 0.0157 & 0.0641 & 0.2649 & 0.3353 & 0.0522 & 0.0394 & 0.0097 \\
\hline C14 & g C/day & 0.0227 & 0.0168 & 0.0121 & 0.0505 & 0.1957 & 0.2477 & 0.0283 & 0.0213 & 0.0052 \\
\hline C15 & g C/day & 0.0213 & 0.0196 & 0.0116 & 0.0541 & 0.1994 & 0.2523 & 0.0392 & 0.0296 & 0.0073 \\
\hline C16 & g C/day & 0.0206 & 0.0181 & 0.0142 & 0.0459 & 0.1611 & 0.2038 & 0.0337 & 0.0255 & 0.0063 \\
\hline C17 & g C/day & 0.0153 & 0.0153 & 0.0126 & 0.0341 & 0.1318 & 0.1668 & 0.0265 & 0.0200 & 0.0049 \\
\hline C18 & g C/day & 0.0095 & 0.0117 & 0.0100 & 0.0212 & 0.0927 & 0.1173 & 0.0180 & 0.0136 & 0.0033 \\
\hline $\mathrm{C} 21$ & g C/day & 0.0000 & 0.0014 & 0.0028 & 0.0527 & 0.0161 & 0.0204 & 0.0000 & 0.0000 & 0.0000 \\
\hline $\mathrm{C} 22$ & g C/day & 0.0000 & 0.0000 & 0.0000 & 0.0000 & 0.0000 & 0.0000 & 0.0000 & 0.0000 & 0.0000 \\
\hline \multicolumn{11}{|c|}{ Alcohols } \\
\hline $\mathrm{C} 1$ & g C/day & 0.0610 & 0.1157 & 0.0160 & 0.1741 & 0.2658 & 0.0908 & 0.0395 & 0.0398 & 0.0320 \\
\hline $\mathrm{C} 2$ & g C/day & 0.0529 & 0.1222 & 0.0102 & 0.2307 & 0.3522 & 0.1204 & 0.0402 & 0.0406 & 0.0326 \\
\hline C6 & g C/day & 0.0177 & 0.0264 & 0.0076 & 0.0143 & 0.0218 & 0.0075 & 0.0000 & 0.0000 & 0.0000 \\
\hline $\mathrm{C} 7$ & g C/day & 0.0119 & 0.0238 & 0.0076 & 0.0507 & 0.0774 & 0.0264 & 0.0000 & 0.0000 & 0.0000 \\
\hline $\mathrm{C} 8$ & g C/day & 0.0081 & 0.0177 & 0.0044 & 0.0359 & 0.0548 & 0.0187 & 0.0000 & 0.0000 & 0.0000 \\
\hline C9 & g C/day & 0.0051 & 0.0121 & 0.0041 & 0.0309 & 0.0472 & 0.0161 & 0.0000 & 0.0000 & 0.0000 \\
\hline C10 & g C/day & 0.0030 & 0.0110 & 0.0037 & 0.0274 & 0.0419 & 0.0143 & 0.0000 & 0.0000 & 0.0000 \\
\hline
\end{tabular}

